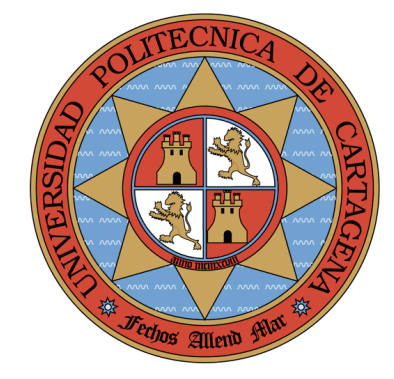

Universidad Politécnica de Cartagena

Departamento de Ingeniería de Materiales y Fabricación

Estudio Experimental de la Formación de Porosidad por Atrapamiento de Aire durante la Etapa Lenta de Inyección en Máquinas de Fundición a Alta Presión

Rosendo Zamora Pedreño

CARTAGENA, julio de 2005 

TESIS DOCTORAL

\title{
Estudio Experimental de la Formación de Porosidad por Atrapamiento de Aire durante la Etapa Lenta de Inyección en Máquinas de Fundición a Alta Presión
}

\author{
por: Rosendo Zamora Pedreño
}

Directores de la Tesis: Dr. Félix Faura Mateu

Dr. Joaquín López Rodríguez 



\section{Resumen}

La formación de porosidad por atrapamiento de aire en los procesos de fundición por inyección a alta presión es un problema que en muchas ocasiones resulta muy difícil de evitar. Las especiales características del flujo en la cámara de inyección así como la elevada velocidad del flujo de metal fundido a la entrada de la cavidad del molde pueden producir la ingestión de una elevada masa de aire, lo que daría lugar a altos niveles de formación de burbujas. En piezas con exigencias de funcionamiento poco severas, la disminución de la calidad por porosidad se ve compensada por las grandes ventajas de estos procesos (velocidades de producción elevadas, excelente precisión dimensional o buen acabado superficial de las piezas fabricadas). Cuando los requerimientos de funcionamiento son mayores, la reducción a un límite admisible del nivel de porosidad es un objetivo esencial que requiere la utilización de tecnología compleja y el conocimiento y control de los factores que determinan el nivel de porosidad de las piezas fabricadas.

En procesos de fundición por inyección a alta presión con cámaras frías horizontales, el metal fundido es inyectado hacia un molde metálico desde una cámara de inyección horizontal en la que el metal es empujado por un pistón. La cámara de inyección se llena parcialmente con un volumen de metal fundido (fracción inicial de llenado), desplazándose a continuación el pistón a lo largo de la longitud de la cámara (carrera del pistón), que normalmente es fija. Para reducir los niveles de porosidad en las piezas fabricadas, el proceso de inyección se suele realizar en dos etapas. En la primera (etapa lenta) el pistón empuja a una velocidad relativamente baja al metal fundido hasta que la cámara de inyección esté completamente llena, y en la segunda (etapa rápida) el pistón empuja al metal a gran velocidad para llenar la cavidad del molde. Para reducir el tamaño de las burbujas de gas atrapado, una vez que el molde está completamente lleno, se eleva la presión que el pistón ejerce sobre el metal y se mantiene durante la solidificación de la pieza.

En la presente tesis doctoral se lleva a cabo un estudio experimental, en condiciones reales de operación, de los mecanismos de atrapamiento de aire en la cámara de inyección durante la etapa lenta del proceso de inyección. Este estudio se lleva a cabo en una máquina industrial de fundición por inyección con cámara fría horizontal utilizando una aleación ligera de aluminio (habitualmente empleada en estos procesos) y diferentes condiciones de operación (fracción 
inicial de llenado y ley de movimiento del pistón). También se han llevado a cabo experimentos con agua en lugar de metal fundido en los que, con la ayuda de un dispositivo especial que incorpora un sensor fotoeléctrico, se ha podido determinar con precisión el instante en el que el agua alcanza la entrada a la cavidad del molde y queda atrapado el aire en la cámara.

Para establecer la relación entre condiciones de operación y cantidades de aire atrapado ha sido necesario determinar de forma precisa, por un lado, los valores de los parámetros de inyección utilizados en cada ensayo, y por otro, las medidas de los niveles de porosidad en las piezas fabricadas. Para ello, ha sido necesario adaptar a la configuración industrial de la máquina de inyección instalada en nuestro taller de fabricación, un nuevo sistema de adquisición de datos y control que permite mejorar la precisión del sistema de inyección y aumentar la repetibilidad de los ensayos realizados. Las condiciones de ejecución de dichos ensayos han sido tratadas estadísticamente para determinar la variabilidad de los resultados. Adicionalmente, ha sido necesario establecer procedimientos de operación que permitan:

- realizar dosificaciones precisas de metal fundido en la cámara de inyección, lo que obviamente dependerá de la fracción inicial de llenado considerada,

- estudiar la etapa lenta de inyección de forma aislada,

- establecer los parámetros de control de inyección de la máquina necesarios para realizar ensayos según una determinada la ley de movimiento,

- verificar el grado de similitud obtenido entre el desplazamiento real del pistón y la ley de movimiento deseada para rechazar aquellas inyecciones que se alejen de las condiciones de ensayo consideradas.

Las mediciones de los niveles de porosidad de cada pieza se han realizado utilizando un método picnométrico basado en el principio de Arquímedes. Este método permite conocer la densidad de un material a partir de la medida de su peso en aire y en agua, para lo que se ha utilizado una balanza hidrostática. Comparando la densidad medida del material con una muestra de la aleación empleada libre de poros se ha obtenido de forma porcentual el nivel de porosidad de la pieza fabricada. Estos experimentos han permitido establecer los valores de la velocidad crítica del pistón que minimizan la cantidad de aire atrapado para diferentes condiciones de operación.

Debe tenerse en cuenta que, si no se conoce la presión a la que se encuentra el gas atrapado, este método no permite determinar cuantitativamente la masa de aire atrapado. Aunque es posible conocer en cada instante la presión que el pistón ejerce sobre el metal durante el proceso de inyección, las incertidumbres experimentales junto con la elevada complejidad de los diferentes fenómenos que se pueden producir durante el flujo y solidificación del metal en la cámara hacen muy difícil estimar las presiones finales de los gases atrapados. Por ello, 
se ha optado por considerar el método de fusión al vacío, que permite evaluar la cantidad de aire atrapado en la pieza a partir de las variaciones de presión y temperatura producidas durante la fusión del metal en una cámara de vacío.

La falta de oferta en el mercado de equipos con la capacidad y precisión suficiente para llevar a cabo mediciones de presión y temperatura mediante la fusión del metal al vacío, ha hecho necesario diseñar y construir un sistema especialmente adaptado a las características de los ensayos programados en este estudio. Para ello, han sido tenidos en cuenta, entre otros factores, los materiales más apropiados para el sistema, el equipo de vacío necesario, el conjunto de sensores y transductores de presión y temperatura y su integración con el sistema de adquisición de datos, las condiciones típicas de presión y temperatura que alcanzan las piezas ensayadas, el tipo de horno y su configuración, y los procedimientos de calibración del equipo. A su vez, se ha realizado una descripción comparativa de otros procedimientos no destructivos utilizados comúnmente para el estudio de la porosidad, tales como inspección mediante rayos $\mathrm{X}$, tomografía computerizada, ultrasonidos, análisis de imagen o análisis de las frecuencias de resonancia.

Los resultados experimentales obtenidos en esta tesis, se han comparado con resultados teóricos previos, observándose una concordancia cualitativa aceptable para las predicciones de la velocidad crítica del pistón durante la etapa lenta de inyección. Así mismo, se ha llevado a cabo un análisis numérico, utilizando un modelo tridimensional, del flujo de metal fundido en la cámara de inyección. Los resultados del volumen de aire atrapado obtenidos con este modelo muestran una excelente concordancia cuantitativa con los resultados experimentales obtenidos en esta tesis, excepto para los casos con velocidades máximas del pistón superiores a las óptimas, ya que la formación de chorros de pared a lo largo del techo requiere un análisis numérico más detallado. Los resultados de este análisis numérico han permitido determinar la aplicabilidad y limitaciones de modelos más sencillos para describir el flujo de metal en la cámara de inyección.

Por otro lado, también se han realizado ensayos de visualización del flujo de agua en un modelo de cámara de inyección, en los que se utiliza una cámara de alta velocidad para visualizar la superficie libre del flujo para diferentes condiciones de operación. Uno de los aspectos más relevantes de este estudio es la confirmación de la existencia de una velocidad crítica del pistón que empuja al líquido en la cámara. Se ha podido visualizar al formación de un chorro de líquido a lo largo del techo de la cámara cuando la velocidad del pistón es superior a la crítica, lo que provoca la distorsión de la superficie libre y el atrapamiento de aire. El estudio comparativo de los resultados de visualización con los resultados experimentales en máquina real y los resultados de las simulaciones numéricas muestra un excelente grado de similitud, especialmente para condiciones de operación próximas a las óptimas. 



\section{Agradecimientos}

Mi más sincero agradecimiento a mis directores de tesis, Dr. Félix Faura Mateu y Dr. Joaquín López Rodríguez, por el constante apoyo, ánimo y ayuda recibida.

Quiero agradecer también la colaboración de todas las personas que forman parte del Departamento de Ingeniería de Materiales y Fabricación de la Universidad Politécnica de Cartagena, especialmente a los oficiales D. Pedro Belmonte y D. Ginés Meroño por su incondicional ayuda a pie de máquina, y a los profesores D. José Sanes, D. José Ojados Hernández, D. Juan José Hernández y con especial cariño a D. José Garrido, por su ayuda y consejo.

Asimismo agradezco al Departamento de Mecánica de la UNED, y en particular al Dr. Julio Hernández, la generosa colaboración dispensada durante la elaboración de esta tesis.

A la Comisión Interministerial de Ciencia y Tecnología (CICYT) y a la Comisión Europea, por la financiación concedida a los Proyectos de Investigación (DPI20011390-C02, TAP 1FD97-2333) en cuyo marco se ha realizado esta tesis, así como a la propia UPCT por su aportación a través de diversas convocatorias para la dotación de infraestructura dedicada a la investigación.

A la empresa Robert Bosch España y particularmente a D. Sebastián Gallardo, así como a las empresas IZAR y PRETRANSA, les agradezco su colaboración y asesoramiento durante el desarrollo del proyecto de investigación anteriormente citado. 



\section{Índice general}

Resumen I

Agradecimientos $\quad$ V

$\begin{array}{ll}\text { Índice de tablas } & \text { XI }\end{array}$

$\begin{array}{lll}\text { Índice de figuras } & \text { XIII }\end{array}$

1. Introducción 1

1.1. Tecnologías de fundición por inyección a alta presión . . . . . . . . 2

1.1.1. Etapas de inyección en máquinas FIAP con cámara fría hori-

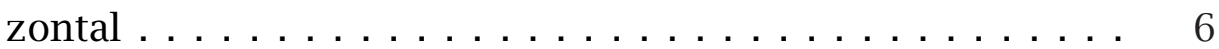

1.2. Formación de porosidad en procesos FIAP . . . . . . . . . . . . . 10

1.2.1. Mecanismos de atrapamiento de aire en la etapa lenta . . . . 15

1.3. Métodos de medida de porosidad . . . . . . . . . . . . . . . 18

1.3.1. Métodos no destructivos . . . . . . . . . . . . . . . . . . 19

1.3.2. Métodos destructivos . . . . . . . . . . . . . . . . 21

1.4. Control del proceso de inyección en máquinas FIAP . . . . . . . . . . . . . . . . . . . . . . . 23

1.5. Objetivos de la tesis . . . . . . . . . . . . . . . . . . . 24

2. Equipamiento experimental para el estudio de la formación de porosi$\begin{array}{ll}\text { dad en la etapa lenta de inyección } & 27\end{array}$

2.1. Instalación experimental . . . . . . . . . . . . . . . . . 27

2.2. Máquina de inyección y equipamiento auxiliar . . . . . . . . . . . . . . 29

2.2.1. Sistema de sujeción y cierre del molde . . . . . . . . . . . . . 29

2.2.1.1. Molde . . . . . . . . . . . . . . . 31

2.2.2. Sistema de inyección $\ldots \ldots \ldots$. . . . . . . . . . . 37

2.2.2.1. Cámara de inyección . . . . . . . . . . . . . 38

2.2.2.2. Dispositivos de refrigeración y engrase del pistón . . 40

2.2.2.3. Elementos de dosificación y colada . . . . . . . . . . . 41

2.3. Horno de fusión y mantenimiento del metal fundido . . . . . . . . . . . . . . . . 42

2.4. Sistema de control de la máquina FIAP . . . . . . . . . . . . . . . . . . 45

2.4.1. Configuración inicial del sistema de control . . . . . . . . . . 46

2.4.1.1. Componentes físicos . . . . . . . . . . . . . . 46

2.4.1.2. Aplicaciones informáticas . . . . . . . . . . . 48 
2.4.2. Modificaciones y desarrollos realizados en el sistema de con-

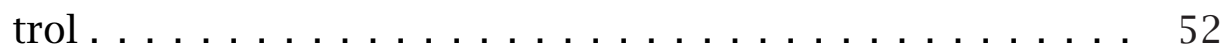

2.4.2.1. Transductor de posición digital . . . . . . . . . 52

2.4.3. Ajuste de la ley de movimiento del pistón $\ldots \ldots \ldots \ldots . .57$

2.4.3.1. Cálculo de la velocidad del pistón . . . . . . . . 58

2.4.3.2. Influencia de la apertura de válvula en la velocidad

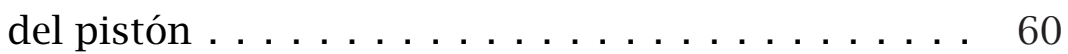

2.5. Sistema de fusión al vacío $\ldots \ldots \ldots \ldots \ldots \ldots \ldots \ldots$

2.5.1. Principios básicos de funcionamiento y características generales del sistema . . . . . . . . . . . . . . 66

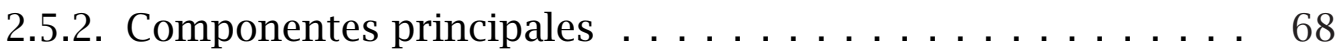

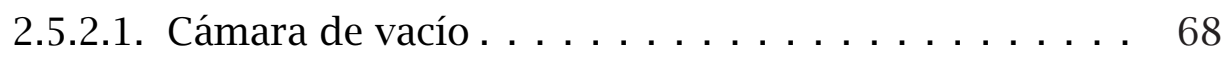

2.5.2.2. Horno de fusión . . . . . . . . . . . . . 72

2.5.2.3. Sistema de control y gestión . . . . . . . . . . 72

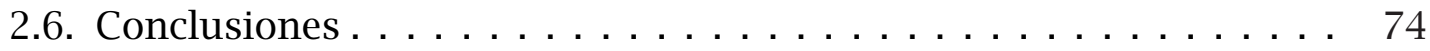

3. Estudio experimental del atrapamiento de aire mediante ensayos con agua. Comparación con resultados teóricos 75

3.1. Efectos del atrapamiento de aire en la cámara de inyección . . . . . 75

3.2. Modelo analítico y numérico . . . . . . . . . . . . . . . 77

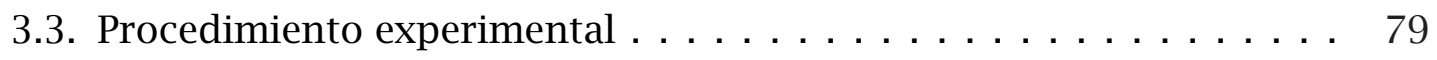

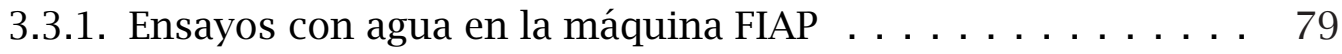

3.3.1.1. Diseño y fabricación del dispositivo para el alojamiento del transductor fotoeléctrico $\ldots \ldots \ldots .81$

3.3.2. Ensayos de visualización . . . . . . . . . . . . . 88

3.3.3. Determinación experimental del volumen de aire atrapado . 90

3.4. Discusión de resultados . . . . . . . . . . . . . . . 94

3.4.1. Comparación entre resultados CFD y analíticos . . . . . . . 94

3.4.2. Comparación con resultados experimentales en máquina FIAP 95

3.4.3. Comparación con resultados de visualización . . . . . . . . 104

3.5. Conclusiones . . . . . . . . . . . . . . . . . . . 110

4. Estudio experimental de la velocidad crítica del pistón mediante ensayos con aluminio $\quad 111$

4.1. Procedimiento experimental . . . . . . . . . . . . . 111

4.1.1. Propiedades físicas de la aleación empleada . . . . . . . . . 112

4.1.2. Estudio de la porosidad debida a la contracción . . . . . . . 117

4.1.3. Equipamiento . . . . . . . . . . . . . . . . . . 121

4.1.3.1. Adaptación de la geometría del molde . . . . . . . 121

4.1.4. Condiciones de ensayo . . . . . . . . . . . . . . . 121

4.1.5. Procedimiento de cálculo de la porosidad . . . . . . . . . 127

4.2. Discusión de resultados . . . . . . . . . . . . . 130

4.2.1. Comparación con los resultados obtenidos con agua . . . . 141 
4.3. Resultados preliminares obtenidos con el sistema de fusión al vacío 142 4.3.1. Pruebas de calibración y ensayos preliminares . . . . . . . . . 145

4.4. Conclusiones . . . . . . . . . . . . . . . . . . . . . . 146

5. Conclusiones finales 149

5.1. Desarrollos futuros . . . . . . . . . . . . . . . . . . . . 152

A. Método gravimétrico basado en el principio de Arquímedes 153

A.1. Fuentes de error y posibilidades para su corrección . . . . . . . . . 153

$\begin{array}{lr}\text { B. Planos del molde } & 157\end{array}$

C. Código fuente implementado 163

C.1. Módulo de adquisición de datos. (C) . . . . . . . . . . . . . . . . . . 163

C.2. Módulos de gestión de información de las inyecciones. (VB) . . . . 166

$\begin{array}{ll}\text { Bibliografía } & 185\end{array}$ 



\section{Índice de tablas}

2.1. Materiales seleccionados para la construcción del molde y los elementos auxiliares. . . . . . . . . . . . . . . . 36

2.2. Holguras utilizadas en la fabricación de pistones de inyección. . . . 39

2.3. Resultados de la posición del pistón registrados en diferentes instantes de tiempo, correspondientes a las zonas A y B, para 5 inyecciones realizadas con una apertura de válvula del $16 \%$. . . . . . .

2.4. Valores medios de la desviación estándar de posicionamiento del pistón obtenidos en las zonas A y B para diferentes porcentajes de apertura de válvula, utilizando el transductor analógico. . . . . . . 54

2.5. Medidas comparativas del transductor digital con un reloj compa-

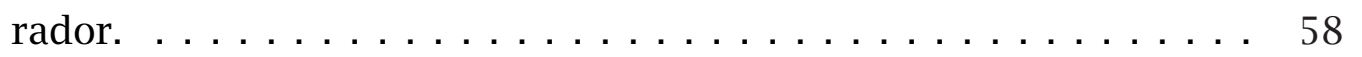

2.6. Valores medios de la desviación estándar de posicionamiento del pistón obtenidos en las zonas A y B para diferentes porcentajes de apertura de válvula, utilizando el transductor digital. . . . . . . . . 59

2.7. Ejemplo de configuración del software de control de máquina (PCM) para inyecciones con apertura constante de válvula del $28 \%$. . . .

2.8. Valores de velocidad máxima medida y desviación estándar para inyecciones realizadas con diferentes porcentajes de apertura cons-

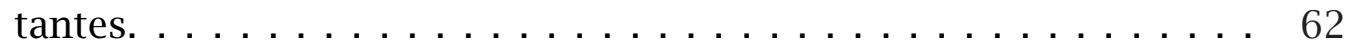

2.9. Retrasos en el comportamiento de la válvula. . . . . . . . . . . 63

3.1. Rangos de condiciones de operación utilizadas en los experimentos en máquina junto con los correspondientes números de inyecciones realizadas y rechazadas. . . . . . . . . . . . . . 87

3.2. Listado de posiciones registradas por el sistema de control. . . . . . 92

3.3. Valores adimensionales de aire atrapado en ensayos de repetibilidad del sistema de visualización realizados para una fracción inicial de llenado $f=0,252$ y velocidad adimensional máxima del pistón $U_{\max } /(g H)^{1 / 2}=0,91 \ldots \ldots \ldots \ldots \ldots \ldots \ldots \ldots \ldots \ldots \ldots \ldots$

3.4. Rango de velocidades máximas de pistón utilizadas en los ensayos de visualización. . . . . . . . . . . . . . . . . . . . . . . . 104

4.1. Composición porcentual de la aleación de aluminio utilizada. . . . . 112

4.2. Medidas de densidad de 10 muestras de la aleación. . . . . . . . . 114 
4.3. Volúmenes calculados a partir de la densidad de 10 muestras de la

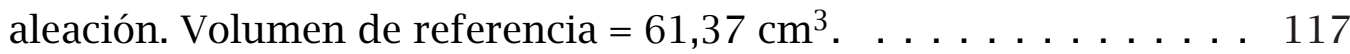

4.4. Medidas de porosidad por contracción en ensayos con $f=0,252$. 120

4.5. Porosidad media para diferentes fracciones iniciales de llenado. . . 120

4.6. Porosidad media expresada en unidades de volumen para diferentes fracciones iniciales de llenado. . . . . . . . . . . . . . . . . . . . . 121

4.7. Velocidades máximas del pistón ensayadas. . . . . . . . . . . . . . . 122

4.8. Ejemplo de configuración del software de control de la máquina (posición del pistón y apertura correspondiente) para conseguir una inyección con velocidad máxima del pistón de $0,63 \mathrm{~ms}^{-1}$ según la ley óptima de la Ecuación 3.1. . . . . . . . . . . . . . . . . . . . . . 124

4.9. Variaciones máximas de la fracción de llenado medidas en las piezas evaluadas. . . . . . . . . . . . . . . . . . . . . . 126

4.10.Rango pesos válidos para inyecciones en cámara de $50 \mathrm{~mm}$ de diámetro y 264,5 mm de longitud $( \pm 0,02 f) \ldots \ldots \ldots \ldots$. . . . . . . 127

4.11.Volúmenes de gas $\left(\mathrm{cm}^{3}\right)$ correspondientes a diferentes porcentajes de porosidad para la aleación utilizada. . . . . . . . . . . . . . . . . 129

4.12.Volumen de gas por cada $100 \mathrm{~g}$ de pieza correspondientes a diferentes porcentajes de porosidad. . . . . . . . . . . . . . . . . . . 129

4.13.Valores de la velocidad crítica del pistón predichos por los modelos de Tszeng y Chu [81] y López et al. [54]. . . . . . . . . . . . . . . . 130

4.14.Resultados experimentales para una fracción $f=0,374$ y una velocidad del pistón de $0,64 \mathrm{~m} \mathrm{~s}^{-1} \ldots \ldots \ldots$. . . . . . . . . . . . . . 132

4.15.Medidas de porosidad en una serie de piezas antes y después de sufrir el proceso de calentamiento. . . . . . . . . . . . . . . . . . . . . . 144

4.16.Volumen de las probetas utilizadas en la calibración del sistema de fusión al vacío. 


\section{Índice de figuras}

1.1. Máquina de fundición por inyección a presión patentada por H.H. Doehler en 1910. . . . . . . . . . . . . . . . . 3

1.2. Esquema de una máquina de fundición por inyección a alta presión con cámara caliente (basado en Kalpakjian [42]). . . . . . . . . . 4

1.3. Esquema de una máquina de fundición por inyección a baja presión (basado en Kalpakjian [42]). . . . . . . . . . . . . . . . 5

1.4. Esquema de una máquina de fundición por inyección a alta presión con cámara fría horizontal (basado en López y Faura [53]). . . . . .

1.5. Distribución porcentual del consumo de productos FIAP de aluminio para diferentes sectores industriales. . . . . . . . . .

1.6. Esquema de diferentes canales de colada habitualmente utilizados para introducir apropiadamente el metal fundido en la cavidad del molde [53]. . . . . . . . . . . . . . . . .

1.7. Fases de la etapa de inyección en los procesos FIAP con cámaras horizontales: a) Etapa lenta, b) Etapa rápida, c) Intensificación de la presión. . . . . . . . . . . 8

1.8. Detalle esquemático de un rebosadero y un viento. . . . . . . . 9

1.9. Ejemplo de diagrama de recorrido y presión en una inyección FIAP donde se aprecian las tres etapas de inyección. . . . . . . . . 10

1.10.Ejemplo de porosidad situada en una pieza FIAP. . . . . . . . . 13

1.11.Representación esquemática de las características geométricas de los distintos tipos de porosidad [37]. . . . . . . . . . 14

1.12.Efecto del incremento de la presión sobre la disminución del tamaño de la burbuja. . . . . . . . . . . . . . . .

1.13.Condiciones que tienden a incrementar el atrapamiento de aire durante la etapa lenta de inyección. a) Velocidad del pistón superior y b) inferior a la crítica (evolución del flujo del metal fundido para tres instantes de tiempo). . . . . . . . . . . . . 16

1.14.Esquema del sistema de fusión al vacío utilizado por Luis y Robla

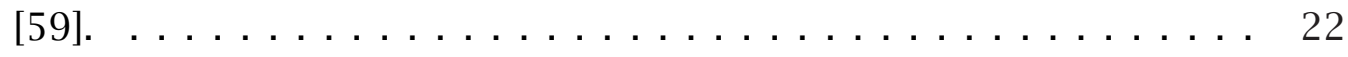

1.15.Esquema del sistema de fusión al vacío utilizado por Brevick y Cheng

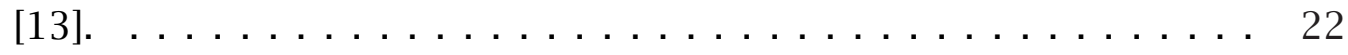


1.16. Regla de cálculo utilizada para determinar los parámetros de llenado del molde, [68]). . . . . . . . . . . . . . . . . . 23

2.1. Representación esquemática de la instalación experimental. . . . . 28

2.2. Instalación experimental disponible en la UPCT. . . . . . . . . . 28

2.3. Instalación experimental. Vista posterior. . . . . . . . . . . . 29

2.4. Sistema de inyección configurado a $-160 \mathrm{~mm} . \ldots \ldots \ldots \ldots$

2.5. Sistema de inyección en 0 y $-160 \mathrm{~mm} . \quad \ldots \ldots \ldots \ldots \ldots \ldots$

2.6. Sistema de pernos dispuestos en el plato móvil para el desplazamiento de la placa de expulsores. . . . . . . . . . . . . 32

2.7. Molde: parte móvil y parte fija montada en la máquina. . . . . . . 33

2.8. Molde e insertos metálicos intercambiables. . . . . . . . . . 34

2.9. Representación esquemática de la cámara de inyección utilizada. . 35

2.10.Cámara de inyección de $50 \mathrm{~mm}$ de diámetro formada por el conjunto (a) casquillo, (b) contenedor y (c) pistón. . . . . . . . . . . . 35

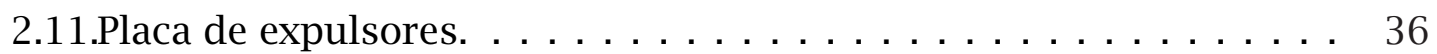

2.12.Precalentamiento de molde y contenedor con llama directa. . . . . 37

2.13.Plano constructivo de un pistón de $50 \mathrm{~mm}$ (a) y su modificación para adaptarla a los experimentos (b). . . . . . . . . . . . 39

2.14.Plano constructivo de los casquillos (a) y su modificación (b). . . . . 40

2.15.Cucharas de colada utilizadas durante los ensayos para diferentes valores de la fracción inicial de llenado de la cámara de inyección. . 41

2.16. Horno de fusión y mantenimiento. . . . . . . . . . . . 42

2.17.Crisol incluido en el horno de fusión y mantenimiento. . . . . . . 43

2.18.Armario de control del horno de fusión y mantenimiento. . . . . . 44

2.19.Espumadera utilizada para la eliminación de escorias en el horno de fusión y mantenimiento. . . . . . . . . . . . . . . . 44

2.20.Lingotera utilizada en la operación de vaciado del crisol. . . . . . . 45

2.21.Esquema básico del sistema de control de la máquina FIAP. . . . . 47

2.22.Panel de operación manual de la máquina FIAP. . . . . . . . . . 48

2.23.Detalle de una de las ventanas de la aplicación informática, PCM, encargada de regular la apertura de la válvula durante el proceso

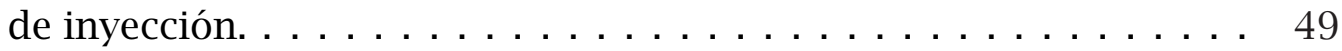

2.24.Ejemplo de listado resumido de datos de una inyección. . . . . . 50

2.25.Software de análisis de las inyecciones realizadas (PCI) instalado por el fabricante. Representación gráfica del recorrido del pistón (rojo) , presión (azul) y velocidad (amarillo) en función del tiempo. . 51

2.26.Versión modificada del software de control de máquina PCM. . . . 52

2.27.Módulo desarrollado para el estudio de la repetibilidad de posicionamiento del pistón. . . . . . . . . . . . . . . . . 53

2.28.Valor medio de la desviación estándar de posicionamiento del pistón en función del porcentaje de apertura de válvula. . . . . . . . . . 55 
2.29.Listado resumido generado por el nuevo módulo de adquisición de datos. . . . . . . . . . . . . . . . .

2.30.Comparación de valores medios de la desviación estándar de posicionamiento del pistón obtenidos en las zonas A y B para diferentes porcentajes de apertura de válvula, utilizando el transductor analógico y el digital. . . . . . . . . . . . . . . . . .

2.31.Representación gráfica de la velocidad del pistón en función del tiempo para diferentes valores del intervalo de diferenciación: (a) corto $=20 \mathrm{~ms}$, (b) largo $=60 \mathrm{~ms}$, (c) utilizado $=140 \mathrm{~ms}$, (en rojo velocidad medida y en azul la velocidad teórica). . . . . . . . . . . . .

2.32.Correlaciones entre el porcentaje de apertura de válvula y la velocidad máxima alcanzada por el pistón para diferentes rangos de apertura $($ Ec. 2.3 y 2.4). . . . . . . . . . . . . . . . . . . . . . .

2.33.Representación gráfica del recorrido del pistón que realiza a velocidad constante antes de comenzar a acelerar (en rojo) y de conseguir la velocidad estimada (en azul). . . . . . . . . . . . . . . .

2.34.Representación gráfica del tiempo que tarda el pistón en comenzar a acelerar (en rojo) y en conseguir la velocidad estimada (en azul). .

2.35.Incremento de presión debido a la liberación del gas de una burbuja de $0,2 \mathrm{~cm}^{3}$ en condiciones atmosféricas, y el aumento de temperatura de $0,15^{\circ} \mathrm{C}$, en una cámara con un volumen de gas de 30 litros, para diferentes valores de la presión existente en la cámara de vacío. 67

2.36.Vista general del sistema de fusión al vacío. . . . . . . . . . . . . 70

2.37.Vista seccionada del modelo de la cámara de vacío y horno de fusión. 70

2.38.Componentes del sistema de vacío y horno de fusión. . . . . . . . . . 71

2.39.Pantalla principal del software de control y gestión del sistema de fusión al vacío. . . . . . . . . . . . . . . . .

3.1. Representación esquemática del problema. (a) Sistema de coordenadas. (b) Esquema de la malla utilizada en el modelo numérico 3D.

3.2. Transductor fotoeléctrico instalado en la máquina FIAP. . . . . . . .

3.3. Vista de detalle del dispositivo específico que incorpora el canal de colada y los extremos de fibra óptica del transductor que permiten detectar el paso del agua por el canal. . . . . . . . . . . . . . . .

3.4. Plano del diseño de la pieza que forma la pared final de la cámara de inyección y aloja a los extremos de la fibra óptica. . . . . . . . . . .

3.5. Plano de diseño de la pieza soporte del dispositivo. . . . . . . . . . .

3.6. Modelo de la máquina FIAP incluyendo el dispositivo fotoeléctrico de detección. . . . . . . . . . . . . . . . . . . .

3.7. Maquina FIAP con el dispositivo para la detección del paso de agua instalado en la parte móvil del molde. . . . . . . . . . . . . . .

3.8. Dispositivo instalado, para una cámara de inyección de $50 \mathrm{~mm}$, con la barrera óptica activada. . . . . . . . . . . . . . . . . 
3.9. Valores de aire atrapado en inyecciones realizadas para el estudio de la influencia del uso de agua tintada con una fracción inicial de llenado $f=0,5$ y una velocidad del pistón máxima entorno a 0,38

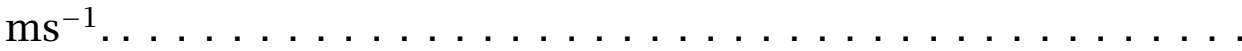

3.10.Representación esquemática del sistema de control utilizado en las inyecciones realizadas con agua en la máquina FIAP. . . . . . . . . . .

3.11.Comparación entre la velocidad del pistón teórica (línea continua) y velocidad medida (línea de cruces), para una ensayo típico con $R^{2}=0,95\left(A_{l 0} / A=0,374\right.$ y $\left.U_{\max }=0,57 \mathrm{~ms}^{-1}\right) \ldots \ldots \ldots$. . . . . 87

3.12.Instalación experimental para ensayos de visualización. . . . . . . . 89

3.13.Vista de la cámara circular de $74 \mathrm{~mm}$ de diámetro utilizada en los ensayos de visualización. . . . . . . . . . . . . . .

3.14.Representación esquemática de la instalación experimental de visualización. . . . . . . . . . . . . . . . .

3.15.Modelo del dispositivo diseñado para la determinación del tiempo de retardo de la señal del transductor fotoeléctrico. . . . . . . . . . .

3.16.Dispositivo instalado en la máquina FIAP. Detalle del instante de cruce del cursor. . . . . . . . . . . . . . . . . . . . . 91

3.17.Correlación para el cálculo del tiempo de retardo de la señal. . . . . 92

3.18.Perfiles de la superficie de la ola en el plano de simetría de una cámara de inyección con $L / H=9$ y $H=0,05 \mathrm{~m}$, para una fracción inicial de llenado $A_{l 0} / A=0,2$, la ley de aceleración de la Eq. (3.1) con $\ell=\frac{4}{3} L$, y el límite de la velocidad máxima del pistón dado por López et al. [54] con el fin de evitar la formación el chorro de pared a lo largo del techo de la cámara. . . . . . . . . . . . . . . .

3.19.Volumen adimensional $V /(A L)$ en función de $L / \ell$ para las mismas dimensiones y fracción inicial de llenado de la Figura 3.18, utilizando la velocidad del pistón máxima propuesta por López et al. [54] para evitar la formación del chorro de pared a lo largo del techo de la cámara. . . . . . . . . . . . . . . . . . . . . . . . .

3.20.Resultados de los perfiles de la superficie de la ola en el plano de simetría de la cámara utilizando el modelo CFD, para $L=5,3 H, H=$ $0,05 \mathrm{~m}, f=0,252$, la ley de aceleración de la Ecuación (3.1) y diferentes velocidades adimensionales máximas de piston $U_{\max } /(g H)^{1 / 2}$ :

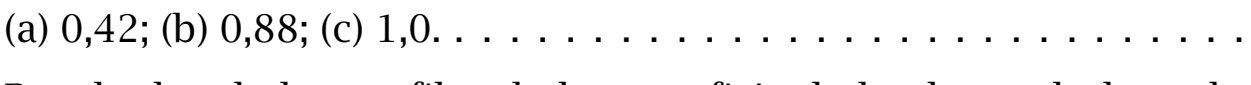

3.21.Resultados de los perfiles de la superficie de la ola en el plano de simetría de la cámara utilizando el modelo CFD, para $L=5,3 H, H=$ 0,05 m, dos fracciones iniciales de llenado diferentes y velocidades adimensionales máximas de pistón $U_{\max } /(g H)^{1 / 2}$ : (a) 0,43 y (b) 0,74 para $f=0,374$; y (c) 0,35 y (d) 0,62 para $f=0,5 \ldots \ldots 8$ 
3.22.Resultados experimentales obtenidos en la máquina FIAP, de las cantidades de aire atrapado en función de la velocidad máxima del pistón $U_{\max }$, para $L=5,3 H, H=0,05 \mathrm{~m}, f=0,252$ y la ley de aceleración de la Ecuación (3.1). . . . . . . . . . . . . .

3.23.Resultados experimentales obtenidos en la máquina FIAP, de las cantidades de aire atrapado en función de la velocidad máxima del pistón $U_{\max }$, para $L=5,3 H, H=0,05 \mathrm{~m}, f=0,374 \mathrm{y}$ la ley de aceleración de la Ecuación (3.1). . . . . . . . . . . . . . . . .

3.24.Resultados experimentales obtenidos en la máquina FIAP, de las cantidades de aire atrapado en función de la velocidad máxima del pistón $U_{\max }$, para $L=5,3 H, H=0,05 \mathrm{~m}, f=0,5$ y la ley de aceleración de la Ecuación (3.1). . . . . . . . . . . . . . . . . . . . . 100

3.25.Resultados experimentales adimensionalizados, obtenidos en la máquina FIAP, de las cantidades de aire atrapado $(V /(A L))$ en función de la velocidad máxima del pistón $\left(U_{\max } /(g H)^{1 / 2}\right)$ para $f=0,252 \ldots$. 101

3.26.Resultados experimentales adimensionalizados, obtenidos en la máquina FIAP, de las cantidades de aire atrapado $(V /(A L))$ en función de la velocidad máxima del pistón $\left(U_{\max } /(g H)^{1 / 2}\right)$ para $f=0,374 \ldots$. 102

3.27.Resultados experimentales adimensionalizados, obtenidos en la máquina FIAP, de las cantidades de aire atrapado $(V /(A L))$ en función de la velocidad máxima del pistón $\left(U_{\max } /(g H)^{1 / 2}\right)$ para $f=0,5$. . . .

3.28.Resultados experimentales y numéricos del volumen adimensional de aire atrapado en función de la velocidad máxima alcanzada por el pistón, utilizando la ley de aceleración de la Ecuación 3.1 para fracciones iniciales de llenado $f$ de 0,252 (a), 0,374 (b) y 0,5 (c). . . .

3.29.Comparación entre los resultados experimentales de visualización y numéricos de los perfiles de la superficie de la ola en el plano de simetría de la cámara para $f=0,374$ y $U_{\max } /(g H)^{1 / 2}=0,43 . \ldots$.

30.Comparación entre los resultados experimentales de visualización y numéricos de los perfiles de la superficie de la ola en el plano de simetría de la cámara para $f=0,374$ y $U_{\max } /(g H)^{1 / 2}=0,74$. . . .

3.31.Resultados numéricos y experimentales de visualización del volumen adimensional de aire atrapado en función de $U_{\max } /(g H)^{1 / 2}$, para una fracción inicial de llenado $f=0,252 \ldots \ldots \ldots$. . . . . . 108

3.32.Resultados numéricos y experimentales de visualización del volumen adimensional de aire atrapado en función de $U_{\max } /(g H)^{1 / 2}$, para una fracción inicial de llenado $f=0,374 \ldots \ldots \ldots$. . . . . . 108

3.33.Resultados de los ensayos experimentales en máquina FIAP y de visualización del volumen adimensional de aire atrapado en función de $U_{\max } /(g H)^{1 / 2}$, para la fracción inicial de llenado $f=0,252$. . . .

3.34.Resultados de los ensayos experimentales en máquina FIAP y de visualización del volumen adimensional de aire atrapado en función de $U_{\max } /(g H)^{1 / 2}$, para la fracción inicial de llenado $f=0,374$. . . . 
4.1. Diagrama de fases de la aleación Al Si. . . . . . . . . . . . . . . 113

4.2. Micrografía de una sección transversal de una pieza ensayada, obtenida con 85 aumentos. . . . . . . . . . . . . . . . . . . 113

4.3. Micrografía de una sección longitudinal de una pieza ensayada, obtenida con 85 aumentos. . . . . . . . . . . . . . . . . . . 114

4.4. Curva de dilatación volumétrica de la aleación en función de la temperatura. . . . . . . . . . . . . . . . . . . . . . 115

4.5. Molde utilizado para la determinación del coeficiente de dilatación volumétrico. . . . . . . . . . . . . . . . . . . . 116

4.6. Ejemplo de pieza fabricada para la determinación del coeficiente de dilatación volumétrico. . . . . . . . . . . . . . . . . . 116

4.7. Cuchara de colada fabricada para la dosificación de una fracción inicial de llenado $f=0,252 \ldots \ldots \ldots \ldots \ldots \ldots \ldots \ldots$

4.8. Modelo del menisco formado en la superficie del metal fundido en la cuchara de colada. . . . . . . . . . . . . . . . . . . . . . . 118

4.9. Medición de altura de menisco mediante el software de análisis de imagen OPTIMAS 6.5. . . . . . . . . . . . . . . . . . . 119

4.10.División efectuada en las piezas inyectadas para el análisis de la distribución de la porosidad. . . . . . . . . . . . . . . . . . . 120

4.11. Modelo de la pieza intercambiable fabricada. . . . . . . . . . . . . 122

4.12.Fotografía de detalle de la pieza intercambiable montada en el molde.122

4.13.Parte móvil del molde adaptado para el estudio de la etapa lenta. . 123

4.14.Pieza fabricada para el estudio de la etapa lenta. . . . . . . . . . . 123

4.15.Ejemplo de una serie de piezas fabricadas con una fracción inicial de llenado $f=0,374 \ldots \ldots \ldots \ldots \ldots$. . . . . . . . . . 124

4.16.Ejemplo de pesada de una pieza de $50 \mathrm{~mm}$ de diámetro y $f=0,374$ en una balanza de resolución de $0,01 \mathrm{~g} . \ldots \ldots \ldots \ldots$

4.17.Procedimiento para la medida de densidad en la balanza hidrostática. a) Pesada en agua b) Pesada en aire. . . . . . . . . . . . . . . . 128

4.18.Dispositivo empleado para la medida de densidad en la balanza hidrostática. . . . . . . . . . . . . . . . . . . . .

4.19.Comparación entre medidas de porosidad efectuadas mediante el método gravimétrico y la medición de longitud de la pieza para piezas inyectadas con fracción inicial $f=0,374$ y velocidades máximas entre 0,19 y $0,73 \mathrm{~ms}^{-1} \ldots \ldots \ldots \ldots \ldots \ldots \ldots$

4.20.Porosidad media e intervalos de confianza del $95 \%$ en función de la velocidad máxima del pistón con $f=0,252 \ldots \ldots \ldots \ldots \ldots$

4.21.Porosidad media e intervalos de confianza del $95 \%$ en función de la velocidad máxima del pistón con $f=0,374 \ldots \ldots \ldots \ldots$.

4.22.Porosidad media e intervalos de confianza del $95 \%$ en función de la velocidad máxima del pistón con $f=0,5 \ldots \ldots \ldots \ldots \ldots$

4.23.Porosidad media e intervalos de confianza del $95 \%$ en función de la velocidad máxima del pistón en la parte "A" con $f=0,252$. . . . . 
4.24.Porosidad media e intervalos de confianza del $95 \%$ en función de la velocidad máxima del pistón en la parte "B" con $f=0,252$. . . . . .

4.25.Porosidad media e intervalos de confianza del $95 \%$ en función de la velocidad máxima del pistón en la parte "A" con $f=0,374$. . . . . 134

4.26.Porosidad media e intervalos de confianza del $95 \%$ en función de la velocidad máxima del pistón en la parte "B" con $f=0,374$. . . . .

4.27.Porosidad media e intervalos de confianza del $95 \%$ en función de la velocidad máxima del pistón en la parte "C" con $f=0,374$. . . . . 135

4.28.Porosidad media e intervalos de confianza del $95 \%$ en función de la velocidad máxima del pistón en la parte "A" con $f=0,5$. . . . . . .

4.29.Porosidad media e intervalos de confianza del $95 \%$ en función de la velocidad máxima del pistón en la parte "B" con $f=0,5$. . . . . . .

4.30.Porosidad media e intervalos de confianza del 95\% en función de la velocidad máxima del pistón en la parte "C" con $f=0,5 \ldots \ldots$. . . 137

4.31.Mecanismos de atrapamiento de aire en la etapa lenta con una velocidad máxima del pistón (a) inferior y (b) superior a la óptima. . . 138

4.32.Sección longitudinal de una pieza previamente seccionada transversalmente, obtenida con velocidad máxima del pistón de $0,31 \mathrm{~ms}^{-1}$.

4.33.Sección longitudinal de una pieza previamente seccionada transversalmente, obtenida con velocidad máxima del pistón de $0,73 \mathrm{~ms}^{-1}$.

4.34.Fotografía de Rayos-X de una pieza fabricada con $f=0,5$ y una velocidad del pistón elevada. . . . . . . . . . . . . . . . .

4.35.Fotografía de una pieza fabricada con $f=0,5$ y una velocidad del pistón elevada. . . . . . . . . . . . . . . .

4.36.Identificación de porosidad por contracción y por gas atrapado en zonas A y B de la pieza presentada en la Figura 4.33. . . . . . . . . . . 142

4.37.Comparativa de valores calculados de volumen de aire atrapado para ensayos realizados con una fracción inicial de llenado (a) $f=$ 0,374 y (b) $f=0,5$ en experimentos en máquina FIAP, con agua y con aluminio. . . . . . . . . . . . . . . . . . . . . . . . 143

4.38.Ejemplo del efecto del tratamiento térmico sobre piezas fabricadas. 144

4.39.Conjunto de probetas fabricadas para la calibración del sistema. . . 145

4.40.Incrementos de presión medidos en función del volumen de gas liberado (en frío $\mathrm{T}=20^{\circ} \mathrm{C}$, en caliente $\mathrm{T}=545^{\circ} \mathrm{C}$ ) . . . . . . . 147

4.41.Registro de presión y temperatura durante un ensayo preliminar de la fusión una pieza FIAP. . . . . . . . . . . . . . . . . . 147

B.1. Parte móvil. . . . . . . . . . . . . . . . . . . . . . . . . . . . . 157

B.2. Sección del molde completo (incluye pernos guía). . . . . . . . . . . 158

B.3. (a) Placa de expulsores, (b) Pieza intercambiable para el viento, (c) Pieza intercambiable para el canal de colada. . . . . . . . . . . . . . . 159

B.4. Sección completa del molde (incluye casquillo intercambiable para cámara de inyección y placa de expulsores). 
B.5. Parte fija del molde (incluye líneas de enfriamiento). . . . . . . . . . . 161

B.6. Cavidad de la pieza en la parte móvil. . . . . . . . . . . . . . . . . . . . 162 


\section{A P Í T U L O 1}

\section{Introducción}

Los procesos de fundición de metales se caracterizan, esencialmente, por su gran versatilidad para fabricar, a bajo coste, piezas de una gran diversidad de tamaños y formas y por procesar determinados materiales de difícil tratamiento mediante otros procesos. Además, son capaces de reproducir geometrías muy complejas, permitiendo también generar cavidades o superficies internas en las piezas de cierta complejidad.

Son muy diversas las tecnologías que hasta la fecha se han desarrollado en el ámbito de los procesos de fundición de metales. Aunque obviamente las distintas tecnologías tienen sus propias características, aplicaciones, ventajas y limitaciones, existen aspectos comunes a todas ellas cuyo conocimiento es indispensable para controlar el proceso y garantizar un adecuado nivel de calidad en el producto. Estos aspectos son los relativos a la transferencia de calor, la solidificación y el flujo del metal fundido, que a su vez están influenciados por otros factores tales como el material y el diseño del molde, el material de la pieza que se va a fabricar o la máquina empleada. Por ejemplo, con respecto al material del molde cabe destacar que los moldes denominados como desechables (construidos con materiales como la arena, yeso o cerámicos) son peores conductores que los denominados permanentes (de hierro fundido, bronce, aleaciones refractarias o grafito) por lo que las velocidades de enfriamiento son menores en los primeros, afectando este hecho a la microestructura o al tamaño de grano y por tanto a las propiedades mecánicas de las piezas fabricadas, por un lado, y a los ritmos de producción y a la economía del proceso, por otro.

Desde principios del siglo XX se están desarrollando nuevas tecnologías que permiten reducir aún más los tiempos de producción introduciendo a gran velocidad el metal líquido en un molde metálico. Estos procesos han evolucionado hacia los denominados procesos de fundición por inyección a alta presión (en adelante procesos FIAP) los cuales están caracterizados por ser capaces de producir piezas de diferentes tamaños y formas, con espesores de pared que pueden llegar a alcanzar valores mínimos del orden de 1 o $2 \mathrm{~mm}$ cuando se usan aleaciones de aluminio. El elevado coste del equipo necesario en estos procesos FIAP, en especial el de los moldes, que puede llegar a suponer aproximadamente el 10\% 
del coste total de producción, hace que estos procesos estén recomendados únicamente para grandes volúmenes de producción. Los altos ritmos de producción permiten conseguir bajos costes de fabricación, que pueden llegar a reducirse aún más mediante la automatización y el control del proceso. En lo que sigue se hará una breve descripción de las principales características tecnológicas de estos procesos de fundición.

\subsection{Tecnologías de fundición por inyección a alta presión}

La industria de la fundición a alta presión nació en los años previos a la I Guerra Mundial. En 1910, Doehler [19] desarrolló una patente de una máquina de fundición por inyección a presión (véase la Figura 1.1) para la producción de componentes metálicos en grandes lotes. Desde entonces, la mayor parte de los avances técnicos que se han llevado a cabo en el ámbito de estos procesos, se desarrollaron, fundamentalmente, en Estados Unidos. Cabe destacar que a partir de 1914 también se instalaron las primeras plantas de fundición en el Reino Unido. La enorme demanda de productos como máquinas de oficina, cajas registradoras así como el notable crecimiento del sector de automoción a principios del siglo XX impulsaron definitivamente el desarrollo de la fundición a alta presión. En la actualidad estos procesos han adquirido una posición importante dentro de los procesos de fabricación en general, y en la industria de automoción en particular [64]. Esto se ha debido fundamentalmente al elevado ritmo de producción que permiten estos procesos, y a los aspectos relacionados con la precisión dimensional, el acabado superficial, la capacidad para reproducir detalles y su bajo coste. Como resultado de la excelente precisión dimensional (tolerancias lineales en torno al 0,3\% en aleaciones de aluminio) y la calidad superficial de las piezas, la mayoría de éstas no requieren mecanizados adicionales salvo un ligero desbarbado y, en ocasiones, operaciones de taladrado y roscado de orificios.

Los materiales más empleados para fabricar piezas mediante estos procesos abarcan desde las aleaciones de bajo y medio punto de fusión, como las de estaño, plomo, zinc, aluminio o magnesio, hasta incluso aleaciones de hierro, tales como los aceros inoxidables. Para obtener piezas de aleaciones de bajo punto de fusión suelen emplearse máquinas de cámara caliente, en las que el horno forma parte del sistema de inyección. En la Figura 1.2 se muestra un esquema típico de una máquina de inyección con cámara caliente.

Debe indicarse que este tipo de máquinas no se puede utilizar para fabricar piezas con materiales como las aleaciones de aluminio, cobre o magnesio ya que estos materiales, por encima de su punto de fusión, tienden a deteriorar los elementos férreos que componen el sistema de inyección. En estos casos se pueden utilizar máquinas de fundición a baja presión en las que el metal fundido es inyectado mediante gas a presión (Figura 1.3) o es succionado ejerciendo vacío en la parte superior del molde, lo que permite eliminar los gases y proporcionar 


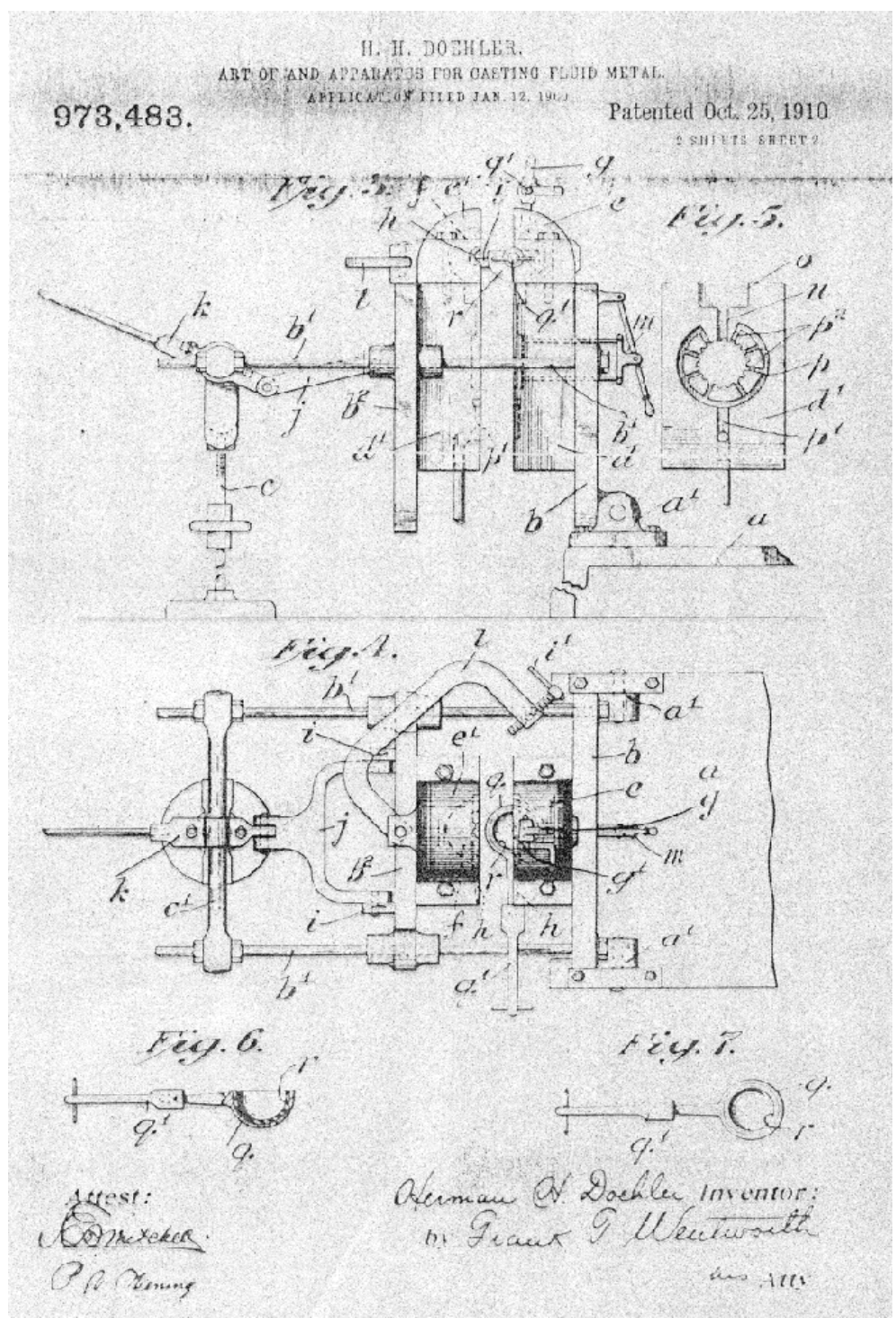

Figura 1.1: Máquina de fundición por inyección a presión patentada por H.H. Doehler en 1910. 


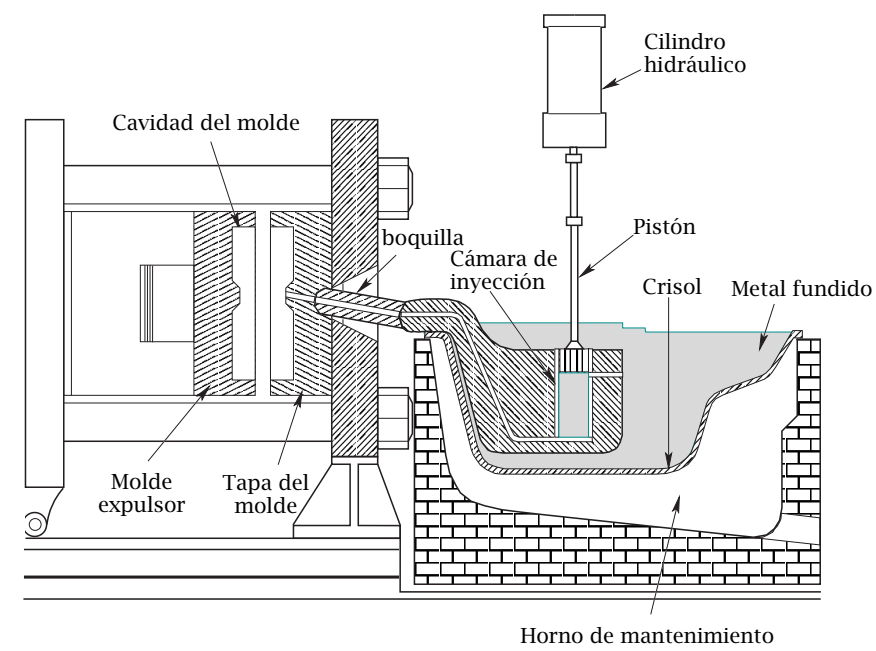

Figura 1.2: Esquema de una máquina de fundición por inyección a alta presión con cámara caliente (basado en Kalpakjian [42]).

piezas con menores niveles de porosidad. Con estos procesos se pueden fabricar incluso piezas de acero.

En la actualidad se están empleando, cada vez más, máquinas de cámara fría en las que la fusión del metal se realiza fuera del sistema de inyección. Este tipo de máquinas pueden presentar la cámara de inyección en posición vertical u horizontal. Las máquinas con cámara horizontal, cuyo esquema se muestra en la Figura 1.4, permiten ejercer presiones más altas sobre el metal, con tiempos de fabricación menores, que las máquinas con cámara vertical.

El uso de este tipo de máquinas ha experimentado un notable incremento particularmente en el sector de automoción en el que compiten diversas aleaciones ligeras de aluminio (A356 y similares). En la actualidad, aproximadamente el $65 \%$ de la producción de piezas de aluminio mediante procesos FIAP se destina a la industria de la automoción, destacando, entre el resto sectores dedicados a la producción de equipamiento informático y de telecomunicaciones, y los de dispositivos de instrumentación y medida (Figura 1.5). Cabe destacar que los criterios de eficiencia y reducción de emisiones contaminantes ha conducido a la industria automovilística al uso intensivo del aluminio en sus vehículos. Por ejemplo, en la producción de camiones articulados, cada tonelada de aluminio utilizada para reemplazar metales más pesados puede llegar a suponer una reducción media de 12 t, aproximadamente, de emisiones de $\mathrm{CO}_{2}$ debido al ahorro de combustible. Según la "European Aluminium Association" [23], una reducción de $100 \mathrm{~kg}$ en el peso de un automóvil permite un ahorro de combustible de hasta 0,6 litros por cada $100 \mathrm{~km}$. Así, por ejemplo, el uso intensivo de aluminio en un vehículo de gama media puede reducir su peso en unos $300 \mathrm{~kg}$, lo que supondría poder ahorrar unos 3000 litros de combustible durante su tiempo de vida. 


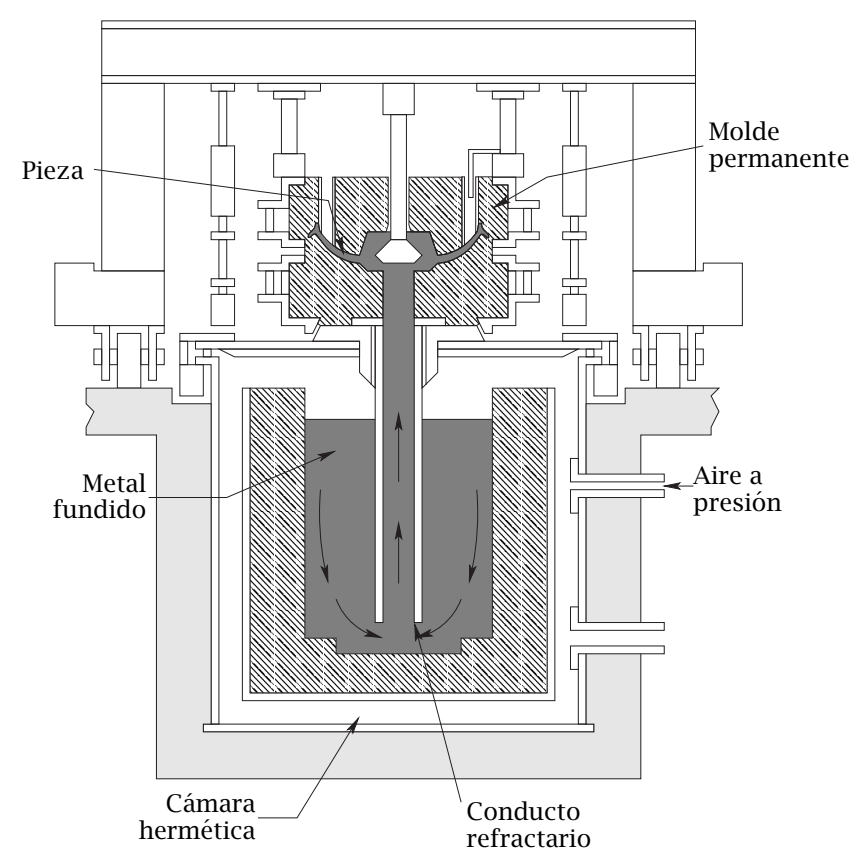

Figura 1.3: Esquema de una máquina de fundición por inyección a baja presión (basado en Kalpakjian [42]).

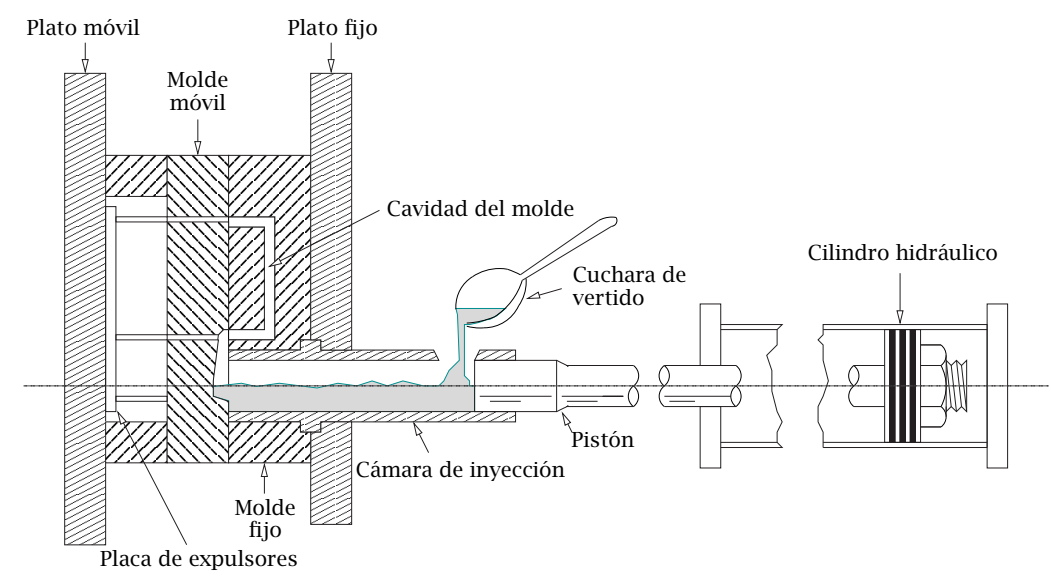

Figura 1.4: Esquema de una máquina de fundición por inyección a alta presión con cámara fría horizontal (basado en López y Faura [53]). 


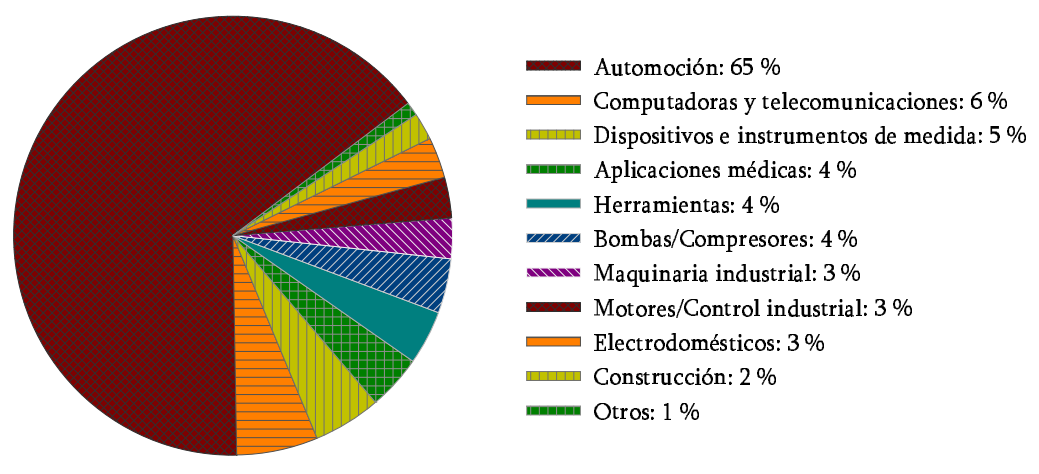

Figura 1.5: Distribución porcentual del consumo de productos FIAP de aluminio para diferentes sectores industriales.

\subsubsection{Etapas de inyección en máquinas FIAP con cámara fría horizon- tal}

En las máquinas FIAP con cámara fría horizontal, que son objeto de estudio en la presente tesis doctoral, una vez aplicado un fluido desmoldeante sobre las paredes del molde con el fin de evitar en lo posible la adherencia entre la pieza y el molde, cerrado el molde y configurados los parámetros del proceso, comienza el proceso de inyección. La inyección en este tipo de máquinas se puede programar en varias etapas, cada una de las cuales podría ser optimizada, en cierta medida, de forma independiente. Cada una de estas etapas se caracteriza por la velocidad del pistón que empuja al metal desde la cámara de inyección horizontal y por la presión que el sistema de inyección ejerce sobre el metal. El metal fundido es dirigido desde la cámara hasta la cavidad del molde a través de un conducto llamado, generalmente, canal de colada. En la Figura 1.6 se muestran algunas de las configuraciones geométricas más utilizadas para el canal de colada, dependiendo esta configuración fundamentalmente de la geometría de la pieza a fabricar y las condiciones de proceso utilizadas.

La cámara de inyección se llena parcialmente con un volumen de metal fundido (fracción inicial de llenado), desplazándose a continuación el pistón a lo largo de la longitud de la cámara (carrera del pistón), que normalmente es fija. Durante el proceso de inyección el aire inicial contenido en el molde y en la cámara de inyección puede ser atrapado en el metal fundido en forma de pequeñas burbujas que provocarían la aparición de porosidad cuando el metal se solidifique. Para minimizar el atrapamiento de aire, el proceso de inyección de metal fundido se suele dividir en una etapa lenta (Figura 1.7a), en la que el pistón empuja al metal fundido hasta que la cámara de inyección esté completamente llena, y una etapa rápida (Figura 1.7b), en la que el pistón empuja al metal a gran velocidad para llenar la cavidad del molde. Una vez que el molde está completamente lleno, 

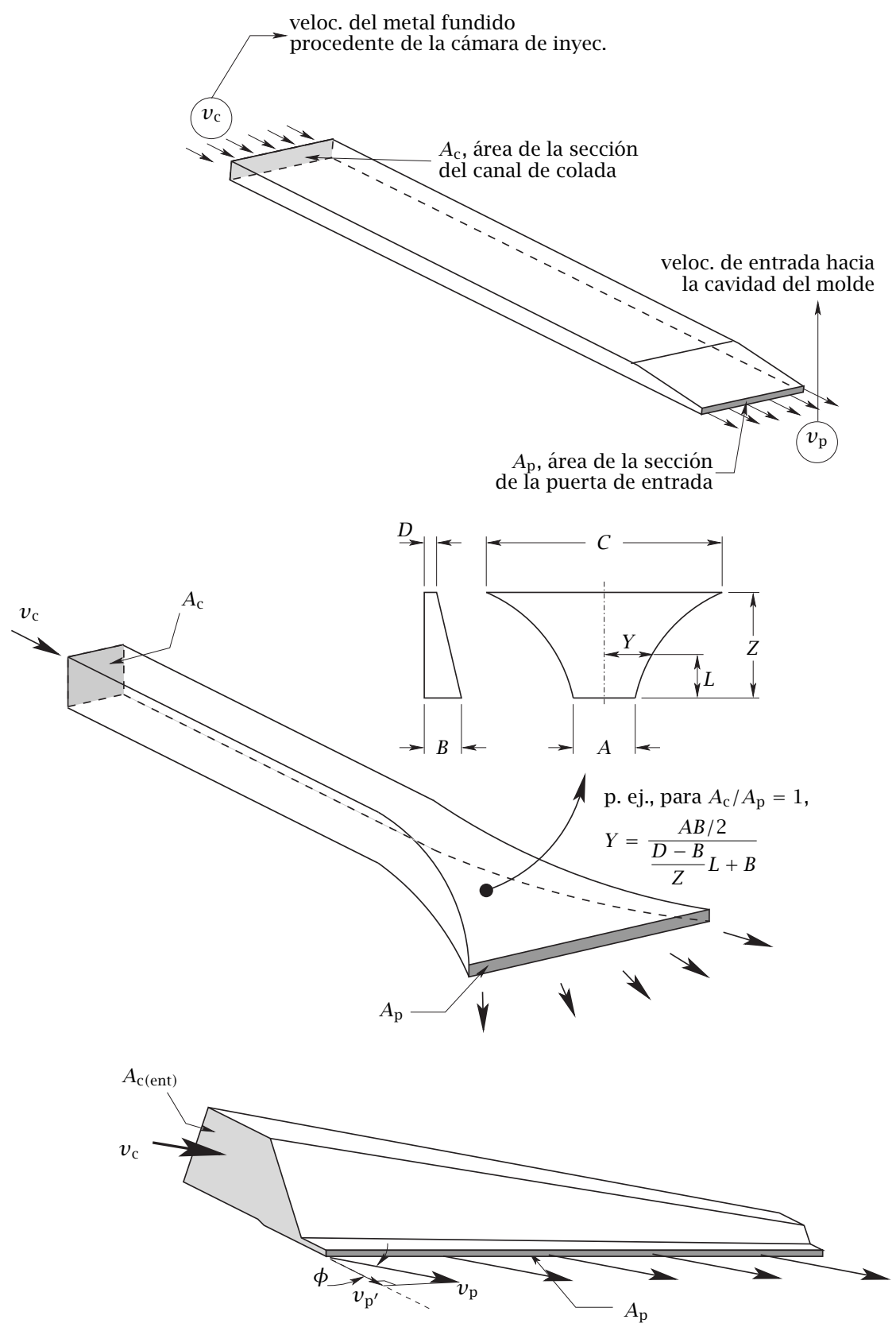

Figura 1.6: Esquema de diferentes canales de colada habitualmente utilizados para introducir apropiadamente el metal fundido en la cavidad del molde [53]. 

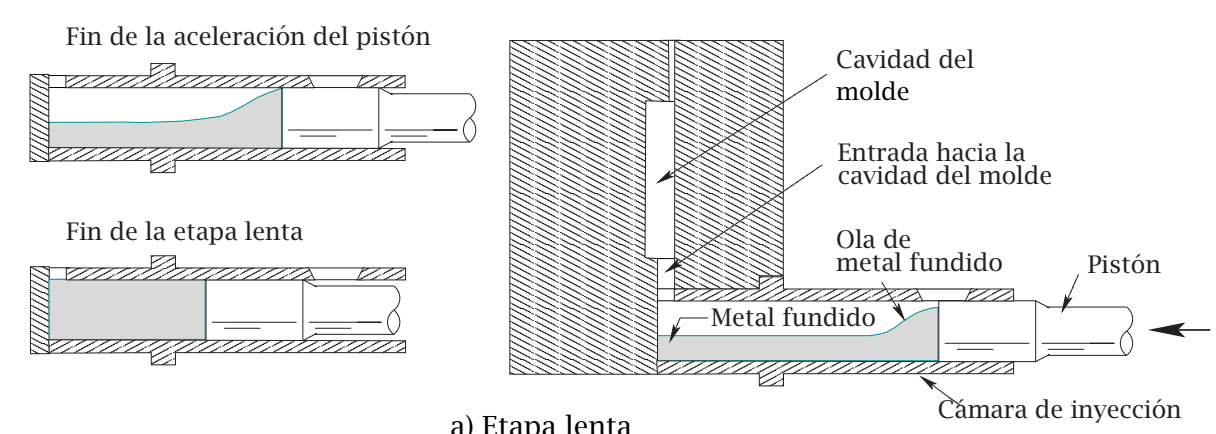

a) Etapa lenta

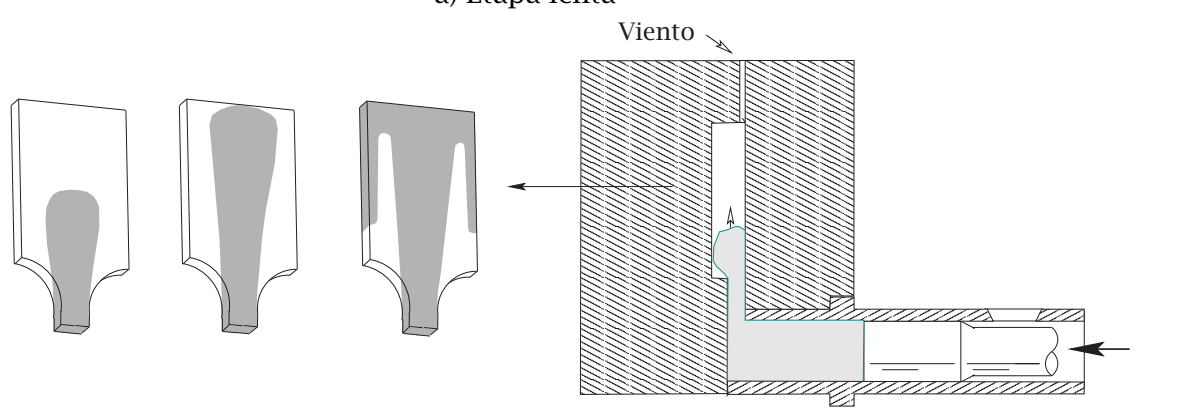

b) Etapa rápida

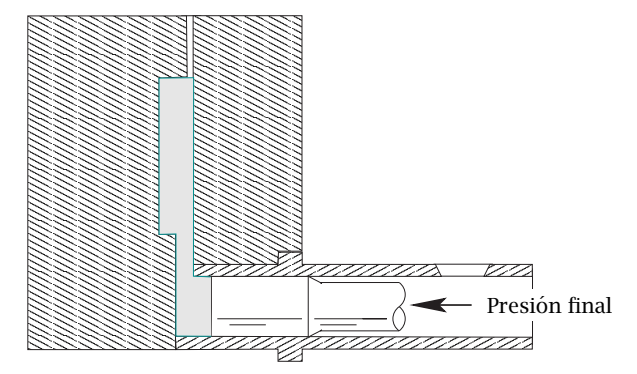

c) Intensificación de la presión

Figura 1.7: Fases de la etapa de inyección en los procesos FIAP con cámaras horizontales: a) Etapa lenta, b) Etapa rápida, c) Intensificación de la presión.

se eleva la presión que el pistón ejerce sobre el metal y se mantiene durante la solidificación de la pieza (Figura 1.7c).

El aire inicial que ocupa la cavidad del molde, el canal de colada y, en los casos de inyección mediante máquinas con cámara fría horizontal, la parte de la cámara de inyección que no está ocupada por el metal fundido, debe ser evacuado para evitar que quede atrapado en la pieza en forma de poros. Normalmente, el aire es evacuado desde la cavidad del molde hacia el medio ambiente a través de unos conductos de pequeña sección llamados vientos. Para que la evacuación sea óptima, los vientos deben situarse en las zonas del molde que se llenan en último lugar, lo cual es imposible en numerosas ocasiones, lo que hace que en determinadas circunstancias pueda existir aire no evacuado que podría quedar atrapado y contribuir a la formación de poros. Es importante indicar que el diseño y la localización de los vientos debe, por un lado, reducir la masa de aire 
residual en la cavidad del molde al final del proceso de inyección, y por otro, minimizar los trabajos de acabado posteriores y asegurar que el metal fundido se solidifique dentro del molde.

La importancia de disponer de un sistema de evacuación de aire apropiado es mayor conforme el tamaño de la pieza aumenta. Con frecuencia, las piezas pequeñas no precisan de vientos, ya que la evacuación de aire producida a través de la superficie de unión de las partes del molde (línea de partición) suele ser suficiente. Además, en piezas relativamente grandes es habitual colocar junto a los vientos pequeños depósitos (rebosaderos) que permiten, entre otras cosas, retener elementos contaminantes como óxidos, escorias, pequeñas burbujas de aire, restos de lubricante, etc., o facilitar una mayor evacuación de calor en zonas donde pueda ser necesario. Barton [9] recomienda usar varios depósitos de este tipo de pequeño tamaño ${ }^{1}$ convenientemente situados en el molde. Cuando el metal se solidifica, los rebosaderos deben ser separados mediante expulsores para impedir que queden pegados unidos al molde. En la Figura 1.8 se muestra un esquema representativo de un rebosadero y un viento. En la práctica, los sistemas

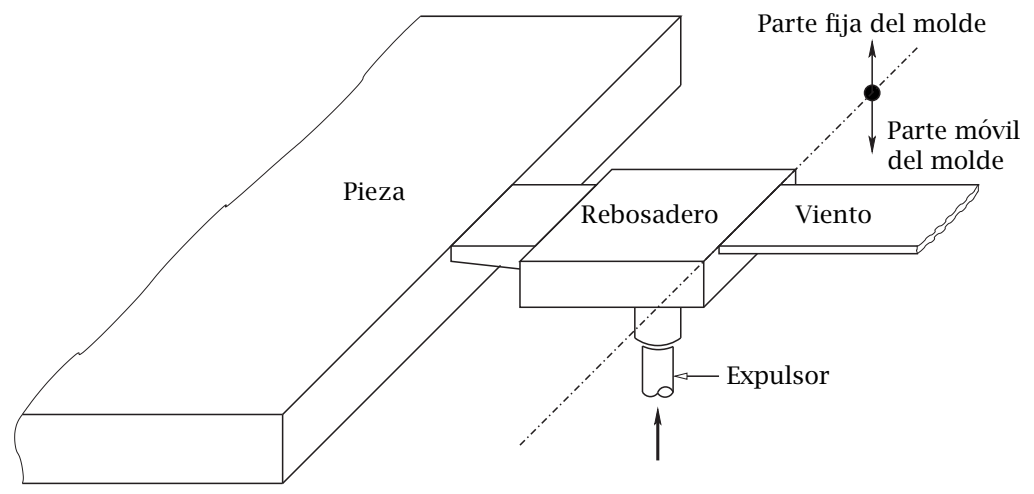

Figura 1.8: Detalle esquemático de un rebosadero y un viento.

de evacuación de aire están formados por varios vientos de sección rectangular y pequeño espesor para evitar que el metal fundido pueda ser expulsado fuera de la cavidad del molde. Los vientos, que, como se ha dicho, deben situarse en lugares estratégicos para facilitar la completa evacuación del aire, se suelen mecanizar a lo largo de la línea de partición del molde.

La presión durante la etapa de intensificación (véase la Figura 1.9), junto con los datos geométricos de la pieza a fabricar, determina la fuerza necesaria para mantener el molde (formado por varias partes que se acoplan) completamente cerrado. Durante esta etapa, la presión que el sistema de inyección ejerce sobre el metal permite reducir el volumen de las burbujas de gas atrapado y, por lo tanto, los niveles de porosidad en la pieza atrapada. En los procesos FIAP con cámara fría horizontal se pueden alcanzar presiones y velocidades de inyección

\footnotetext{
${ }^{1}$ Para el aluminio, Barton [9] sugiere que un tamaño apropiado para estos depósitos podría ser aproximadamente de $22 \mathrm{~mm}$ de ancho, $32 \mathrm{~mm}$ de largo y $8 \mathrm{~mm}$ de espesor.
} 


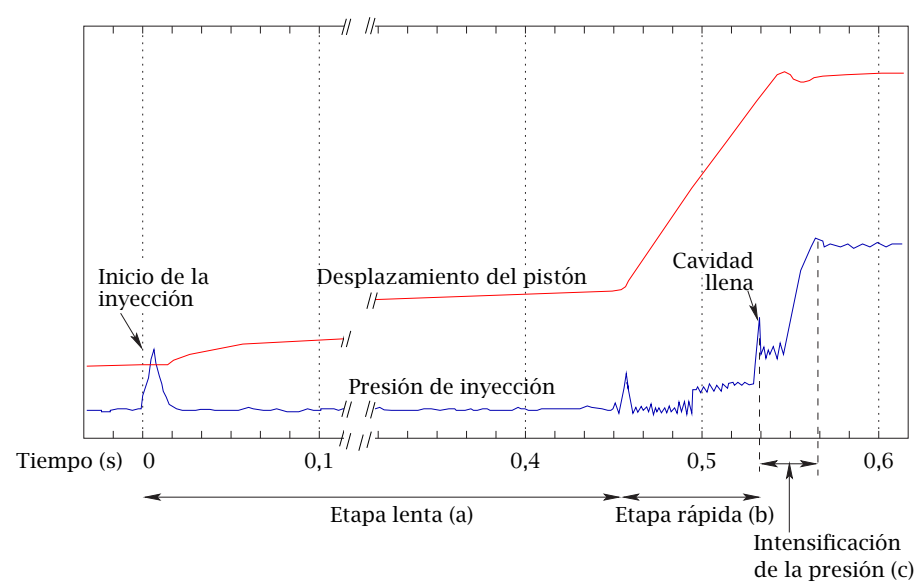

Figura 1.9: Ejemplo de diagrama de recorrido y presión en una inyección FIAP donde se aprecian las tres etapas de inyección.

del orden de $1000 \mathrm{~kg} \mathrm{~cm}^{-2}$ y $6 \mathrm{~m} \mathrm{~s}^{-1}$ respectivamente, existiendo en el mercado máquinas de hasta 5000 toneladas de fuerza de cierre del molde capaces de inyectar más de $40 \mathrm{~kg}$ de aleación de aluminio en cada inyección. Una vez finalizada la etapa de inyección y transcurrido el tiempo necesario para asegurar la solidificación de la pieza, se procede a la apertura del molde mediante el desplazamiento de la parte móvil del mismo, lo que permitirá la extracción de la pieza fabricada. Para facilitar la extracción de la pieza del molde, se activa el mecanismo de expulsión, que permite empujar a la pieza mediante una serie de expulsores situados en la parte móvil del molde, que se distribuyen estratégicamente en la llamada placa de expulsores con el fin de evitar dañar las superficies funcionales de la pieza. Extraída la pieza comenzaría un nuevo ciclo con la aplicación del fluido desmoldeante.

\subsection{Formación de porosidad en procesos FIAP}

Un problema muy difícil de evitar en los procesos FIAP es el debido a la mayor tendencia a la aparición de niveles elevados de porosidad en las piezas. En piezas con exigencias de funcionamiento poco severas, la disminución de la calidad por porosidad se ve compensada por las grandes ventajas de los procesos FIAP ya mencionadas. Cuando los requerimientos de funcionamiento son mayores, la reducción a un límite admisible del nivel de porosidad es un objetivo esencial que requiere la utilización de tecnología compleja y el conocimiento y control de los factores que determinan el nivel de porosidad de las piezas fabricadas. En este sentido se está realizando actualmente un gran esfuerzo de investigación para superar las limitaciones de los procesos FIAP y hacerlos aún más competitivos.

Los primeros trabajos que se realizaron para tratar de predecir la aparición de porosidad en piezas fundidas en general partieron de planteamientos basa- 
dos únicamente en el estudio de fenómenos de transferencia de calor durante la solidificación del metal líquido (una revisión de dichos trabajos puede verse en la referencia [25]). De esta forma se identificaron dos de los parámetros que frecuentemente controlan la aparición de porosidad: el tiempo de solidificación [16] y los gradientes de temperatura durante la solidificación del metal fundido $[66,63]$. En otros trabajos más recientes sobre el tema se trata de acoplar las dos causas básicas de formación de porosidad, analizando sus efectos combinados. Dichas causas son la existencia de gases disueltos y atrapados en el metal fundido (que no fueron considerados en estudios previos) y la resistencia a la alimentación líquida que se presenta en las zonas en solidificación para compensar la contracción volumétrica que experimenta el metal al solidificarse [46, 67, 84].

A continuación se describirán detalladamente los distintos mecanismos que dan lugar a la formación de porosidad debido a las dos causas que se acaban de mencionar.

A nivel "microgeométrico", la porosidad (microporosidad) producida por la contracción volumétrica del metal al solidificarse puede generarse por distintos mecanismos. Los problemas de alimentación líquida pueden dar lugar a porosidad interna producida por un mecanismo de nucleación interna [1] o de iniciación superficial (típica esta última de las aleaciones con grandes rangos de solidificación). En algunos casos, las dificultades de alimentación líquida dan lugar a que se produzca una porosidad externa (en la superficie de la pieza) como consecuencia de un mecanismo de alimentación sólida desde el exterior de la pieza. Este tipo de porosidad se ve agravada conforme disminuye la velocidad de enfriamiento. La macroporosidad por contracción que encontramos en las piezas fundidas es debida al hueco producido debido al cambio volumétrico que tiene lugar durante la solidificación de la aleación fundida. Este tipo de porosidad se produce a lo largo del eje de la pieza fundida donde la temperatura de la aleación durante la solidificación es máxima. En los puntos de este eje, el calor se dirige hacia ambos lados del molde por lo que suele estar situado en la zona central de la sección de la pieza, siempre que las características térmicas de ambas partes del molde sean similares. Es común encontrar este tipo de porosidad en las secciones que solidifican en último lugar y que se sitúan en zonas alejadas de la puerta de entrada de metal hacia el molde ya que en éstas se dificulta el aporte de metal líquido que ocuparía el hueco debido a la contracción de la aleación. Este efecto se ve incrementado en el caso de aleaciones que presentan un amplio rango de temperaturas de solidificación. Debe mencionarse que los efectos producidos por la formación de porosidad por contracción son muy difíciles de evitar por completo [47], por lo que al menos se debe intentar que su presencia se sitúe en zonas de la pieza que no afecte negativamente a los requerimientos de funcionamiento de la pieza. En el ámbito de los procesos FIAP esto se suele conseguir modificando, en la medida de lo posible, la geometría de la pieza y molde así como utilizando líneas de enfriamiento en determinadas zonas del molde que permitan conseguir gradientes de temperatura más favorables. 
El mecanismo de generación de porosidad que tiene lugar como consecuencia de la posible existencia de aire que queda atrapado en el interior del metal fundido durante el proceso de inyección es particularmente relevante en los procesos FIAP. Las especiales características del flujo en la cámara de inyección y la turbulencia en el flujo de metal fundido a la entrada del molde pueden producir la ingestión de una elevada masa de aire, lo que daría lugar a altos niveles de formación de burbujas. Esto se ve agravado por los pequeños tiempos de solidificación característicos de estos procesos (el molde es metálico y generalmente refrigerado) y por la dificultad de evacuación de los gases en moldes metálicos. Obviamente, si el aire inicial que ocupa la cavidad del molde y la parte superior de la cámara de inyección fuese evacuado completamente se podría evitar la formación de poros en la pieza por atrapamiento de aire. Como se indicó en la sección anterior, normalmente, en estos procesos el aire puede ser evacuado desde la cavidad del molde hacia el medio ambiente a través de los vientos. El diseño y la localización de los vientos debe tender a reducir la masa de aire residual en la cavidad del molde al final del proceso de inyección, pero también minimizar los trabajos de acabado posteriores y asegurar que el metal fundido se solidifique dentro del molde. Por otra parte, la importancia del mecanismo de generación de porosidad debido al aire atrapado durante el proceso de inyección es mucho menor si la velocidad de elevación de las burbujas de gas producidas en la entrada del metal fundido al molde es suficientemente grande, de forma que el tiempo característico de ascenso de las burbujas es pequeño frente al de solidificación. Sin embargo, esta circunstancia no se da en procesos de fundición a alta presión, y menos aún cuando se trata de piezas con paredes delgadas que se solidifican rápidamente.

Sin olvidar la importancia que la porosidad por contracción tiene en los procesos de fundición por inyección a alta presión [47], cabe destacar que la porosidad por atrapamiento de gas es probablemente la que con mayor frecuencia se presenta. Como ejemplo, se presenta la Figura 1.10) donde se puede observar la porosidad aparecida en una zona mecanizada de una pieza FIAP. El gas atrapado puede estar formado básicamente [83] por hidrógeno precipitado durante la solidificación del metal fundido, gases procedentes de los lubricantes utilizados en la cámara de inyección, vapor de agua y aire inicial que ocupa la cámara de inyección y la cavidad del molde. Debe mencionarse que es bastante difícil de evitar el hidrógeno liberado durante la solidificación del metal en piezas de aluminio. Para ello, la fusión y colada del metal se debería realizar en ambientes de bajo contenido en hidrógeno lo que, desde el punto de vista práctico, resultaría muy difícil conseguir. Por otro lado, con respecto al uso de lubricantes y desmoldeantes en el proceso de inyección, las máquinas FIAP suelen incorporar actualmente sistemas automatizados que sistematizan el uso de lubricantes reduciendo las cantidades utilizadas y por lo tanto disminuyendo las cantidades de gas generadas. En cualquier caso, debe mencionarse que las cantidades de gas atrapado debidas al hidrógeno, gases volátiles procedentes de lubricación o vapor de agua 


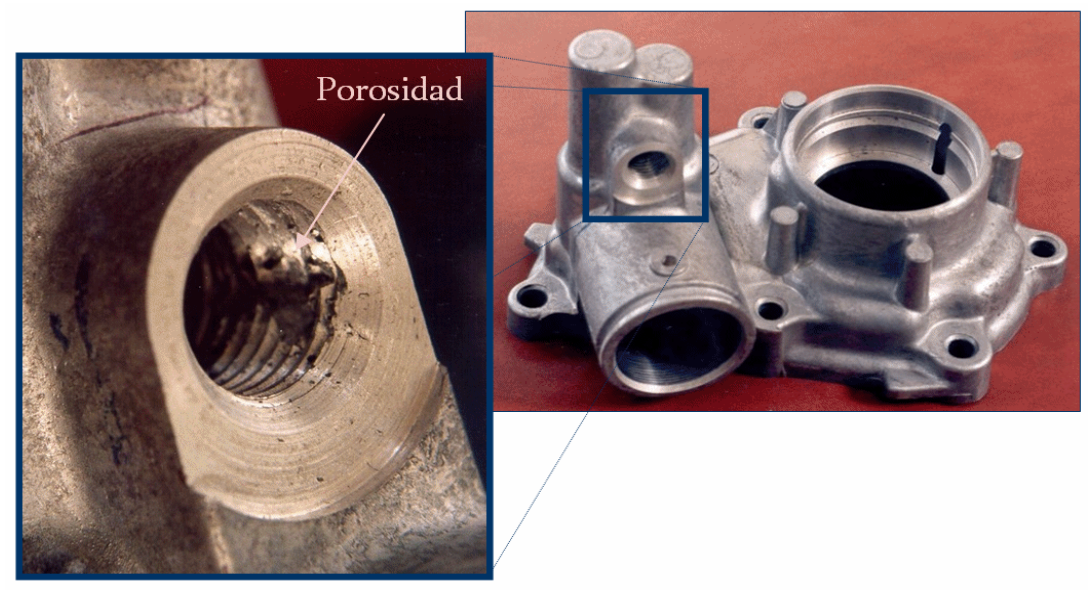

Figura 1.10: Ejemplo de porosidad situada en una pieza FIAP.

suelen ser muy inferiores a las del aire atrapado [83].

Una de las dificultades más importantes que se presentan para evaluar los niveles de porosidad en las piezas fundidas se debe a que la mayoría de los métodos de medida no permiten cuantificar los niveles de porosidad debidos a las distintas causas que se acaban de mencionar. Debe mencionarse que las normas existentes relativas a la evaluación de porosidad en piezas fundidas (ISO [41] o ASTM [6]) hacen referencia exclusivamente a una inspección de tipo visual, utilizando como referencia figuras y/o radiografías patrón. Klein y Wimmer [48] utilizaron un método que permite cuantificar porcentualmente, en piezas de cinc, los niveles de porosidad debidos a gases atrapados, por un lado, y a la contracción del metal al solidificarse por otro. Este método esta basado fundamentalmente en el estudio de la variación de densidad medida en una pieza antes y después de ser sometida a un tratamiento térmico de recocido.

En los trabajos de Andrews et al. [3] y Walkington [83] se puede encontrar un estudio detallado sobre la identificación de las distintas causas de formación de porosidad. La porosidad debida al atrapamiento de gas suele presentar un aspecto suave y redondeado mientras que las formas rugosas e irregulares suelen producirse por la contracción del metal. Huang y Lu [37] presentaron un estudio sobre la medida y morfología de la porosidad utilizando un análisis fractal basado en las medidas de área y perímetro de los poros. Este método utiliza dos parámetros adimensionales ( $D$ rugosidad y $\beta$ esfericidad) para describir la forma y redondez de los poros. Según este estudio, se observa que los poros debidos a gas atrapado presentan un aspecto más suave y redondeado (zona inferior derecha de la Figura 1.11), mientras que los poros debidos a la contracción presentan un aspecto más rugoso e irregular (zona superior izquierda de la Figura 1.11).

Dada la complejidad que presenta el estudio de los métodos y condiciones de operación que permitan disminuir los niveles de aire atrapado, la solución que tradicionalmente se ha utilizado en la práctica para resolver los problemas que 


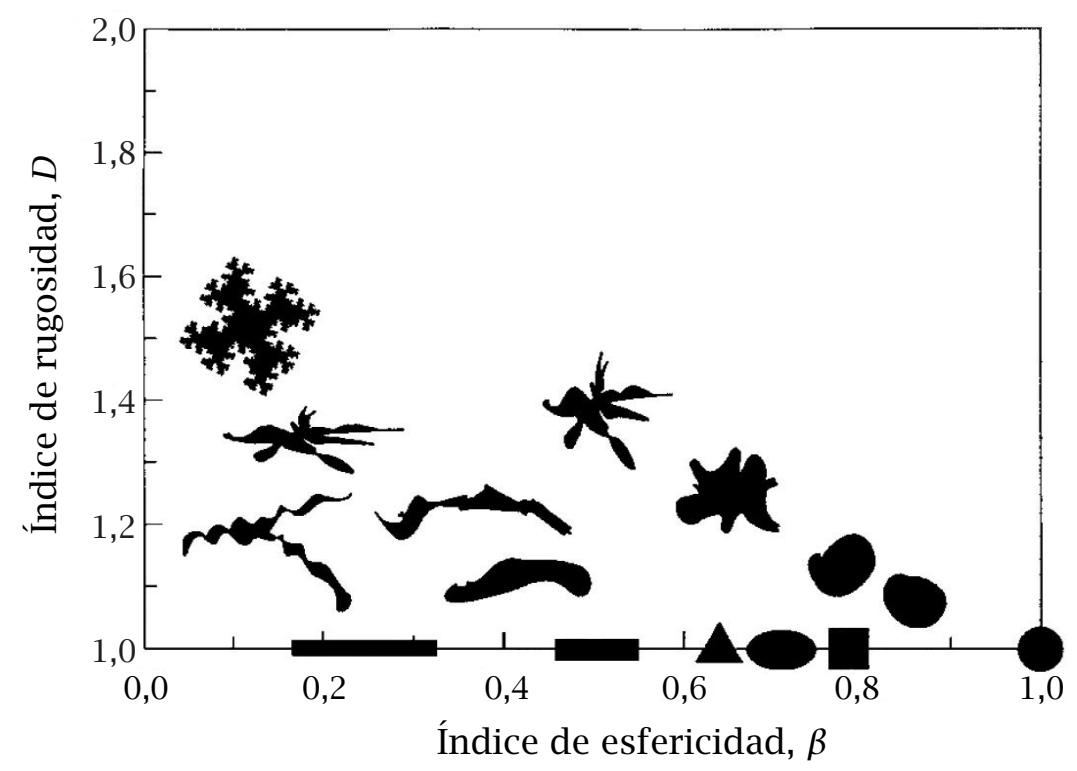

Figura 1.11: Representación esquemática de las características geométricas de los distintos tipos de porosidad [37].

presenta la porosidad en los procesos FIAP consisten básicamente en la utilización de la anteriormente comentada etapa de intensificación o tercera etapa de inyección, durante la cual se aplica una elevada presión (presión de multiplicación) sobre el metal mientras se solidifica con el fin de reducir el volumen de las burbujas de gas atrapadas en el metal fundido. Existen numerosos estudios de tipo experimental $[80,79,76,38,43,27]$ que demuestran como la porosidad medida desciende conforme se incrementa el valor de la presión de multiplicación ejercida.

Este procedimiento es eficaz debido a la relación geométrica que existe entre la presión y el tamaño de las burbujas, aunque debido a la relación exponencial que afecta al radio de la burbuja hay que tener en cuenta que a partir de un factor de aumento de la presión determinado, el efecto que tendrá sobre el tamaño de la burbuja puede ser mínimo. Por ejemplo, a temperatura constante, el aumento de la presión inicial de la burbuja a una presión 500 veces mayor provocaría que la burbuja tuviera un radio aproximadamente 8 veces menor (véase la Figura 1.12). Por ello es necesario aplicar la presión de multiplicación con un cierto criterio ya que el uso de presiones demasiado elevadas podría acarrear otros problemas como la apertura del molde y la salida del metal por la línea de partición (“flashing”), entre otros ${ }^{2}$. En las máquinas FIAP es posible ajustar la llamada presión de contrapresión que permite una ajuste fino sobre la presión de multiplicación establecida.

\footnotetext{
${ }^{2}$ Por regla general se recomienda el uso de presiones estáticas superiores a 20 MPa llegando a los $40 \mathrm{MPa}$ en los casos en que aparezcan problemas graves de porosidad. Las presiones de multiplicación recomendadas suelen estar entre 2,5 y 3 veces la presión estática.
} 


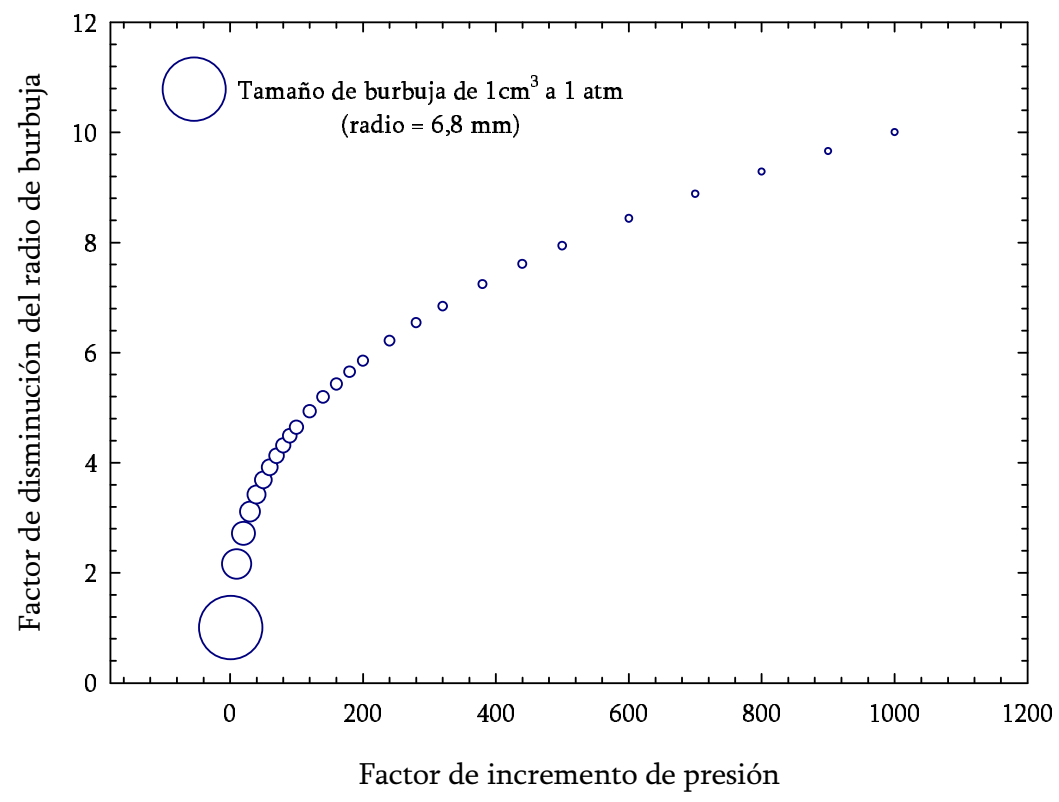

Figura 1.12: Efecto del incremento de la presión sobre la disminución del tamaño de la burbuja.

Debe mencionarse que si el molde o el metal fundido no tienen una temperatura suficientemente elevada durante el proceso de inyección, o la velocidad de inyección es relativamente baja, se pueden producir solidificaciones prematuras del metal en determinadas secciones que impedirían, por un lado, el completo llenado del molde, y por otro reducir lo suficiente el volumen de las burbujas de gas atrapado.

También cabe destacar que la cantidad de aire atrapado en la cámara de inyección durante la etapa lenta puede ser muy importante, especialmente cuando la fracción inicial de llenado de la cámara es baja. Por ejemplo en una inyección de unos $600 \mathrm{~g}$ de aluminio con una cámara de $5 \mathrm{~cm}$ de diámetro, $30 \mathrm{~cm}$ de longitud y fracción de llenado del $40 \%$, se deben de evacuar $353 \mathrm{~cm}^{3}$ de aire.

\subsubsection{Mecanismos de atrapamiento de aire en la etapa lenta}

En la etapa lenta de inyección, que es objeto de estudio en esta tesis, generalmente el pistón empuja el metal fundido hasta que alcanza y llena la parte superior de la cámara de inyección, desplazándose a continuación a velocidad constante hasta que la cámara esté completamente llena de metal fundido. Durante el movimiento del pistón se formará una ola. Las observaciones experimentales realizadas por Garber [28] muestran que existe una velocidad crítica del pistón para que la ola de metal líquido se eleve hasta alcanzar el techo de la cámara de inyección sin romperse. Autores, entre los que se incluyen Garber 


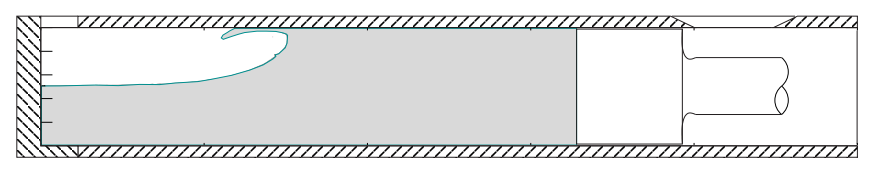

(a)
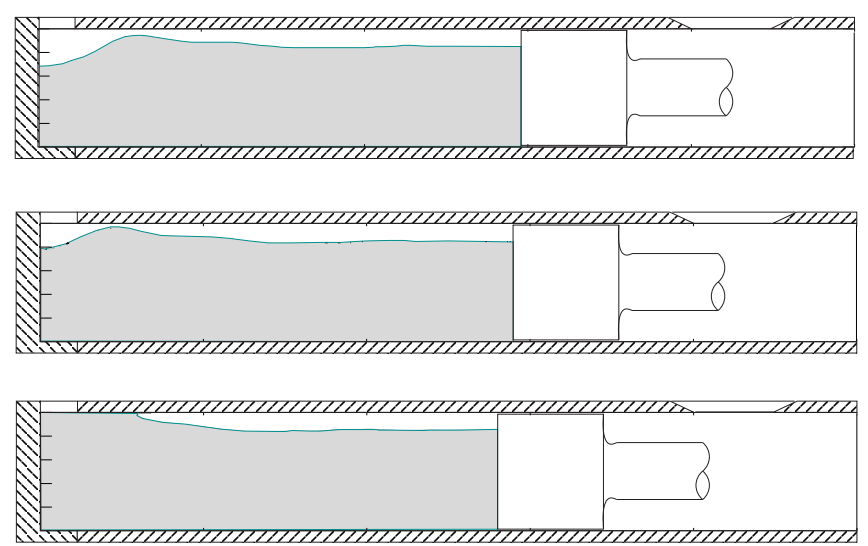

(b)

Figura 1.13: Condiciones que tienden a incrementar el atrapamiento de aire durante la etapa lenta de inyección. a) Velocidad del pistón superior y b) inferior a la crítica (evolución del flujo del metal fundido para tres instantes de tiempo).

[28], Karni [44] y Tszeng y Chu [81], propusieron expresiones analíticas (no muy acertadas en los dos primeros casos) para obtener esta velocidad crítica. Kuo y Hwang [49] utilizaron un modelo matemático para simular el flujo tridimensional de metal fundido en la cámara de inyección con el que determinaron las velocidades críticas correspondientes a varias fracciones iniciales de llenado. Si el pistón alcanza una velocidad mayor que la crítica (Figura 1.13a), la ola se reflejará en el techo de la cámara de inyección y el frente de ola podría romperse provocando el atrapamiento de aire. Por otro lado, si la velocidad del pistón no alcanza la velocidad crítica (Figura 1.13b), la ola podría reflejarse en la pared final de la cámara y atrapar aire entre el pistón y la parte superior de la cámara de inyección.

Para alcanzar la velocidad crítica, el pistón debe ser acelerado inicialmente. La evolución del perfil de la ola dependerá obviamente de la ley de aceleración del pistón empleada. Aunque existen algunos estudios teóricos y experimentales relativos a la influencia de la aceleración del pistón en el proceso de inyección, en la práctica se pone poco énfasis en la planificación del proceso para controlar la aceleración y el movimiento del pistón hasta alcanzar la velocidad crítica. Esta falta de énfasis no es debido a que no se reconozca la importancia de utilizar condiciones de operación adecuadas, sino a la inexistencia de criterios suficientemente generales para seleccionar dichas condiciones. Lo que se hace 
en la práctica es recurrir a la propia experiencia y a la realización de un número suficiente de pruebas que permitan determinar condiciones aceptables, sin que se pueda generalmente determinar si dichas condiciones son próximas a las óptimas. En Thome y Brevick [77] y [78], Brevick et al. [15] y Tszeng y Chu [81] se pueden encontrar varios estudios teóricos al respecto. Para casos en los que el pistón se mueve con una velocidad que aumenta linealmente con la distancia recorrida (lo que proporciona una aceleración que crece exponencialmente con el tiempo tras un cierto periodo inicial), se han realizado algunos estudios experimentales como los de Karni [44] y Duran et al. [20]. La razón de esta elección se debe a que en muchas máquinas de fundición por inyección a alta presión los perfiles de velocidad del pistón se suelen programar especificando la velocidad en función de la posición del pistón. Con esta ley de movimiento, Duran et al. [20] observaron que, para una geometría y una fracción inicial de llenado de la cámara de inyección dadas, existe una aceleración óptima que minimiza el volumen de aire atrapado. Tszeng y Chu [81] desarrollaron un modelo matemático para estudiar la evolución de la ola formada en la cámara de inyección para el mismo tipo de movimiento del pistón y con las mismas condiciones usadas en los experimentos de Duran et al. [20]. Analizaron los perfiles del frente de la ola y obtuvieron valores de la aceleración óptima del pistón para algunos casos concretos, imponiendo como condición que la ola empiece a romperse cuando la parte superior del frente de ola llegue al final de la cámara de inyección, pero el estudio fue poco sistemático y de validez poco general. Encontraron que los valores de la aceleración óptima obtenida de esta forma se aproximaba bastante bien a las mediciones experimentales realizadas por Duran et al. [20].

Cabe destacar los estudios teóricos referidos precisamente al estudio de condiciones de operación durante la inyección (particularmente la ley de aceleración del pistón) que minimizan la cantidad de aire atrapado llevados a cabo por miembros de nuestro grupo de investigación (véanse por ejemplo las referencias $[35,57,55,52,56,33,36,34,54,24])$.

Son relativamente escasas las publicaciones que pueden encontrarse en la literatura sobre estudios experimentales orientados a la determinación de la porosidad en las piezas fabricadas y al análisis de los mecanismos de generación de dicha porosidad por ingestión de aire bajo diferentes condiciones de operación en la etapa lenta de inyección. Smith y Wallace [75] estudiaron experimentalmente, con agua y metales de bajo punto de fusión, los mecanismos de atrapamiento de aire durante las dos primeras etapas del proceso de inyección. Los resultados de sus estudios mostraron que el uso de una velocidad lenta del pistón hasta que la cámara de inyección esté completamente llena reduce apreciablemente el aire atrapado en el metal fundido. Otros autores como Sheptak [74] o Garber [28] utilizaron técnicas similares centrándose exclusivamente en el estudio de la etapa lenta del proceso. Algunos trabajos numéricos realizados por Elmore et al. [22] muestran un incremento de hasta un $50 \%$ en la cantidad de aire atrapado cuando se incluye la etapa lenta en las simulaciones de llenado. Autores como 
Lindsey y Wallace [51] fueron los primeros que realizaron ensayos en máquinas de inyección con cámaras frías horizontales y aleaciones de aluminio, centrándose, aunque parcialmente, en la etapa lenta del proceso. Emplearon, entre otros, un método tradicional utilizado para estimar los niveles de porosidad interna en piezas fabricadas de Aluminio A380. Con este método, los niveles de porosidad debidos (principalmente) al atrapamiento de aire y a la contracción volumétrica que experimenta el metal cuando se solidifica se estimaron a partir de la densidad de las piezas determinada mediante una balanza hidrostática. El inconveniente de este método consiste en que no siempre puede ser aplicado debido a la existencia de cavidades en la superficie de piezas de geometría de cierta complejidad, que pueden impedir una determinación suficientemente precisa de la porosidad. Los resultados experimentales obtenidos por Lindsey y Wallace [51], indican que la fracción inicial de llenado tiene una influencia significativa en la calidad de las piezas fabricadas. Observaron la escasa influencia sobre la calidad de las piezas fabricadas del lubricante que se utiliza, entre otras razones, para evitar que el metal de la pieza se suelde a la superficie de la cavidad del molde, facilitar el desplazamiento de las partes móviles del molde o reducir el desgaste del pistón y de la cámara de inyección.

\subsection{Métodos de medida de porosidad}

A la hora de afrontar la evaluación de la cantidad de aire presente en piezas FIAP es posible encontrar en la literatura diversas técnicas capaces de aportar información de forma directa o indirecta sobre la cantidad de gas que se encuentra atrapada en una pieza aunque, como se expondrá mas adelante, son técnicas basadas en principios diversos que las hacen mas o menos aconsejables según los medios disponibles y las restricciones que se impongan al proceso de evaluación. Cuando se estudia la porosidad que pueda aparecer en una pieza fundida, la idoneidad de los diferentes métodos para examinarla depende de en qué medida la porosidad afecte a las propiedades de la pieza fabricada.

Las propiedades más significativas que han de ser consideradas son sin duda las relacionadas con características mecánicas tales como resistencia a la tracción, resistencia a la fluencia, tensión de rotura, dureza o resistencia a la fatiga. También son relevantes otros aspectos relacionados con la soldabilidad de la pieza, su tratabilidad térmica o las propiedades superficiales de la pieza para realizar recubrimientos posteriores. Del mismo modo se debe tener en cuenta que el problema de la porosidad en las piezas fundidas depende de su localización, su caracterización y el grado de exigencia funcional que se le exija. Esto significa que no todos los métodos de ensayo son aconsejables para todas las aplicaciones aunque se podría identificar un perfil básico con algunos requisitos mínimos necesarios que debieran cumplir dichos métodos. Estos requisitos podrían ser los siguientes: 
- debe ser reproducible,

- debe ser, en la medida de lo posible, no destructivo,

- debe permitir identificar las características generales de la porosidad así como su influencia sobre la funcionalidad de la pieza fundida, y

- la relación coste/beneficio del método de ensayo debe permanecer dentro de unos límites razonables.

Cabe destacar que los métodos existentes se adecúan de forma diferente a la detección y distinción entre microporosidad y macroporosidad o la diferenciación entre porosidad por contracción y porosidad por atrapamiento de aire. Con respecto a la idoneidad del método para su uso práctico, los métodos comúnmente empleados para la determinación de porosidad podrían dividirse en métodos destructivos y no destructivos. Entre los primeros podemos destacar los métodos basados en la inspección visual, el radiografiado, la tomografía computerizada, el uso de ultrasonidos, el estudio de frecuencias de resonancia o el método gravimétrico. En el grupo de los métodos destructivos destacan el análisis de imagen de distintas secciones de la pieza y la fusión al vacío. En lo que sigue se hará una breve descripción de los métodos que se acaban de mencionar indicando sus características más relevantes.

\subsubsection{Métodos no destructivos}

- Inspección visual. Se trata de un método ${ }^{3}$ muy sencillo aunque tiene grandes limitaciones, como por ejemplo, el que únicamente permite distinguir cualitativamente la presencia de porosidad superficial. Este método es apropiado en el caso de fabricación de piezas donde únicamente las consideraciones estéticas son importantes como por ejemplo en el caso de la fabricación de modelos.

- Radiografiado. Los métodos de radiografiado (rayos $X$ o $\gamma$ ), están muy extendidos en el ámbito de la fundición industrial ya que permiten detectar, además de la porosidad, otros defectos internos tales como la presencia de grietas o fisuras, segregaciones o inclusiones de impurezas. En cuanto a la evaluación de la porosidad, este método permite localizar e identificar con precisión las zonas donde se concentra, aunque la información es bidimensional lo que impide una evaluación cuantitativa de los niveles de porosidad. Estas limitaciones se unen al hecho de que los resultados obtenidos dependen en gran medida de varios factores tales como el tipo de exposición, la toma de imágenes y su ajuste, la posición de la pieza respecto a la trayectoria de la radiación, el material de la pieza o incluso la experiencia del personal que realiza la interpretación. Cabe destacar que

\footnotetext{
${ }^{3}$ Recogido en la norma ISO (10049) [41] para el caso de aleaciones de aluminio.
} 
existen normas (ASTM-E 155-95, ASTM-E 505 o ASTM E155-00 [6]) que ofrecen imágenes de referencia para la valoración de la porosidad en piezas fundidas.

- Tomografía computerizada. Los desarrollos crecientes en el campo de la automatización e informatización de los procesos de inspección han incrementado tanto la capacidad como la velocidad de operación del equipamiento radiográfico. Una técnica adicional en este campo es la tomografía computerizada de rayos $\mathrm{X}$ que representa la simbiosis, en un ensayo no destructivo, de las técnicas de rayos $\mathrm{X}$ junto con las de análisis de imagen mediante mecanizado descrita en la siguiente sección. Mediante esta técnica se consigue información tridimensional generada por un ordenador a partir de una gran cantidad de imágenes 2D generadas por el sistema de rayos $\mathrm{X}$, lo que permite valorar la porosidad de la pieza fabricada [82]. Mediante una calibración apropiada es posible realizar medidas de densidad con elevada precisión [5].

- Ultrasonidos. La detección de defectos mediante el uso de ultrasonidos también es aplicable a la medida de porosidad en piezas fundidas aunque de manera cualitativa y con cierto grado de incertidumbre. Autores como Palanisamy et al. [65] continúan investigando la posibilidad de identificar defectos internos usando la inspección ultrasónica antes de mecanizar la piezas de fundición. También estudian la automatización de la clasificación de defectos detectados a partir de las señales ultrasónicas usando varias técnicas de procesamiento de señal (transformada rápida de Fourier y "Wavelet Transform") para eliminar el ruido perturbador que aparece en las señales obtenidas debido a la rugosidad superficial y al tamaño de grano.

- Frecuencias de resonancia. Existen trabajos como los de Prucha et al. [70] donde se han desarrollado métodos de detección de defectos, incluyendo la porosidad, basados en el estudio de las frecuencias de resonancia de la pieza (que depende principalmente del módulo elástico, densidad y dimensiones), aunque a día de hoy no es posible discriminar cuantitativamente los defectos debidos exclusivamente a la porosidad.

- Gravimetría. Este método está basado en el principio de Arquímedes y permite conocer la densidad de un sólido mediante el uso de una balanza hidrostática donde se pesa el sólido en aire así como sumergido en agua una vez conocida la densidad del líquido utilizado [4]. Conocida la densidad de la muestra, el cálculo de la porosidad se realiza en función de la densidad teórica de la muestra $\sin$ poros $^{4}$. De entre los métodos no destructivos que han sido expuestos, es precisamente éste el mas utilizado a la hora de valorar la porosidad en piezas fundidas, [27], [61], [58], [60], [59], [13], [12],

\footnotetext{
${ }^{4}$ Comúnmente, los valores de porosidad se expresan en formato porcentual.
} 
[27], [2], [79], [43]. Cabe destacar que este método ha sido utilizado en los experimentos realizados en esta tesis. En el Anexo A se expone con mayor detalle las características del mismo.

\subsubsection{Métodos destructivos}

- Análisis de imagen mediante mecanizado. Dentro del grupo de los métodos destructivos, el más empleado es el de mecanizado de la pieza a estudiar y posterior inspección de las superficies seccionadas. El estudio de la porosidad a nivel micro o macrogeométrico dependerá del tratamiento que se proporcione a las superficies estudiadas y de los métodos de visualización empleados (lupas y microscopios fundamentalmente). Actualmente se está extendiendo cada vez más el uso del ordenador, cámaras digitales, tarjetas de adquisición de imagen y software de tratamiento de imagen (Huang et al. [38]).

Aunque la técnica de análisis de imagen presenta la capacidad de medir el porcentaje de porosidad local, se utiliza una sencilla técnica para relacionar el porcentaje de porosidad de varias imágenes con el porcentaje de porosidad global de una pieza de fundición [62]. Así, los porcentajes de porosidad de cada sección se ponderan con los volúmenes de la sección para calcular el porcentaje medio de porosidad de toda la pieza fundida. Esta técnica presenta el inconveniente de que pudieran quedar zonas de porosidad no seccionadas por lo que, a pesar de que según McClain [62] esta técnica tiene una incertidumbre menor que la picnometría, se recomienda su uso en los casos en que se requieran estudios de porosidad locales.

- Fusión al vacío. Esta técnica permite la cuantificación de la cantidad de gas atrapado en una pieza mediante la fusión de la misma en el interior de una cámara en la que las condiciones de presión, volumen y temperatura son conocidas. El principio básico de funcionamiento de este método consiste en relacionar las variaciones de presión y temperatura experimentadas con la cantidad de gas atrapado que se libera durante la fusión de la pieza. Obviamente las variaciones de presión y temperatura vendrán condicionadas por el volumen y presión de las burbujas de gas atrapado en la pieza.

Existen trabajos experimentales, como los de Luis y Robla [59] Robla et al. [71], donde se describe el diseño de un sistema de fusión al vacío y se obtienen resultados sobre la cantidad de aire atrapado en piezas fabricadas en Zamak-3 (aleación de cinc con 4\% de $\mathrm{Al}, 0,1 \% \mathrm{Cu}$ y 0,032\% Mg ) y Zamak-5 (4\% de Al, $1 \% \mathrm{Cu}$ y 0,055\% Mg). Este diseño (véase la Figura 1.14) contempla la disposición de una cámara de vacío rodeada por un horno de fusión que permite alcanzar temperaturas entorno a los $400{ }^{\circ} \mathrm{C}$ con niveles de vacío cercanos a los 0,4 Torr. Las limitaciones de este diseño se deben a la temperatura máxima que es capaz de soportar las juntas de la cámara 
de vacío. Posteriormente Brevick y Cheng [13] realizaron una comparación entre medidas de porosidad obtenidas mediante el método gravimétrico y las procedentes de un sistema de fusión al vacío (véase la Figura 1.15), de diseño muy similar al anterior, en pequeñas piezas de aluminio fabricadas en máquinas FIAP, por lo que las temperaturas de fusión eran superiores (en torno a $\operatorname{los} 600^{\circ} \mathrm{C}$ ). Las conclusiones aportadas destacan que el método de fusión al vacío es superior al gravimétrico a la hora de evaluar la inyección FIAP ya que este último mezcla las cantidades de gas atrapado con la contracción debida a la solidificación.

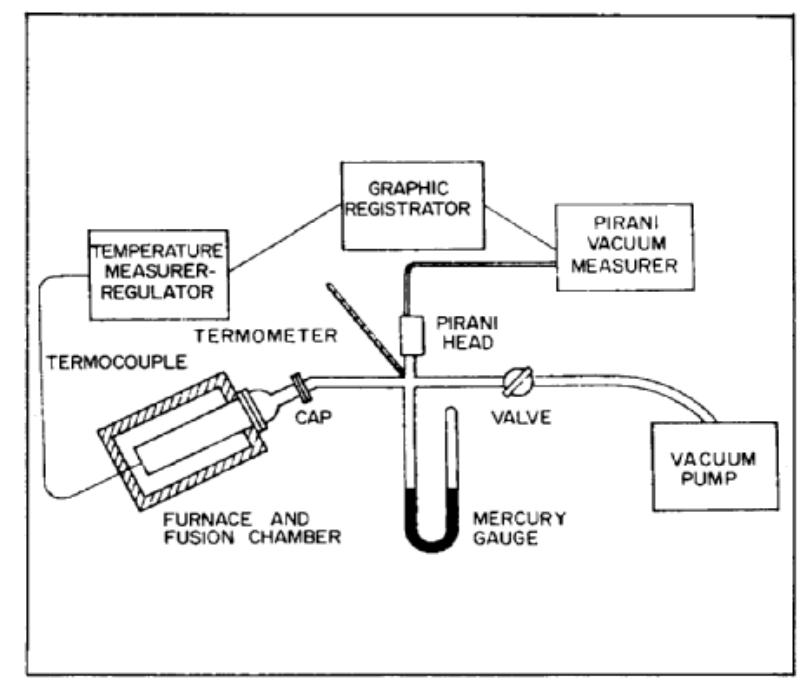

Figura 1.14: Esquema del sistema de fusión al vacío utilizado por Luis y Robla [59].

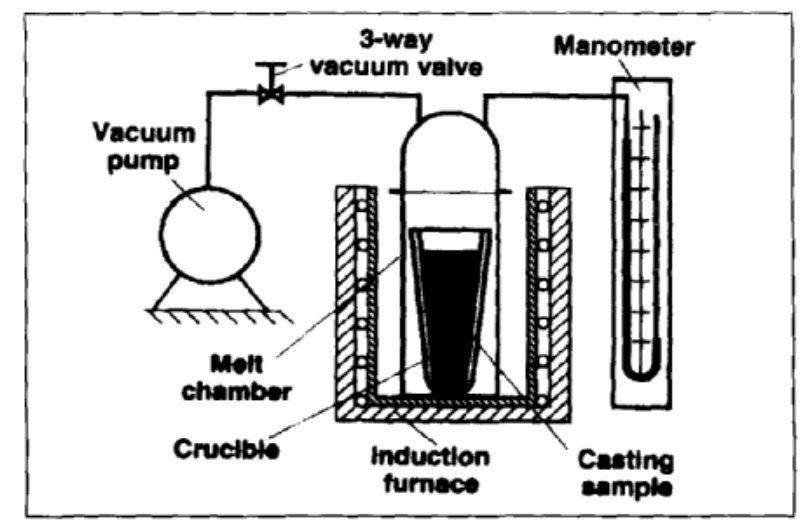

Figura 1.15: Esquema del sistema de fusión al vacío utilizado por Brevick y Cheng [13]. 


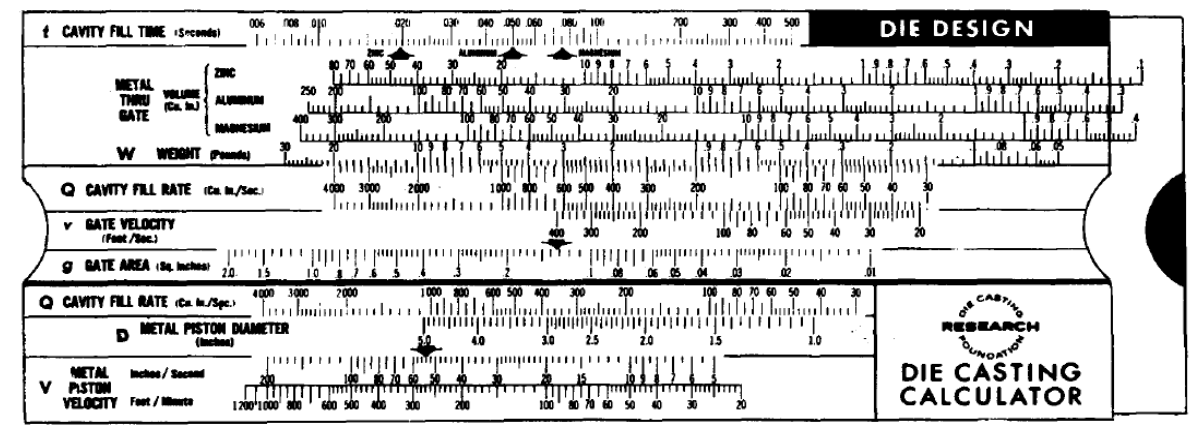

Figura 1.16: Regla de cálculo utilizada para determinar los parámetros de llenado del molde, [68]).

\subsection{Control del proceso de inyección en máquinas FIAP}

Como ya se ha mencionado, una parte importante de la porosidad en las piezas FIAP se debe a los fenómenos de atrapamiento de aire que se producen durante la primera etapa del proceso de inyección, y éstos dependen principalmente de la ley de movimiento del pistón utilizada por lo que es importante establecer un sistema de control eficiente que sea responsable de la ejecución del proceso de inyección conforme a la ley de movimiento escogida.

El control de cualquier proceso de fabricación pasa por una primera etapa en la que se establecen los valores teóricos de los parámetros a controlar que permitirán conseguir el objetivo buscado. Posteriormente es necesario medir las variables afectadas comparándolas con los resultados esperados adoptando entonces los ajustes necesarios que corrijan las desviaciones observadas. En el caso de los procesos FIAP, el objetivo principal es obtener piezas geométricamente correctas y con valores de porosidad aceptables. Centrando el estudio en la porosidad, el problema surge a la hora de identificar los parámetros a controlar que influyen directa o indirectamente sobre su formación. Concretamente existen trabajos como el de Anastasiou [2], donde se identifican hasta 14 parámetros del proceso que afectan a la formación de la porosidad. De entre éstos, el autor escoge 5 como los más significativos entre los que se encuentra la velocidad del pistón durante la primera etapa así como la temperatura del horno de mantenimiento del caldo, la temperatura del molde, la velocidad del pistón durante la segunda etapa y la presión de multiplicación. Aún así, la cantidad de combinaciones que surgen a la hora de configurar correctamente estos parámetros es enorme apareciendo incluso variables que se compensan entre sí [80, 79, 76].

Como se ha comentado con anterioridad, tradicionalmente la configuración de los parámetros de inyección en las máquinas FIAP se realizaba mediante ensayos de prueba y error basados en la experiencia previa. Era común el uso de reglas de cálculo diseñadas por el fabricante de la máquina, como la mostrada en la Figura 1.16, para la obtención de los parámetros de llenado del molde.

Las opciones de parametrización que presentan las máquinas FIAP han ido 
creciendo conforme ha evolucionado la automatización industrial, aunque cabe destacar que hoy en día existe una gran cantidad de máquinas FIAP instaladas en las que, por ejemplo, el único parámetro a configurar en la primera etapa de inyección se reduce al establecimiento de un cierto porcentaje de apertura de válvula, lo que provocará una mayor o menor velocidad máxima del pistón durante esta etapa, siendo totalmente imposible regular la aceleración del pistón.

En cuanto al proceso de medida y comparación, cabe destacar la aportación realizada por Rosa et al. [72], presentando un procedimiento mecánico de medida de velocidad de desplazamiento del pistón basado en la transmisión del movimiento a un cabezal trazador que registraba gráficamente el desplazamiento en función del tiempo. Esto permitió descubrir como evoluciona el pistón durante cada inyección, consiguiendo relacionar dicha evolución con los cambios observados entre piezas fabricadas bajo unas condiciones de inyección dadas y entre inyecciones realizadas con distintas condiciones. Hoy en día los sistema de adquisición de datos de inyección están informatizados pero en su gran mayoría únicamente aportan ventajas en la gestión de la información ya que la configurabilidad de las máquinas sigue estando aún muy limitada. Respecto al control de la inyección, básicamente podemos hablar de sistemas de control en lazo abierto en los que no existe una realimentación en tiempo real, con lo que el control del proceso se suele realizar mediante el registro de gráficos de control (X R), donde se expresan la media y el rango de valores admisibles de los parámetros controlados [31]. Cabe destacar los desarrollos en automatización de las máquinas FIAP desarrollados por empresas como Bühler Druckguss AG que incorporan sistemas de gestión a nivel de célula de fundición integrando en un único sistema de control de proceso ("dat@net") diversas tareas automatizadas que rodean al proceso de inyección como son la colada de metal fundido, la pulverización de desmoldeantes y la manipulación de piezas fabricadas. Este tipo de máquinas cuenta con un sistema de control de inyección en bucle cerrado incorporando servoválvulas capaces de actuar en tiempo real que permiten asegurar una alta repetibilidad para las condiciones de inyección programadas.

\subsection{Objetivos de la tesis}

El objetivo principal de la presente tesis doctoral consiste en estudiar experimentalmente la formación de porosidad por atrapamiento de aire durante la etapa lenta de inyección en procesos FIAP con el fin de minimizar, o eliminar en los casos que sea posible, su aparición. Para alcanzar este objetivo principal se plantean los siguientes objetivos concretos:

- Determinación experimental del volumen de aire atrapado en la cámara de inyección de máquinas FIAP para diferentes velocidades máximas del pistón y fracciones iniciales de llenado. Este objetivo implica la realización de ensayos utilizando agua como material de trabajo, lo que requerirá de la ins- 
talación y puesta a punto de un sistema específico que permita determinar el instante en el que el agua alcanza el conducto de entrada a la cavidad del molde. Adicionalmente se realizarán experimentos de visualización del flujo de agua durante la inyección en un modelo de cámara con objeto de establecer, de un modo más preciso, los distintos mecanismos de atrapamiento de aire que pueden tener lugar durante la etapa lenta de inyección y comparar sus resultados con los experimentos realizados en la máquina.

- Determinación de la velocidad crítica del pistón que minimice la porosidad en piezas fabricadas con aluminio para diferentes condiciones de operación así como su influencia sobre la distribución de la masa de aire atrapado en distintas zonas de la cámara. Para conseguir este objetivo se realizarán diferentes ensayos con aluminio en la máquina FIAP, para lo que se diseñará y construirá un molde configurable que permita el estudio de la etapa lenta del proceso. Este estudio permitirá identificar las zonas en las que se suelen presentar los distintos mecanismos de formación de porosidad, incluidos los debidos a la contracción del metal, para las distintas condiciones de operación consideradas. La evaluación de la porosidad obtenida en las piezas ensayadas se realizará utilizando el método gravimétrico.

- Comparación de los resultados experimentales obtenidos con los resultados de estudios teóricos previos sobre el atrapamiento de aire durante la etapa lenta de inyección así como con los obtenidos mediante un modelo numérico tridimensional basado en una formulación de elementos finitos para resolver las ecuaciones de conservación de la masa y cantidad de movimiento, y el método VOF ("volume of fluid") para el tratamiento de superficies libres.

- Diseño y construcción de un sistema basado en el método de fusión al vacío para determinar con precisión la masa total de aire atrapado en piezas fabricadas con aluminio, con el fin de superar las limitaciones que presenta el método gravimétrico. Junto con la puesta en funcionamiento del sistema se realizarán algunos ensayos preliminares.

Como se ha comentado, los ensayos se realizarán en una máquina FIAP industrial bajo condiciones reales de operación. Esto requerirá de un estudio sistemático del control de inyección que está instalado en la máquina FIAP de la que se dispone. Los resultados de este estudio permitirán determinar los cambios necesarios que se han de realizar en el sistema de control de inyección para conseguir que los ensayos planificados se realicen con un grado suficiente de precisión y repetibilidad. Estos cambios podrán afectar tanto a los dispositivos físicos instalados en la máquina como a las aplicaciones informáticas implementadas en el sistema de control. Asimismo, será necesaria la adaptación y el uso de diferentes dispositivos auxiliares necesarios para el correcto funcionamiento 
de la instalación FIAP, como por ejemplo los sistemas de dosificación y colada, el horno de fusión y mantenimiento o los utillajes de manipulación, entre otros. 


\section{A P Í T U L O 2}

\section{Equipamiento experimental para el estudio de la formación de porosidad en la etapa lenta de inyección}

En el presente capítulo se expondrán las características generales de la instalación experimental utilizada para realizar los ensayos. También se detallarán los desarrollos que han sido necesarios llevar a cabo, especialmente los relacionadas con el control del sistema de inyección, para establecer las condiciones de ensayo necesarias y poder así estudiar los distintos mecanismos de atrapamiento de aire que pueden tener lugar en la primera etapa del proceso de inyección. Finalmente se presentará el diseño y las características de un sistema de fusión al vacío que permita evaluar la cantidad de gas atrapado en las piezas FIAP ensayadas.

\subsection{Instalación experimental}

Los ensayos en máquina llevados a cabo en esta tesis se han realizado en una instalación disponible en los talleres del Área de Ingeniería de los Procesos de Fabricación de la UPCT. Esta instalación fué cofinanciada con fondos FEDER y de la CICYT (TAP 1FD97-2333, DPI2001-1390-C02), así como de la propia UPCT.

En lo que sigue se describirán las características generales de esta instalación (véanse las Figuras 2.1, 2.2 y 2.3), formada básicamente por una máquina FIAP de cámara fría horizontal equipada con un molde especialmente diseñado para realizar los ensayos previstos en esta tesis, y un horno para fundir el metal. Así mismo, la instalación ha sido dotada de una serie de elementos y dispositivos auxiliares utilizados para la refrigeración de pistón, dosificación y colada del metal fundido, limpieza de caldo, engrase de pistón, precalentamiento de la cámara y el molde o pulverización de desmoldeantes entre otros. Debe destacarse que las características de esta instalación exceden el alcance de esta tesis y 


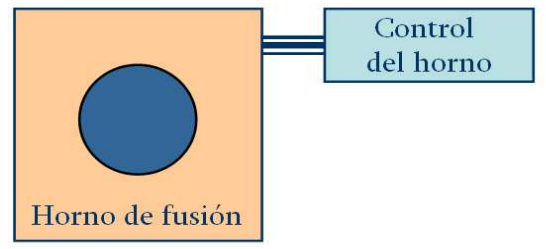

$$
\begin{aligned}
& \text { Control de máquina } \\
& \mathrm{PLC}=\mathrm{PC}
\end{aligned}
$$

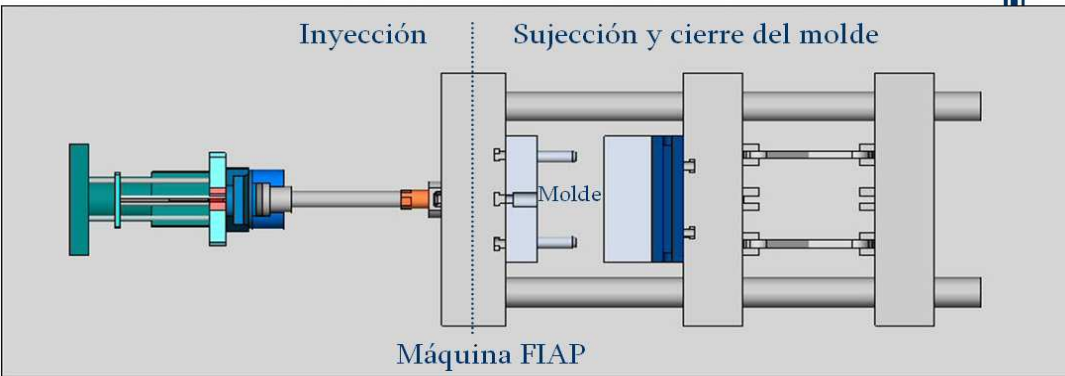

Figura 2.1: Representación esquemática de la instalación experimental.

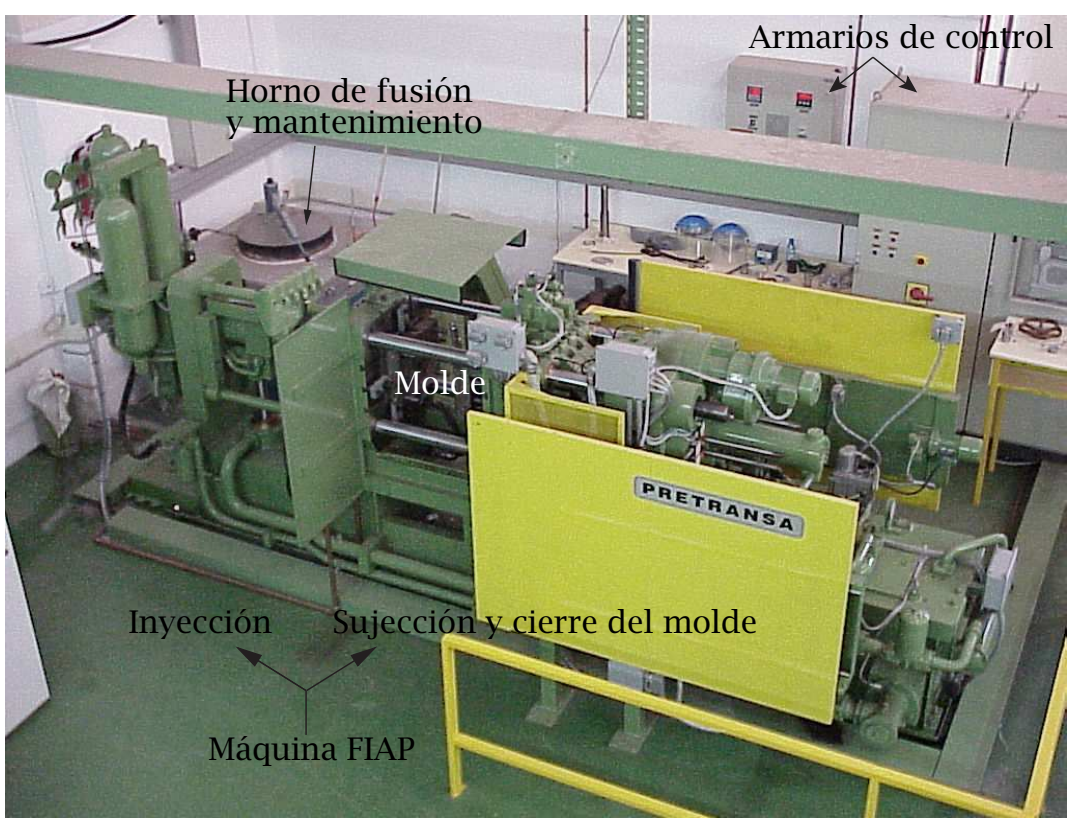

Figura 2.2: Instalación experimental disponible en la UPCT. 


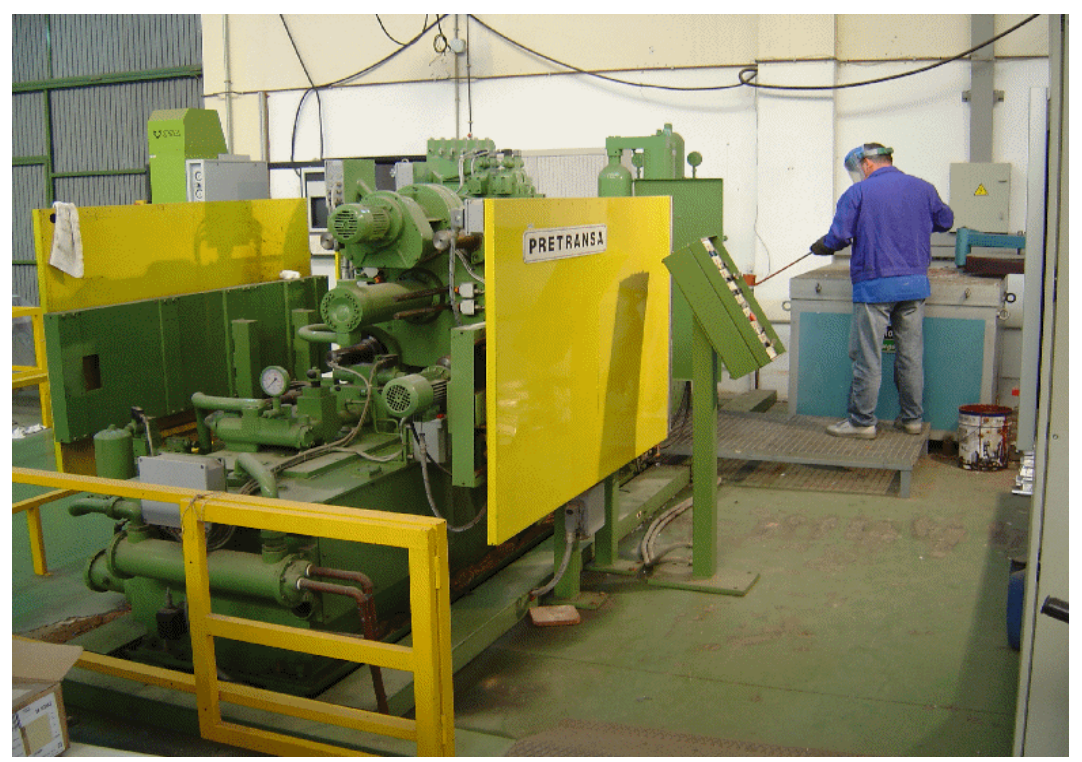

Figura 2.3: Instalación experimental. Vista posterior.

podría aplicarse a estudios concretos en diferentes etapas del proceso de inyección y condiciones de operación muy diversas, aunque como se ha comentado con anterioridad, la presente tesis se centrará exclusivamente en la etapa lenta del proceso de inyección.

\subsection{Máquina de inyección y equipamiento auxiliar}

La máquina de inyección utilizada fue fabricada en el año 2000 por la empresa Prensas y Transformaciones S.A.. Las dimensiones generales de esta máquina son de $4913 \mathrm{~mm}$ de longitud y $1420 \mathrm{~mm}$ de anchura. Los componentes de esta máquina se clasifican en dos grupos, los relacionados con el sistema sujección y cierre del molde, responsables de mantener el molde cerrado durante su llenado, y los relacionados con el sistema de inyección, el cual permite introducir apropiadamente el metal fundido dentro del molde. Finalmente se describirá el sistema de control de la máquina.

\subsubsection{Sistema de sujeción y cierre del molde}

El sistema de cierre, además de sujetar convenientemente las dos partes del molde para extraer con facilidad la pieza fabricada y preparar el molde para una nueva inyección, permite ejercer la fuerza necesaria para que las dos partes del molde permanezcan cerradas durante el proceso de inyección. En este sistema se pueden identificar básicamente los tres elementos que se enumeran a continuación:

1. Los platos de sujeción permiten apoyar y sujetar las dos partes del molde, 


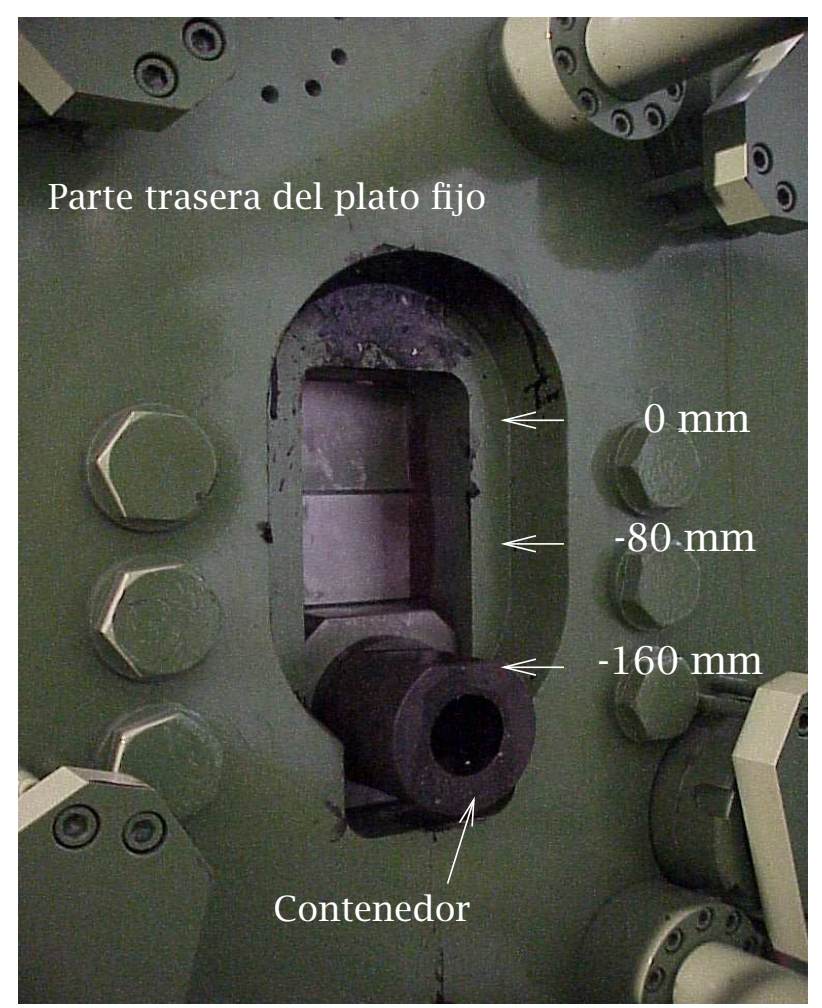

Figura 2.4: Sistema de inyección configurado a -160 mm.

para lo cual incorporan ranuras capaces de fijarlos mediante bridas y tornillos. En uno de los platos, que es fijo, existe un alojamiento que permite centrar la posición de amarre de la parte fija del molde, donde se acopla el contenedor, el cual conformará la cámara de inyección junto a un casquillo de ajuste. Este alojamiento permite modificar la altura relativa entre el contenedor y el plato fijo con lo que es posible instalar en la máquina moldes de diferente geometría. En concreto, esta máquina permite su configuración en tres alturas distintas referenciadas como 0, -80 y -160 mm (véanse las Figuras 2.4 y 2.5). El otro plato sujeta la parte móvil del molde en el que normalmente se encuentra la cavidad principal que alojará la
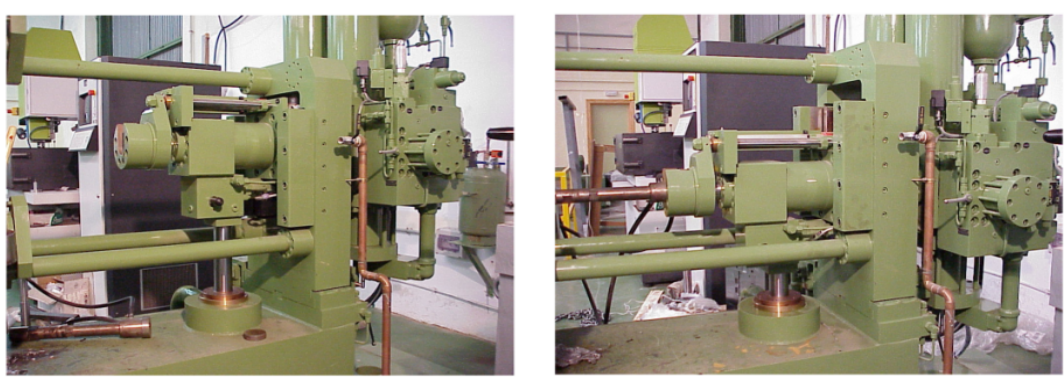

Figura 2.5: Sistema de inyección en 0 y -160 mm. 
pieza fabricada. La apertura y cierre de los platos, y por tanto del molde, se realiza desplazando linealmente el plato móvil sobre los ejes de centrado, más conocidos como columnas de guiado. La carrera de desplazamiento del plato en esta máquina es de $325 \mathrm{~mm}$. Independientemente de la carrera disponible, es necesario modificar la distancia entre platos con el fin de poder montar moldes de diferentes alturas ${ }^{1}$. La máquina dispone de un procedimiento para la adaptación de esta distancia mediante husillos engranados a un motor eléctrico, lo que produce el desplazamiento lineal del plato móvil a muy baja velocidad. Este ajuste, necesario únicamente cuando se realiza un cambio de molde, es muy importante para que el sistema de cierre pueda ejercer la fuerza máxima justo al final de su carrera, asegurando de esta forma el cierre de las dos partes del molde. La distancia entre columnas de esta máquina es de $500 \mathrm{~mm}$ permitiendo la instalación de moldes de hasta $420 \mathrm{~mm}$ de anchura.

2. Sistema hidráulico. Con este sistema se pueden alcanzar fuerzas de cierre de hasta $1500 \mathrm{kN}$. Este parámetro limita las posibilidades de la máquina ya que la máxima superficie proyectada de la cavidad, y por tanto el tamaño de la pieza a fabricar, dependerá de la presión de multiplicación ejercida por el pistón durante la última etapa del proceso de inyección. El sistema hidráulico está formado básicamente por una bomba hidráulica que genera la presión necesaria para el accionamiento de los dispositivos de cierre del molde. En esta máquina se trabaja con un nivel de presión general de funcionamiento de $4000 \mathrm{kPa}$, alcanzando hasta $8000 \mathrm{kPa}$ mientras que la máquina mantiene el molde cerrado durante el proceso de inyección.

3. El sistema mecánico de cierre permite la transmisión del movimiento de cierre mediante un conjunto de rodilleras que se bloquean al final de su recorrido, asegurando así el cierre de los platos de la máquina. Este sistema también es el responsable del desplazamiento de la placa de expulsores utilizados para la extracción de la pieza del molde después de cada inyección. Esta placa suele estar alojada en la parte móvil del molde y es accionada mediante unos pernos que atraviesan el plato móvil que son desplazados por un dispositivo mecánico, (véase la Figura 2.6). Este dispositivo permite una regulación manual de la carrera de los expulsores (la carrera máxima es, en este caso, igual a $120 \mathrm{~mm}$ ).

\subsubsection{Molde}

Una de las tareas más complejas y costosas en el mundo de los procesos FIAP es sin duda el diseño y la fabricación del molde. Este proceso de diseño del molde no se limita a plasmar la compleja geometría de la pieza a fabricar sino

\footnotetext{
${ }^{1}$ El término de altura de molde corresponde a la distancia entre las superficies de contacto del molde con la máquina cuando esté cerrado.
} 


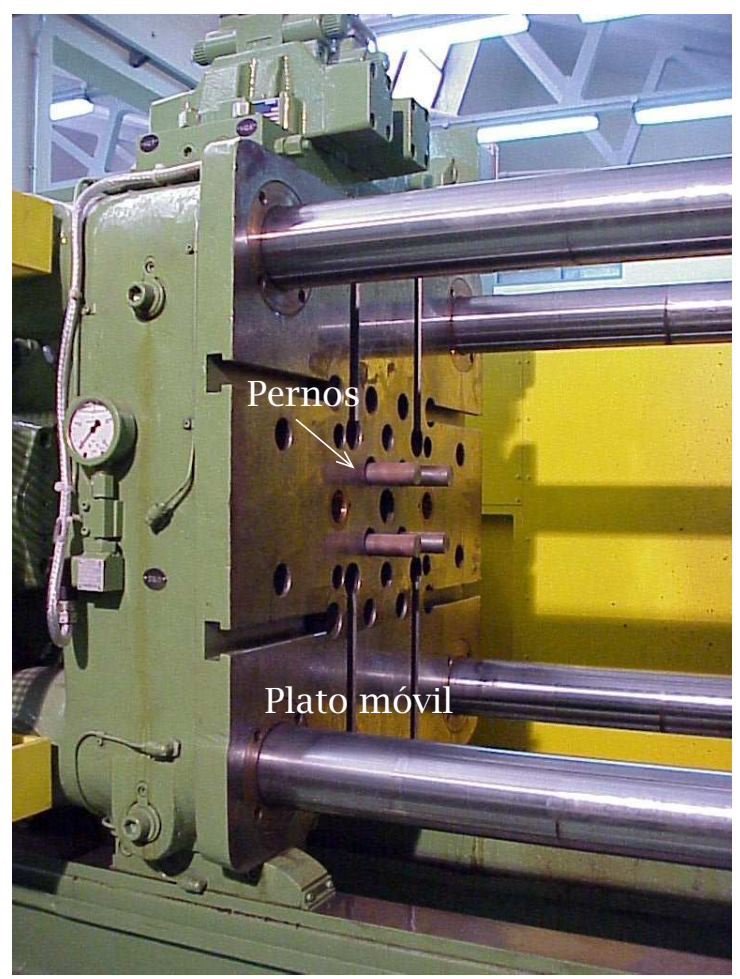

Figura 2.6: Sistema de pernos dispuestos en el plato móvil para el desplazamiento de la placa de expulsores.

que debe incorporar la información geométrica correspondiente a los canales de colada, vientos, rebosaderos, extractores, radiales ${ }^{2}$ y líneas de enfriamiento. Llevar a cabo un diseño correcto y eficiente es pues una tarea compleja que requiere un esfuerzo técnico y económico muy importante y cuyo resultado es decisivo en el correcto desarrollo del proceso. De hecho, es posible encontrar moldes utilizados hoy en día en el sector de la automoción cuyo precio final supera el millón de euros.

Teniendo en cuenta las circunstancias económicas del marco en el que se ha desarrollado la presente tesis, y los objetivos generales del grupo de investigación usuario de las instalaciones, se ha diseñado un molde de geometría sencilla, (véase la Figura 2.7) pero que resulta totalmente configurable en cuanto a los elementos complementarios anteriormente citados. La geometría de la cavidad del molde se puede ver en la Figura 2.7. Se trata de un prisma rectangular de dimensiones 101, $6 \times 152,4 \times 4 \mathrm{~mm}$ cuyos detalles pueden observarse en Anexo B. Trabajos experimentales llevados a cabo por otros autores $[48,75,2]$ también utilizan geometrías de este tipo simplificando así el estudio del proceso. Del mismo modo, la construcción del molde resulta más económica ya que no es necesario utilizar radiales. Tanto los rebosaderos, como los vientos y el canal

\footnotetext{
${ }^{2}$ Dispositivos mecánicos que se desplazan hacia el interior y el exterior de la cavidad del molde antes, y después respectivamente, del llenado del mismo.
} 

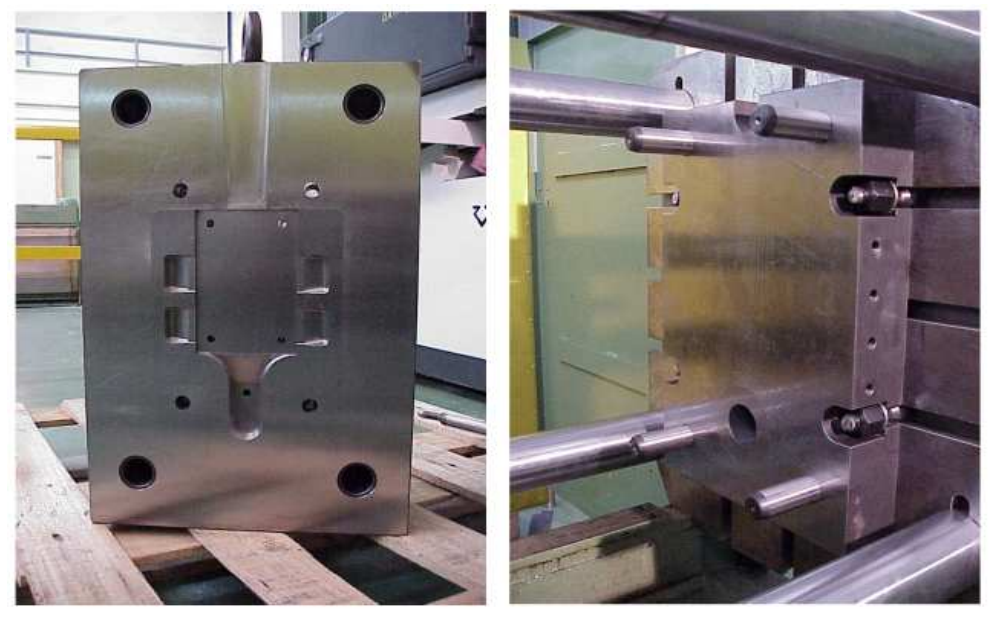

Figura 2.7: Molde: parte móvil y parte fija montada en la máquina.

de colada son intercambiables mediante pequeñas piezas postizas que quedan integradas en el molde. Esto permite realizar ensayos con diferentes configuraciones en las que se pueden incluso anular dichos componentes. En la Figura 2.8 se pueden observar los vientos e insertos de rebosaderos y canal de colada. Se diseñaron y construyeron inicialmente un total de tres vientos con espesores de 50,100 y $150 \mu \mathrm{m}$.

La parte fija del molde queda posicionada con respecto al plato fijo de la máquina mediante el acceso al contenedor de inyección. En este caso se optó por utilizar un casquillo intercambiable de unión entre el molde y el contenedor. De esta forma, como ya se ha anticipado, la cámara de inyección quedará compuesta por la cavidad interior del contenedor junto con la del casquillo (véanse las Figuras 2.9 y 2.10). Esto permite realizar ensayos con diferentes diámetros de cámara de inyección y, según el diseño finalmente adaptado, es posible realizar inyecciones con diámetros de hasta de $70 \mathrm{~mm}$.

Se dispusieron cuatro líneas de enfriamiento de $9 \mathrm{~mm}$ de diámetro equidistantes $50 \mathrm{~mm}$ entre ellas y situadas en la zona central del molde. La placa de expulsores (véase la Figura 2.11), aloja cinco expulsores normalizados de $8 \mathrm{~mm}$ y cuatro de $16 \mathrm{~mm}$. En cuanto a los materiales seleccionados y sus tratamientos térmicos se pueden consultar en la Tabla 2.1. En el anexo B se pueden consultar los planos constructivos del mismo.

La elevada complejidad geométrica de las piezas obtenidas en estos procesos y las elevadas presiones ejercidas sobre el metal fundido durante su solidificación, hace que se produzcan habitualmente problemas a la hora de separar la pieza del molde una vez fabricada, incluso cuando se usan los dispositivos mecánicos de extracción anteriormente mencionados. Para evitar, o en cualquier caso minimizar, el efecto de adhesión que se produce durante la solidificación a presión antes de cada inyección, se aplica en ambas partes del molde un fluido desmoldeante hidrosoluble con base de silicona, el cual se pulveriza quedando 


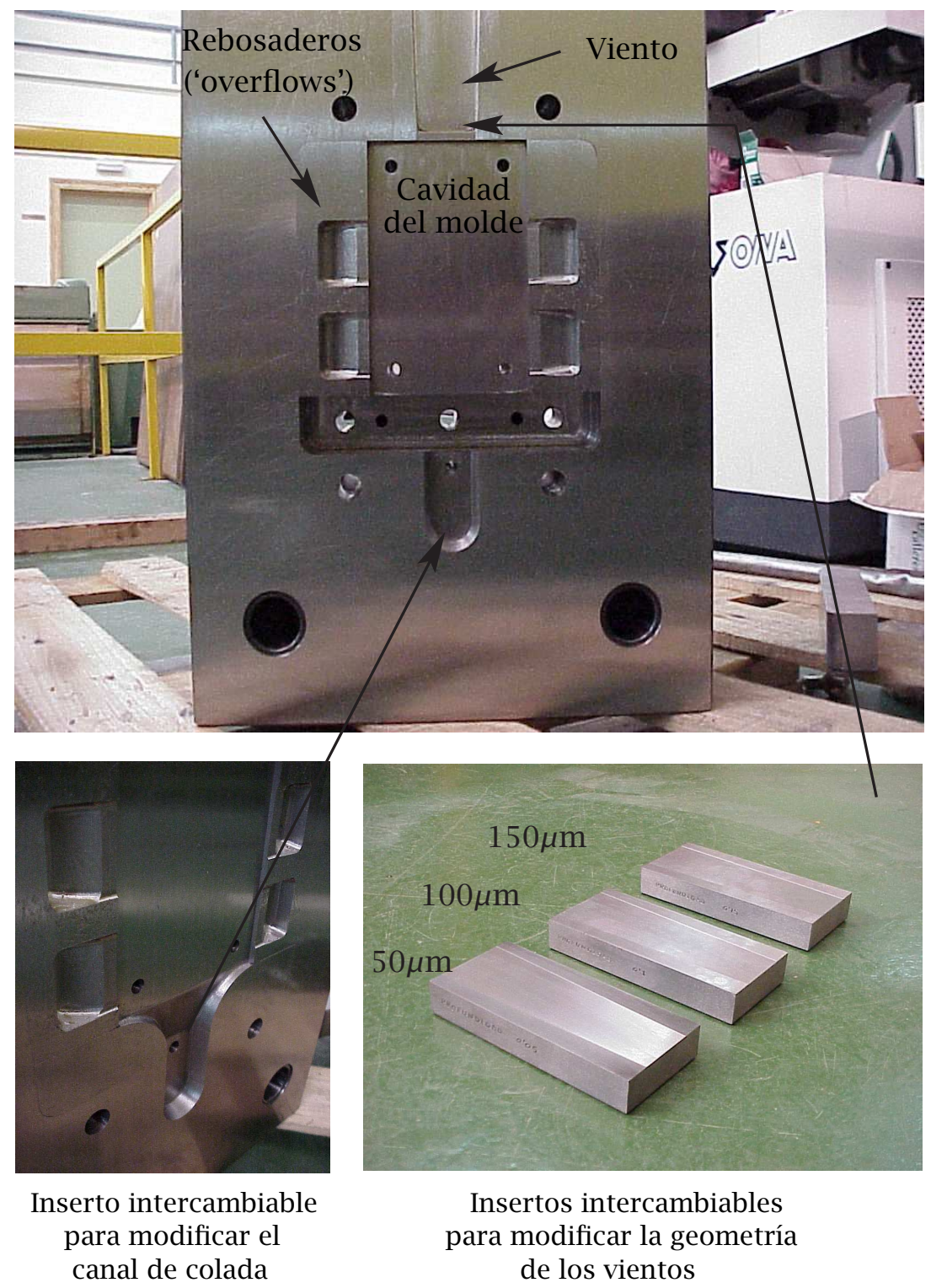

Figura 2.8: Molde e insertos metálicos intercambiables. 


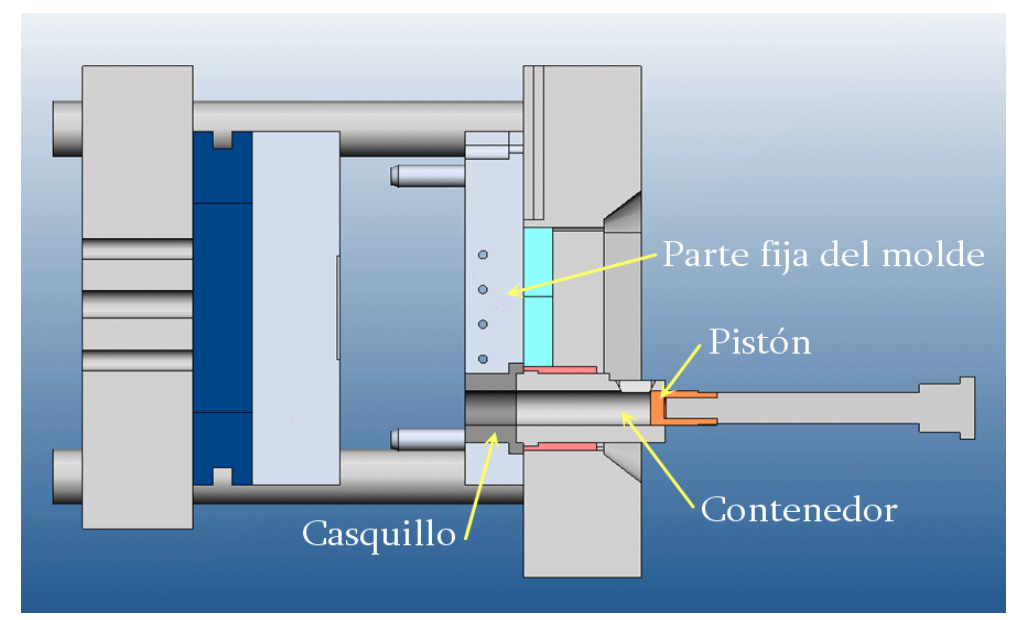

Figura 2.9: Representación esquemática de la cámara de inyección utilizada.

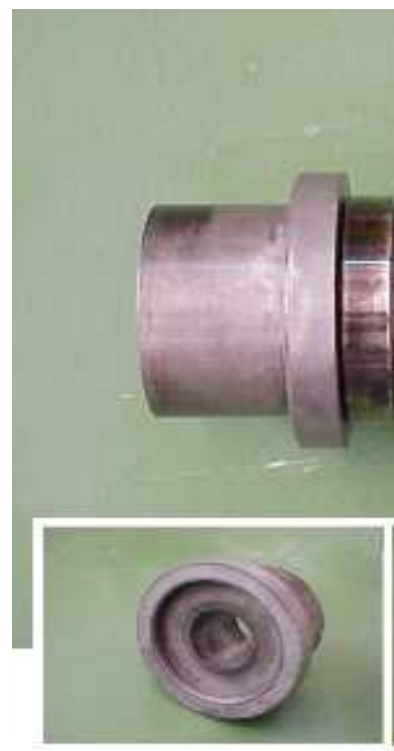

(a)

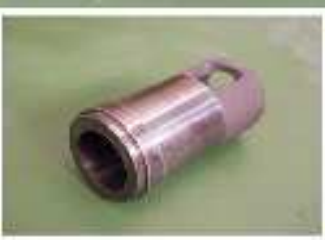

(b)

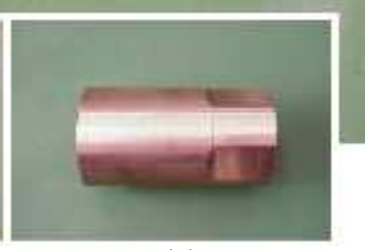

(c)

Figura 2.10: Cámara de inyección de $50 \mathrm{~mm}$ de diámetro formada por el conjunto (a) casquillo, (b) contenedor y (c) pistón. 


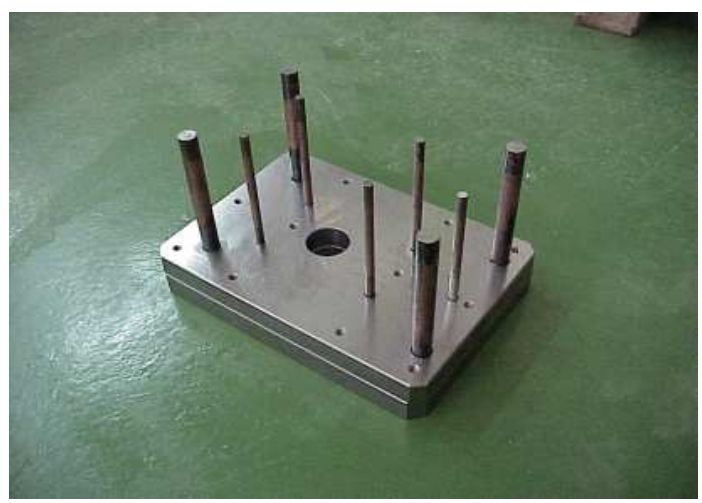

Figura 2.11: Placa de expulsores.

\begin{tabular}{|c|c|c|}
\hline & Material & Tratamiento \\
\hline $\begin{array}{l}\text { Molde } \\
\text { (parte fija) }\end{array}$ & $\begin{array}{l}\text { ORVAR -2 } \\
\text { UDDELHOM }\end{array}$ & $\begin{array}{l}\text { Templado Revenido } \\
\text { 44-46 HRc }\end{array}$ \\
\hline $\begin{array}{l}\text { Molde } \\
\text { (parte móvil) }\end{array}$ & $\begin{array}{l}\text { ORVAR -2 } \\
\text { UDDELHOM }\end{array}$ & $\begin{array}{c}\text { Templado Revenido } \\
\text { 44-46 HRc }\end{array}$ \\
\hline $\begin{array}{l}\text { Placa } \\
\text { expulsores }\end{array}$ & $\mathrm{F}-111$ & $\begin{array}{c}\text { Templado Revenido } \\
\text { 44-46 HRc }\end{array}$ \\
\hline Casquillos & F-174 & $\begin{array}{c}\text { Templado Revenido HRc } 36 \\
\text { Nitrurar HVi 1000-1100, Esp. 0,2 }\end{array}$ \\
\hline Postizos & $\begin{array}{c}\text { ORVAR -2 } \\
\text { UDDELHOM }\end{array}$ & $\begin{array}{c}\text { Templado Revenido } \\
44-46 \mathrm{HRc}\end{array}$ \\
\hline $\begin{array}{l}\text { Guías y } \\
\text { pernos }\end{array}$ & $F-523$ & $\begin{array}{l}\text { Templado Revenido } \\
\text { 56-60 HRc }\end{array}$ \\
\hline
\end{tabular}

Tabla 2.1: Materiales seleccionados para la construcción del molde y los elementos auxiliares. 

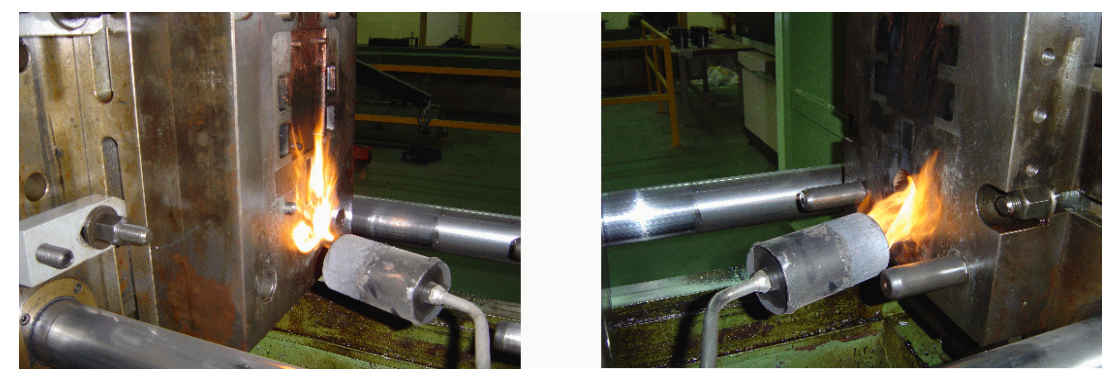

Figura 2.12: Precalentamiento de molde y contenedor con llama directa.

solidificado al contacto con las paredes calientes del molde. Para ello se utiliza una pistola manual que pulveriza el fluido desmoldeante mediante aire comprimido. La aplicación del desmoldeante entraña cierto riesgo para el operario, ya que requiere el acceso a la parte interior del molde por lo que se suele automatizar y regular mediante dispositivos sencillos controlados por el PLC del sistema de control de la máquina, ofreciendo parámetros de configuración tales como el caudal o el tiempo de pulverizado.

Una vez inyectada la pieza y abierto el molde, se transporta la pieza, aún caliente, hacia los sistemas de transporte intermedios o directamente a las prensas de desbarbado donde se separan los canales de llenado, rebosaderos y otros restos de metal que deben ser eliminados. En algunos casos se suele realizar algún proceso de mecanizado adicional para llevar a cabo un acabado más específico. En este caso, y debido a la simplicidad de la geometría requerida para el estudio de la etapa lenta del proceso, el postprocesado de la pieza se ha limitado al corte y separación manual del canal de colada.

Uno de los principales motivos de deterioro de los moldes y contenedores suele ser la aparición de grietas y fugas por fatiga térmica. Téngase en cuenta que el molde recibe el impacto periódico de una masa de metal fundido a temperatura y presión elevadas. Este efecto se ve multiplicado cuando se inicia la jornada productiva ya que el salto térmico es mucho mayor. Para minimizar este efecto, existen dispositivos de precalentamiento de moldes y contenedores, la mayoría de los cuales, usan circuitos de aceite caliente para alcanzar lo antes posible una temperatura de trabajo estables. La utilización de estos sistemas suele situar la vida media de los moldes entre 150000 y 200000 inyecciones. Por motivos principalmente económicos en este caso se ha realizado el precalentamiento mediante la aplicación de una llama de una lámpara de propano (véase Figura 2.12), controlando la temperatura alcanzada mediante un termopar de contacto.

\subsubsection{Sistema de inyección}

El sistema de inyección se encarga de accionar al pistón durante el proceso de inyección. Como ya se ha comentado, es necesario configurar el desplazamiento del pistón según las diferentes etapas de inyección en las que se encuentre el 
proceso. El control sobre la velocidad del pistón se realiza mediante una válvula de descarga hidráulica proporcional (Parker Hidraulics TDAD-A-1097). El fluido es liberado con un caudal proporcional a la apertura de la misma lo que hace que se consiga mayor velocidad conforme aumenta el caudal. Durante la inyección, la presión aplicada sobre el pistón cae proporcionalmente a la velocidad de descarga pero se recupera rápidamente mediante la aportación adicional del acumulador. Se debe destacar que durante las últimas etapas del proceso se necesitan velocidades y aceleraciones elevadas, así como grandes presiones de accionamiento. Por ello el sistema de inyección utiliza, además del correspondiente circuito de aceite, un subsistema acumulador de nitrógeno seco que permite, mediante su descarga, conseguir las elevadas velocidades necesarias. En concreto, esta máquina es capaz de conseguir velocidades máximas de inyección de 1,55 $\mathrm{ms}^{-1}$ en un recorrido de $300 \mathrm{~mm}$ y aplicar presiones de hasta $300 \mathrm{~kg} \mathrm{~cm}^{-2}$. Para conseguir el gran aumento de presión necesario durante la última etapa de la inyección, el sistema utiliza un cilindro multiplicador que se introduce en la zona posterior del circuito de fluido hidráulico con la válvula antirretorno cerrada, consiguiendo el aumento de presión mediante una disminución del volumen disponible por el fluido.

\subsubsection{Cámara de inyección}

Antes de empezar la producción de una determinada pieza, es importante decidir correctamente el diámetro apropiado de la cámara de inyección. Esta elección viene determinada por factores tales como la capacidad de la máquina, la presión, el tiempo de enfriamiento y sobre todo el volumen de metal a inyectar. Como se expondrá mas adelante, fracciones de llenado pequeñas conllevan, en general, mayor tendencia al atrapamiento de aire. Por otro lado, fracciones muy altas pueden provocar la expulsión del fluido por la boca de colada o problemas de otro tipo relacionados con la economía del proceso (una gran cantidad de material de exceso implica un sobre coste de reciclado).

Como se ha comentado con anterioridad, la cámara de inyección está formada por un contenedor unido a un casquillo que permite adaptar el diámetro escogido a la parte fija del molde (véase la Figura 2.10). En cuanto a los materiales empleados, es común encontrar pistones fabricados en aleaciones de cobre-berilio $(\leq 2 \%)$ y contenedores y casquillos de acero F-174 templado, revenido y nitrurado. Se debe tener en cuenta que las altas presiones y velocidades alcanzadas durante el proceso de inyección pueden provocar que el metal escape hacia atrás entre las paredes del pistón y el contenedor. Para evitar esto, se deben utilizar ajustes con tolerancias inferiores a 0,03 $\mathrm{mm}$ en los diámetros interiores de contenedor y pistón. En la Tabla 2.2 se expresan las holguras recomendadas para la fabricación de pistones de inyección en función del diámetro del mismo.

A pesar de no existir ninguna norma al respecto, en el entorno industrial de la fundición por inyección se suele utilizar entre otras, una geometría específica 


\begin{tabular}{|c|c|c|c|c|}
\hline Diámetro (mm) & 45 & 50 & 55 & 60 \\
\hline Holgura & $-0,02$ & $-0,03$ & $-0,03$ & $-0,04$ \\
\hline (mm) & $-0,04$ & $-0,05$ & $-0,05$ & $-0,06$ \\
\hline Diámetro (mm) & 65 & 70 & 75 & 80 \\
\hline Holgura & $-0,04$ & $-0,05$ & $-0,05$ & $-0,06$ \\
\hline (mm) & $-0,06$ & $-0,07$ & $-0,07$ & $-0,08$ \\
\hline
\end{tabular}

Tabla 2.2: Holguras utilizadas en la fabricación de pistones de inyección.

de la cara del pistón aunque no se ha encontrado ningún trabajo o referencia que lo justifique formalmente. Esta modificación incorpora un pequeño chaflán de 8 mm a $45^{\circ}$ mecanizado en la cara del pistón con un escalón a un diámetro $6 \mathrm{~mm}$ menor que el nominal (véase la Figura 2.13). Del mismo modo, en la cámara de inyección, se suele mecanizar en la zona de expulsión de la pieza, un ángulo de salida de unos $5^{\circ}$ con longitudes de unos $30 \mathrm{~mm}$ para facilitar la expulsión del metal sobrante que queda solidificado en la cámara, el cual es empujado por el pistón durante la apertura. Estos diseños hacen que la geometría final de la cámara de inyección no se corresponda con una geometría cilíndricamente perfecta. Dado que las modificaciones geométricas antes mencionadas tienen como finalidad fundamental aumentar la vida de la cámara de inyección y pistón, requisito que no es esencialmente importante para llevar a cabo los experimentos considerados en la presente tesis, y con el fin de conseguir una mayor generalidad en los resultados obtenidos, se realizaron modificaciones en las geometrías de los pistones y casquillos utilizados en esta máquina para conseguir una cámara de inyección totalmente cilíndrica (véanse las Figuras 2.13 y 2.14).

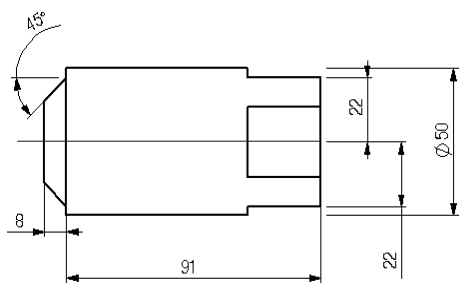

(a)

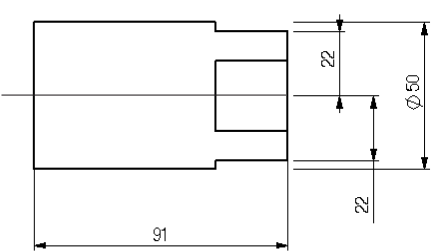

(b)

Figura 2.13: Plano constructivo de un pistón de $50 \mathrm{~mm}$ (a) y su modificación para adaptarla a los experimentos (b). 


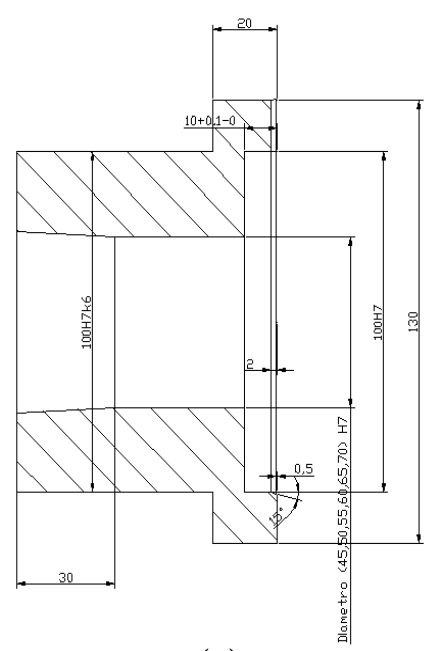

(a)

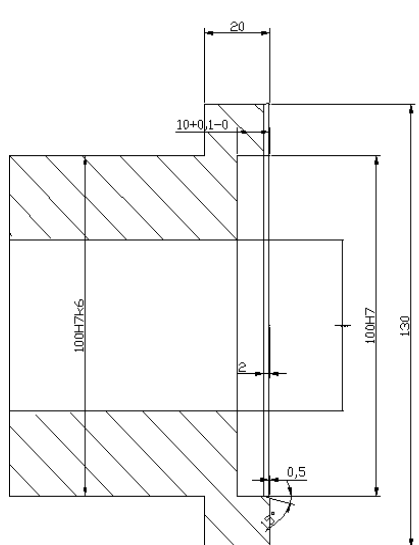

(b)

Figura 2.14: Plano constructivo de los casquillos (a) y su modificación (b).

\subsubsection{Dispositivos de refrigeración y engrase del pistón}

Como se acaba de indicar, es necesario mantener tolerancias muy estrechas entre el pistón y el contenedor. Esto puede resultar bastante complicado debido a las temperaturas elevadas que se alcanzan y a la menor masa y coeficiente de conductividad térmica del pistón. Para evitar los problemas que podrían surgir debido a los diferentes valores de dilatación térmica entre el pistón y el contenedor, se emplea un dispositivo que permite la refrigeración por agua del pistón mediante un circuito abierto adaptado en el interior del vástago porta pistón, minimizando así los problemas de rozamiento y desgaste prematuro. Debido a la importancia de esta refrigeración, las máquinas FIAP suelen incorporar elementos de control de flujo en el circuito de refrigeración. Las versiones más sencillas se limitan a una simple visualización de la circulación del agua en alguna zona del circuito. Para minimizar aún más los fenómenos de fricción y desgaste entre pistón y contenedor, es necesaria una correcta lubricación de las zonas de contacto. Para ello se suelen lubricar las paredes exteriores del pistón en cada inyección. En ocasiones también se debe realizar el engrase del interior del contenedor, lo que provoca el rechazo de una serie muy corta de piezas que arrastran el exceso de lubricante. Esto hace que la pieza pueda quedar manchada e incluso que los elementos volátiles del lubricante puedan quedar atrapados en el interior de la pieza. En el entorno industrial encontramos sistemas automatizados que realizan los procesos de engrase del pistón y cámara así como de los componentes móviles del molde (expulsores y pernos guía). 


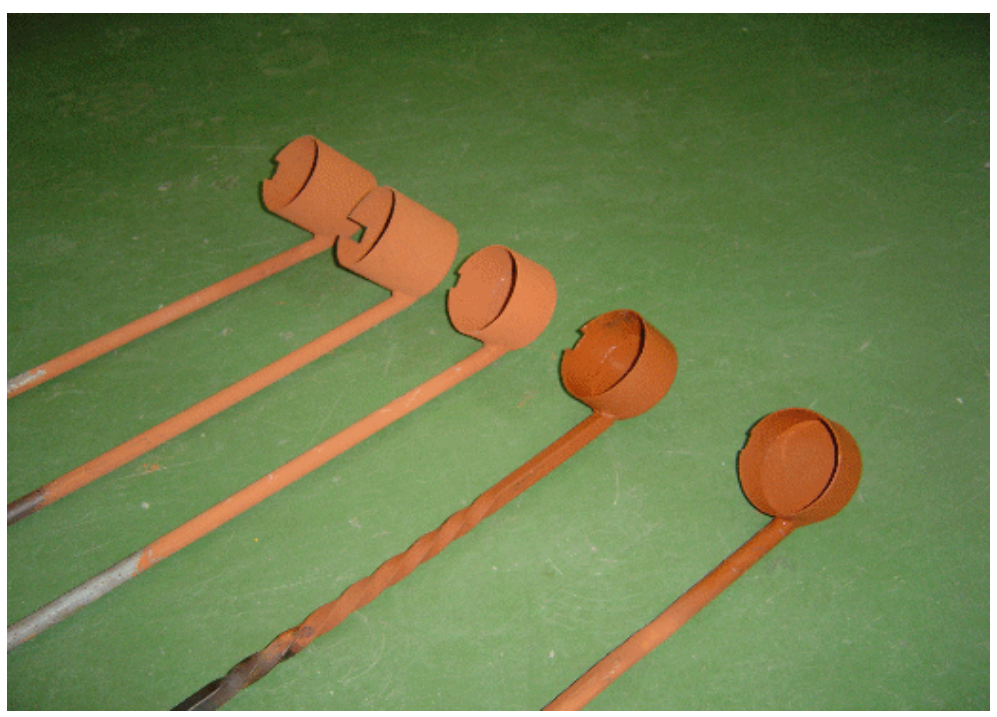

Figura 2.15: Cucharas de colada utilizadas durante los ensayos para diferentes valores de la fracción inicial de llenado de la cámara de inyección.

\subsubsection{Elementos de dosificación y colada}

El proceso de dosificación del metal fundido en la cámara de inyección puede presentar dos dificultades a tener en cuenta:

- En primer lugar se debe tener en cuenta que la manipulación de metal fundido a altas temperaturas, puede conllevar riesgos de derramamiento y quemaduras graves de quien maneja la cuchara de vertido.

- Por otro lado es necesario realizar dosificaciones precisas, tanto desde el punto de vista experimental como desde el económico, ya que una dosificación excesiva conlleva gastos de materia prima y energía innecesarios. Desde el punto de vista del proceso, en el estudio experimental que se ha llevado a cabo cabe destacar la extraordinaria influencia que sobre los fenómenos de atrapamiento de aire tiene la fracción inicial de llenado de la cámara de inyección. Más adelante se estudiarán los procedimientos escogidos que permiten optimizar el procedimiento de dosificación para el caso que nos ocupa.

Hoy en día, en muchas instalaciones FIAP es común encontrar dispositivos automatizados de dosificación que disminuyen los problemas de seguridad y dosificación que se acaban de comentar. En nuestro caso, obviamente, no se justifica el uso de sistemas automatizados por lo que se ha optado por la fabricación de diferentes cucharas de colada manuales que permiten dosificar las cantidades correspondientes a cada fracción inicial de llenado ensayada (véase la Figura 2.15). 


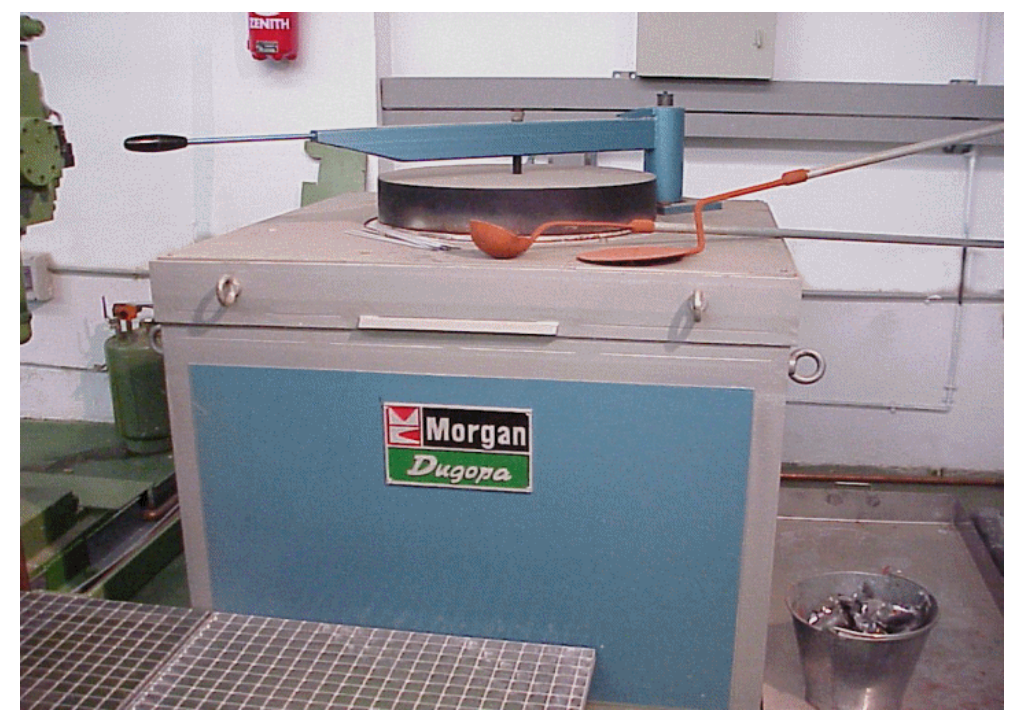

Figura 2.16: Horno de fusión y mantenimiento.

\subsection{Horno de fusión y mantenimiento del metal fundido}

Para disponer de metal fundido en cada inyección, se usa un horno de fusión y mantenimiento junto con dispositivos auxiliares tales como precalentadores, elementos de limpieza de caldo, manipulación y vaciado entre otros. A continuación se realizará una breve descripción de este tipo de equipos así como las modificaciones, ajustes y acondicionamientos que ha sido necesario realizar.

Para trabajar en condiciones reales de operación se debe disponer de un equipo de fusión y mantenimiento de la aleación fundida con el que se realizarán los experimentos, suficientemente próximo a la máquina de inyección. En este caso, se optó por utilizar un único horno tanto para la fusión como para el mantenimiento del caldo fundido ya que el volumen de metal fundido que se requiere para los experimentos no justifica el uso de dos hornos diferentes. Teniendo en cuenta los requerimientos experimentales, se decidió escoger un horno de crisol calentado por resistencias eléctricas (MORGAN/DUGOPA tipo MARK III) con una potencia total de $42 \mathrm{~kW}$. La capacidad de carga es de unos $85 \mathrm{~kg}$ de aleación de aluminio y presenta unas dimensiones externas de $1180 \times 940 \times 1250 \mathrm{~mm}$ (véase la Figura 2.16). Este horno cuenta con tres componentes principales:

El cuerpo del horno integra los paneles de resistencias, el crisol, la peana que sirve de soporte del crisol, los conjuntos aislantes y juntas, la tapa de brazo deslizante y el sistema de seguridad. El tipo de crisol utilizado para la fusión del aluminio (véase la Figura 2.17) es de carburo de silicio recubierto por material aislante que queda vitrificado durante el calentamiento inicial. La vida media de este tipo de crisoles es de unas 2000 horas. Esto hace necesario la incorporación de un sistema de recogida del metal fundido para el momento en el que se produzca la rotura del crisol. Este sistema está com- 


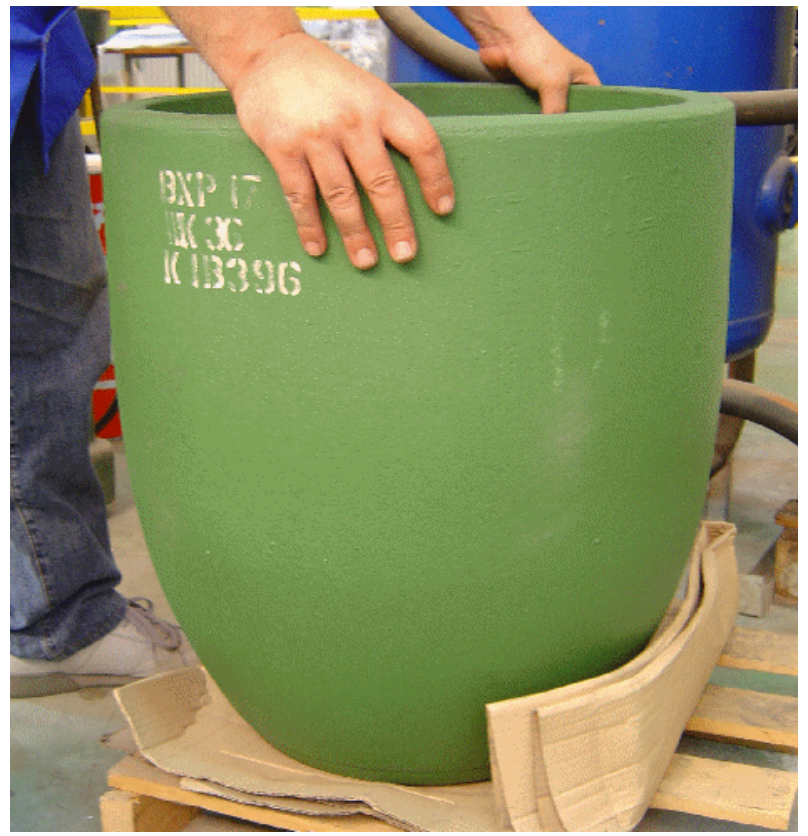

Figura 2.17: Crisol incluido en el horno de fusión y mantenimiento.

puesto por unas guías interiores que recogen el caldo y lo dirigen hacia el exterior a través de un orificio que normalmente se encuentra tapado mediante una lámina de zinc que se fundirá al contacto con la aleación fundida. En el caso de rotura se dispone de un recipiente externo que permite la recogida del metal fundido.

El equipo de pirometría está compuesto por dos termopares de tipo $\mathrm{K}$ y los correspondientes cables de compensación, que proporcionan información de la temperatura del caldo y de la temperatura de las resistencias.

En el armario de control se encuentra el regulador del horno, el controlador de temperatura de las resistencias, el panel luminoso indicativo del funcionamiento de cada una de las resistencias, un contador de horas de funcionamiento del crisol y la botonera de los modos de operación (véase la Figura 2.18). El regulador es un CN500 de CONATEC gobernado por microprocesador. Permite, entre otras funciones, la configuración del tipo de control PID y ON/OFF con histéresis por relé, la gestión de alarmas y la asignación de temperaturas de consigna. Adicionalmente existe un mando de control de la temperatura de las resistencias, que evita un sobrecalentamiento de las mismas fijando una temperatura máxima de operación, que en este caso está fijada en $1050^{\circ} \mathrm{C}$. En el caso de que se alcance esta temperatura en las resistencias, éstas no se conectarán aunque la temperatura del caldo esté por debajo de su temperatura de consigna. Esta situación se suele presentar durante el proceso de carga debido, principalmente, a las inercias térmicas y se ve acentuado conforme se intenta fundir la carga a una mayor 


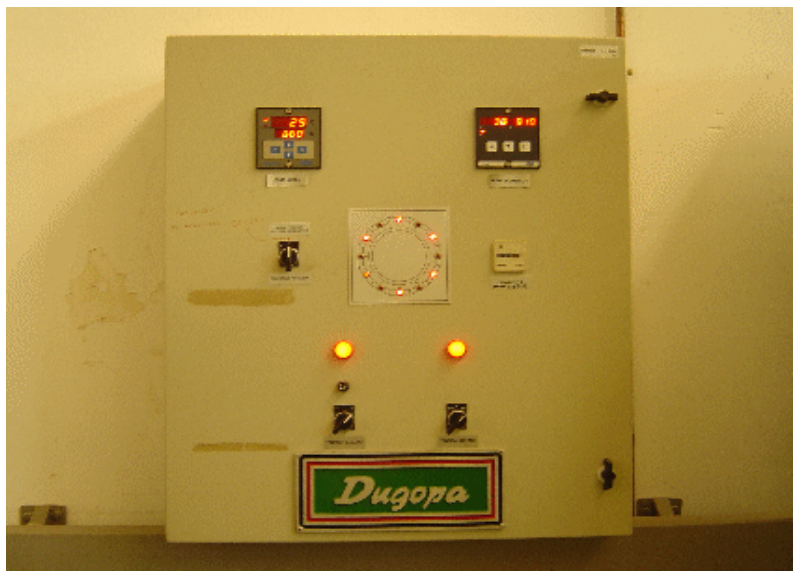

Figura 2.18: Armario de control del horno de fusión y mantenimiento.

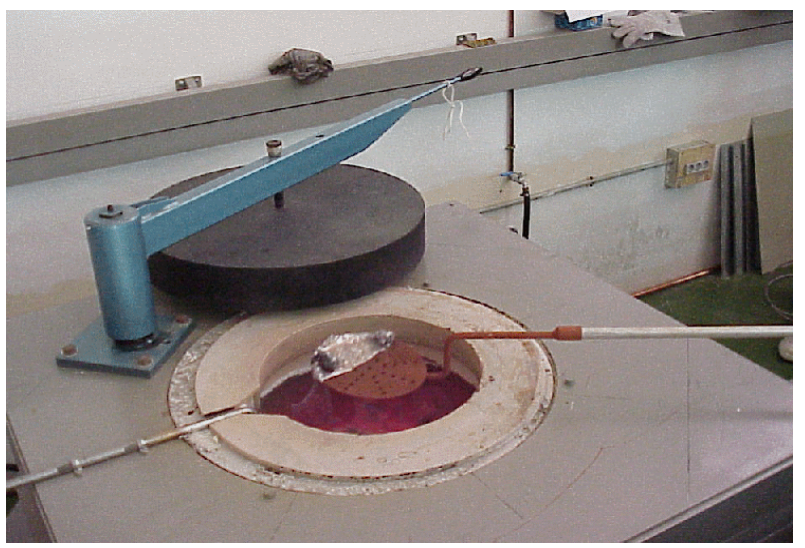

Figura 2.19: Espumadera utilizada para la eliminación de escorias en el horno de fusión y mantenimiento.

velocidad.

Antes de realizar los ensayos o después de efectuar alguna de las siguientes operaciones; reposición de metal fundido, refusión de metal o cambios y limpieza de crisoles; es necesario realizar un proceso de limpieza del caldo. En el mejor de los casos dicha limpieza se reduce a eliminar la capa de óxido de aluminio que se genera en la superficie del caldo una vez abierto el horno. Cuando se producen refusiones o se limpia el crisol es necesario que, una vez fundido el caldo, se realice una limpieza con elementos desoxidantes, sales fundentes de protección y desgasificación. Estos elementos vienen presentados en forma de pastillas que se sumergen en el metal fundido provocando un arrastre de los contaminantes que acaban formando una capa de escoria en la superficie del caldo que finalmente se elimina de forma manual mediante un utensilio similar a una espumadera (véase la Figura 2.19).

Para vaciar el horno se utilizan lingoteras como la mostrada en la Figura 2.20. 


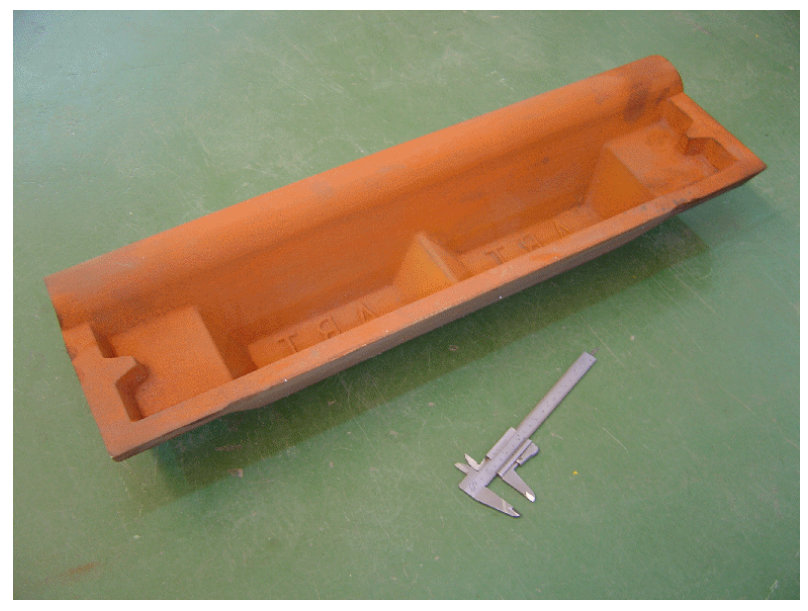

Figura 2.20: Lingotera utilizada en la operación de vaciado del crisol.

El vaciado se suele realizar cuando se prevén pausas prolongadas, reduciendo así el consumo eléctrico y aumentando la vida del crisol. Con el fin de evitar adherencias de metal en las lingoteras se aplica un desmoldeante con denominación comercial Moldline 100.

\subsection{Sistema de control de la máquina FIAP}

El sistema de control instalado en la máquina permite básicamente lo siguiente:

- Por un lado, establecer la lógica de operación general de la máquina. Esto incluye tareas como, por ejemplo, el control de la posición de los extractores y del pistón antes de cerrar el molde con el fin de evitar su aplastamiento, o la activación de las alarmas de operación (temperaturas elevadas, niveles de fluidos de engrase o sistemas de seguridad personal del operario, entre otras),

- y por otro, controlar el sistema de inyección. Este último es el encargado de gestionar las válvulas y dispositivos del sistema de inyección que permiten programar el movimiento del pistón según convenga.

En el estudio experimental llevado a cabo en la presente tesis se pretende determinar la influencia de la ley de movimiento del pistón en los fenómenos de atrapamiento de aire durante la etapa lenta de inyección, por lo que el trabajo realizado en torno al sistema de control de la máquina FIAP se ha dedicado al estudio de la repetibilidad del sistema de inyección así como a la implantación de mejoras, tanto a nivel software como hardware, que permitan aumentar la precisión del sistema. 
A continuación se describirán los componentes físicos y las aplicaciones informáticas instaladas inicialmente en la máquina por el fabricante. Posteriormente, en la Sección 2.4.2, se describirán las modificaciones de la configuración inicial que ha sido necesario realizar para llevar a cabo los experimentos previstos en la presente tesis doctoral.

\subsubsection{Configuración inicial del sistema de control}

\subsubsection{Componentes físicos}

EL control se realiza desde el punto de vista físico mediante un Controlador Lógico Programable (PLC) que utiliza un PC estándar como interface con el usuario y diversos dispositivos auxiliares tales como sensores, relés o transductores entre otros. El PLC (Siemens S7-300) es el elemento principal de control de la máquina. Dispone de 128 entradas y 48 salidas lo que le permite controlar todos los componentes instalados en la máquina. Cuenta también con un módulo de comunicaciones RS-232 que le permite intercambiar información con el PC. El ordenador personal (PC Intel Pentium II a 400 Mhz con sistema operativo MS Windows 98) permite, por un lado, introducir los parámetros de control de la máquina, y por otro, captar los datos de las inyecciones realizadas en los distintos ensayos. El PC incorpora una tarjeta de adquisición de datos, ADAC 5500MF, bajo bus PCI de 12 bits y $25 \mathrm{MHz}$, con un total de $16 \mathrm{E} / \mathrm{S}$ digitales y un convertidor A/D de 8 canales. Mediante esta tarjeta se incorporan al sistema de control las señales analógicas emitidas por los transductores de presión y posición descritos posteriormente.

La información que procesa el PC y el PLC proviene de los diversos dispositivos auxiliares instalados en la máquina, los cuales a su vez reciben señales de control emitidas por el PLC. Entre estos dispositivos se pueden destacar los sensores de proximidad capacitivos, que actúan como sensores de final de carrera, transductores, relés inductivos, acondicionadores de señal, termopares o diversos motores eléctricos, como por ejemplo, los encargados del movimiento de las puertas de seguridad. La información emitida por el transductor de posición del pistón durante el proceso de inyección, debe ser utilizada por el PLC para regular la apertura de la válvula principal de descarga, que es la que permite ajustar la velocidad del pistón para conseguir la ley de movimiento deseada. En la sección 2.4.3 se lleva a cabo un estudio detallado sobre la influencia de la apertura de esta válvula en el movimiento del pistón, lo que permitirá un mejor control de la posición del pistón en función de las condiciones de ensayo deseadas.

Los transductores disponibles en la máquina son de tipo analógico. Este tipo de transductores, sencillos de instalar y configurar, generan una señal analógica, en este caso una tensión entre 0 y $10 \mathrm{~V}$, que es proporcional a la magnitud medida en cada momento. Por ejemplo, el transductor de posición tiene un rango de medida de $300 \mathrm{~mm}$, generando una salida de $10 \mathrm{~V}$ para dicha posición. Así una 


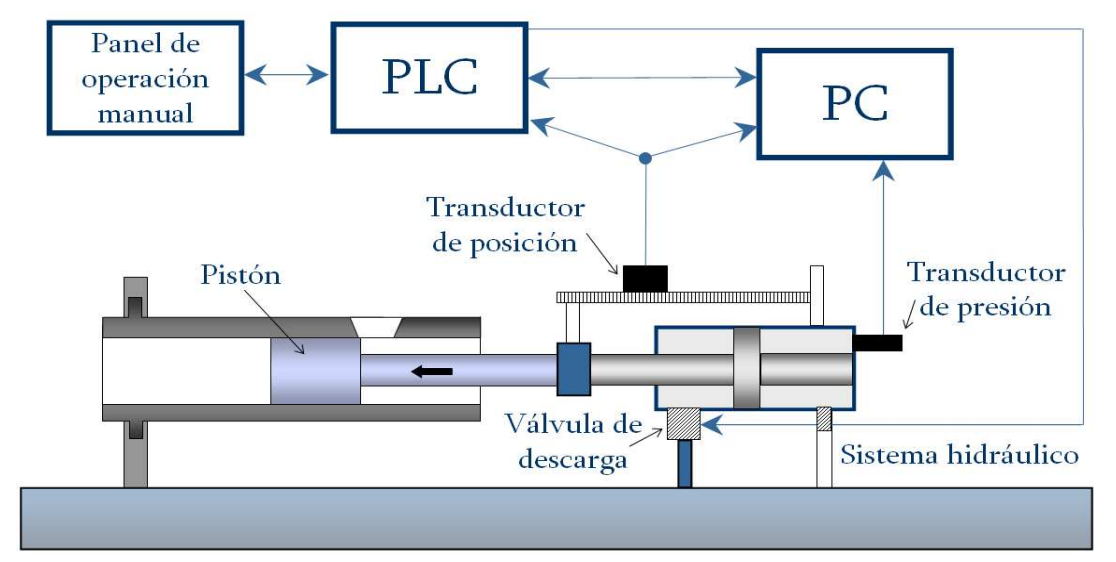

Figura 2.21: Esquema básico del sistema de control de la máquina FIAP.

lectura de $5 \mathrm{~V}$ correspondería a una posición del pistón de $150 \mathrm{~mm}$. Concretamente se trata de una regla de tipo inductivo que desplaza un cursor solidario al pistón, sobre una bobina lineal fija en la bancada de la máquina. La resolución de la regla es de $0,1 \mathrm{~mm}$ y permite trabajar con velocidades de desplazamiento de hasta $5 \mathrm{~ms}^{-1}$. El transductor de presión es de tipo capacitivo y se encuentra localizado en la zona posterior del cilindro hidráulico principal (véase la Figura 2.21).

En la Figura 2.22 se muestra el panel de operación manual dispuesto de forma independiente del armario de control en el que se encuentran el PC y el PLC. Este panel posee una botonera que incluye las funciones de operación de la máquina necesarias para la ejecución del proceso incluyendo las relacionadas con la seguridad del operario. Podemos citar por ejemplo, el cierre automático del molde, orden de inicio de inyección, manejo manual de apertura y cierre del molde, cambio de altura del molde, reinicialización de alarmas o pulsador de emergencia. Los problemas de seguridad principales que se podrían producir en estas instalaciones son, básicamente:

- el atrapamiento del operario en la zona de cierre del molde y

- el vertido o la proyección incontrolada de metal fundido fuera de la máquina.

Para minimizar el riesgo de este tipo de situaciones se cuenta con puertas laterales correderas que aíslan la zona de la línea de partición del molde, lugar por donde se suelen producir proyecciones de metal fundido. Estas puertas incorporan bandas de contacto y barreras mecánicas que impiden el acceso del operario durante la operación de cierre. Otro dispositivo de seguridad utilizado es la botonera de doble pulsación que requiere el uso de dos manos para cerrar el molde. 


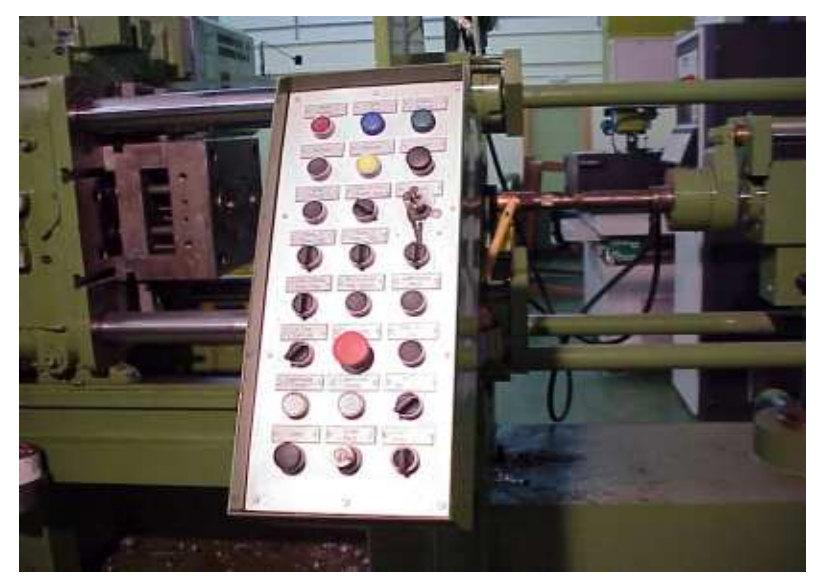

Figura 2.22: Panel de operación manual de la máquina FIAP.

\subsubsection{Aplicaciones informáticas}

Todas las secuencias de control se programan a través de aplicaciones informáticas de alto nivel que proporcionan una interface de fácil uso y configuración. Concretamente el fabricante proporciona dos aplicaciones encargadas de realizar las tareas de control y configuración de la máquina y del proceso. En primer lugar, el Programa de Control de Máquina (PCM) permite configurar el PLC para regular, entre otros, los parámetros siguientes:

- el tiempo que debe mantenerse cerrado el molde una vez realizada la inyección,

- la velocidad de desplazamiento del pistón para cada etapa del proceso (incluido el desplazamiento final para expulsar el metal remanente que ha quedado solidificado en la cámara de inyección),

- el tiempo de espera antes de actuar el expulsor central de la pieza,

- el recorrido del expulsor central,

- la contrapresión utilizada para reducir la presión final aplicada por el pistón durante la solifidicación del metal, o

- el número de inyecciones que deben transcurrir antes de realizar una determinada acción como, por ejemplo, lubricación central cada 20 inyecciones.

Los cambios en la configuración de éstos parámetros se realiza de forma esporádica y suelen quedar fijos una vez instalado el molde. Es importante una correcta configuración de los mismos ya que los parámetros temporales, tales como los tiempos de enfriamiento o el tiempo de espera antes de activar los expulsores, entre otros, tienen una relación directa con la productividad del proceso, con lo que se deben ajustar tratando de minimizar los tiempos no productivos. 
A pesar de la importancia de estos parámetros hay que destacar los dedicados al control de la ley de movimiento del pistón que, como se indicó en el Capítulo 1, influyen directamente sobre la cantidad de aire atrapado en la etapa lenta del proceso de inyección y presentan una mayor dificultad a la hora de ser seleccionados.

La versión original de esta aplicación (véase la Figura 2.23) permite planificar la inyección de una forma bastante limitada, ya que sólo establece un porcentaje de apertura de válvula para cada etapa de inyección. Esto genera desplazamientos del pistón con velocidades constantes durante las dos etapas sin más opción que determinar la posición del pistón en el que empieza cada una. Por último, la aplicación también permite establecer la duración de la etapa en la que se incrementa la presión que ejerce el pistón (presión de multiplicación) durante la solidificación del metal para reducir así el tamaño de las posibles burbujas de gas atrapado.

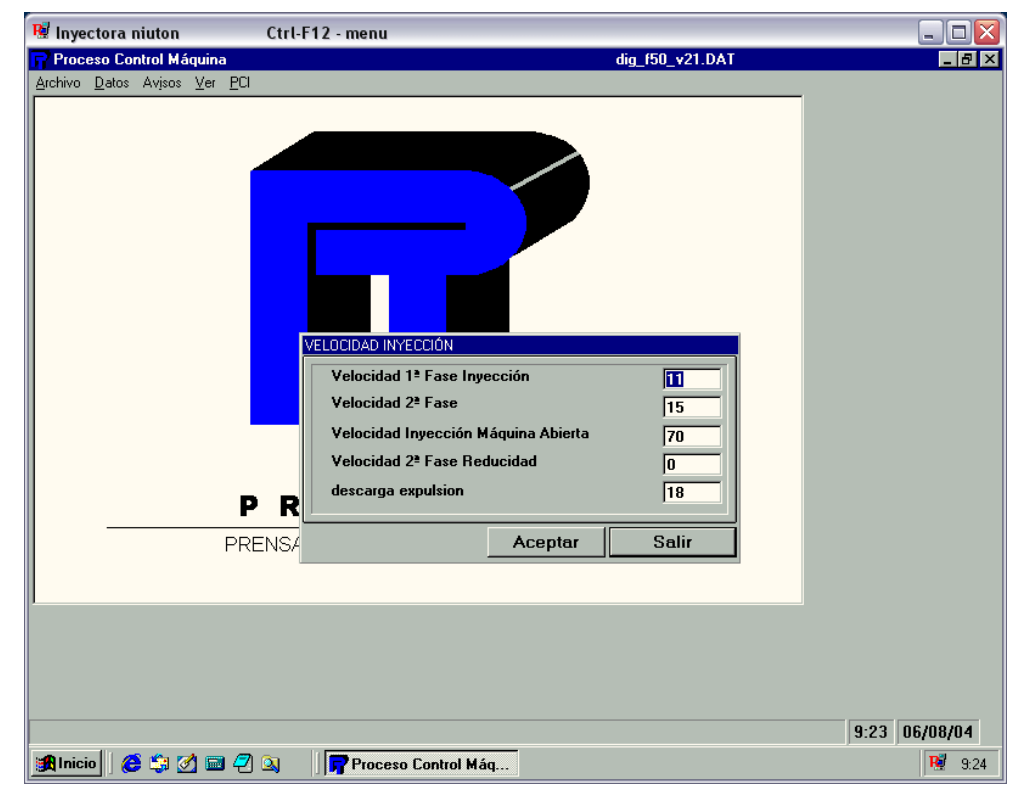

Figura 2.23: Detalle de una de las ventanas de la aplicación informática, PCM, encargada de regular la apertura de la válvula durante el proceso de inyección.

El fabricante de la máquina también proporciona una aplicación (PCI) que permite, entre otras cosas, registrar y analizar estadísticamente las posiciones del pistón en función del tiempo. Esta aplicación recibe información y la procesa pero no actúa sobre el PLC ni, por tanto, sobre la máquina. Su mayor utilidad reside en su capacidad de adquisición de datos (con una frecuencia de lectura configurable) y la posterior exportación de estos datos en formato digital (ASCII). Entre la información incluida en estos ficheros se puede citar, por ejemplo, la identificación del ensayo realizado, las condiciones de operación utilizadas, el número de datos adquiridos o el tiempo de adquisición, junto con el listado 
de las posiciones del pistón, presión en el cilindro hidráulico y velocidades para todos los instantes considerados. La Figura 2.24 presenta un ejemplo de un listado resumido generado por este módulo. Así mismo, esta aplicación es capaz de

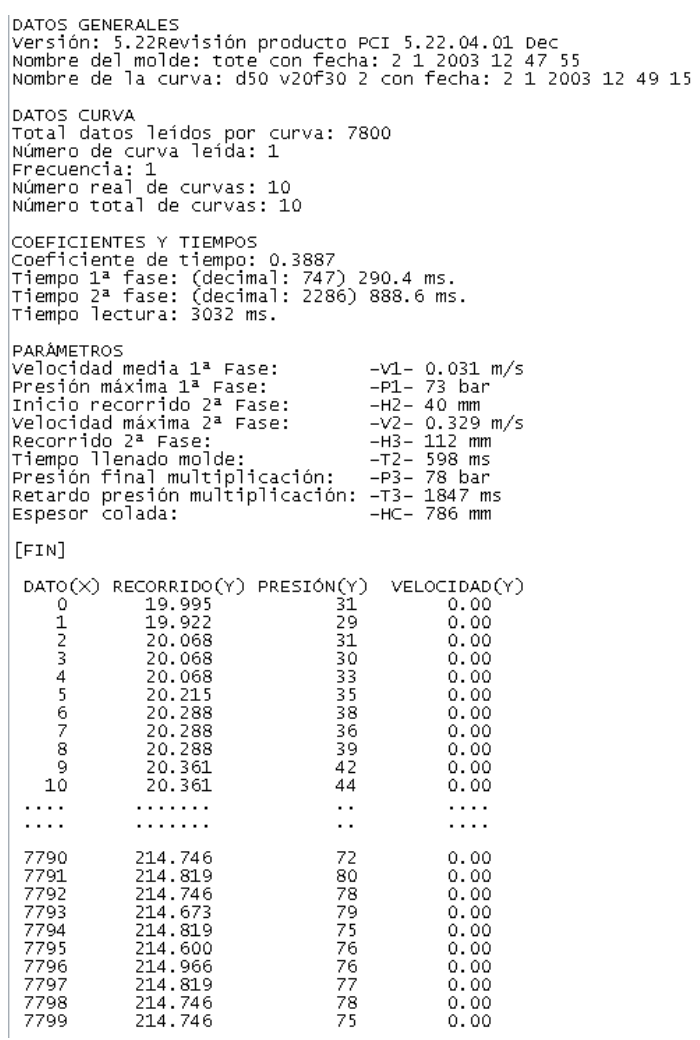

Figura 2.24: Ejemplo de listado resumido de datos de una inyección.

generar representaciones gráficas tanto de posición y velocidad del pistón como de presión en el cilindro hidráulico frente al tiempo a partir de los datos registrados durante las inyecciones realizadas (véase la Figura 2.25). Junto con ellas se presentan una serie de alarmas que avisan al operario cuando alguno de los parámetros, como por ejemplo la velocidad máxima alcanzada en cada una de las etapas, no está dentro de los rangos establecidos por el usuario. También es posible la intercomparación gráfica entre curvas de varias inyecciones y dispone de un amplio módulo para el control estadístico del proceso. Así mismo posee una utilidad para el cálculo de parámetros tales como:

- Fracción inicial de llenado de la cámara de inyección (\%).

- Posición del pistón para la que, si no se atrapa aire, la cámara quedaría completamente llena de metal fundido $(\mathrm{mm})$. Esta posición determinaría el inicio de la etapa rápida.

- Posición del pistón en la que debería comenzar a llenarse la cavidad del molde (mm). 


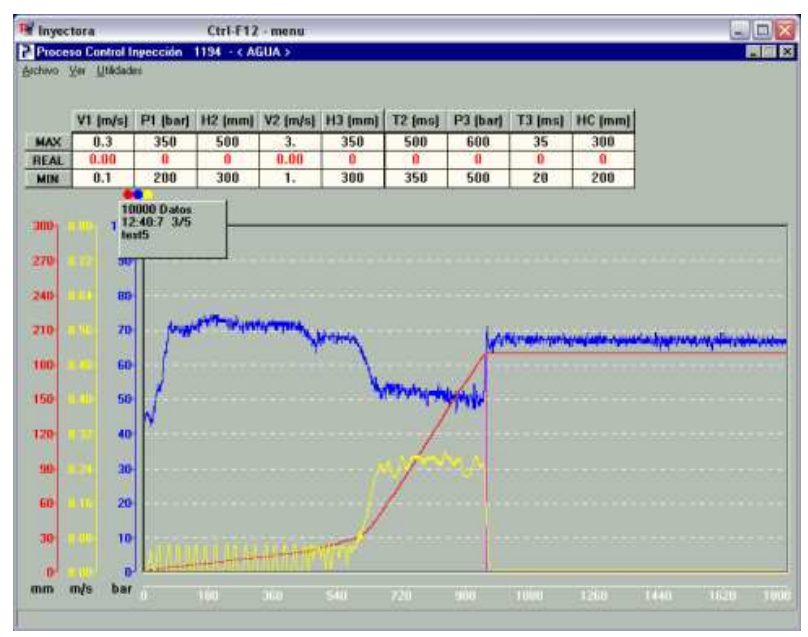

Figura 2.25: Software de análisis de las inyecciones realizadas (PCI) instalado por el fabricante. Representación gráfica del recorrido del pistón (rojo) , presión (azul) y velocidad (amarillo) en función del tiempo.

- Presión estimada ejercida por el pistón sobre el metal fundido (bar).

- Fuerza ejercida sobre el molde durante el proceso de inyección (t). Este valor determina la fuerza máxima necesaria para mantener cerrado el molde.

- Velocidad del pistón durante el proceso de inyección $\left(\mathrm{ms}^{-1}\right)$.

- Velocidad del metal en la zona de entrada a la cavidad del molde durante el llenado $\left(\mathrm{ms}^{-1}\right)$.

- Caudal de metal en la zona de entrada a la cavidad del molde $\left(\mathrm{m}^{3} \mathrm{~s}^{-1}\right)$.

Para calcular los parámetros anteriores es necesario introducir en la aplicación la siguiente información:

- Presión de multiplicación (bar).

- Tiempo estimado de llenado (ms).

- Peso total de la pieza (g).

- Peso total de metal vertido en la cámara (g).

- Densidad del material de trabajo $\left(\mathrm{g} \mathrm{cm}^{-3}\right)$.

- Diámetro del pistón (mm).

- Diámetro del pistón hidráulico (mm).

- Recorrido útil del pistón (mm). 
- Superficie total de la entrada de metal en la cavidad del molde ( $\left.\mathrm{mm}^{2}\right)$.

- Superficie proyectada total de la pieza a fabricar $\left(\mathrm{cm}^{2}\right)$.

\subsubsection{Modificaciones y desarrollos realizados en el sistema de control}

Una vez estudiadas las características del equipo disponible en la máquina FIAP se han realizado diferentes modificaciones y desarrollos. Se ha sustituido el sistema analógico de adquisición de datos por uno digital y se ha desarrollado una nueva aplicación informática que mejora la capacidad de adquisición de datos y su posterior análisis estadístico. También ha sido necesario modificar el software PCM descrito anteriormente. La nueva aplicación (véase la Figura 2.26) permite regular la velocidad de inyección mediante el control del porcentaje de apertura de la válvula principal de descarga en un total de diez puntos dentro del recorrido del pistón (300 mm), (recuérdese que la anterior aplicación permite sólo dos).

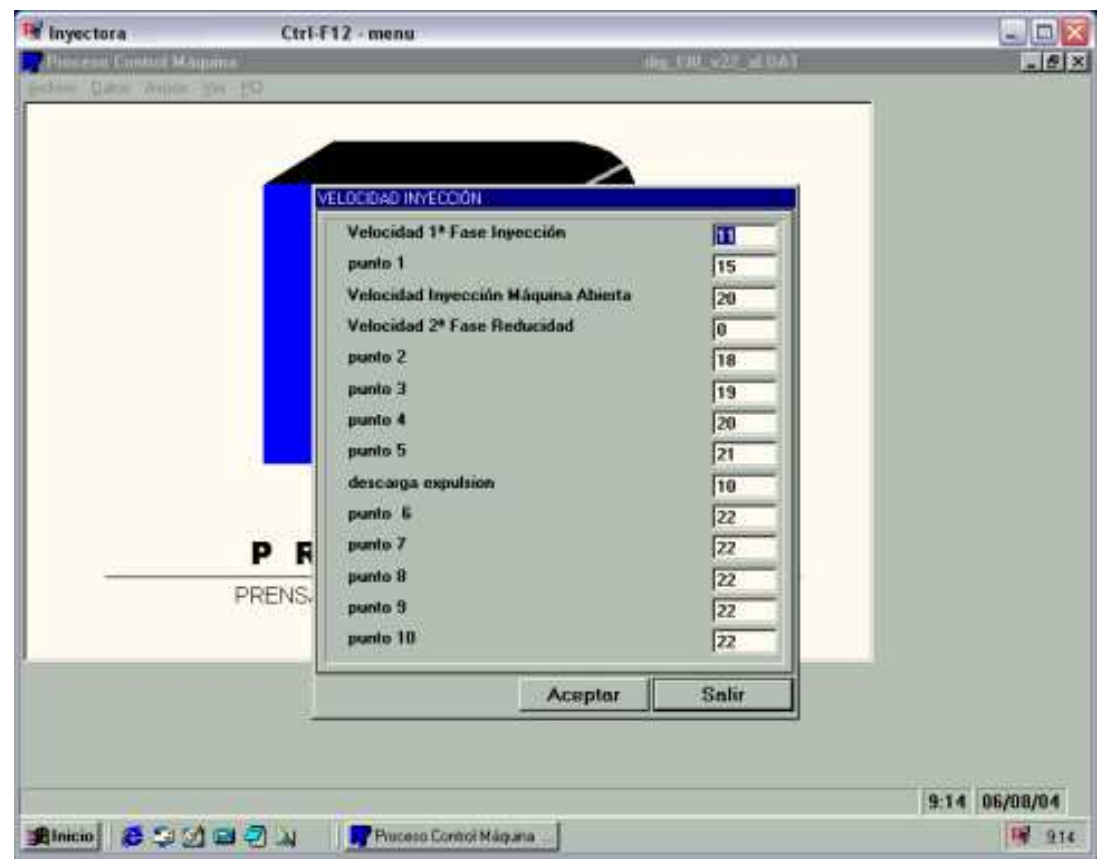

Figura 2.26: Versión modificada del software de control de máquina PCM.

\subsubsection{Transductor de posición digital}

Antes de describir las características del nuevo transductor digital se ha evaluado la repetibilidad de posicionamiento del pistón del sistema de inyección utilizando el antiguo transductor analógico instalado originalmente en la máquina FIAP. Para ello se repitieron varias inyecciones para diferentes valores de la apertura de la válvula principal de descarga (comprendido entre 15 y 27\%). En 
concreto se realizaron 5 inyecciones para cada valor de apertura de válvula. Una vez registrados los datos de cada inyección, se establecieron dos zonas de estudio. La primera zona ("zona A") corresponde a la zona de aceleración de la curva, y la otra zona (“zona B”) corresponde a la zona en la que el pistón alcanza la velocidad correspondiente a la apertura de válvula seleccionada.

Con el fin de automatizar el proceso, se desarrolló la aplicación antes comentada (en la Figura 2.27 se muestra una pantalla de la aplicación elaborada para éste análisis con los datos de inyección capturados en uno de los ensayos), que permite escoger dos secuencias de 7 datos consecutivos, cada una de ellas tomada en las dos zonas antes mencionadas. Se han estudiado las posiciones registradas por el sistema en los mismos instantes de tiempo (segunda columna de datos de la Figura 2.27), para cada una de las 5 inyecciones de cada serie. Sobre los 5 datos de cada instante se ha calculado su desviación estándar (última columna de datos de la Figura 2.27). Finalmente se ha calculado la media de las 7 desviaciones de cada zona. Como ejemplo, en la Tabla 2.3 se presentan los datos correspondientes a 5 inyecciones realizadas con una apertura de válvula del $16 \%$, lo que corresponde a una velocidad del pistón de $0,12 \mathrm{~ms}^{-1}$, aproximadamente. En el Anexo C se puede consultar el código fuente de todas las aplicaciones software implementadas.

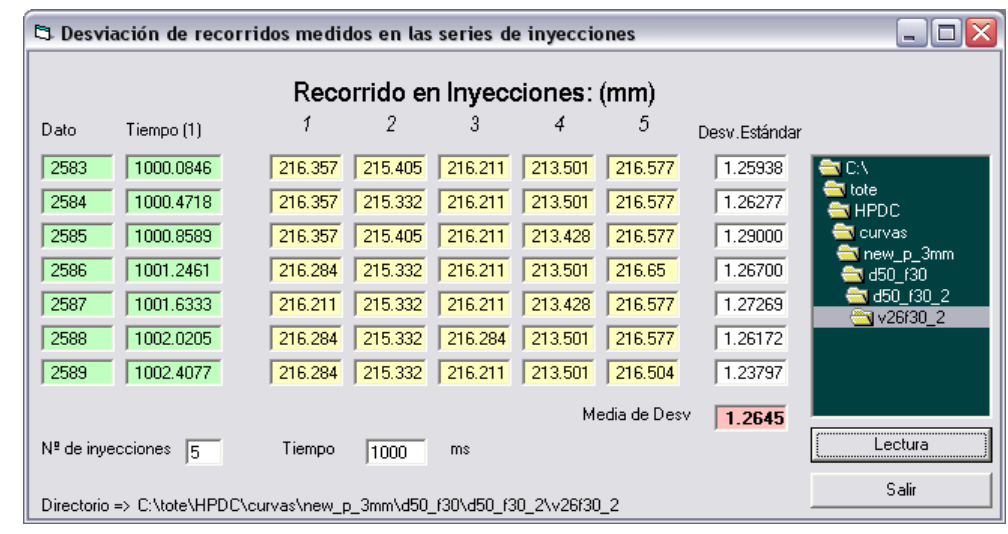

Figura 2.27: Módulo desarrollado para el estudio de la repetibilidad de posicionamiento del pistón.

En la Tabla 2.4 y Figura 2.28 se muestra la desviación típica media obtenida de forma similar para los diferentes valores de apertura de válvula considerados (valores entre $15 \%$ y $27 \%$ equivalen a velocidades de inyección comprendidas entre 0,11 y $0,86 \mathrm{~ms}^{-1}$, respectivamente).

Puede observarse una variabilidad relativamente elevada de las medidas realizadas, incluso se pueden apreciar valores descendentes de la posición de pistón con el tiempo. Para evaluar de una forma más detallada la repetibilidad del transductor analógico, el software de control de inyección, PCI, fue modificado para obtener información sobre la tensión que estaba recibiendo y procesando el canal analógico de la tarjeta de adquisición de datos instalada en el PC. Adicionalmen- 


\begin{tabular}{|c|c|c|c|c|c|c|}
\hline \multirow{2}{*}{ Zona A } & \multicolumn{5}{|c|}{$\mathrm{N}^{0}$ de inyección } & \multirow[b]{2}{*}{ Desv.Est. (mm) } \\
\hline & 1 & 2 & 3 & 4 & 5 & \\
\hline Instante (ms) & \multicolumn{5}{|c|}{ Posición (mm) } & \\
\hline 485,8 & 49,219 & 49,219 & 49,219 & 51,563 & 52,588 & 1,51 \\
\hline 486,0 & 50,537 & 48,926 & 49,512 & 51,416 & 52,441 & 1,42 \\
\hline 486,3 & 50,098 & 48,779 & 49,512 & 51,123 & 52,441 & 1,43 \\
\hline 486,5 & 50,098 & 49,219 & 49,512 & 51,563 & 52,734 & 1,49 \\
\hline 486,8 & 50,391 & 49,219 & 49,365 & 52,295 & 52,588 & 1,59 \\
\hline 487,0 & 50,244 & 49,072 & 49,658 & 52,148 & 52,441 & 1,51 \\
\hline \multirow{2}{*}{487,3} & 50,244 & 49,072 & 49,658 & 52,588 & 52,734 & 1,70 \\
\hline & & & & & Valor medio & 1,52 \\
\hline
\end{tabular}

\begin{tabular}{|c|c|c|c|c|c|c|}
\hline & \multicolumn{5}{|c|}{$\mathrm{N}^{0}$ de inyección } & \multirow[b]{2}{*}{ Desv.Est. (mm) } \\
\hline Zona B & 1 & 2 & 3 & 4 & 5 & \\
\hline Instante (ms) & \multicolumn{5}{|c|}{ Posición (mm) } & \\
\hline \multirow{7}{*}{$\begin{array}{l}607,3 \\
607,5 \\
607,7 \\
608,0 \\
608,2 \\
608,5 \\
608,7\end{array}$} & 65,479 & 64,014 & 64,014 & 66,943 & 67,822 & 1,72 \\
\hline & 65,625 & 64,307 & 64,600 & 66,797 & 67,969 & 1,53 \\
\hline & 65,479 & 64,307 & 64,307 & 67,236 & 68,115 & 1,73 \\
\hline & 65,771 & 64,014 & 64,160 & 66,943 & 68,115 & 1,77 \\
\hline & 65,771 & 64,600 & 64,453 & 66,650 & 67,969 & 1,47 \\
\hline & 65,332 & 64,453 & 64,453 & 67,090 & 68,115 & 1,65 \\
\hline & 65,918 & 64,160 & 64,307 & 66,943 & 67,969 & 1,65 \\
\hline & & & & & Valor medio & 1,64 \\
\hline
\end{tabular}

Tabla 2.3: Resultados de la posición del pistón registrados en diferentes instantes de tiempo, correspondientes a las zonas A y B, para 5 inyecciones realizadas con una apertura de válvula del $16 \%$.

\section{\begin{tabular}{|l|l|}
\hline Zona A & Zona B \\
\hline
\end{tabular}}

\begin{tabular}{|c|c|c|}
\hline$\%$ & $(\mathrm{~mm})$ & $(\mathrm{mm})$ \\
\hline 15 & 2,11 & 2,55 \\
\hline 16 & 1,52 & 1,64 \\
\hline 17 & 0,93 & 1,24 \\
\hline 18 & 1,65 & 2,16 \\
\hline 19 & 1,63 & 1,32 \\
\hline 20 & 2,00 & 3,06 \\
\hline 21 & 1,85 & 2,22 \\
\hline 22 & 0,53 & 0,88 \\
\hline 23 & 2,74 & 4,27 \\
\hline 24 & 1,82 & 3,08 \\
\hline 25 & 3,33 & 2,62 \\
\hline 26 & 4,43 & 3,44 \\
\hline 27 & 3,08 & 6,97 \\
\hline
\end{tabular}

Tabla 2.4: Valores medios de la desviación estándar de posicionamiento del pistón obtenidos en las zonas A y B para diferentes porcentajes de apertura de válvula, utilizando el transductor analógico. 


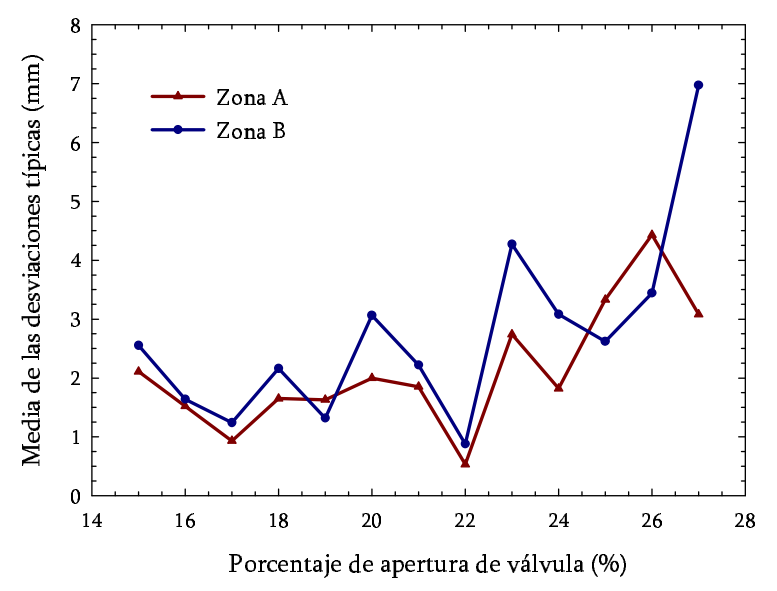

Figura 2.28: Valor medio de la desviación estándar de posicionamiento del pistón en función del porcentaje de apertura de válvula.

te se modificó la configuración de la tarjeta de adquisición de datos para trabajar en el rango de tensiones de $0 \mathrm{~V}$ a $+10 \mathrm{~V}$. La tarjeta utilizada es de 12 bits $\left(2^{12}=\right.$ 4096 estados), por lo que se consigue una resolución de

$$
10 \mathrm{~V} / 4096=0,0024 \mathrm{~V}
$$

Con esta configuración se comprobó que cuando el pistón está en reposo se producen oscilaciones en la lectura de la señal entorno a $\pm 0,030 \mathrm{~V}$, lo que supone una variación de $\pm 1 \mathrm{~mm}$ en la posición del pistón. Esto se debe a que las señales de tipo analógico son muy sensibles a las fuentes de ruido electromagnético que pueden existir en el entorno de trabajo (se realizaron pruebas con otro tipo de máquinas trabajando en el entorno de la máquina de inyección comprobando que el efecto del ruido podía llegar incluso a quintuplicarse). Este efecto se agrava, particularmente en esta máquina, debido a que el transductor de posición está situado en un extremo de la máquina debiendo recorrer el cableado de la señal una gran longitud hasta alcanzar el armario de control. Para reducir el efecto del ruido electromagnético se trató de aislar lo máximo posible el cableado de la señal analógica consiguiendo una variación de esta señal, cuando el pistón está en reposo, de $\pm 0,007 \mathrm{~V}$ lo que supone $\pm 0,21 \mathrm{~mm}$.

Para evitar este tipo de problemas finalmente se optó por desechar el transductor analógico reemplazándolo por uno digital, lineal e incremental. La ventaja principal del sistema digital es su mayor inmunidad frente al ruido electromagnético ya que la información de posición se genera a partir de la recepción de pulsos de tensión. Una vez establecido el origen, o cero del transductor, los desplazamientos se transforman en pulsos que incrementan o decrementan un contador. Dependiendo de la resolución del sistema, existe una relación directa entre los pulsos y la distancia recorrida, es decir, a cada pulso le corresponde 
un desplazamiento de una unidad de resolución. En concreto se instaló un transductor digital magneto-resistivo lineal (SIKO MSK320) que hace las funciones de cursor sobre una banda magnética (MB320) adherida a la carrera de desplazamiento. La resolución del sistema es de $0,1 \mathrm{~mm}$ con error máximo según el fabricante de $\pm 0,1 \mathrm{~mm}$ y permite velocidades de desplazamiento de hasta 25 $\mathrm{ms}^{-1}$.

La instalación del nuevo transductor hizo que el software de control de inyección (PCI) inicialmente instalado en la máquina no fuese capaz de comunicarse con los controladores de los nuevos dispositivos instalados, por lo que se desarrolló una nueva aplicación capaz de captar y evaluar los datos digitales de posición del pistón durante el proceso de inyección. Con este fin, se incorporó en la aplicación la capacidad de incluir en los listados de posición los estados de hasta ocho señales digitales de entrada que pueden ser conectadas a otros tantos dispositivos adaptables al proceso, así como opciones sobre la cantidad de datos a adquirir, su frecuencia e incluso opciones para la denominación automática de los ficheros generados durante los ensayos para su posterior análisis. Por cuestiones de compatibilidad con cualquier otra aplicación externa se mantuvo el formato de texto ASCII para los ficheros de salida. Entre la información generada por la aplicación de adquisición de datos desarrollada se puede citar, por ejemplo, la identificación del ensayo realizado, las condiciones de operación generales, el número de datos adquiridos o el tiempo de adquisición, junto con el listado de las posiciones del pistón y valores de las entradas digitales para todos los instantes considerados. La Figura 2.29 muestra, como ejemplo, un fichero resumido del nuevo formato generado. La aplicación se implementó en $\mathrm{C}++\mathrm{y}$ puede consultarse su código fuente en el Anexo C.

La instalación del transductor digital requirió la incorporación al PC de una tarjeta de control de encoder junto con una nueva tarjeta de adquisición de datos. El acondicionamiento de la señal del transductor enviada al PLC y al PC se resolvió mediante la instalación de optoacopladores ya que los tiempos de activación de los relés instalados en la máquina anteriormente utilizados eran demasiado elevados, pudiendo tener problemas de pérdida de pulsos junto con una mayor variabilidad en los tiempos de respuesta.

Para evaluar la precisión del transductor digital se realizaron 10 inyecciones en vacío, utilizando como referencia un reloj comparador de 0,01 $\mathrm{mm}$ de resolución. El reloj se situó en un punto fijo del recorrido ordenando la parada del pistón en la posición de $151 \mathrm{~mm}$. Las inyecciones se realizaron con un porcentaje de apertura de válvula constante e igual al 15\%. La Tabla 2.5 muestra las desviaciones registradas por el reloj comparador junto con la lectura de recorrido registrada con el nuevo dispositivo digital. La posición real del pistón se podrá obtener, por tanto, sumando a $151 \mathrm{~mm}$ la desviación obtenida por el reloj comparador. La diferencia entre estos valores y las posiciones registradas por el PCI se muestran en la última columna de la tabla. La desviación estándar de estas diferencias se muestra en la parte inferior de la tabla. Se puede comprobar que 


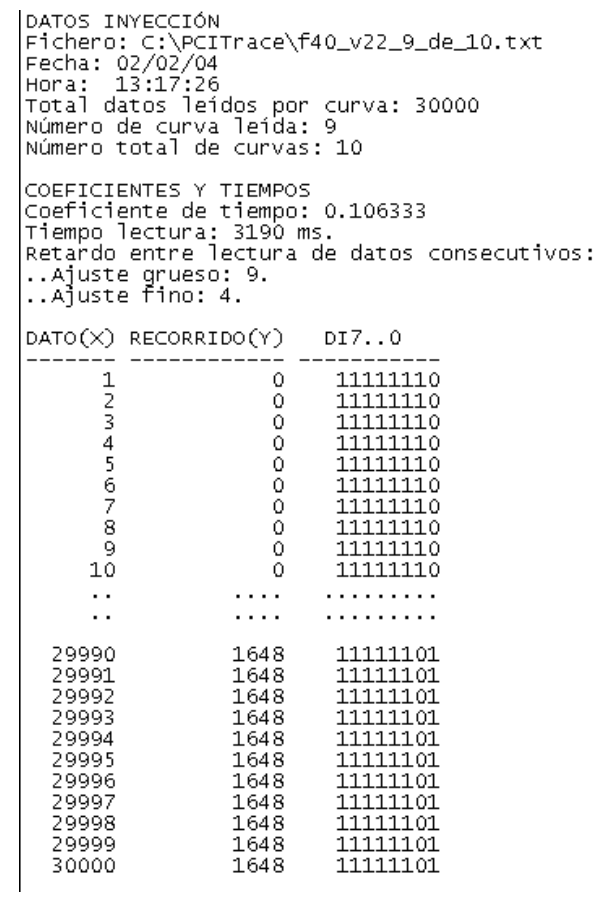

Figura 2.29: Listado resumido generado por el nuevo módulo de adquisición de datos.

la inercia del sistema, junto con los retardos del sistema de control, provocan que la parada del pistón se consiga con un decalaje medio de $+0,36 \mathrm{~mm}$ para la apertura de válvula considerada en este ensayo.

En la Tabla 2.6 se muestran los resultados equivalentes a los de la Tabla 2.4 obtenidos en este caso con el transductor de posición digital. En la Figura 2.30 se comparan estos valores con los obtenidos con el sistema analógico observando una mejoría apreciable en la repetibilidad del sistema con el nuevo transductor.

\subsubsection{Ajuste de la ley de movimiento del pistón}

La instalación del nuevo transductor de posición ha permitido reducir los errores de posicionamiento del pistón durante el proceso de inyección. A partir de esta información se ha calculado la velocidad y aceleración del pistón, lo que ha permitido ajustar, mediante un proceso de ensayo y error, los parámetros del sistema de inyección para conseguir la ley de movimiento del pistón deseada.

\subsubsection{Cálculo de la velocidad del pistón}

Teniendo en cuenta que la frecuencia de lectura de datos es constante durante cada inyección, el intervalo de tiempo transcurrido entre dos lecturas consecutivas se puede obtener del siguiente modo:

$$
c_{t}=\frac{t_{l}}{n}
$$




\begin{tabular}{|c|c|c|c|}
\hline $\begin{array}{c}\text { Inyección } \\
\left(\mathrm{n}^{\circ}\right)\end{array}$ & $\begin{array}{l}\text { PCI } \\
(\mathrm{mm})\end{array}$ & $\begin{array}{l}\text { Reloj comp. } \\
\text { (mm) }\end{array}$ & $\begin{array}{l}\text { Diferencia } \\
(\mathrm{mm})\end{array}$ \\
\hline 1 & 151,30 & 151,39 & 0,09 \\
\hline 2 & 151,20 & 151,29 & 0,09 \\
\hline 3 & 151,40 & 151,50 & 0,10 \\
\hline 4 & 151,50 & 151,61 & 0,11 \\
\hline 5 & 151,30 & 151,41 & 0,11 \\
\hline 6 & 151,40 & 151,55 & 0,15 \\
\hline 7 & 151,30 & 151,42 & 0,12 \\
\hline 8 & 151,50 & 151,58 & 0,08 \\
\hline 9 & 151,60 & 151,72 & 0,12 \\
\hline 10 & 151,10 & 151,18 & 0,08 \\
\hline & \multicolumn{2}{|c|}{ Desviación estándar } & 0,02 \\
\hline
\end{tabular}

Tabla 2.5: Medidas comparativas del transductor digital con un reloj comparador.

siendo $t_{l}$ el tiempo total de lectura durante el ensayo y $n$ el número total de datos leídos. Por tanto, el instante correspondiente al número de lectura $i$ (primera columna de la Figura 2.29), se podrá obtener como:

$$
t_{i}=i \times c_{t}
$$

La aplicación de adquisición de datos se ha configurado para obtener 30000 datos por inyección con tiempo de lectura entorno a 3 segundos, lo que supone disponer de alrededor de 10 datos por milisegundo. Esta frecuencia de muestreo permite registrar recorridos con velocidades de hasta $1 \mathrm{~ms}^{-1}$ con una resolución igual a la del transductor de posición digital $(0,1 \mathrm{~mm})$. Esto provoca que para velocidades inferiores del pistón, aparezcan datos consecutivos con la misma posición, lo que dificulta el cálculo numérico de la velocidad del pistón. Éste cálculo se ha realizado utilizando una fórmula de diferencias finitas centrada en el tiempo con un intervalo temporal de diferenciación suficientemente amplio (140ms) para evitar las dificultades antes comentadas. El error máximo de la velocidad del pistón, estimado a partir del error del transductor de posición, es de $\pm 0,003 \mathrm{~ms}^{-1}$.

En la Figura 2.31 podemos observar las representaciones gráficas de la velocidad del pistón de una misma inyección calculadas con diferentes intervalos de diferenciación. En ellas se representa adicionalmente la curva de la velocidad teórica. 


\section{Zona A}

\begin{tabular}{|l|c|c|}
\hline$\%$ & $(\mathrm{~mm})$ & $(\mathrm{mm})$ \\
\hline 15 & 1,05 & 1,33 \\
\hline 16 & 0,57 & 1,24 \\
\hline 17 & 0,85 & 0,64 \\
\hline 18 & 0,24 & 1,31 \\
\hline 19 & 0,60 & 1,05 \\
\hline 20 & 1,22 & 1,67 \\
\hline 21 & 0,09 & 1,45 \\
\hline 22 & 0,55 & 0,30 \\
\hline 23 & 1,24 & 1,84 \\
\hline 24 & 0,45 & 1,49 \\
\hline 25 & 1,22 & 2,30 \\
\hline 26 & 1,47 & 0,87 \\
\hline 27 & 1,56 & 1,86 \\
\hline
\end{tabular}

Tabla 2.6: Valores medios de la desviación estándar de posicionamiento del pistón obtenidos en las zonas A y B para diferentes porcentajes de apertura de válvula, utilizando el transductor digital.

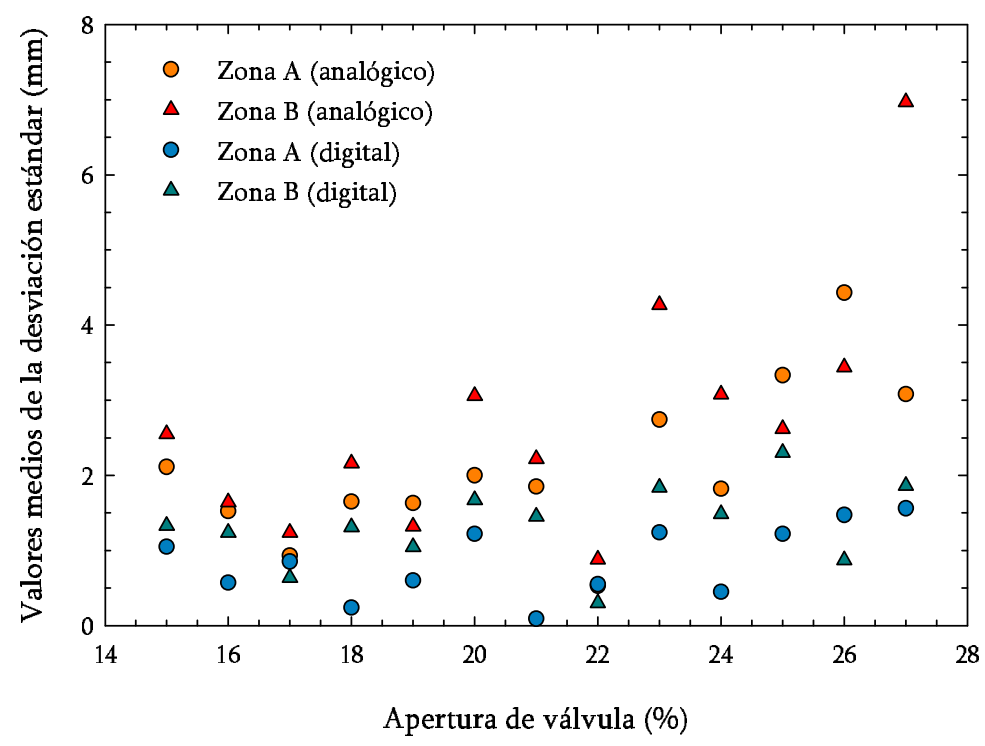

Figura 2.30: Comparación de valores medios de la desviación estándar de posicionamiento del pistón obtenidos en las zonas A y B para diferentes porcentajes de apertura de válvula, utilizando el transductor analógico y el digital. 


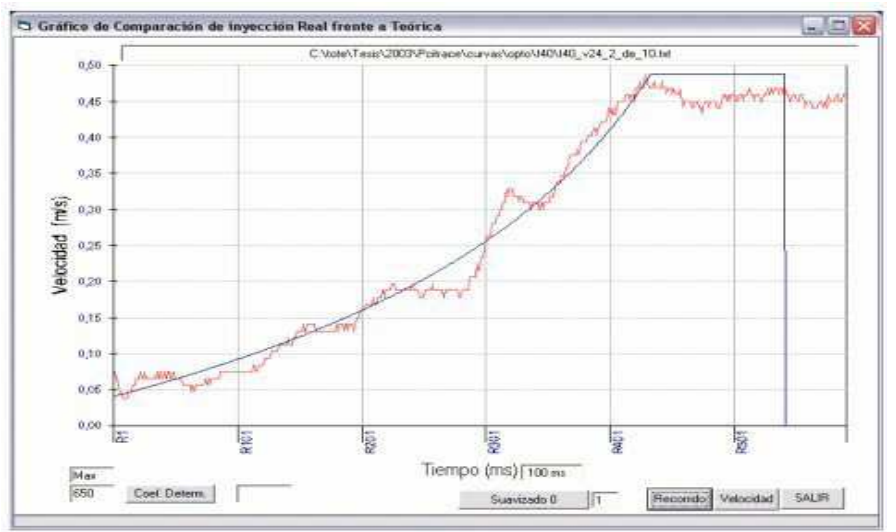

(a)

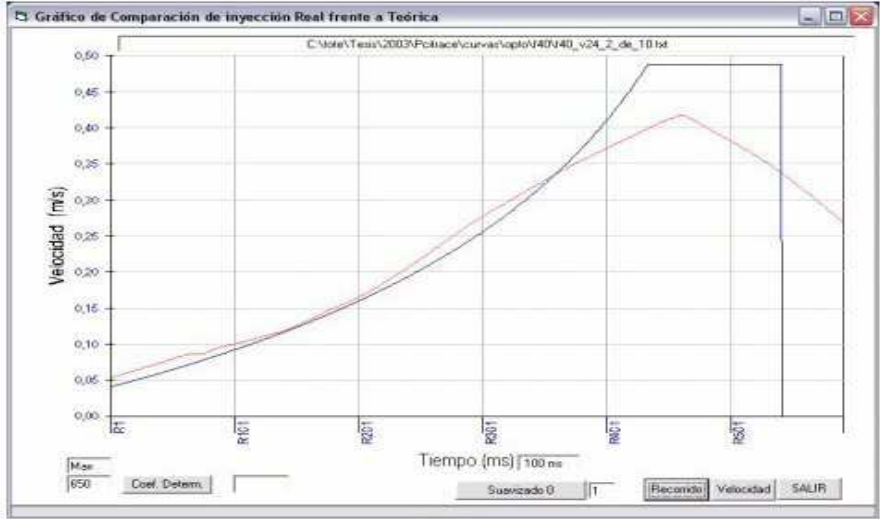

(b)

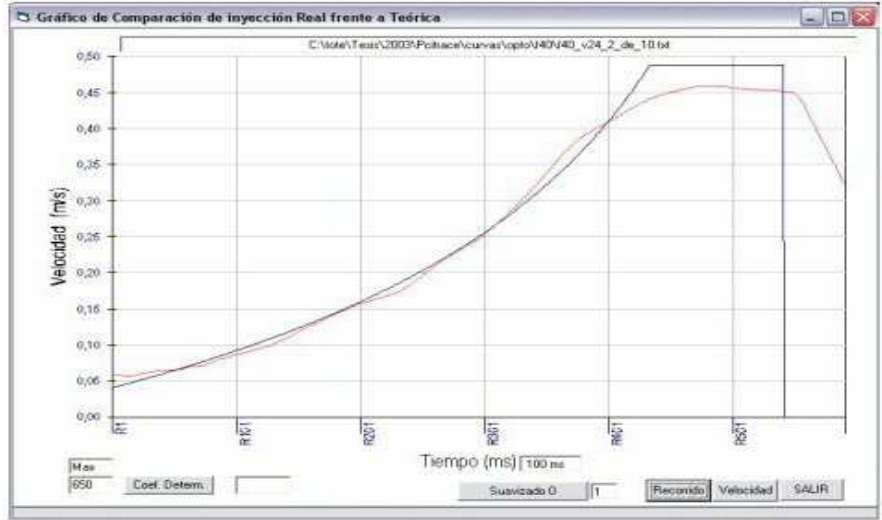

(c)

Figura 2.31: Representación gráfica de la velocidad del pistón en función del tiempo para diferentes valores del intervalo de diferenciación: (a) corto $=20 \mathrm{~ms}$, (b) largo $=60 \mathrm{~ms}$, (c) utilizado $=140 \mathrm{~ms}$, (en rojo velocidad medida y en azul la velocidad teórica). 


\begin{tabular}{|c|c|c|c|c|c|}
\hline & P1 & P2 & P3 & $\mathrm{P} 4$ & P5 \\
\hline Posición (mm) & 40 & 60 & 80 & 100 & 110 \\
\hline Apertura (\%) & 28 & 28 & 28 & 28 & 28 \\
\hline & P6 & P7 & P8 & P9 & P10 \\
\hline Posición (mm) & 130 & 150 & 170 & 190 & 220 \\
\hline Apertura (\%) & 28 & 28 & 28 & 28 & 28 \\
\hline
\end{tabular}

Tabla 2.7: Ejemplo de configuración del software de control de máquina (PCM) para inyecciones con apertura constante de válvula del $28 \%$.

\subsubsection{Influencia de la apertura de válvula en la velocidad del pistón}

Como se ha comentado anteriormente, la velocidad de desplazamiento del pistón está determinada por la apertura de la válvula principal de descarga. Se han realizado series de inyecciones con aperturas de válvula constante, calculando la velocidad máxima alcanzada. Concretamente se han ejecutado un total de 20 series de 5 inyecciones cada una con valores comprendidos entre 12 y $31 \%$ de apertura de válvula consiguiéndose velocidades del pistón entre 0,07 y 1,25 ms ${ }^{-1}$ (como ejemplo, en la Tabla 2.7 se muestran los parámetros de configuración del sistema para una apertura de válvula del $28 \%$.

En la Tabla 2.8 se muestran los valores medios de la velocidad máxima del pistón y su desviación estándar para cada valor del porcentaje de apertura de válvula utilizado. En la Figura 2.32 se ha representado los valores medios anteriores en función del porcentaje de apertura, observándose un comportamiento lineal claramente diferenciado en dos zonas. La primera abarca los porcentajes comprendidos entre 12 y $19 \%$ y la segunda entre el 20 y $31 \%$. Las correlaciones lineales correspondientes se muestran en las siguientes expresiones:

$$
\begin{array}{ll}
V_{\max (1)}=0,0132 \times \text { apertura }-0,0884, & R^{2}=0,988 \\
V_{\max (2)}=0,0987 \times \text { apertura }-1,8124, & R^{2}=0,996
\end{array}
$$

Para ajustar la velocidad del pistón a la ley de movimiento deseada es necesario tener en cuenta las inercias y errores de medida que afectan al sistema de control de la inyección. Por ello se han realizado ensayos con diferentes porcentajes de apertura de válvula observando un cierto retraso que se produce desde que se ordena la apertura hasta que el sistema responde y comienza a acelerar. El segundo retraso observado es el que se produce desde que comienza el movimiento hasta que se alcanza la velocidad máxima correspondiente a dicha apertura. La Tabla 2.9 y las Figuras 2.33 y 2.34 presentan estos retrasos en función del porcentaje de apertura de válvula expresados como posición y tiempo 


\begin{tabular}{|c|c|c|c|c|c|}
\hline \multirow[b]{2}{*}{$\%$} & \multicolumn{2}{|c|}{ Velocidad máxima } & \multirow[b]{2}{*}{$\%$} & \multicolumn{2}{|c|}{ Velocidad máxima } \\
\hline & $\begin{array}{l}\text { Media } \\
\left(\mathrm{ms}^{-1}\right)\end{array}$ & $\begin{array}{c}\text { Desviación } \\
\text { estándar }\end{array}$ & & $\begin{array}{l}\text { Media } \\
\left(\mathrm{ms}^{-1}\right)\end{array}$ & $\begin{array}{l}\text { Desviación } \\
\text { estándar }\end{array}$ \\
\hline 12 & 0,070 & 0,001 & 22 & 0,350 & 0,007 \\
\hline 13 & 0,080 & 0,001 & 23 & 0,430 & 0,009 \\
\hline 14 & 0,100 & 0,001 & 24 & 0,520 & 0,010 \\
\hline 15 & 0,110 & 0,001 & 25 & 0,630 & 0,012 \\
\hline 16 & 0,120 & 0,002 & 26 & 0,760 & 0,012 \\
\hline 17 & 0,130 & 0,006 & 27 & 0,860 & 0,008 \\
\hline 18 & 0,150 & 0,003 & 28 & 0,960 & 0,013 \\
\hline 19 & 0,160 & 0,004 & 29 & 1,060 & 0,010 \\
\hline 20 & 0,210 & 0,002 & 30 & 1,160 & 0,008 \\
\hline 21 & 0,270 & 0,008 & 31 & 1,250 & 0,013 \\
\hline
\end{tabular}

Tabla 2.8: Valores de velocidad máxima medida y desviación estándar para inyecciones realizadas con diferentes porcentajes de apertura constantes.

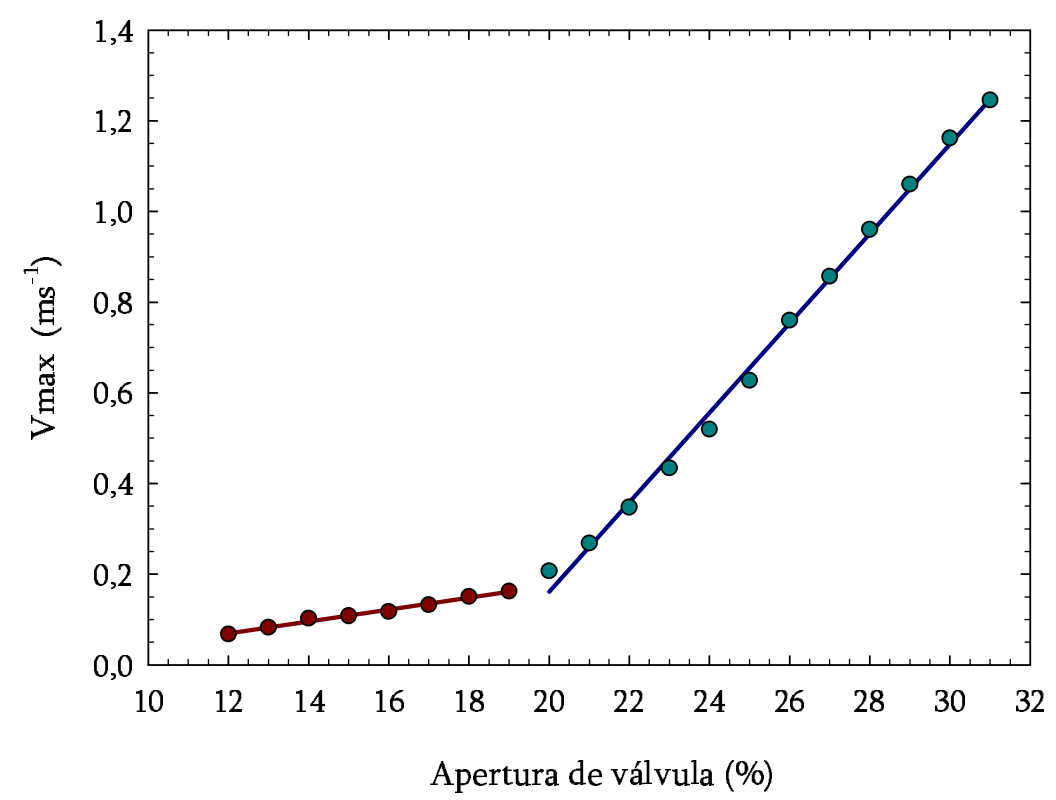

Figura 2.32: Correlaciones entre el porcentaje de apertura de válvula y la velocidad máxima alcanzada por el pistón para diferentes rangos de apertura (Ec.2.3 y 2.4). 
RETRASO

\begin{tabular}{|c|c|c|c|c|c|}
\hline \multicolumn{3}{|c|}{ En acelerar } & \multicolumn{3}{|c|}{ En alcanzar } \\
\hline$(\%)$ & $\mathrm{mm}$ & $\mathrm{ms}$ & $\mathrm{mm}$ & $\mathrm{ms}$ & $\mathrm{V}\left(\mathrm{ms}^{-1}\right)$ \\
\hline 15 & 2,1 & 373,2 & 6,4 & 428,0 & 0,11 \\
\hline 16 & 2,4 & 364,8 & 7,4 & 420,8 & 0,12 \\
\hline 17 & 2,3 & 364,6 & 9,0 & 437,2 & 0,13 \\
\hline 18 & 2,0 & 377,7 & 10,5 & 458,8 & 0,15 \\
\hline 19 & 2,1 & 379,1 & 11,9 & 469,2 & 0,16 \\
\hline 20 & 2,0 & 361,7 & 16,0 & 467,3 & 0,21 \\
\hline 21 & 2,0 & 352,9 & 22,0 & 472,9 & 0,27 \\
\hline 22 & 2,1 & 365,5 & 22,3 & 488,7 & 0,35 \\
\hline 23 & 2,4 & 367,1 & 28,2 & 498,7 & 0,43 \\
\hline 24 & 1,7 & 361,8 & 34,0 & 507,9 & 0,52 \\
\hline 25 & 1,8 & 354,8 & 45,5 & 515,3 & 0,63 \\
\hline 26 & 1,8 & 350,9 & 51,9 & 521,9 & 0,76 \\
\hline 27 & 1,8 & 369,9 & 63,2 & 550,1 & 0,86 \\
\hline
\end{tabular}

Tabla 2.9: Retrasos en el comportamiento de la válvula.

respectivamente. Cabe destacar que los retrasos mencionados dependerán de la inercia, es decir de la velocidad del pistón en el momento en el que se le ordena una nueva apertura de válvula. Los datos presentados corresponden a ensayos en los que se ha comenzado con la apertura de válvula mínima (10\%) constante, ordenando la apertura correspondiente a cada caso en un punto fijo del recorrido (120 mm).

Para tratar de ajustar el movimiento del pistón a una determinada ley de movimiento se deberían tener en cuenta todos los aspectos que se acaban de mencionar. Con los datos anteriores es posible determinar de forma aproximada los porcentajes de apertura de válvula en distintas posiciones del pistón, a lo largo de su carrera, para conseguir la ley de aceleración del pistón que se desee ensayar. Estos valores aproximados de apertura de válvula y su posición en el recorrido se han reajustado mediante un proceso de ensayo y error hasta conseguir el grado de precisión deseado. Debe comentarse que son muchos los factores que pueden afectar a la repetibilidad del proceso. Entre otros, se puede citar la temperatura exterior, los coeficientes de rozamiento que dependen del tipo de engrase realizado, la temperatura del fluido hidráulico o los desgastes y holguras. No obstante, la aplicación desarrollada ofrece unos valores iniciales bastante aproximados que permiten ajustar definitivamente las condiciones de inyección tras realizar unas pocas inyecciones.

Cuando la velocidad del pistón medida por el sistema para una determinada inyección no se ajusta lo suficiente a la ley de movimiento deseada el ensayo 


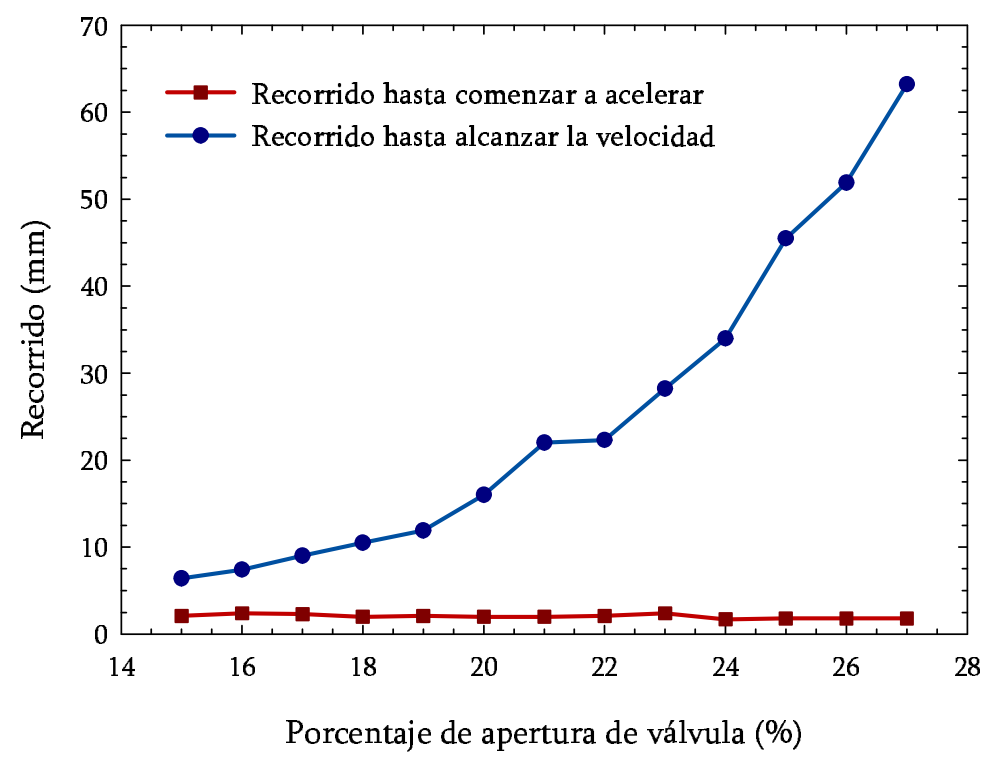

Figura 2.33: Representación gráfica del recorrido del pistón que realiza a velocidad constante antes de comenzar a acelerar (en rojo) y de conseguir la velocidad estimada (en azul).

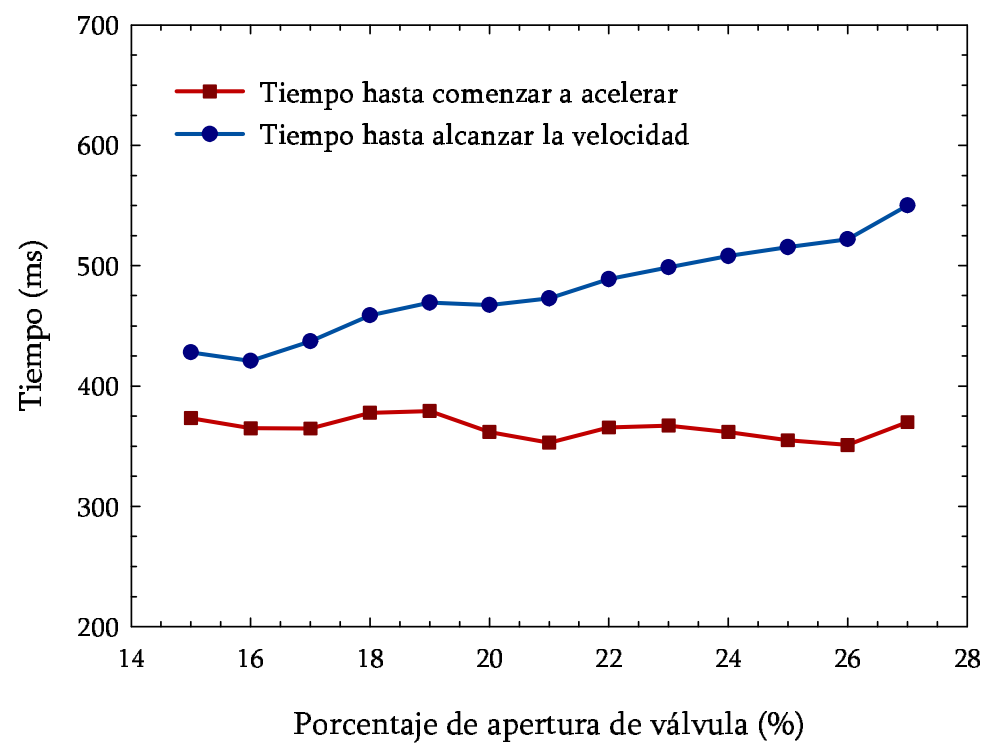

Figura 2.34: Representación gráfica del tiempo que tarda el pistón en comenzar a acelerar (en rojo) y en conseguir la velocidad estimada (en azul). 
debe ser rechazado. Para determinar el grado de concordancia entre ambas se ha utilizado un coeficiente de determinación estadístico el cual queda expresado en la siguiente ecuación (2.5),

$$
R^{2}=1-\frac{\sum_{i=1}^{n}\left(X_{i}^{\prime}-\widehat{X}_{i}^{\prime}\right)^{2}}{\sum_{i=1}^{n}\left(X_{i}^{\prime}-\overline{X^{\prime}}\right)^{2}}
$$

donde $n$ representa el número de medidas, $X_{i}^{\prime}$ y $\widehat{X}_{i}^{\prime}$ son las velocidades de pistón medida y deseada respectivamente, y $\overline{X^{\prime}}$ es el valor medio de la velocidad del pistón durante la inyección. Evidentemente, cuando la inyección realizada y la deseada coinciden exactamente se obtiene un valor de $R^{2}=1$. Debe hacerse notar que la comparación con valores teóricos puede llevar a situaciones de "baja similitud" cuando éstos no sean totalmente reproducibles por un sistema mecánico, como por ejemplo al realizar aceleraciones extremas en una parada brusca. En estos casos se acotarán los intervalos de comparación, evitando así estos problemas.

\subsection{Sistema de fusión al vacío}

Tal y como se comentó en la Introducción, existen diversos métodos de medida de porosidad. Entre éstos, el basado en el principio de Arquímedes (método gravimétrico) permite calcular, con relativa precisión, el volumen de las burbujas de gas atrapado. En el caso de los procesos FIAP la mayor parte de la porosidad en las piezas fabricadas se debe al atrapamiento de gas durante el proceso de inyección. El gas en estas burbujas se puede encontrar a diferentes presiones por lo que para evaluar cuantitativamente la cantidad de gas atrapado se debería determinar las presiones de gas en cada burbuja. El método de fusión al vacío, descrito brevemente en la sección 1.3.2, permite, mediante la fusión de la pieza a muy baja presión, cuantificar de forma precisa la cantidad total de gas atrapado en la pieza. En el mercado existen hornos para fundir metales en atmósfera controlada que normalmente se utilizan para realizar tratamientos térmicos (temple, revenido, recocido brillante, hipertemple, recocidos magnéticos, precipitados o solubilizados) y que trabajan con niveles de bajo vacío, aunque sin llegar a alcanzar las condiciones de vacío requeridas para medir porosidad en piezas fundidas. Existen hornos capaces de alcanzar presiones más bajas, aunque se utilizan para realizar tareas tales como metalización superficial o recubrimientos superficiales por deposición. El problema principal que presentan estos últimos es que están diseñados para trabajar con muestras de tamaño muy pequeño. Adicionalmente, muchos de estos hornos, ubicados generalmente en el interior de la cámara de vacío, utilizan resistencias muy sensibles a la oxidación que se provocaría al entrar en contacto con el gas liberado durante la fusión de la pieza. En esta tesis se ha decidido diseñar y fabricar un sistema de fusión al vacío que permita evaluar 
la cantidad de gas atrapado en las piezas obtenidas de los ensayos realizados en la máquina FIAP. Actualmente este equipo se encuentra en fase de verificación y calibración, por lo que solamente se presentarán resultados preliminares en el capítulo 4.

\subsubsection{Principios básicos de funcionamiento y características genera- les del sistema}

Como se indicó en el Capítulo anterior, el sistema de fusión al vacío permite estimar la cantidad de gas atrapado a partir de los cambios bruscos de presión registrados durante la fusión de la pieza. Obviamente estos cambios de presión dependerán del volumen del poro y de la presión del gas en su interior. Téngase en cuenta que las variaciones de la presión registradas por el sistema debidas a la liberación de las burbujas serán más apreciables cuanto menor sea la presión de la cámara de vacío.

Para diseñar y construir el horno, se ha de tener en cuenta que los ensayos que se llevarán a cabo en esta tesis requieren la fusión de piezas cilíndricas de unos $50 \mathrm{~mm}$ de diámetro y $120 \mathrm{~mm}$ de longitud. También se ha tenido en cuenta su futuro uso para el estudio de la fase rápida por lo que también se prevé fundir piezas como la descrita en la Sección 2.2.1.1. El material de trabajo es una aleación de aluminio-silicio con temperatura de fusión entorno a los 600 ${ }^{\circ}$ C. Esta temperatura de trabajo es muy elevada para construir la cámara de vacío en el interior del horno de fusión debido al calentamiento que sufren las juntas de vacío (este diseño fue elegido por Luis y Robla [59] para fundir piezas de Zamak $-5^{3}$, y por Brevick y Cheng [13] utilizando un horno de inducción para piezas de $\mathrm{Al} \mathrm{390).}$

En este caso se optó por una configuración en la que el horno estuviese dentro de la cámara de vacío y así poder refrigerar ésta convenientemente. El diseño y la fabricación del sistema de fusión al vacío ha sido realizada con la empresa MICROTEST S.A., y financiada a cargo del proyecto de investigación DPI20011390-C02. Los resultados obtenidos por Luis y Robla [59] y Brevick y Cheng [13] muestran que la cantidad de gas atrapado en condiciones similares a las de esta tesis se encuentra entre 2,6 y 20,1 ml por cada $100 \mathrm{~g}$ de aleación en condiciones atmosféricas. En este caso el sistema se ha diseñado para que permita detectar liberaciones de volumen de gas de incluso $0,2 \mathrm{~cm}^{3}$ en condiciones atmosféricas.

Durante el calentamiento y fusión de la pieza la presión en la cámara variará por diversas causas. La más importante es sin duda la liberación de las burbujas de gas atrapado aunque también se debe tener en cuenta la expansión del gas que ocupa el interior de la cámara, la dilatación de los componentes internos (horno, crisol, termopares, cableado, pieza, entre otros) o la dilatación de la propia cámara. De entre éstos otros factores, la expansión del gas de la cámara provoca incrementos de presión más importantes cuanto mayor sea la presión

\footnotetext{
${ }^{3}$ La temperatura de fusión del Zamak-5 es de alrededor de $380{ }^{\circ} \mathrm{C}$
} 
inicial del gas. Concretamente el sistema de medida de presión y temperatura tiene una frecuencia máxima de lectura de 1 dato por segundo y la rampa de calentamiento del horno en las temperaturas próximas a la fusión de la aleación es de unos $9{ }^{\circ} \mathrm{C}$ por minuto. En la Figura 2.35 se puede observar el incremento de presión debido a la liberación del gas de una burbuja de $0,2 \mathrm{~cm}^{3}$ en condiciones atmosféricas en el interior de la cámara de volumen de 30 litros para diferentes valores de la presión existente en la cámara de vacío. Según la rampa de calen-

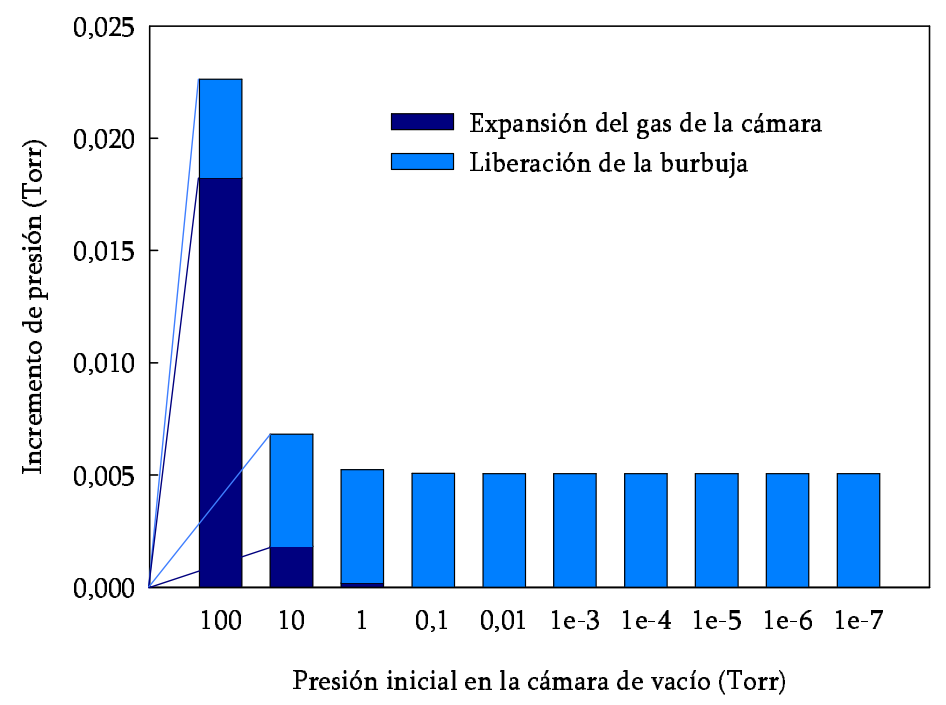

Figura 2.35: Incremento de presión debido a la liberación del gas de una burbuja de $0,2 \mathrm{~cm}^{3}$ en condiciones atmosféricas, y el aumento de temperatura de $0,15^{\circ} \mathrm{C}$, en una cámara con un volumen de gas de 30 litros, para diferentes valores de la presión existente en la cámara de vacío.

tamiento y la frecuencia de lectura indicadas, se obtiene un gradiente de temperatura de unos $0,15{ }^{\circ} \mathrm{C}$ entre dos lecturas de presión consecutivas. Así según las condiciones comentadas, por ejemplo, para el caso de una presión de cámara de 100 Torr, la pendiente de la presión debida a la expansión del gas se ve modificada muy ligeramente cuando se le incorpora la debida a la liberación de la burbuja pudiendo llegar a quedar ésta última confundida entre las incertidumbres de medida. Como puede observarse este efecto se hace despreciable para presiones de cámara inferiores a $10^{-1}$ Torr. Según esto, y añadiendo un margen de seguridad suficiente, el sistema se ha diseñado para poder trabajar con presiones de hasta $10^{-3}$ Torr.

Antes de empezar a realizar vacío, se deben limpiar todos los elementos del sistema. Este proceso se realiza en varias fases. En primer lugar se realiza un simple lavado mediante agua y detergente. Posteriormente se utiliza acetona y finalmente se limpia con una mezcla al $50 \%$ de éter dietílico y etanol para elimi- 
nar cualquier resto orgánico. A continuación, se coloca la muestra en un crisol rodeado por el horno y se procede a cerrar la cámara y comenzar a extraer el aire de la cámara mediante la conexión de las bombas de vacío. Una vez estabilizada la presión se pone en funcionamiento el horno manteniendo conectado el sistema de vacío con el fin de extraer todos los elementos volátiles que puedan quedar aún en la cámara. Lógicamente, la temperatura dentro de la cámara no debe superar la de fusión de la aleación mientras estén conectadas las bombas de vacío por lo que se ha establecido una temperatura máxima de $50{ }^{\circ} \mathrm{C}$ inferior a la de fusión. Una vez alcanzada y mantenida el tiempo suficiente para asegurar que no se produce más desgasificación se desconecta el sistema de vacío y se eleva rápidamente la temperatura del horno para fundir la pieza. Para evitar el calentamiento excesivo de las juntas de cierre de la cámara de vacío, se ha diseñado un sistema de refrigeración mediante un circuito de agua. Durante esta etapa de calentamiento y fusión de la pieza se registrarán los cambios y la evolución de las condiciones de presión y temperatura que se produzcan en el interior de la cámara.

\subsubsection{Componentes principales}

El equipo de fusión al vacío cuenta con los siguientes componentes:

1. Cámara de vacío, que a su vez incluye los sistemas de cierre, válvulas, bombas de vacío y sistemas de fijación, entre otros.

2. Horno de fusión, formado fundamentalmente por el horno de fusión y su controlador.

3. Sistema de control y gestión del equipo, en el que se incluyen los sensores, transductores de presión y de temperatura, las tarjetas de adquisición de datos y la aplicación software de control y gestión junto con el hardware correspondiente (PC).

\subsubsection{Cámara de vacío}

Los requisitos fundamentales de la cámara de vacío deben ser los siguientes:

- debe tener capacidad suficiente para albergar el horno y los componentes auxiliares necesarios para la fusión de piezas con la geometría especificada,

- capacidad de mantener un nivel de vacío suficientemente alto para detectar pequeñas burbujas de gas atrapado,

- disponer de diferentes puertos de acceso con el fin de albergar los diferentes transductores de presión y temperatura, así como los sistemas de control y alimentación eléctrica del horno, y 
- su configuración debe permitir una manipulación sencilla y segura, teniendo en cuenta que se trabajará con metales fundidos a altas temperaturas.

Según esto se ha diseñado una cámara de cuerpo cilíndrico (véanse las Figuras 2.36, 2.37 y 2.38) fabricada en acero inoxidable AISI 316, con doble pared terminada en sus extremos, dos bridas y dos tapas, una inferior y otra superior. En la tapa superior se encuentran dispuestos tres puertos de acceso de $44 \mathrm{~mm}$ de diámetro interior con acoplamientos del tipo NW40(ISO), admitiendo cada puerto la conexión de dos termopares. Ambas tapas están construidas con un doble fondo dejando una cámara de aire que dispone de dos conexiones, una de entrada y otra de salida, para permitir la circulación interior de líquido refrigerante. El cuerpo de la cámara también dispone de una refrigeración similar. En cuanto al sistema de cierre, la tapa superior se encuentra fijada al cuerpo mediante tornillos de $12 \mathrm{~mm}$. La hermeticidad del cierre del cuerpo con las tapas se consigue mediante el uso de juntas de Vitón ${ }^{4}$ dispuestas sobre ranuras mecanizadas en ambas tapas. La tapa inferior será la que permitirá el acceso al interior del horno alojado en el cuerpo de la cámara y soportará al crisol que alojará la pieza a estudiar. Con este fin, la tapa inferior tiene un sistema de cierre manual mediante varios fijadores y dispone de dos orejetas que, mediante unos casquillos, se deslizan linealmente a lo largo de dos ejes. Estos ejes están situados diametralmente opuestos y fijados a la estructura de soporte del conjunto. El desplazamiento de la tapa inferior se realiza mediante una manivela y una reductora unida a una cadena que permite la carga y descarga del crisol. El cuerpo de la cámara dispone de cinco puertos laterales. Los tres primeros se utilizan para alojar las conexiones eléctricas de alimentación del horno, el cuarto para el transductor de presión y el quinto para la conexión con las bombas de vacío. El volumen total de la cámara es de $65093 \mathrm{~cm}^{3}$.

El sistema de bombas de vacío esta compuesto por una bomba de pre-vacío mecánica rotatoria y una bomba difusora conectadas en serie, que permiten alcanzar presiones de vacío, según las especificaciones del fabricante, de hasta $5 \times$ $10^{-8}$ Torr. En cuanto a la medida de presión, el sistema utiliza tres transductores:

Capacitivo encargado de registrar los incrementos de presión que se producen en la cámara de vacío. Dispone de una resolución de 0,005 Torr en un rango de hasta 100 Torr.

Convectivo de respuesta rápida para controlar la bomba difusora en el rango desde la presión atmosférica hasta $10^{-3}$ Torr.

Cátodo frío para registrar presiones en el rango de $10^{-3}$ a $10^{-8}$ Torr.

La conexión de las bombas con la cámara de vacío está regulada mediante electroválvulas gobernadas por el sistema de control.

\footnotetext{
${ }^{4}$ Elastómero con alta resistencia al calor $\left(200^{\circ} \mathrm{C}\right)$ fabricado por la empresa Dupont Dow.
} 


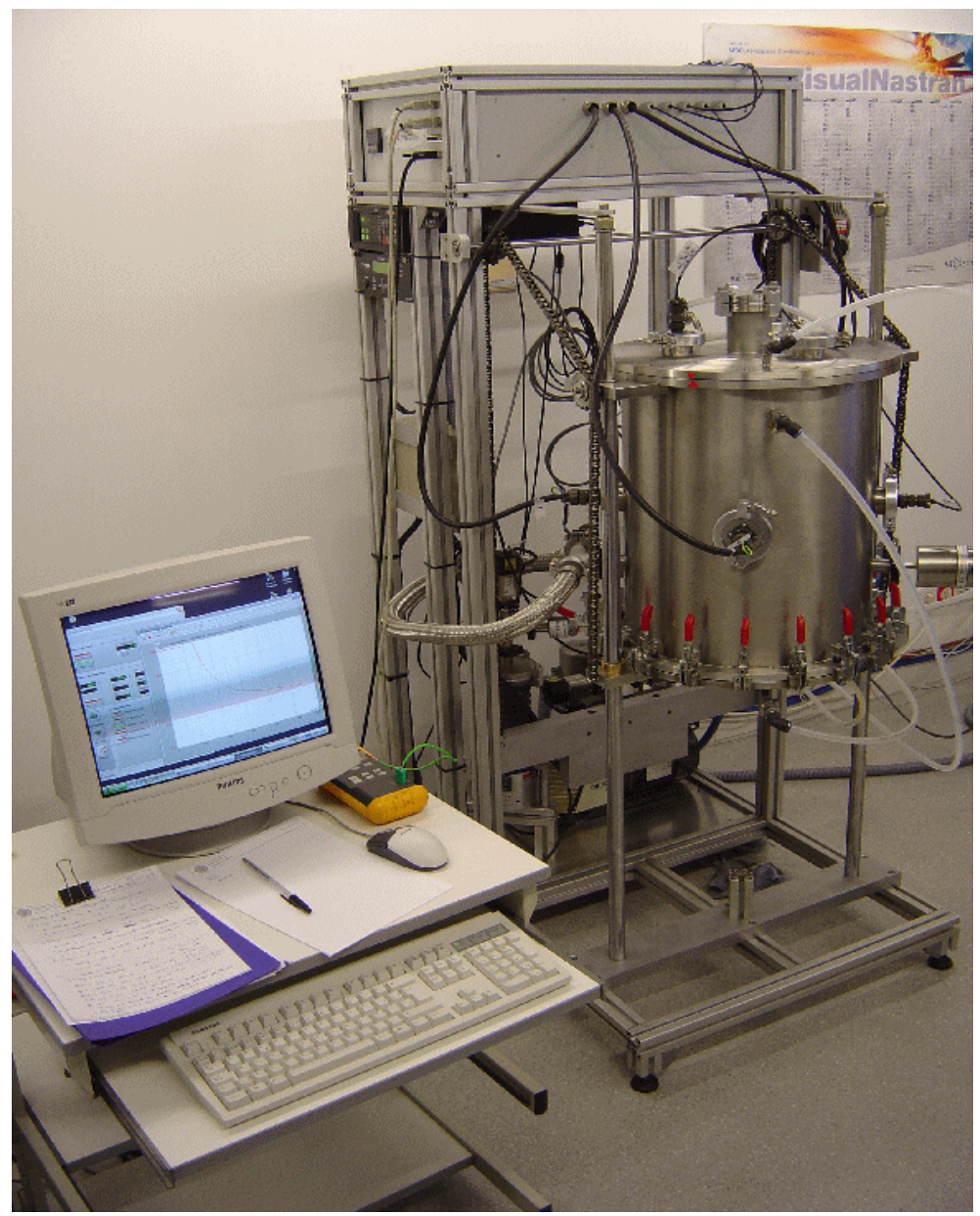

Figura 2.36: Vista general del sistema de fusión al vacío.

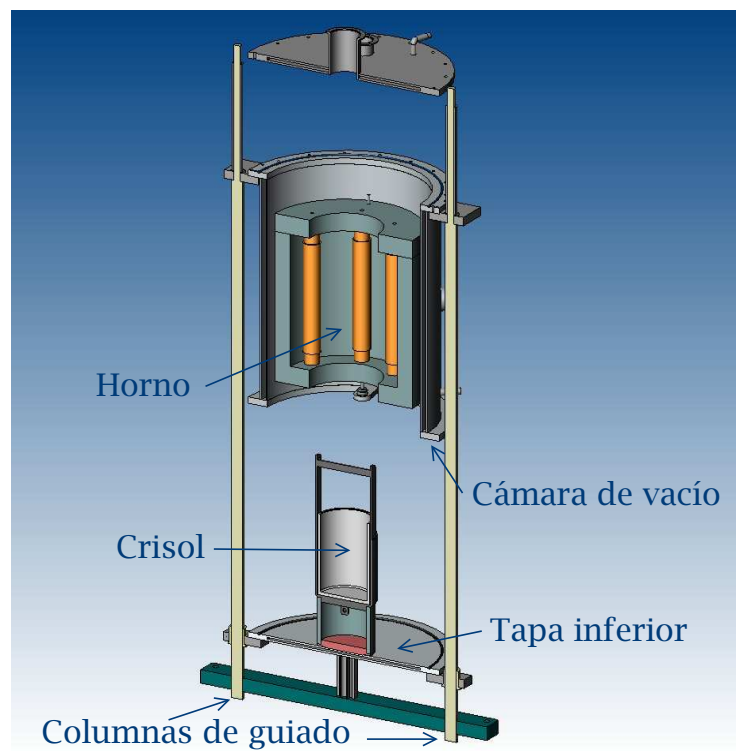

Figura 2.37: Vista seccionada del modelo de la cámara de vacío y horno de fusión. 


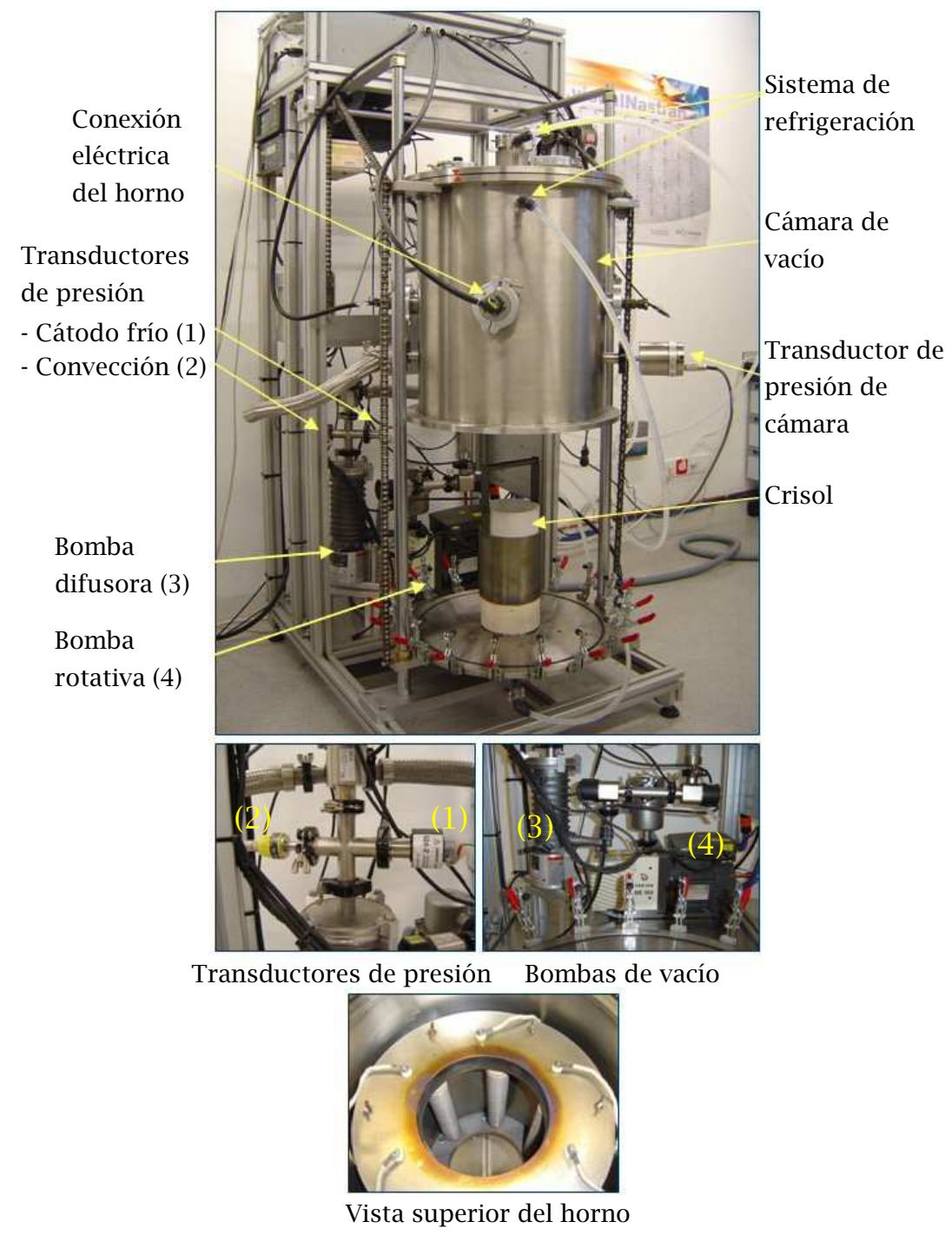

Figura 2.38: Componentes del sistema de vacío y horno de fusión. 


\subsubsection{Horno de fusión}

El horno es de tipo eléctrico con resistencias de hilo distribuidas en seis arrollamientos situados de forma radial alrededor del crisol. Como ya se ha comentado con anterioridad, el horno queda situado en el interior de la cámara de vacío y cuenta con los elementos aislantes necesarios para aislar las parades interiores de la cámara de vacío. El horno tiene alimentación trifásica de $220 \mathrm{~V}$ y posee una potencia por fase de 2500 W. Las resistencias están fabricadas en hilo de aleación Kanthal A1 de 1,8 mm arrollado en espiral sobre tubos cerámicos.

En cuanto al crisol utilizado, se ha escogido el Titanato de Aluminio debido a su buen comportamiento térmico y a la escasa adherencia con la aleación de aluminio utilizada en los ensayos.

\subsubsection{Sistema de control y gestión}

El control del sistema se realiza mediante un ordenador personal que incorpora una tarjeta de adquisición de datos y el software de gestión correspondiente. Este ordenador se comunica con el controlador del horno por medio de un puerto serie RS-232C. Mediante el software de gestión (véase la Figura 2.39) es posible acceder a todos los accionamientos como electroválvulas y bombas así como recoger la información de los transductores de presión y temperatura disponibles. La secuencia de operación y adquisición de datos durante el ensayo están automatizadas y se generan registros de datos con posibilidades de representación gráfica combinando los canales de datos disponibles.

Como se ha comentado anteriormente, en el Capítulo 4 se presentará el procedimiento de calibración escogido junto con los datos y correlaciones obtenidas. Así mismo se presentarán los resultados preliminares obtenidos hasta la fecha. 


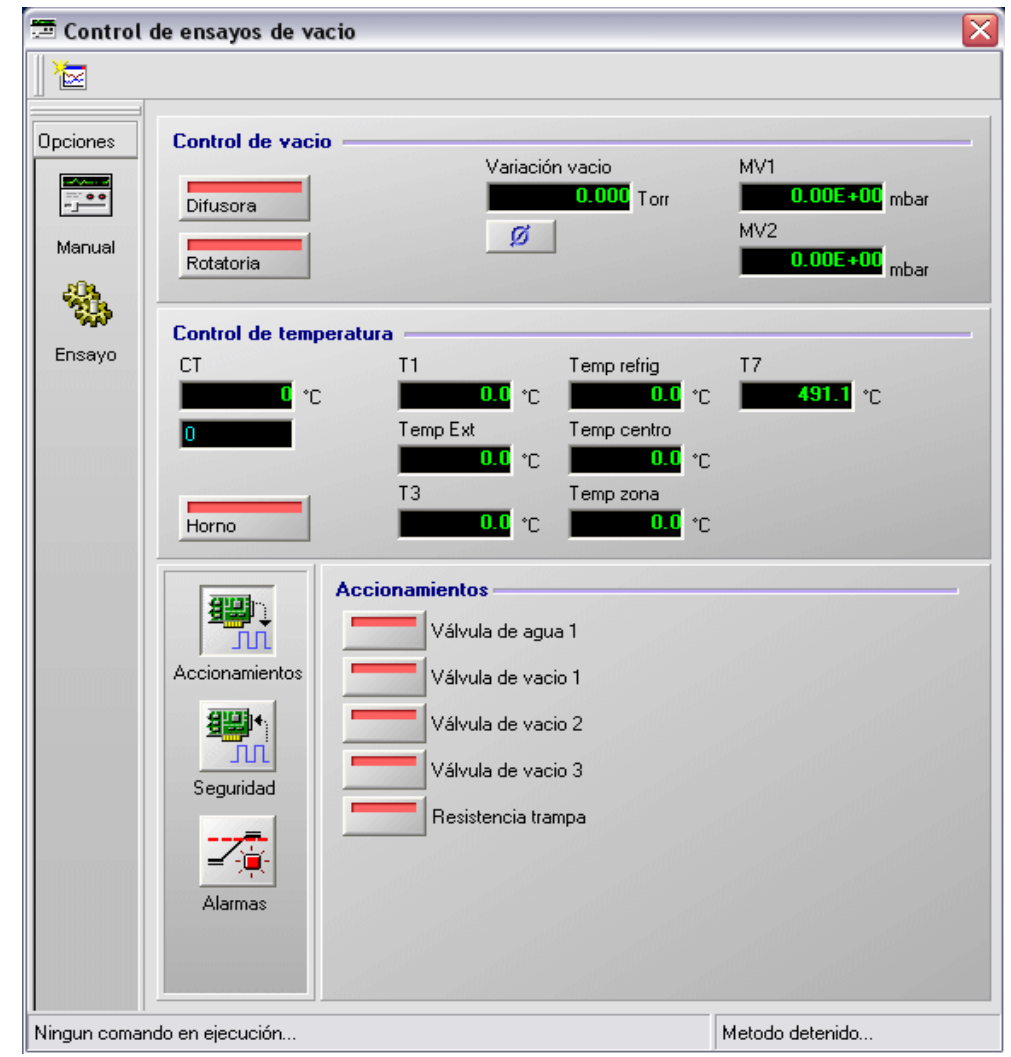

Figura 2.39: Pantalla principal del software de control y gestión del sistema de fusión al vacío. 


\subsection{Conclusiones}

Se han descrito los componentes de la instalación experimental disponible para la realización de ensayos en los talleres del Área de Ingeniería de los Procesos de Fabricación destacando las dificultades encontradas y las soluciones aportadas en el equipo a la hora de realizar ensayos para el estudio de la influencia de las condiciones de operación sobre el atrapamiento de aire en la etapa lenta. Estas dificultades se han resuelto mediante la incorporación de nuevos dispositivos encargados del control del movimiento del pistón así como con el desarrollo de nuevas aplicaciones de software. Mediante el uso de estas aplicaciones y junto con la información extraída de diferentes tipos de ensayos es posible configurar, de forma bastante aproximada, el sistema de inyección de manera que se consigan desplazamientos del pistón de inyección conforme a las diferentes leyes de movimiento deseadas. Así mismo se ha diseñado un molde apropiado para el estudio de la etapa lenta del proceso configurable para estudios sobre etapas posteriores.

Para mejorar el proceso de medición de la cantidad de aire atrapado en las piezas inyectadas, se ha diseñado y construido un sistema de fusión al vacío. Este sistema permite evaluar la cantidad de gas atrapado en las piezas mediante el estudio de las variaciones de presión y temperatura que se producen en una cámara. Se ha establecido el nivel de vacío necesario para que las variaciones de presión se deban principalmente a la liberación de las burbujas de gas durante la fusión de la pieza. 


\section{A P Í T U L O 3}

\section{Estudio experimental del}

atrapamiento de aire mediante ensayos con agua. Comparación con resultados teóricos

En el presente capítulo se ha desarrollado un estudio experimental de la velocidad máxima óptima del pistón en la etapa lenta de una máquina FIAP de cámara fría. El estudio ha requerido la fabricación, puesta a punto e instalación en la cámara de inyección de la máquina, de un sistema específico que usa un sensor fotoeléctrico para determinar el instante en que el fluido de trabajo alcanza el conducto de entrada a la cavidad del molde. Se ha comparado el volumen de aire que queda en la cámara en dicho instante, para varias velocidades máximas del pistón y diferentes valores de la fracción inicial de llenado con los calculados mediante un modelo numérico tridimensional basado en una formulación de elementos finitos para resolver las ecuaciones de conservación de la masa y cantidad de movimiento y el método VOF ("volume-of-fluid") para el tratamiento de superficies libres. Adicionalmente los resultados numéricos se han comparado con experimentos llevados a cabo en un banco de ensayos, también con agua, que permite visualizar el flujo y determinar la cantidad de aire atrapado en la cámara de inyección durante el proceso de inyección.

\subsection{Efectos del atrapamiento de aire en la cámara de in- yección}

Como se comentó en el Capítulo 1, esta tesis se ha centrado en el estudio de la etapa inicial de inyección, en la que el pistón empuja al metal fundido provocando su ascenso hacia la zona superior de la cámara de inyección, para posteriormente continuar con un movimiento a velocidad constante que se mantiene hasta el momento en el que el fluido llena la cámara por completo. La 
cantidad de aire atrapado durante esta etapa puede representar una parte importante de la cantidad total de aire atrapado durante todo el proceso de inyección especialmente cuando se utilizan parámetros de operación inapropiados.

El atrapamiento de aire en la cámara de inyección está relacionado con el comportamiento de la superficie de la ola de metal fundido formada por el movimiento del pistón. Como se indicó en el Capítulo 1, si el pistón alcanza una velocidad máxima superior a un cierto valor óptimo la ola se reflejará contra el techo de la cámara (como se muestra en la Figura 1.13 a)) provocando la rotura de la ola o que se forme un chorro en el techo de la cámara que alcanzaría anticipadamente el canal de colada. Por otro lado, si la velocidad máxima es inferior al valor óptimo, la ola podría reflejarse contra la pared final de la cámara de inyección y atrapar aire entre la cara del pistón y el techo de la cámara (como se muestra en la Figura 1.13 b)).

Sheptak [74], Garber [28], Karni [44], Duran et al. [20], Brevick et al [14], Bennett [11] y Davis y Asquith [18], entre otros, realizaron experimentos utilizando agua como fluido de trabajo en una cámara de inyección transparente y técnicas de visualización para analizar la influencia de las diferentes condiciones de operación sobre la cantidad de aire atrapado de aire durante la etapa lenta. Los estudios de Karni [44], Duran et al. [20] y Brevick et al [14] se centraron principalmente en la influencia de la ley de aceleración del pistón sobre la cantidad de aire atrapado en la cámara. Utilizaron un interruptor fotosensible con el fin de determinar el instante en el que el agua alcanza el conducto de entrada a la cavidad del molde. Tal y como se comentó en el Capitulo 1, los estudios experimentales llevados a cabo en condiciones reales de operación son relativamente escasos. Aunque autores tales como Smith y Wallace [75], Lindsey y Wallace [51], Brevick et al. [15] o Huang et al. [38] realizaron experimentos en máquinas FIAP con cámara fría, los resultados obtenidos están referidos principalmente con la etapa rápida de inyección.

Con respecto a los trabajos teóricos centrados en la etapa lenta de inyección se pueden clasificar en analíticos [28, 77, 15, 13, 81, 55, 24] y numéricos [49, 7, 35, 32, 54, 45, 34]. Backer y Sant [7] utilizaron el código "Wrafts" [73] para simular el flujo de metal fundido en la cámara de inyección. Este código está basado en una formulación de elementos finitos para la resolución de las ecuaciones de conservación de masa y de cantidad de movimiento y en un método de tipo VOF para describir la superficie libre, y fue utilizado por López et al. [54] para obtener la velocidad óptima máxima del pistón para diferentes fracciones iniciales de llenado y leyes de aceleración del pistón. Las simulaciones en este caso, se llevaron a cabo sin tener en cuenta la reflexión de la ola de metal fundido contra la pared final de la cámara. En trabajos previos la reflexión de la ola contra la pared final sólo de consideró para una configuración bidimensional de la cámara [35, 32]. Cabe destacar que también existen trabajos [54] donde se ha estudiado la posibilidad de estimar la velocidad del pistón óptima utilizando modelos más sencillos basados en la aproximación unidimensional de las aguas 
poco profundas $[81,55,54]$.

En la presente tesis, se ha determinado experimentalmente en una máquina FIAP la velocidad máxima óptima del pistón que minimiza el atrapamiento de aire en la cámara de inyección. Se ha utilizado una ley de aceleración propuesta por López et al. [55], que reduce teóricamente la cantidad de aire atrapado. Para determinar el instante en el que el fluido de trabajo (agua) alcanza el conducto de entrada a la cavidad del molde, se ha instalado un dispositivo específicamente diseñado que utiliza un sensor fotoeléctrico capaz de detectar el paso del fluido. Se ha determinado el volumen de aire remanente en la cámara en dicho instante en función de la velocidad máxima del pistón para diferentes fracciones iniciales de llenado. Los resultados experimentales se han comparado con los de un modelo numérico tridimensional, similar al utilizado por López et al. [54], pero teniendo en cuenta, en este caso, la reflexión de la ola contra la pared final de la cámara. También se han realizado comparaciones con los resultados obtenidos en un banco de ensayos experimental que permite determinar, mediante ensayos de visualización, la evolución de la superficie libre para diferentes condiciones de operación.

\subsection{Modelo analítico y numérico}

Los resultados obtenidos sobre la cantidad de aire atrapado en la cámara de inyección se han comparado con los obtenidos mediante un modelo analítico y otro numérico. Los resultados analíticos se obtuvieron a partir de un modelo unidimensional sencillo basado en la aproximación de las aguas poco profundas [54], el cual se soluciona utlizando el método de las características y un procedimiento basado en el "inverse marching method" en una malla deformable de diferencias finitas. El código CFD [73] utilizado está basado en el método de los elementos finitos que resuelve las ecuaciones de conservación de masa y de cantidad de movimiento. Para calcular la posición de la superficie libre del metal fundido en cada instante se emplea el método VOF ("volume of fluid"). Como se ha mencionado con anterioridad, López et al. [54] aplicaron este modelo al estudio del flujo en una cámara de sección circular sin considerar el efecto de la reflexión de la ola contra la pared final de la cámara de inyección.

Se ha considerado que el líquido vertido en la cámara se encuentra inicialmente en reposo y que la superficie libre es plana (Figura 3.1). La duración típica de la fase lenta de inyección es del orden de un segundo por lo que se han despreciado los efectos debidos a la transferencia de calor y a la solidificación. Debido a la simetría del problema solamente se ha resuelto la mitad del dominio físico. Se ha utilizado una malla con elementos hexahédricos de 8 nodos (Figura 3.1(b)), excepto en la zona de la pared cilíndrica de la cámara donde algunos elementos tienen 6 nodos. El valor de la presión definida en los elementos de la superficie libre se ha fijado y se ha impuesto una condición de no deslizamiento en las 


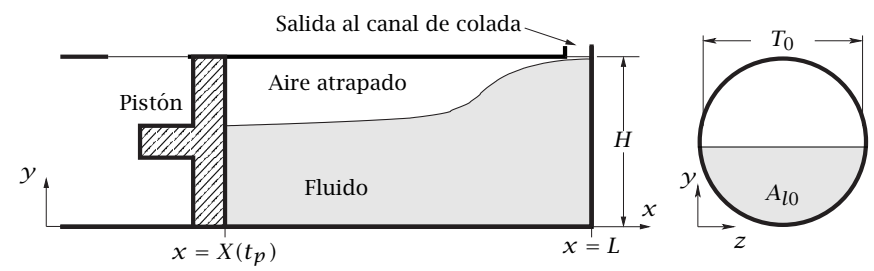

(a)

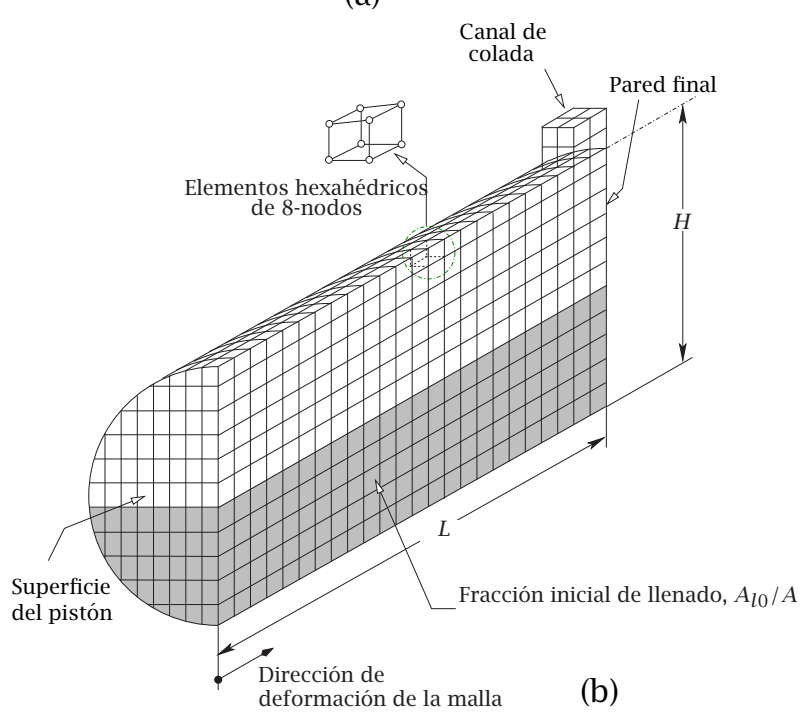

Figura 3.1: Representación esquemática del problema. (a) Sistema de coordenadas. (b) Esquema de la malla utilizada en el modelo numérico 3D. 
paredes de la cámara de inyección. En la cara del pistón, se ha fijado la velocidad horizontal según la ley de aceleración de la ecuación:

$$
X^{\prime \prime}(t)=\frac{2}{3} \frac{c_{0}^{2}}{L}\left[1-\frac{c_{0}}{L} t\right]^{-4 / 3}, \quad \text { para } t \leq t_{H},
$$

donde $t_{H}$ es el tiempo en el que el pistón alcanza la velocidad máxima y cesa la aceleración $\left(X^{\prime \prime}(t)=0\right.$ para $\left.t>t_{H}\right)$, $\ell$ es una constante positiva y $c_{0}=$ $\left(g A_{l 0} / T_{0}\right)^{1 / 2}$ es la velocidad de la ola relativa al fluido de una ola de pequeña amplitud ( $g$ es la aceleración de la gravedad, $A_{l 0}$ el área de la sección transversal inicialmente llena con fluido, and $T_{0}$ la correspondiente anchura de la superficie libre; véase la Figura 3.1). Así mismo, se han impuesto condiciones de contorno apropiadas en el plano de simetría. El estudio numérico se ha centrado en simulaciones que se aproximan a las condiciones óptimas del proceso en las que se espera que los efectos debidos a la tensión superficial tengan una influencia muy pequeña en la dinámica de la superficie libre, por lo que se han despreciado dichos efectos. No se han considerado condiciones de operación alejadas de las óptimas en las que aparecen, durante los primeros instantes de la inyección, fenómenos como los involucrados en los procesos de rotura de olas o formación de chorros de pared. Se pueden consultar detalles numéricos adicionales sobre el código utilizado en la referencia [32], donde se realiza una comparación con algunos datos experimentales y en la referencia [54].

\subsection{Procedimiento experimental}

En la presente sección se describirán los equipos auxiliares instalados en la máquina necesarios para realizar los ensayos con agua y la instalación experimental utilizada para realizar los ensayos de visualización.

\subsubsection{Ensayos con agua en la máquina FIAP}

Entre las principales razones por las que se decidió realizar ensayos con agua, se pueden citar las siguientes:

- el cálculo de la cantidad de aire atrapado se realiza sobre la propia máquina de inyección mediante la incorporación de un dispositivo sencillo,

- es posible estimar de forma directa la cantidad de aire atrapado sin requerir la intervención de métodos y equipos adicionales de medida de porosidad (medida de densidades, incremento de presiones o análisis de imagen entre otros), y

- al tratarse de ensayos "en frío", se minimiza el número de variables que afectan a la porosidad debidas a la temperatura. 
Sin embargo, debe tenerse en cuenta que se utiliza un fluido con propiedades físicas diferentes a las aleaciones comúnmente utilizadas por lo que es necesario tener en cuenta las diferencias existentes en cuanto a su comportamiento [28, 21].

Al no disponer de piezas sobre las que medir la porosidad resultante, el proceso de medición del aire atrapado en la primera etapa de inyección mediante ensayos con agua se llevará a cabo a partir del estudio del aire restante en la cámara de inyección en el momento en el que el fluido comience a ascender hacia la cavidad del molde a través del canal de colada, por lo que se hace necesario contar con un dispositivo que sea capaz de detectar y registrar el momento exacto en el que se produce dicho evento.

Para determinar de forma precisa el instante en el que el agua alcanza el conducto de entrada a la cavidad del molde se presentan varias dificultades:

- la velocidad de paso del fluido es elevada (en algunos casos superior a 1 $\left.\mathrm{ms}^{-1}\right), \mathrm{y}$

- existe un tiempo de reacción del sistema que debería ser corto y en cualquier caso constante.

En la selección del tipo de transductor a utilizar, las características descritas descartan los de tipo capacitivo, resistivo o inductivo, principalmente debido a los altos y variables tiempos de respuesta, por lo que se decidió utilizar un transductor de tipo óptico como el más adecuado. Dentro de la gama de transductores de tipo óptico, existe una gran variedad, entre los que se pueden citar los siguientes: retroreflectivos, de proximidad por barrido difuso, de contraste, de luminiscencia, de color o de fibra óptica entre otros. En este caso se ha optado por el uso de un transductor fotoeléctrico de fibra óptica montado con configuración de haces de luz pasante. Según esta configuración, el receptor se encuentra enfrentado al emisor quedando situados ambos a cada lado de la barrera óptica establecida. Así, se pretende que el transductor sea capaz de detectar el paso del fluido cuando éste atraviese la barrera óptica establecida entre sus extremos. Estos extremos están formados por una pareja compuesta por un emisor y un receptor de luz en los que se acoplan unas extensiones de fibra óptica. Esto permite, en función del tipo de transductor y fibra empleados, situar el elemento transductor incluso a varios metros de distancia del lugar donde se coloca la barrera óptica. Concretamente, el transductor utilizado ha sido un Siemens Opto-BERO 3RG70 con configuración PNP, (véase la Figura 3.2). Este dispositivo de pequeñas dimensiones $(30 \times 30 \times 15 \mathrm{~mm})$, dispone de un tiempo de ciclo de 0,5 ms. También cabe destacar la disponibilidad de una graduación de sensibilidad mediante un potenciómetro manual y de un diodo emisor de luz (LED) que se ilumina cuando el sensor recibe luz. Las características de la detección dependen del tipo y características de la fibra óptica que se escoja en su configuración. En este caso se ha utilizado una fibra óptica plástica de 1,2 mm de diámetro y $2 \mathrm{~m}$ de longitud que permite detecciones con barreras hasta de $400 \mathrm{~mm}$ de longitud. 


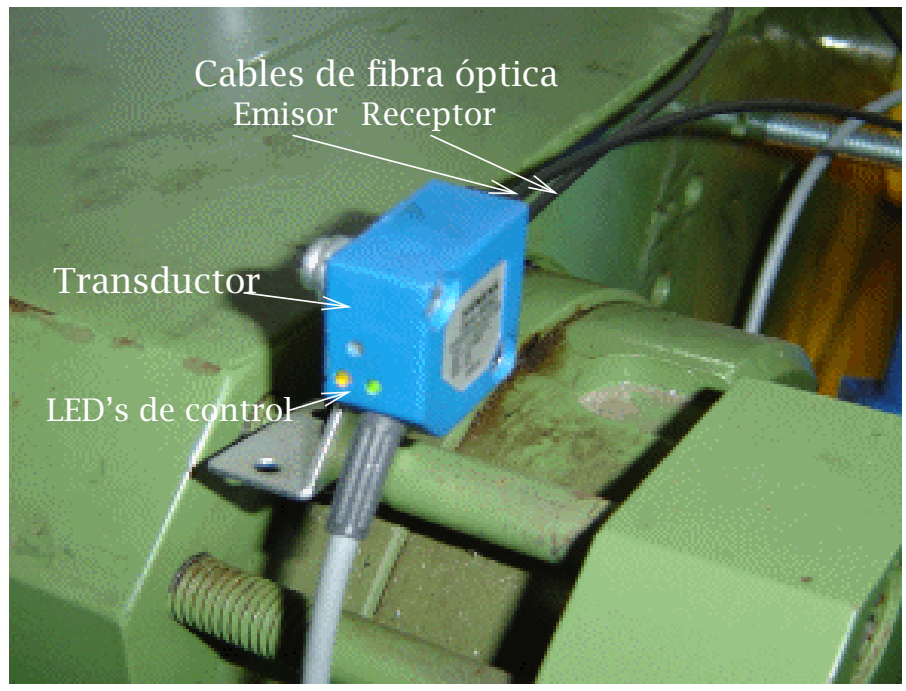

Figura 3.2: Transductor fotoeléctrico instalado en la máquina FIAP.

La elección del tipo de fibra ha venido condicionada por las características del ensayo a realizar. En este caso, la detección del paso del agua en el conducto de entrada hacia la cavidad del molde requiere la construcción de un dispositivo que permita alojar la barrera óptica de forma que ésta quede dispuesta de forma tangencial a la parte cilíndrica superior de la pared final de la cámara de inyección.

\subsubsection{Diseño y fabricación del dispositivo para el alojamiento del trans- ductor fotoeléctrico}

Debido a las complicaciones que presenta la modificación del molde existente, se ha optado por fabricar un elemento intercambiable que permita su instalación en el molde de forma sencilla. Este dispositivo debe permitir trabajar con la máquina en modo de operación estándar por lo que debe adaptarse al molde permitiendo su apertura y cierre dentro de cada ciclo de inyección. Así mismo, debe permitir el acceso a los elementos de captación, en este caso los extremos de la fibra óptica, para realizar las tareas de limpieza y mantenimiento por lo que se ha optado por fijarlo en la parte móvil del molde.

Teniendo en cuenta las posibles irregularidades que se pueden presentar en el frente del fluido durante su paso por la zona de detección, se ha diseñado y fabricado un dispositivo, (véanse las Figuras 3.3 y 3.4), que una vez instalado junto con la cámara de inyección incorpora un canal de colada de geometría rectangular con un espesor igual al diámetro de la fibra óptica empleada (1,2 mm). De esta forma se asegura que la detección será correcta, sea cual sea la forma en la que el fluido ascienda hacia la cavidad del molde, y su vez se proporciona un viento capaz de evacuar el aire contenido en la cámara de inyección. Este dispositivo sitúa la barrera óptica al final de la cámara de inyección, con lo que la parte final 


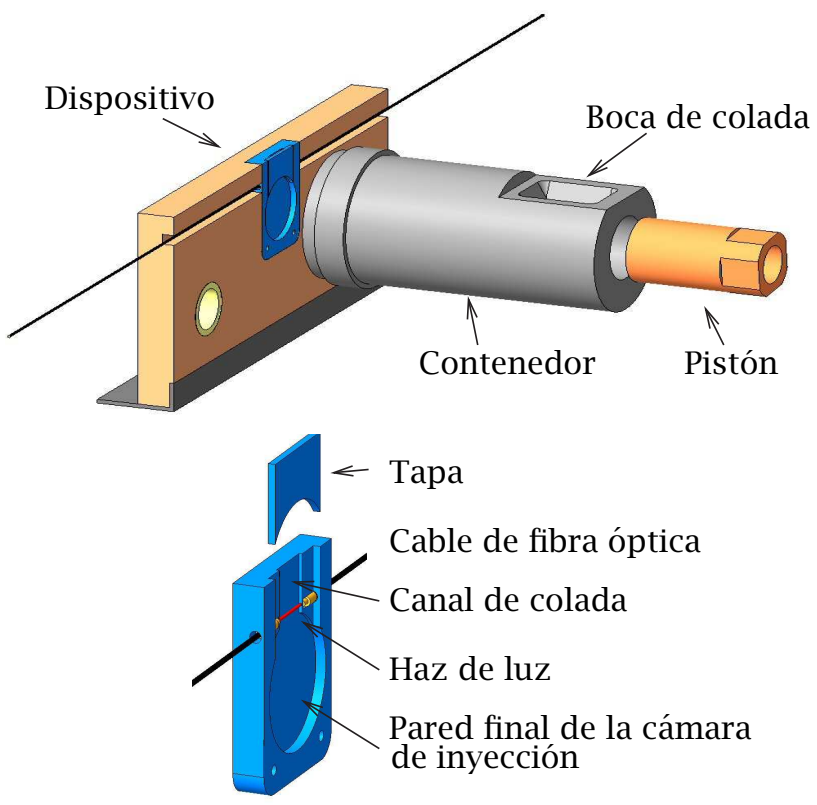

Figura 3.3: Vista de detalle del dispositivo específico que incorpora el canal de colada y los extremos de fibra óptica del transductor que permiten detectar el paso del agua por el canal.

de la cámara de inyección estará situada en el nuevo dispositivo. Para asegurar una concentricidad perfecta entre la cámara de inyección y el dispositivo fabricado, aprovechando los dos pernos guía de centrado inferiores de que dispone el molde en uso, se han mecanizado dos alojamientos en el dispositivo para unos casquillos, que permiten el montaje rápido y preciso requerido. Esto ha requerido una medición previa de las distancias entre centros de los pernos y la cámara de inyección utilizando una fresadora CNC con un palpador de contacto.

Los alojamientos de los extremos de la fibra óptica deben ser estancos y transparentes para permitir establecer el haz de luz. Para ello se optó por su fabricación utilizando poli-metil-metacrilato ya que no interfiere en el paso de luz. El inconveniente de este material es su elevada fragilidad lo que presenta ciertos problemas para soportar la presión de cierre de la máquina durante las inyecciones. En consecuencia se ha fabricado un dispositivo que combina el uso de tres materiales diferentes: bronce para los casquillos de guía, poli-metil-metacrilato para la zona de alojamiento de la fibra óptica, canal de colada y extensión de la cámara, y una resina polimérica, habitualmente utilizada en el mecanizado de prototipos, para el cuerpo del dispositivo que aloja a los dos anteriores e incorpora la flexibilidad necesaria en el cierre.

La fabricación de este dispositivo se realizó en una fresadora Soraluce con CNC Siemens 820, programada mediante el software CAD/CAM Procam, a partir de geometrías generadas en el CAD Solidworks. El mecanizado de los casquillos se realizó en un torno DANOBAT con CNC FAGOR 8050T. Ambos equipos se encuentran disponibles en el taller del Área de Ingeniería de los Procesos de 


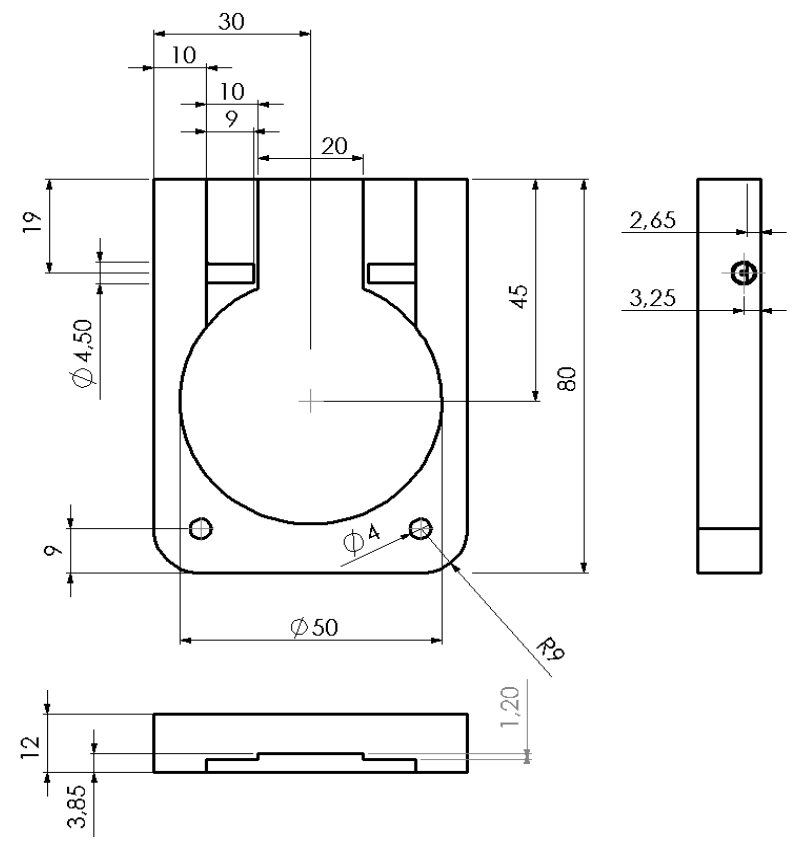

Figura 3.4: Plano del diseño de la pieza que forma la pared final de la cámara de inyección y aloja a los extremos de la fibra óptica.

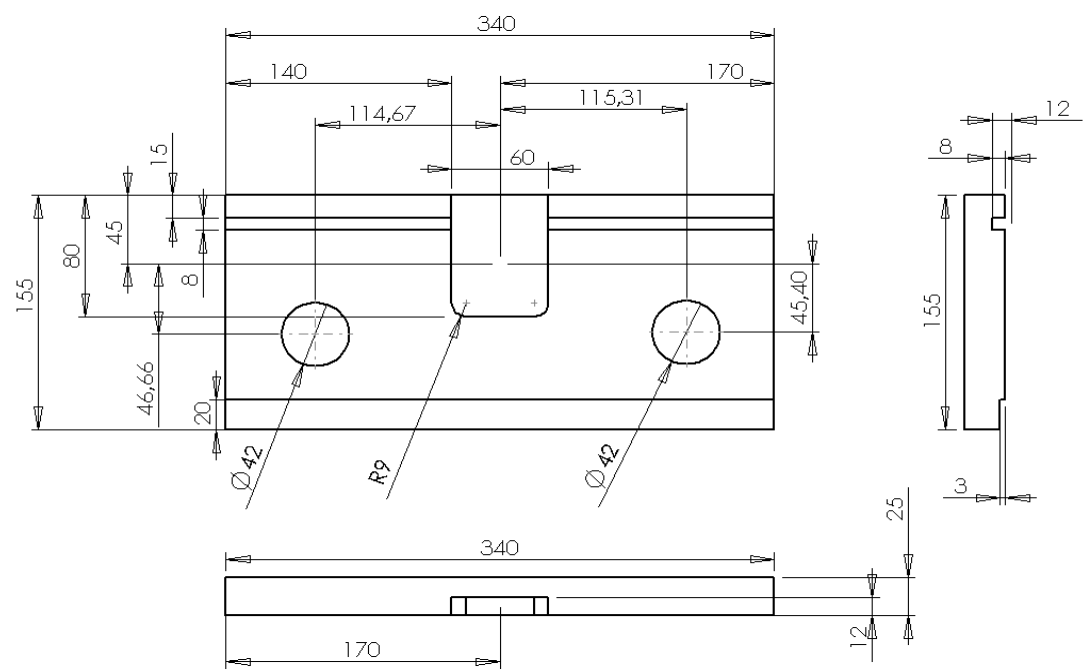

Figura 3.5: Plano de diseño de la pieza soporte del dispositivo. 
Fabricación de la UPCT. En la Figura 3.6 se puede apreciar un modelo CAD 3D del dispositivo instalado en la máquina. En las figuras 3.7 y 3.8 se muestran dos fotografías de dicho dispositivo.

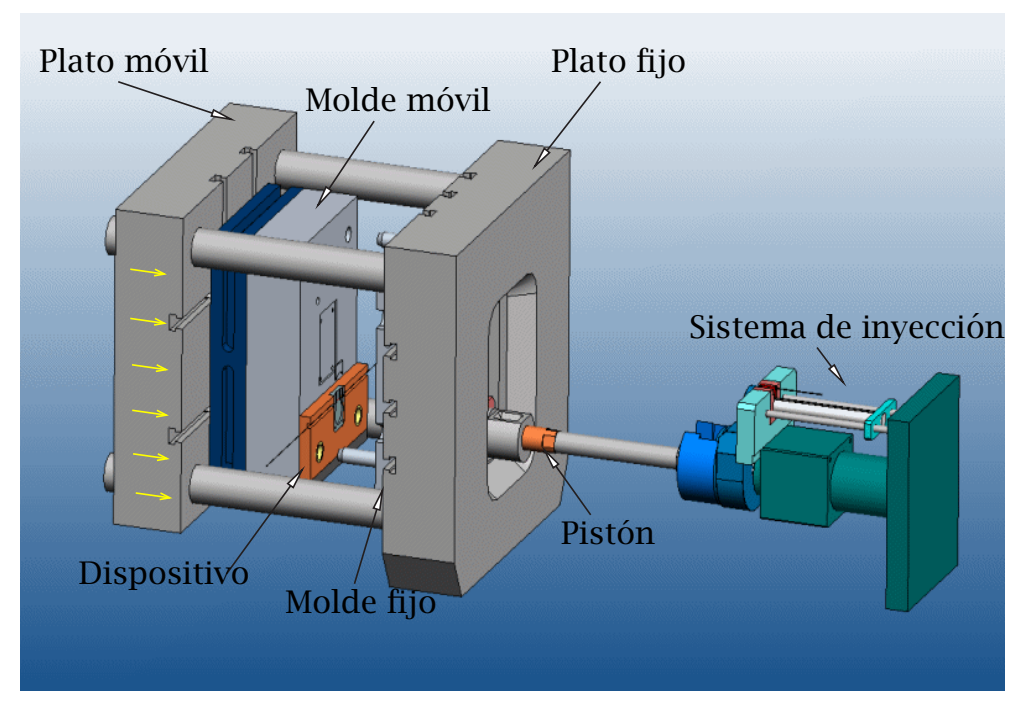

Figura 3.6: Modelo de la máquina FIAP incluyendo el dispositivo fotoeléctrico de detección.
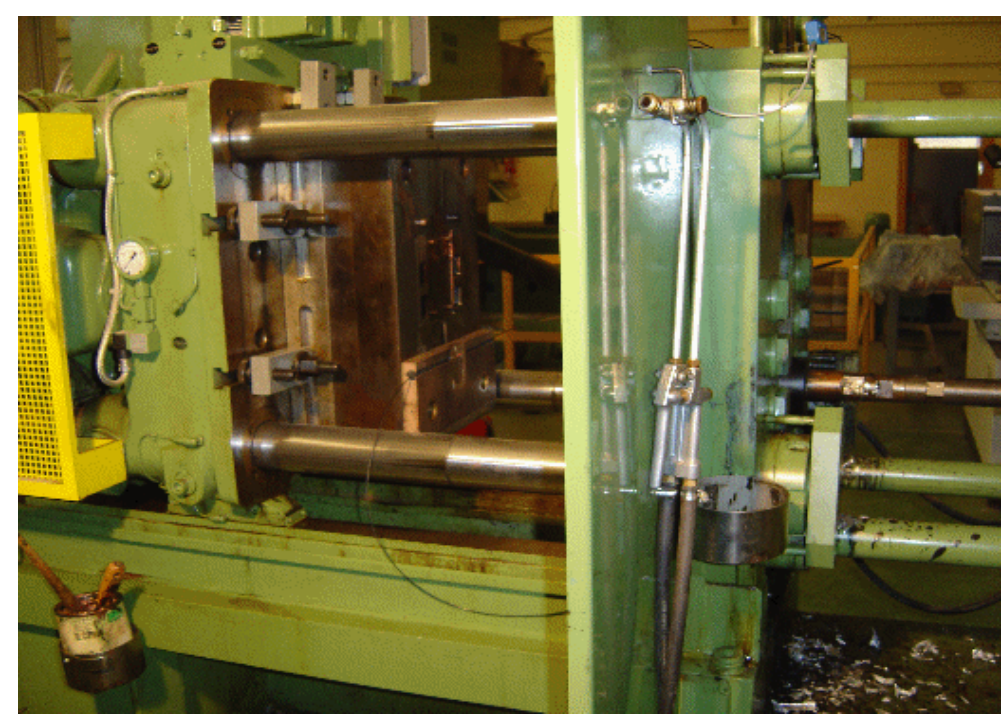

Figura 3.7: Maquina FIAP con el dispositivo para la detección del paso de agua instalado en la parte móvil del molde.

Tal y como se ha comentado, el dispositivo instalado en la máquina incluye un canal de colada abierto a la atmósfera, lo que permite la correcta evacuación del aire contenido en la cámara y la colocación de los extremos de fibra óptica del transductor utilizado para la determinación del instante en que el agua comienza a fluir a través del mismo. 


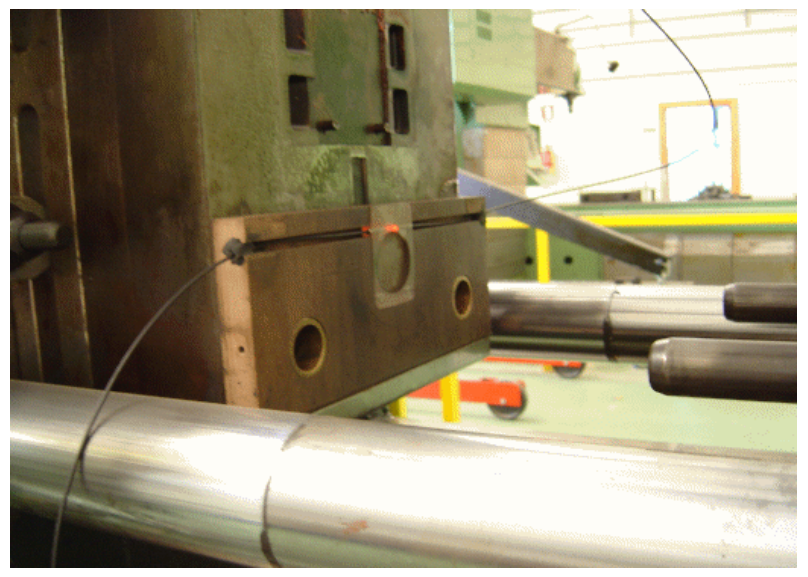

Figura 3.8: Dispositivo instalado, para una cámara de inyección de 50 $\mathrm{mm}$, con la barrera óptica activada.

Según las referencias disponibles donde se describen experimentos que utilizan agua como fluido de trabajo como la de Karni [44], se comprobó la sensibilidad del sensor fotoeléctrico ante el uso de colorantes o tintes que oscurecen el agua. Como puede observarse en la Figura 3.9, no se observaron diferencias significativas en los resultados, por lo que decidió no utilizar ningún tipo de colorante en los ensayos posteriores.

La Figura 3.10 muestra una representación esquemática del sistema de control de la máquina incluyendo el transductor instalado. La información generada por el transductor fotoeléctrico, de tipo binario, se incorpora a los listados de posición y tiempo generados por la aplicación de control de inyección PCI desarrollada en la presente tesis. Tal y como se comentó en el Capítulo 2, un autómata programable regula el movimiento del pistón en diez puntos del recorrido, asignando porcentajes de apertura de la válvula principal de descarga ente el $10 \mathrm{y}$ el $100 \%$, a través de la aplicación informática de control de máquina PCM. Cabe recordar que los valores de los porcentajes de válvula requeridos para reproducir una cierta ley de movimiento del pistón dependen de diversas variables: fracción inicial de llenado, diámetro del pistón, longitud de la cámara, presión y temperatura del sistema hidráulico, y los efectos de rozamiento entre el pistón y la cámara de inyección, entre otros. Los valores de apertura de válvula apropiados se ajustaron usando un procedimiento de prueba y error asistidos por la información generada por la aplicación informática comentada en el Capítulo anterior. La posición de la cara del pistón en el tiempo $t, X(t)$, se ha medido utilizando el nuevo transductor digital instalado en la máquina FIAP. Cuando la ley velocidad del pistón, medida durante una inyección dada, no se acercaba lo suficiente a la ley de velocidad deseada, ésta fue rechazada. En este caso se han rechazado aquellas curvas que han presentado un coeficiente estadístico de determinación (Eq. 2.5) $R^{2}<0,90 .{ }^{1}$ La Tabla 3.1 muestra el número de inyecciones

\footnotetext{
${ }^{1}$ Para el cálculo de este coeficiente no se ha tenido en cuenta la rampa de deceleración y frenada
} 


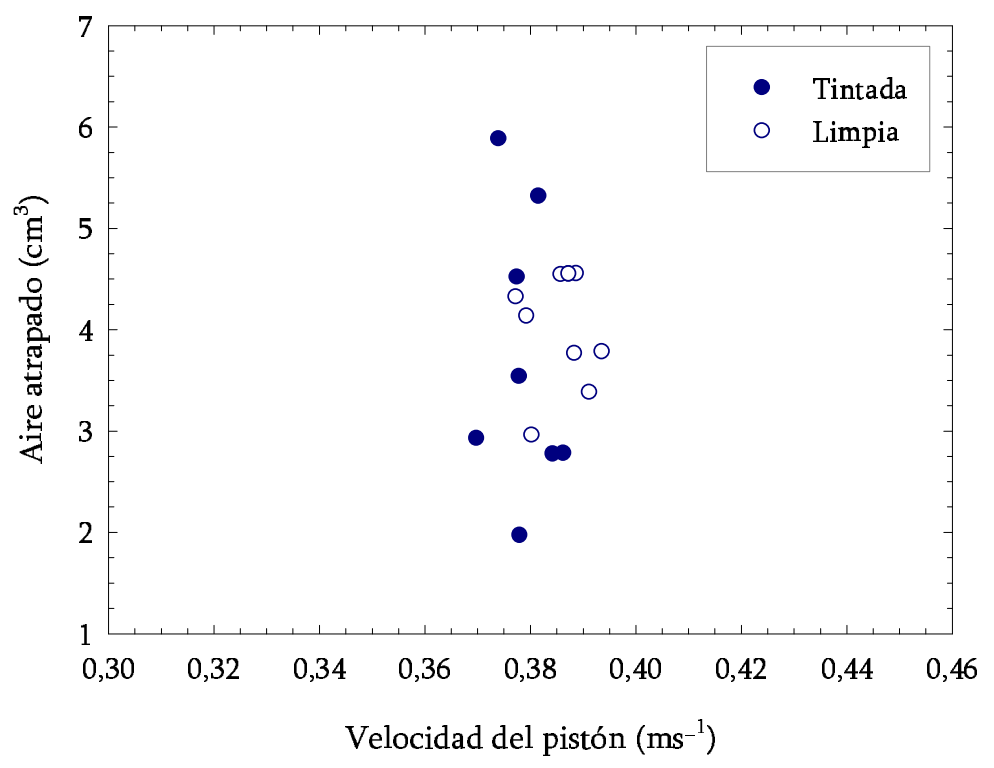

Figura 3.9: Valores de aire atrapado en inyecciones realizadas para el estudio de la influencia del uso de agua tintada con una fracción inicial de llenado $f=0,5$ y una velocidad del pistón máxima entorno a $0,38 \mathrm{~ms}^{-1}$.

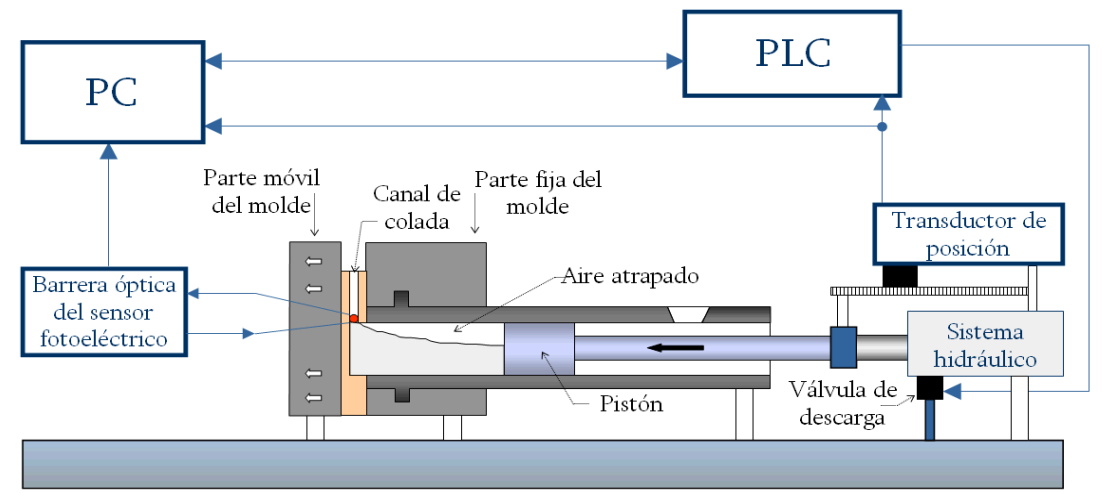

Figura 3.10: Representación esquemática del sistema de control utilizado en las inyecciones realizadas con agua en la máquina FIAP. 


\begin{tabular}{|c|c|c|c|c|}
\cline { 3 - 5 } \multicolumn{1}{c|}{} & \multicolumn{3}{c|}{ Fracción inicial de llenado } \\
\cline { 3 - 5 } \multicolumn{1}{c|}{} & 0,252 & 0,374 & 0,5 \\
\hline Velocidad del pistón & Max. & 0,409 & 0,446 & 0,361 \\
$U_{\max } /(g H)^{1 / 2}$ & Min. & 1,206 & 1,266 & 1,090 \\
\hline \multicolumn{2}{|c|}{ Inyecciones realizadas } & 146 & 142 & 129 \\
\hline \multicolumn{2}{|l|}{ Inyecciones rechazadas } & 1 & 21 & 35 \\
\hline
\end{tabular}

Tabla 3.1: Rangos de condiciones de operación utilizadas en los experimentos en máquina junto con los correspondientes números de inyecciones realizadas y rechazadas.

realizadas y rechazadas para las diferentes condiciones de operación utilizadas en los experimentos.

Cabe destacar que el $86 \%$ de las inyecciones con $R^{2}<0,90$ tienen un coeficiente $R^{2}$ mayor de 0,95. Como ejemplo, se puede observar en la Figura 3.11 el buen grado de concordancia existente entre la velocidad del pistón deseada (línea continua) y la medida (línea discontinua) para una inyección típica con $R^{2}=0,95$.

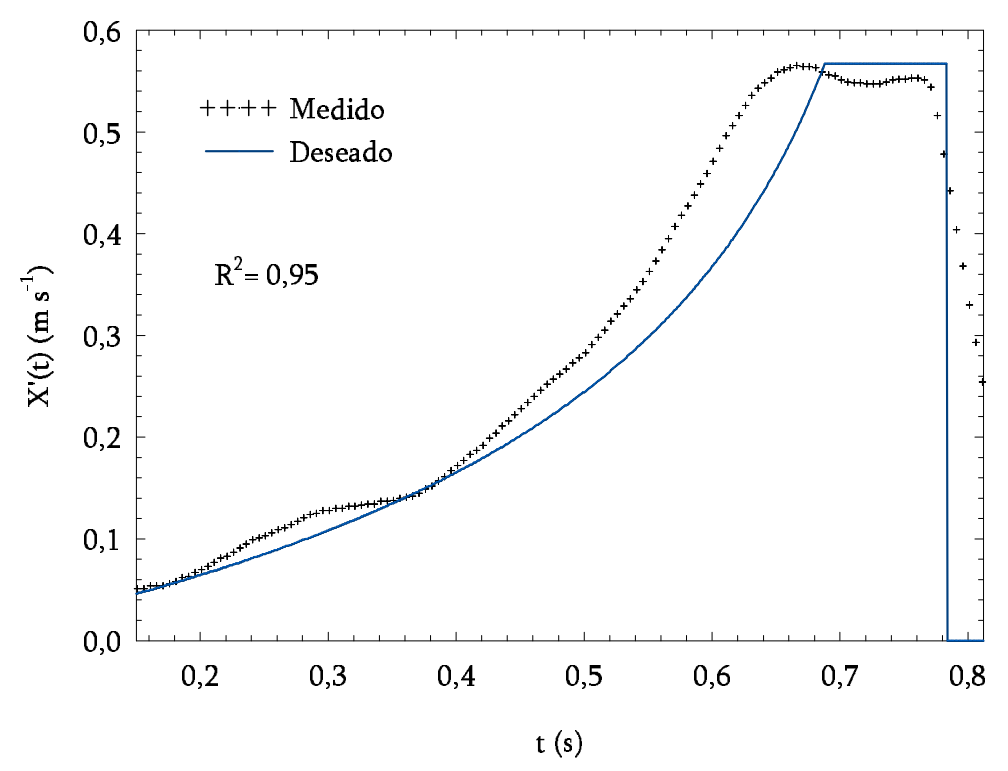

Figura 3.11: Comparación entre la velocidad del pistón teórica (línea continua) y velocidad medida (línea de cruces), para una ensayo típico con $R^{2}=0,95\left(A_{l 0} / A=0,374\right.$ y $\left.U_{\max }=0,57 \mathrm{~ms}^{-1}\right)$.

Se han realizado experimentos para las tres fracciones iniciales de llenado

considerando el rango máximo de valores a comparar, el punto en el que la velocidad del pistón decrece en un $5 \%$ de su valor máximo. 
comentadas en la Tabla 3.1, lo que requirió el uso de cucharas de diferentes volúmenes. Las diferentes cucharas fueron calibradas utilizando una balanza de alta precisión con resolución de $10^{-4} \mathrm{~g}$ y una repetibilidad de $\pm 2 \times 10^{-4} \mathrm{~g}$. El máximo error cometido en el volumen dosificado usando las diferentes cucharas resultó ser inferior a $\pm 0,2 \%$ del volumen total de la cámara de inyección $(A L)$. La longitud inicial de la cámara utilizada fue de $L=0,264 \mathrm{~m}$, y el diámetro correspondiente $H$ de $0,05 \mathrm{~m}$ con lo que resulta una relación $L / H$ de 5,3. Se realizaron series de al menos 10 inyecciones para cada combinación de fracción inicial de llenado y velocidad ensayadas. Todas los ensayos se realizaron utilizando la ley de aceleración expresada en la Ecuación 3.1 [55, 24]. La carrera de la inyección en cada ensayo se detuvo en una posición fija del recorrido (que depende de la fracción inicial de llenado) tal que aseguraba que el agua había comenzado a fluir a través del canal de colada. Al finalizar cada inyección, se limpió el canal de colada con aire comprimido con objeto de evitar cualquier suciedad en la zona de la barrera óptica.

\subsubsection{Ensayos de visualización}

El proyecto de investigación en el que se enmarca la presente tesis (formado por dos subproyectos) consta de un subproyecto dedicado, fundamentalmente, al estudio, mediante técnicas de visualización, de la evolución de la ola de metal fundido que causa el movimiento del pistón, las condiciones bajo las que se produce su rotura y las características generales del proceso de rotura en las condiciones típicas que pueden darse dentro de la cámara de inyección, así como a la validación experimental de las predicciones de modelos analíticos y numéricos desarrollados previamente. Evidentemente, aunque sus objetivos no coinciden con los de esta tesis, se complementan bastante. Desde esta perspectiva es muy interesante realizar ensayos con el equipo de visualización disponible, en condiciones similares a los realizados en la máquina FIAP, y obtener resultados comparables directamente con los obtenidos en condiciones reales de producción en la máquina FIAP.

La instalación experimental empleada para llevar a cabo los ensayos de visualización se encuentra situada en los laboratorios del Departamento de Mecánica de la UNED. Dicha instalación fue financiada con cargo al subproyecto DPI20011390-C02-02 y puesta en marcha durante el año 2003 (véase la Figura 3.12).

Todos los experimentos se llevaron a cabo utilizando agua como fluido de trabajo y una cámara de inyección transparente de sección circular fabricada con poli-metil-metacrilato, con un diámetro $H=0,074 \mathrm{~m}$ (véase la Figura 3.13), y la misma relación $L / H=5,3$ utilizada tanto en los experimentos realizados en la máquina como en las simulaciones teóricas. El movimiento del pistón se realiza a través de un husillo conectado a un motor "Brushless" (véase la Figura 3.14). El motor está controlado por un sistema CNC el cual puede ser programado, a través de un PC, para que el pistón siga la ley de movimiento deseada 


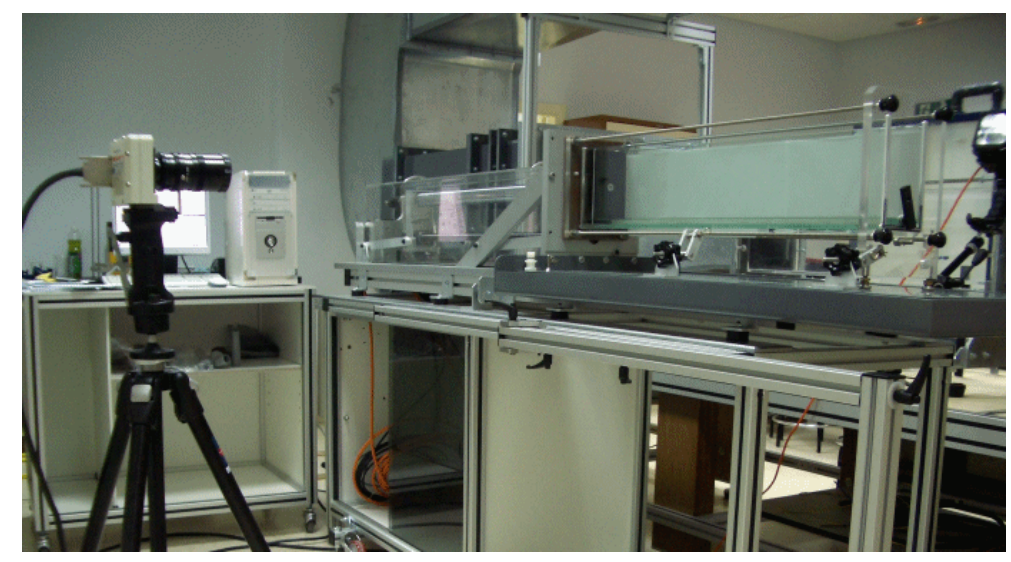

Figura 3.12: Instalación experimental para ensayos de visualización.

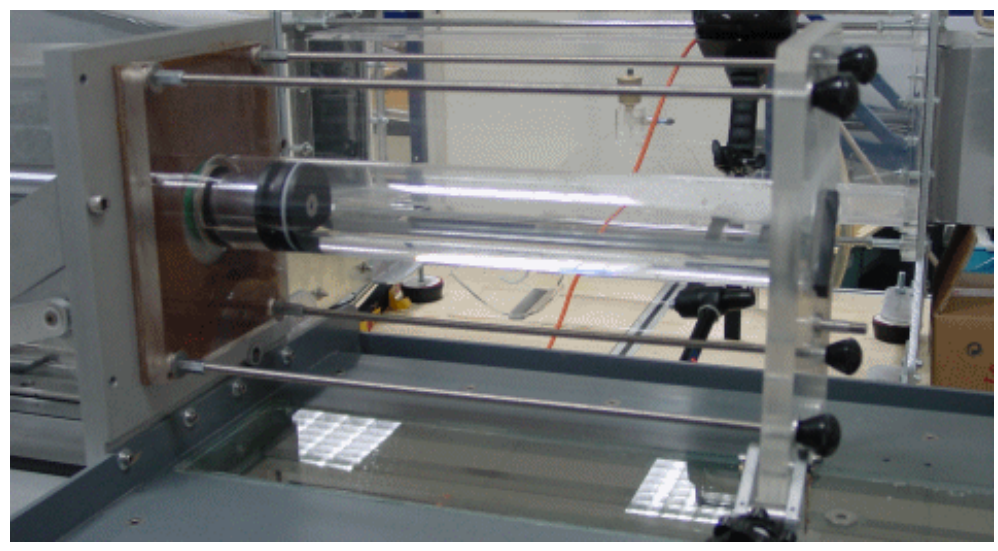

Figura 3.13: Vista de la cámara circular de $74 \mathrm{~mm}$ de diámetro utilizada en los ensayos de visualización.

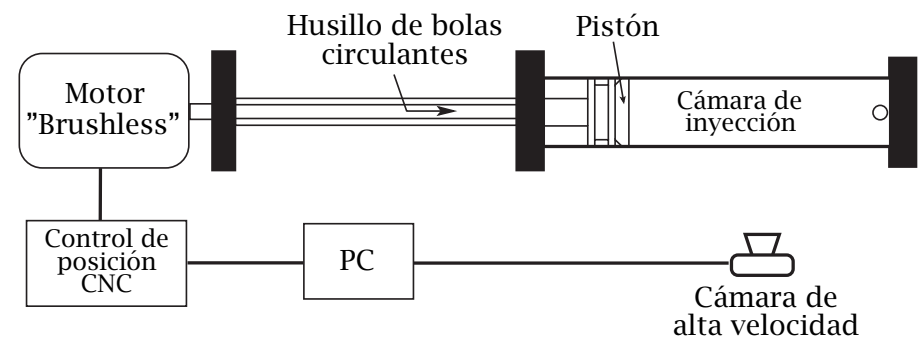

Figura 3.14: Representación esquemática de la instalación experimental de visualización. 


\subsubsection{Determinación experimental del volumen de aire atrapado}

Todas las inyecciones comenzaron una vez transcurrido un cierto tiempo después de haber realizado el vertido manual del agua en la cámara de inyección para permitir que líquido permaneciera en reposo y la superficie libre quedara plana. El volumen de aire remanente en la cámara de inyección en el instante $t_{p}$ en el que el agua comienza a fluir a través del canal de colada, adimensionalizado con el volumen inicial de la cámara queda calculado como:

$$
\frac{V}{A L}=\frac{L-X\left(t_{p}\right)}{L}-f,
$$

donde $X\left(t_{p}\right)$ es la distancia recorrida por el pistón en el instante $t_{p}$ y $f=A_{l 0} / A$ es la fracción inicial de llenado (obsérvese que el volumen restante en la cámara en el instante $t_{p}$ es $A\left(L-X\left(t_{p}\right)\right)$ y el volumen de agua vertido es $\left.A L f\right)$. Se espera que éste volumen esté relacionado con el volumen de aire atrapado en el líquido y que una fracción considerable de la porosidad de la pieza fabricada sea causada por este aire atrapado.

Con respecto a los ensayos realizados en la máquina FIAP, el software desarrollado para el sistema de control de inyección proporciona datos discretizados de la posición del pistón $X$ y el estado del sensor fotoeléctrico en función del tiempo $t$, con una frecuencia de muestreo de unos 10000 datos por segundo. La velocidad instantánea del pistón $X^{\prime}$ se ha calculado a partir de la posiciones discretas del pistón utilizando una ecuación de diferencias finitas centrada en el tiempo. Se ha utilizado un intervalo de tiempo de diferenciación suficientemente grande para evitar los errores debidos a la resolución limitada del transductor de posición. El error máximo de la velocidad del pistón obtenido de este modo se estimó que se encuentra entorno a $\pm 0,003 \mathrm{~ms}^{-1}$.

Para determinar la posición del pistón en el instante en el que el agua empieza a fluir a través del canal de colada, es necesario estimar el ligero retraso que se produce en la transmisión de la señal desde el transductor fotoeléctrico hacia el sistema de control. Con este propósito, se llevaron a cabo una serie de ensayos en los que se utilizó el transductor fotoeléctrico para detectar el momento en el que un cursor opaco (véanse las Figuras 3.15 y 3.16), unido de forma solidaria al desplazamiento del pistón en un punto fijo, cruzaba la barrera óptica mientras el pistón se movía con diferentes velocidades constantes $X^{\prime}$ (dentro del rango de 0,16 y $0,81 \mathrm{~ms}^{-1}$ ). La Tabla 3.2 y la Figura 3.17 muestran la posición del pistón registrada por el transductor de posición magneto-resistivo, $X\left(t_{m}\right)$, correspondiente al instante $t_{m}$ en el que el sistema de control registra el paso de la marca de referencia en función de la velocidad del pistón, $X^{\prime}\left(t_{m}\right)$. Cabe destacar que si el retardo de la señal, $t_{e}$, es constante, la posición $X\left(t_{m}\right)$ debe incrementarse linealmente con la velocidad del pistón, por lo que la posición real del sensor puede ser estimada como $X\left(t_{m}\right)-t_{e} X^{\prime}\left(t_{m}\right)$. El retardo de la señal se ha obtenido como la pendiente de la curva de correlación lineal calculada ${ }^{2}$ sobre los datos

\footnotetext{
${ }^{2}$ Se ha utilizado el algoritmo fitexy [69] el cual considera el valor de los intervalos de confian-
} 


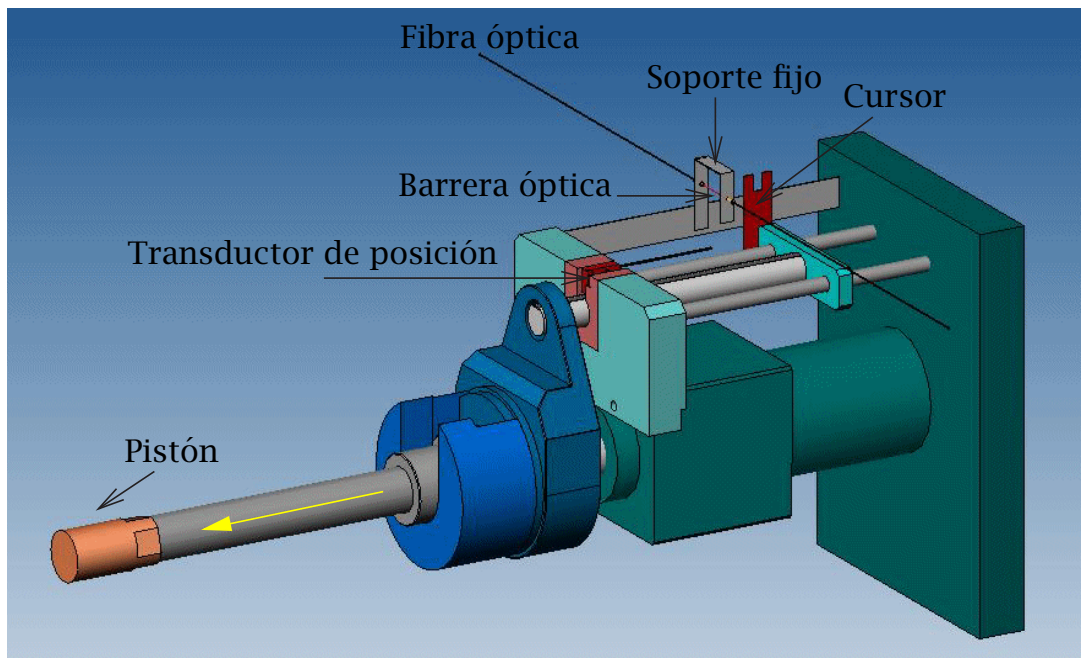

Figura 3.15: Modelo del dispositivo diseñado para la determinación del tiempo de retardo de la señal del transductor fotoeléctrico.

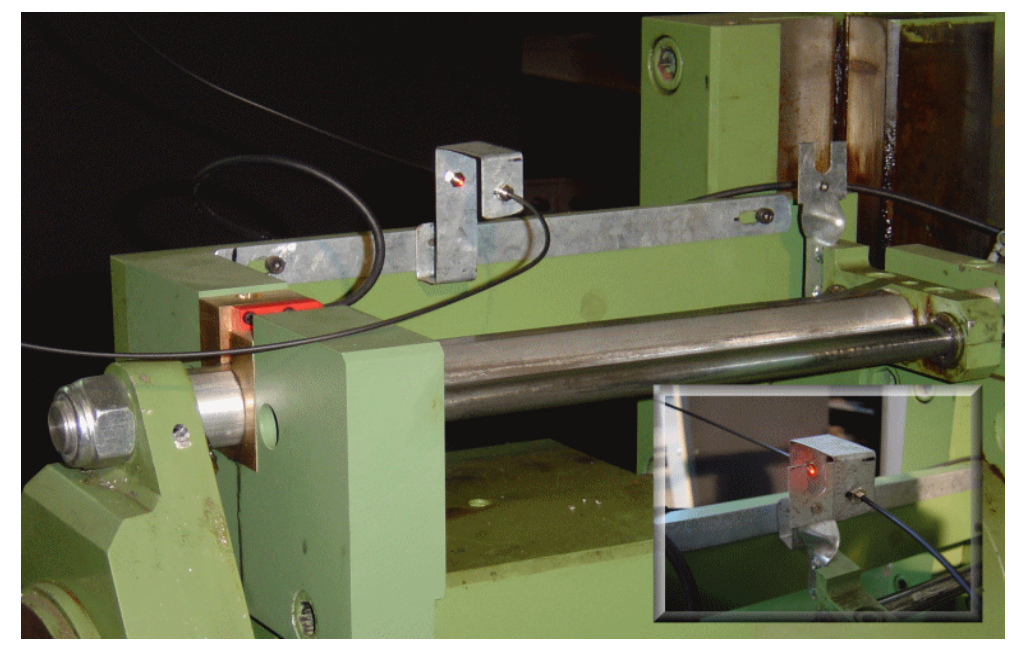

Figura 3.16: Dispositivo instalado en la máquina FIAP. Detalle del instante de cruce del cursor. 


\begin{tabular}{|c|c|}
\hline $\begin{array}{c}\text { Velocidad del pistón } \\
\mathrm{X}^{\prime}\left(\mathrm{ms}^{-1}\right)\end{array}$ & $\begin{array}{c}\text { Registro de recorrido } \\
(\mathrm{mm})\end{array}$ \\
\hline 0,16 & 177,3 \\
\hline 0,20 & 177,4 \\
\hline 0,27 & 177,5 \\
\hline 0,36 & 177,6 \\
\hline 0,44 & 177,7 \\
\hline 0,53 & 177,8 \\
\hline 0,65 & 178,0 \\
\hline 0,74 & 178,1 \\
\hline 0,81 & 178,2 \\
\hline
\end{tabular}

Tabla 3.2: Listado de posiciones registradas por el sistema de control.

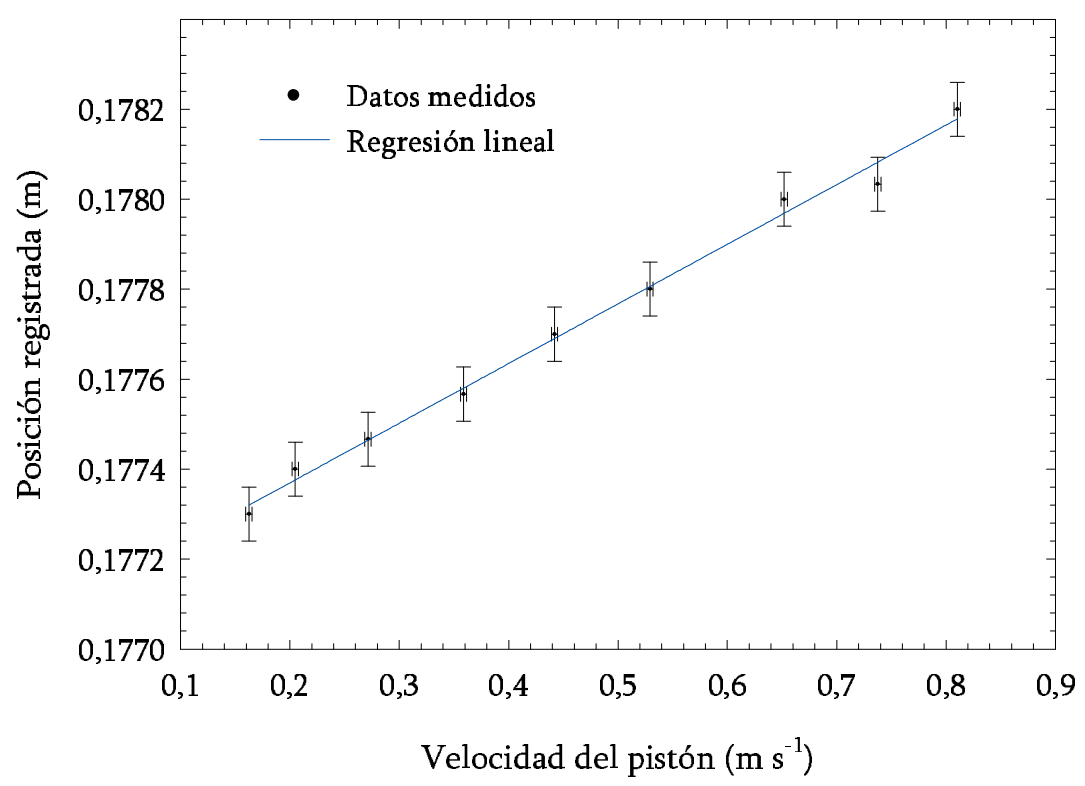

Figura 3.17: Correlación para el cálculo del tiempo de retardo de la señal. 


\begin{tabular}{|c|c|c|}
\hline Ensayo & $U_{\max } /(g H)^{1 / 2}$ & $V /(A L)$ \\
\hline 1 & 0,91 & $1,973 \mathrm{E}-02$ \\
\hline 2 & 0,91 & $3,938 \mathrm{E}-05$ \\
\hline 3 & 0,91 & $1,186 \mathrm{E}-02$ \\
\hline 4 & 0,91 & $1,580 \mathrm{E}-02$ \\
\hline 5 & 0,91 & $5,948 \mathrm{E}-03$ \\
\hline
\end{tabular}

Tabla 3.3: Valores adimensionales de aire atrapado en ensayos de repetibilidad del sistema de visualización realizados para una fracción inicial de llenado $f=0,252$ y velocidad adimensional máxima del pistón $U_{\max } /(g H)^{1 / 2}=0,91$.

experimentales (con un coeficiente de correlación de 0,997), resultando ser de $t_{e}=1,32 \pm 0,01 \mathrm{~ms}$. Así pues, si $t_{m}$ es el tiempo en el que el sistema de control detecta la señal emitida por el sensor fotoeléctrico cuando el agua comienza a fluir a través del canal de colada, la posición real del pistón $X\left(t_{p}\right)$ de la Ecuación (3.2) se obtiene de

$$
X\left(t_{p}\right)=X\left(t_{m}\right)-t_{e} X^{\prime}\left(t_{m}\right)
$$

donde $X\left(t_{m}\right)$ representa la posición del pistón registrada por el transductor de posición y $X^{\prime}\left(t_{m}\right)$ la velocidad del pistón correspondiente ${ }^{3}$.

En el caso de los ensayos de visualización, para determinar el instante $t_{p}$ en el que el líquido alcanza el canal de colada se ha utilizado en todos los ensayos una cámara de alta velocidad con un periodo de muestreo de 1000 fotogramas por segundo y una velocidad de obturación de $1 / 1000$ segundos. Una vez determinado este instante se obtuvo la posición del pistón correspondiente $X\left(t_{p}\right)$ a partir de la Ecuación 3.1, y el volumen adimensional de aire remanente en la cámara se calculó según la Ecuación 3.2. Con el fin de estimar la repetibilidad del sistema para calcular el volumen adimensional $V /(A L)$, se realizó una serie de cinco inyecciones con una velocidad adimensional máxima del pistón $U_{\max } /(g H)^{1 / 2}=$ 0,91 y una fracción inicial de llenado $f=0,252$ (véase la Tabla 3.3) obteniendo un valor medio de 0,0107 con una desviación estándar de 7,83 × $10^{-3}$.

za.

${ }^{3}$ Es necesario destacar la importancia que tiene el determinar con la mayor exactitud posible este tiempo de retardo ya que debido a las altas velocidades que desarrolla el pistón durante la inyección, retardos muy pequeños de tiempo introducen grandes errores en los cálculos de volumen. Por ejemplo, en una geometría de cámara cilíndrica de $50 \mathrm{~mm}$ de diámetro durante una inyección de $1 \mathrm{~ms}^{-1}$ de velocidad, un retraso de $t_{e}=1 \mathrm{~ms}$ genera un error de 1,96 $\mathrm{cm}^{3}$. 


\subsection{Discusión de resultados}

\subsubsection{Comparación entre resultados CFD y analíticos}

Los resultados del modelo CFD se han comparado en primer lugar con los del modelo de aguas poco profundas presentado en [54] para condiciones de inyección que provocan una reflexión relativamente intensa de la ola contra la pared final de la cámara. A estas inyecciones le corresponden un valor del parámetro $\ell$ de la Eq. (3.1) suficientemente alto $\left(\ell=\frac{4}{3} L\right)$. Por ejemplo, la Figura 3.18 muestra los resultados de los perfiles de la superficie de la ola en el plano de simetría de una cámara de inyección con $L / H=9$ y $H=0,05$ m y una fracción inicial de llenado $A_{l 0} / A=0,2$ relativamente baja. Los resultados del modelo CFD se obtuvieron con mallas de tres tamaños diferentes, utilizando la viscosidad dinámica y la densidad del aluminio puro en el punto de fusión $\left(1,3 \times 10^{-3}\right.$ Pa s y $2385 \mathrm{~kg} \mathrm{~m}^{-3}$, respectivamente). Los resultados analíticos se obtuvieron utilizando un modelo sencillo basado en una aproximación unidimensional de aguas poco profundas [54], el cual se resuelve mediante el método de las características y un procedimiento basado en el "Inverse Marching Method" con una malla de diferencias finitas deformable. La escala vertical de la figura se ha incrementado utilizando un factor de 2,34 con el fin de enfatizar las diferencias existentes entre ambos tipos de resultados. El tiempo se ha adimensionalizado con el tiempo

$$
t_{f}=t_{H}+\frac{L(1-f)-X\left(t_{H}\right)}{U_{\max }},
$$

en el que la cámara de inyección quedaría completamente llena con líquido (tiempo de llenado). $U_{\max }$ representa la velocidad máxima alcanzada por el pistón (por ejemplo, $X^{\prime}(t)=U_{\max }$ para $t>t_{H}$ ). Con el fin de evitar la formación de un chorro en el techo de la cámara en la simulación CFD, la aceleración del pistón cesó cuando su velocidad alcanzó el valor máximo óptimo predicho por López et al. [54] (es posible observar en la figura que la altura de la superficie libre predicha por el modelo 1D, alcanza un valor máximo de $y / H=0,94$ en los dos últimos perfiles representados). Del mismo modo, cabe destacar que se han obtenido resultados prácticamente independientes de la malla para los tamaños de malla considerados en la Figura 3.18. El resto de resultados presentados se obtuvieron con la malla de tamaño intermedio de $230 \times 60 \times 30$ elementos. Por otra parte puede observarse en esta figura una concordancia relativamente elevada entre los perfiles de los modelos 1D y 3D, incluso en los últimos instantes representados. Sin embargo es destacable que, según el modelo de aguas poco profundas, el fluido alcanza el canal de colada con una ligera anticipación, lo cual, en este caso, se debe a la reflexión de la ola contra la pared final.

Sería necesario utilizar una aceleración del pistón mas elevada que la utilizada en la Figura 3.18 con el fin de evitar el atrapamiento de aire que se produce como resultado de la reflexión de la ola contra la pared final de la cámara (nótese que cuanto menor sea el valor de $\ell$, mayor será la aceleración del pistón). La 


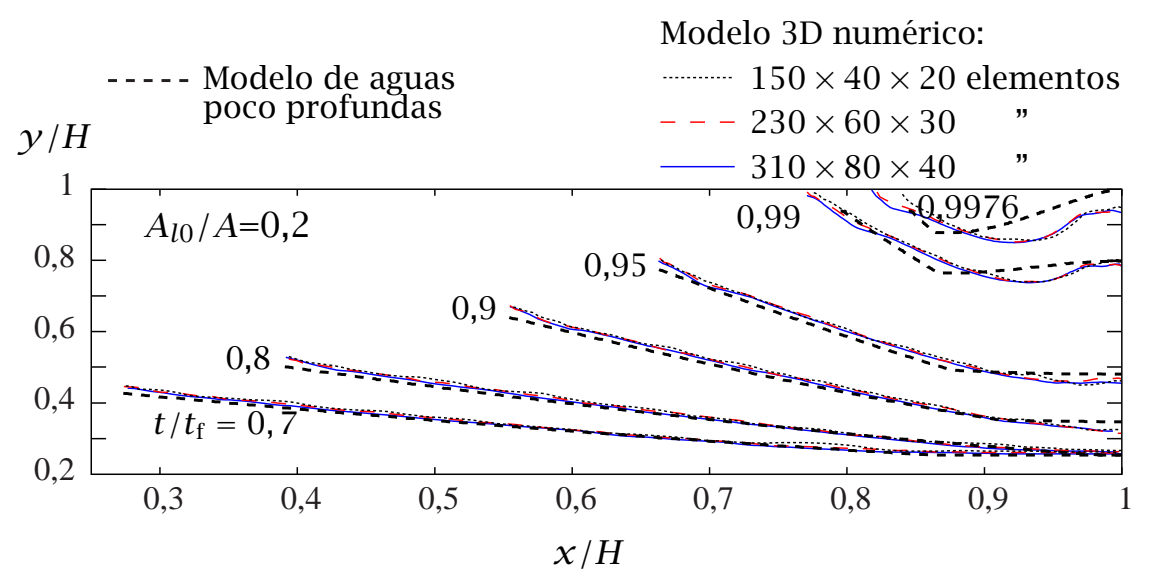

Figura 3.18: Perfiles de la superficie de la ola en el plano de simetría de una cámara de inyección con $L / H=9$ y $H=0,05 \mathrm{~m}$, para una fracción inicial de llenado $A_{l 0} / A=0,2$, la ley de aceleración de la Eq. (3.1) con $\ell=\frac{4}{3} L$, y el límite de la velocidad máxima del pistón dado por López et al. [54] con el fin de evitar la formación el chorro de pared a lo largo del techo de la cámara.

Figura 3.19 muestra los resultados predichos por los modelos CFD y de aguas poco profundas para el volumen adimensional $V /(A L)$ ocupado por el aire en la cámara de inyección cuando el líquido alcanza el canal de colada en función del parámetro adimensional de aceleración $L / \ell$, para una cámara de las mismas dimensiones y fracción inicial de llenado que la de la Figura 3.18. Para valores de $L / \ell$ superiores a un valor en torno a 0,8 , el modelo de aguas poco profundas predice que la ola se romperá antes de que el líquido alcance el canal de colada, por lo que solamente se representan los resultados del modelo CFD. Para $L / \ell<0,8$ se puede observar que el cierre anticipado del canal de colada predicho por el modelo de aguas poco profundas produce volúmenes de aire atrapado superiores a los obtenidos mediante el modelo CFD. Es posible observar que el valor óptimo de $L / \ell$ que minimiza el atrapamiento de aire manteniendo el tiempo de llenado de la cámara lo mas bajo posible $\left(t_{f}\right.$ decrece conforme $L / \ell$ crece) está muy próximo al valor óptimo $(L / \ell)_{o p t}=1$ predicho analíticamente por el modelo de aguas poco profundas para una cámara equivalente con una configuración bidimensional de la sección transversal [55].

\subsubsection{Comparación con resultados experimentales en máquina FIAP}

Los trabajos experimentales de Garber [28] y numéricos de López et al. [54] muestran que para ciertas condiciones de operación existe una tendencia a la formación de chorros de pared a lo largo del techo de la cámara de inyección, lo que puede provocar la rotura de la superficie libre y por tanto, el atrapamiento de 


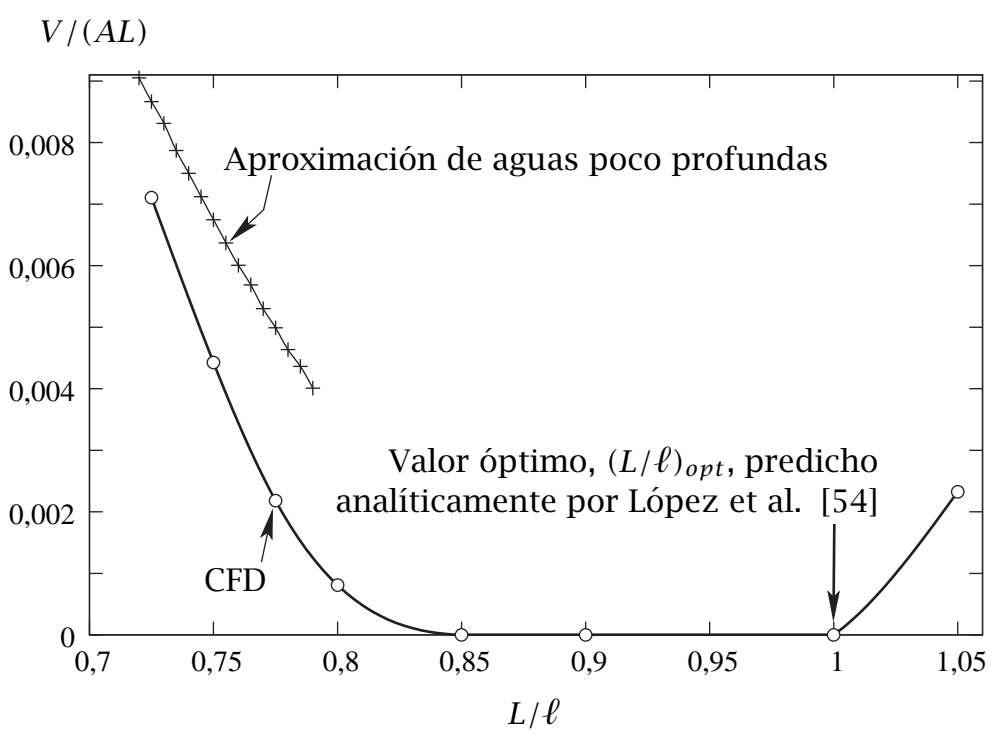

Figura 3.19: Volumen adimensional $V /(A L)$ en función de $L / \ell$ para las mismas dimensiones y fracción inicial de llenado de la Figura 3.18, utilizando la velocidad del pistón máxima propuesta por López et al. [54] para evitar la formación del chorro de pared a lo largo del techo de la cámara.

aire en la cámara. Así mismo, se sugiere que el chorro de la pared podría evitarse, o minimizar sus efectos en lo posible, deteniendo la aceleración del pistón en un cierto instante previo al momento en el que el líquido cubre completamente la cara del pistón.

La Figura 3.20, que corresponde a una fracción inicial de llenado de 0,252, y las Figuras 3.21(a,b) y 3.21(c,d) para fracciones iniciales de llenado de 0,374 y 0,5 respectivamente, muestran los resultados numéricos de los perfiles de la superficie de la ola en el plano de simetría obtenidos con el modelo CFD tridimensional para diferentes velocidades máximas de pistón. Todas las simulaciones se han realizado, al igual que en los experimentos, para una cámara de inyección con $H=0,05 \mathrm{~m}$ y $L / H=5,3$. En todas las simulaciones presentadas se ha utilizado el parámetro óptimo de aceleración del pistón $\ell=L$ predicho analíticamente por López et al. [54], y la viscosidad dinámica y densidad del agua. Puede observarse que cuando la velocidad máxima del pistón es demasiado elevada (véanse las Figuras 3.20(c), 3.21(b) y 3.21(d)), se forma un chorro de pared a lo largo del techo de la cámara, mientras que cuando es demasiado baja, la reflexión de la ola contra la pared final de la cámara tiende a incrementar el atrapamiento de aire (véanse los resultados correspondientes a la menor velocidad máxima del pistón en cada figura).

Los resultados correspondientes al valor óptimo $U_{\max }$ predichos numéricamente por López et al. [54] y representados en la Figura 3.20(b), muestran que el chorro de pared formado a lo largo del techo de la cámara puede ser evitado, 


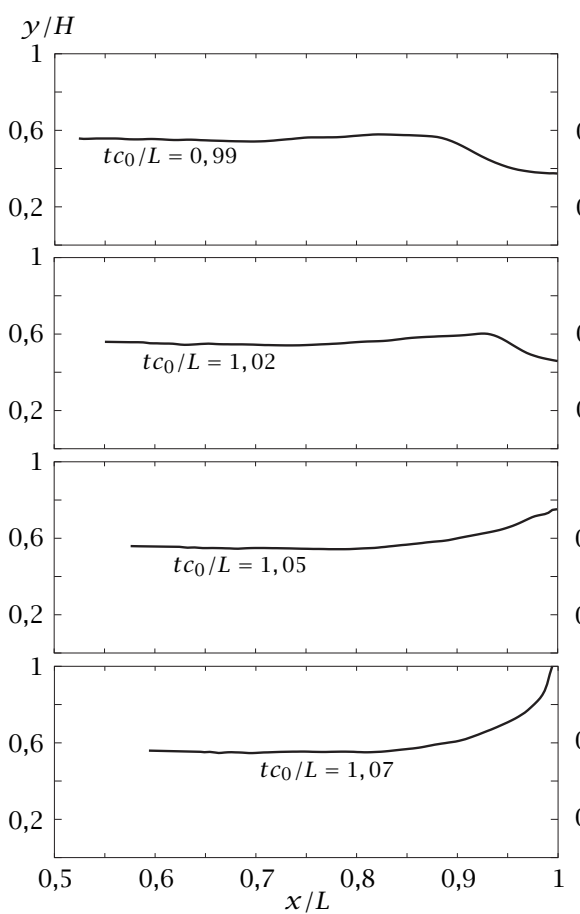

(a)

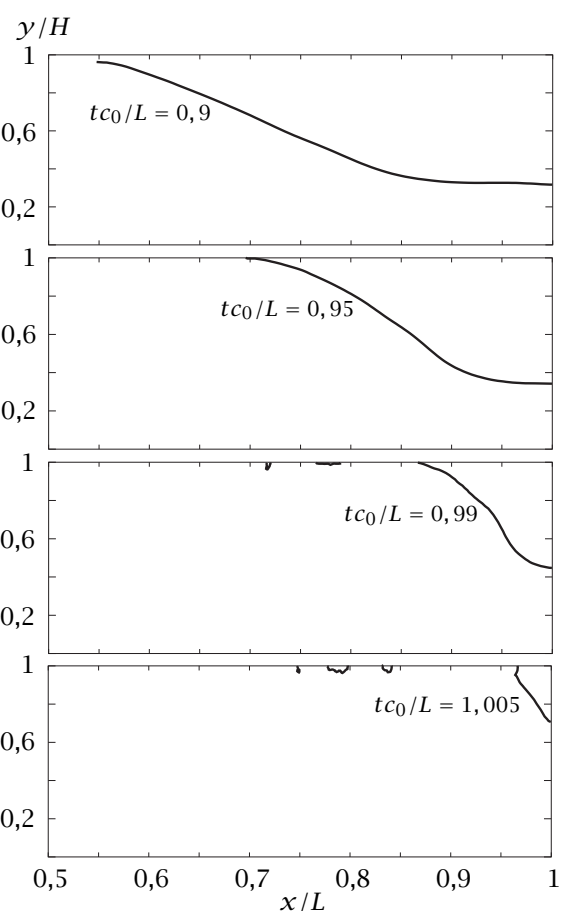

(b)

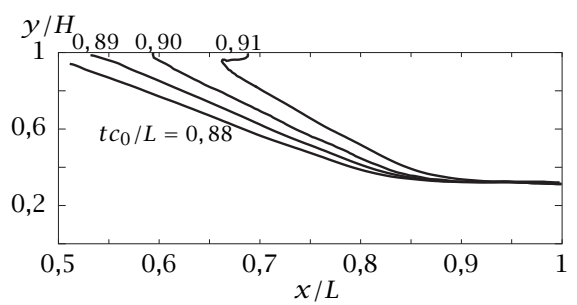

(c)

Figura 3.20: Resultados de los perfiles de la superficie de la ola en el plano de simetría de la cámara utilizando el modelo CFD, para $L=5,3 H, H=0,05 \mathrm{~m}, f=0,252$, la ley de aceleración de la Ecuación (3.1) y diferentes velocidades adimensionales máximas de piston $U_{\max } /(g H)^{1 / 2}$ : (a) 0,42 ; (b) 0,88 ; (c) 1,0 . 


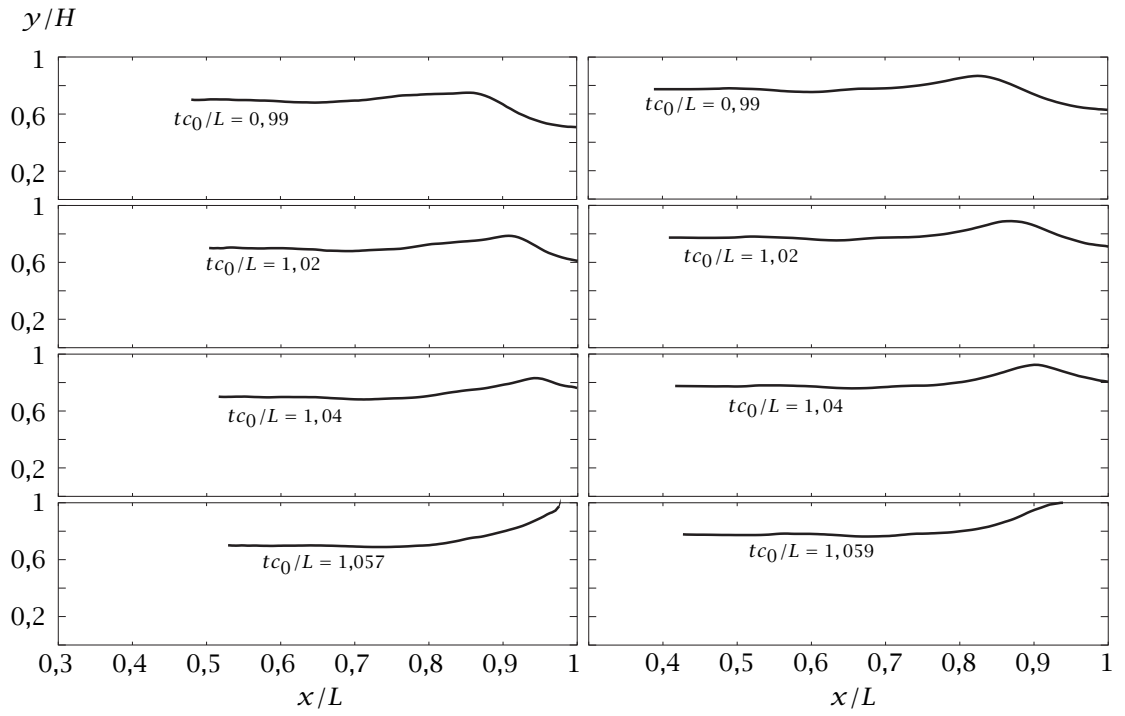

(a)

(c)

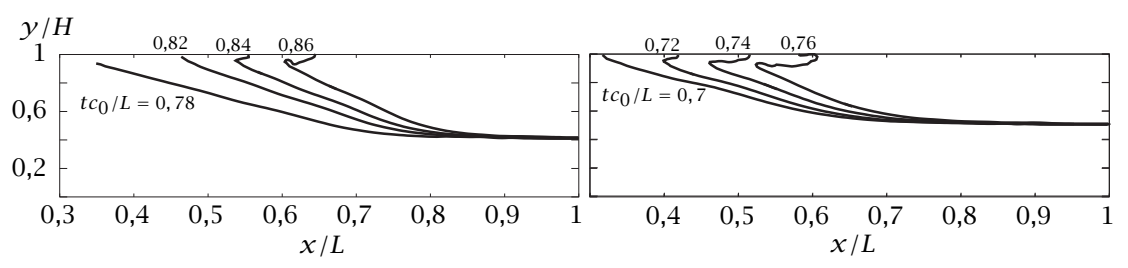

(b)

(d)

Figura 3.21: Resultados de los perfiles de la superficie de la ola en el plano de simetría de la cámara utilizando el modelo CFD, para $L=5,3 H, H=0,05 \mathrm{~m}$, dos fracciones iniciales de llenado diferentes y velocidades adimensionales máximas de pistón $U_{\max } /(g H)^{1 / 2}$ : (a) 0,43 y (b) 0,74 para $f=0,374$; y (c) 0,35 y (d) 0,62 para $f=0,5$ 
y que la cantidad de aire atrapado puede ser reducida considerablemente si la aceleración del pistón cesa en un cierto instante previo a que el fluido cubra por completo la cara del pistón.

En la Figura 3.22 se representan resultados experimentales obtenidos en la máquina FIAP de las cantidades de aire atrapado en función de la velocidad del pistón máxima utilizada para una cámara con las mismas dimensiones utilizadas en las simulaciones y con una fracción inicial de llenado $f=0,252$.

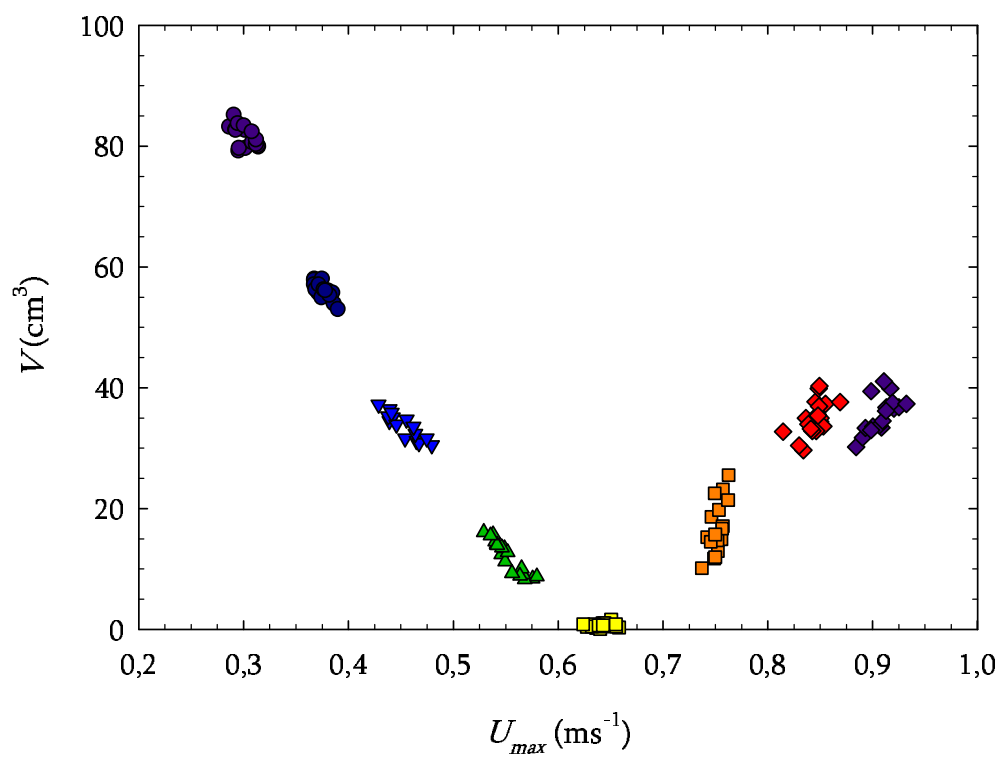

Figura 3.22: Resultados experimentales obtenidos en la máquina FIAP, de las cantidades de aire atrapado en función de la velocidad máxima del pistón $U_{\max }$, para $L=5,3 H, H=0,05 \mathrm{~m}, f=$ 0, 252 y la ley de aceleración de la Ecuación (3.1).

Se puede observar claramente como existe una velocidad máxima del pistón (velocidad crítica), en torno a $0,64 \mathrm{~ms}^{-1}$, para la que el volumen de aire atrapado durante la inyección en la etapa lenta es mínimo llegando incluso a reducirse a cero. Por el contrario, valores inferiores o superiores a la velocidad máxima provocan un aumento de la cantidad de aire atrapada llegando a superar incluso los $80 \mathrm{~cm}^{3}$. Del mismo modo se observa una mayor dispersion en los datos cuando se sobrepasan los valores de la velocidad crítica.

En las Figuras 3.23 y 3.24 se muestran resultados similares a los de la Figura 3.22 para fracciones de llenado $f=0,374$ y $f=0,5$ respectivamente. En el caso de la fracción $f=0,374$ se observa una velocidad crítica en torno a $0,52 \mathrm{~ms}^{-1}$ con volúmenes de aire atrapado menores a $60 \mathrm{~cm}^{3}$. Para la fracción $f=0,5 \mathrm{la}$ velocidad crítica se sitúa en torno a los $0,38 \mathrm{~ms}^{-1}$ quedando los volúmenes de aire por debajo de $42 \mathrm{~cm}^{3}$.

Según esto es posible observar que existen valores críticos de la velocidad de 


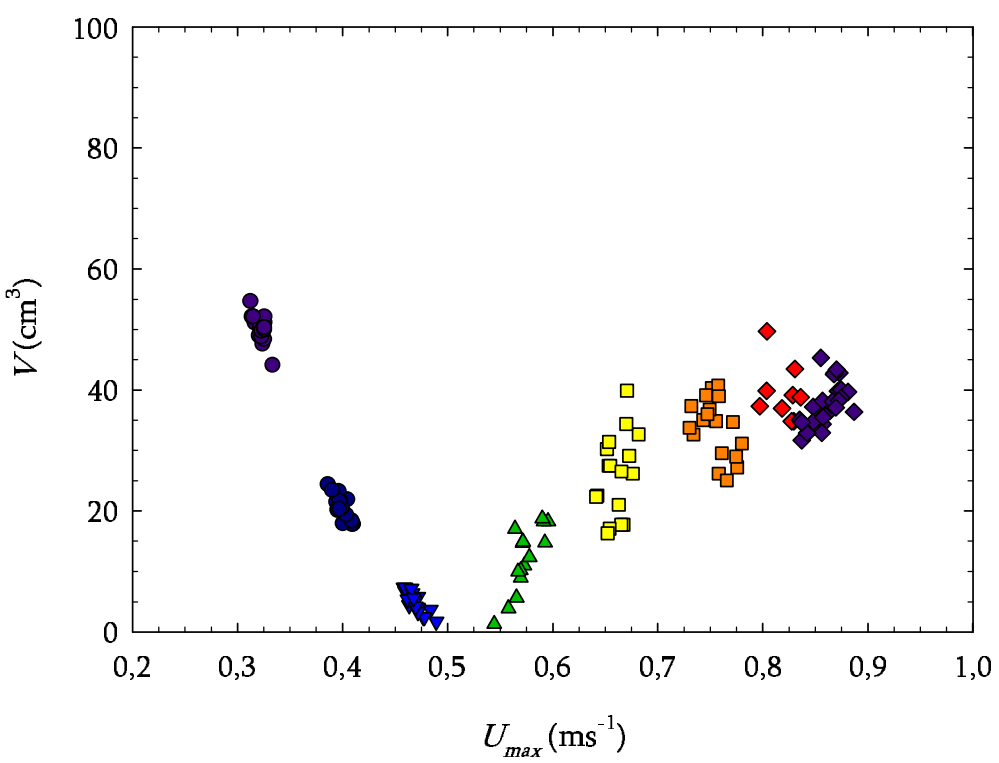

Figura 3.23: Resultados experimentales obtenidos en la máquina FIAP, de las cantidades de aire atrapado en función de la velocidad máxima del pistón $U_{\max }$, para $L=5,3 H, H=0,05 \mathrm{~m}, f=$ 0, 374 y la ley de aceleración de la Ecuación (3.1).

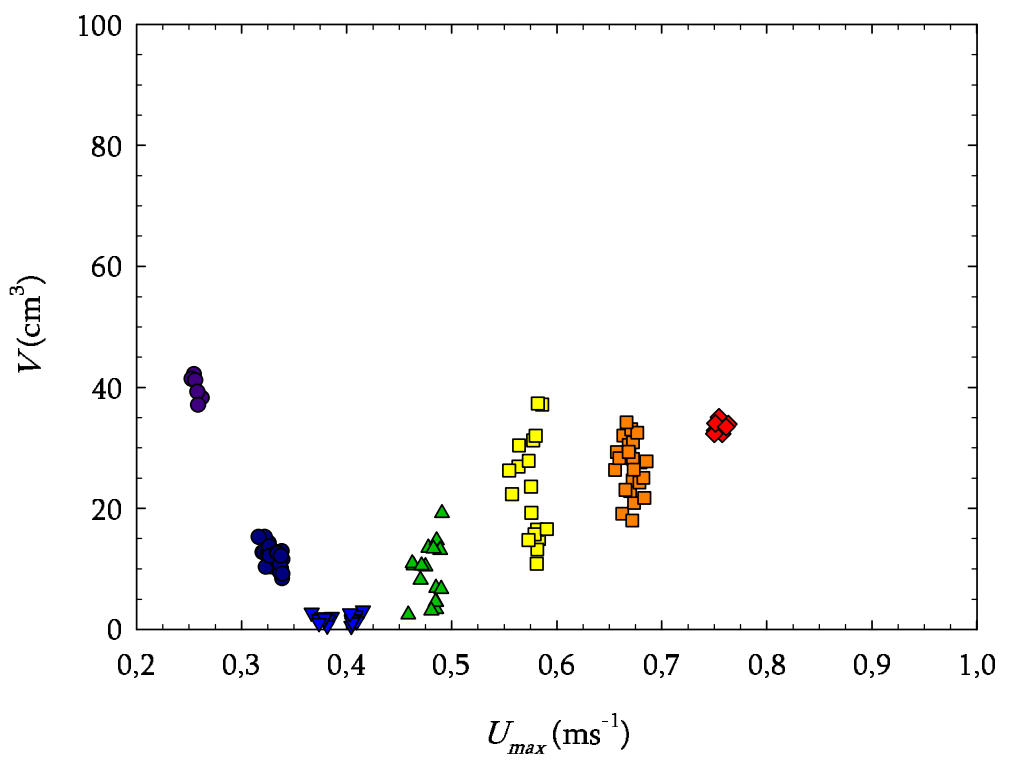

Figura 3.24: Resultados experimentales obtenidos en la máquina FIAP, de las cantidades de aire atrapado en función de la velocidad máxima del pistón $U_{\text {max }}$, para $L=5,3 H, H=0,05 \mathrm{~m}, f=0,5$ y la ley de aceleración de la Ecuación (3.1). 
inyección para la ley de aceleración ensayada que podrían minimizar o incluso eliminar el atrapamiento de aire en la etapa lenta. Del mismo modo se observa como la velocidad crítica disminuye conforme aumenta la fracción inicial de llenado así como las cantidades de aire atrapado.

En las Figuras 3.25, 3.26 y 3.27, se pueden observar estos resultados una vez se han adimensionalizado las variables correspondientes. Concretamente el volumen de aire queda expresado relativo al volumen de la cámara de inyección $(V /(A L))$, y la velocidad del pistón relativa a la aceleración de la gravedad y el diámetro de la cámara $\left(U_{\max } /(g H)^{1 / 2}\right)$.

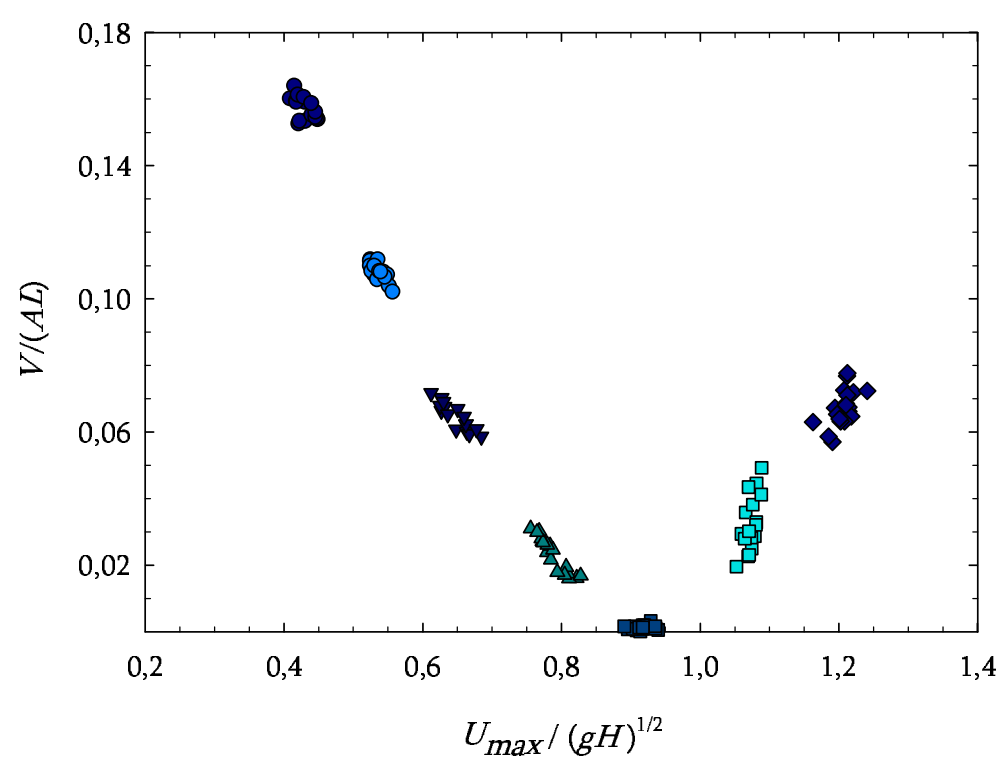

Figura 3.25: Resultados experimentales adimensionalizados, obtenidos en la máquina FIAP, de las cantidades de aire atrapado $(V /(A L))$ en función de la velocidad máxima del pistón $\left(U_{\max } /(g H)^{1 / 2}\right)$ para $f=0,252$.

Como era de esperar, las representaciones adimensionalizadas no sufren variación alguna en cuanto a las tendencias observadas en las figuras anteriores.

En la Figura 3.28 se han comparado los resultados numéricos y experimentales del volumen adimensional $V /(A L)$ ocupado por el aire en la cámara de inyección en el instante en el que el líquido empieza a fluir a través del canal de colada. Las Figuras 3.28 (a), (b) y (c) muestran, para fracciones iniciales de llenado $f=0,252,0,374$ y 0,5 , respectivamente, el valor medio y el intervalo de confianza del $95 \%$ de $V /(A L)$ en función de la velocidad máxima alcanzada por el pistón, $U_{\max }$. Los resultados numéricos 3D también se representan con círculos blancos. Se puede observar que existe una buena concordancia cuantitativa entre los resultados numéricos y experimentales, excepto en los casos en los que las velocidades del pistón son mayores que la óptima, para los que la aparición del 


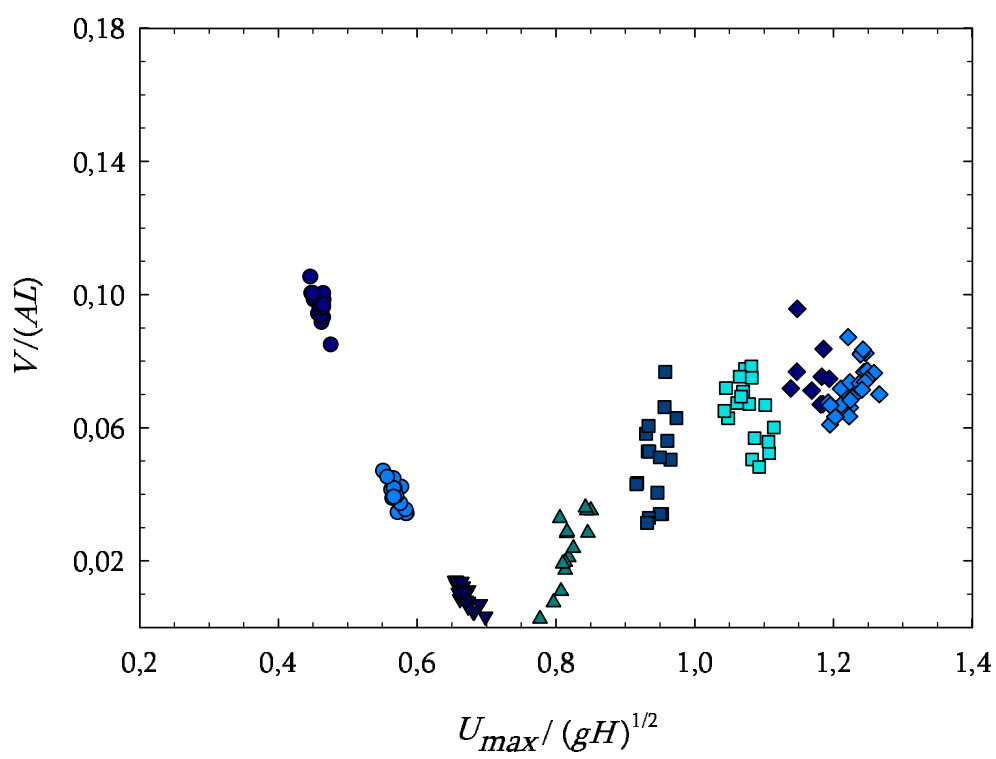

Figura 3.26: Resultados experimentales adimensionalizados, obtenidos en la máquina FIAP, de las cantidades de aire atrapado $(V /(A L))$ en función de la velocidad máxima del pistón $\left(U_{\max } /(g H)^{1 / 2}\right)$ para $f=0,374$.

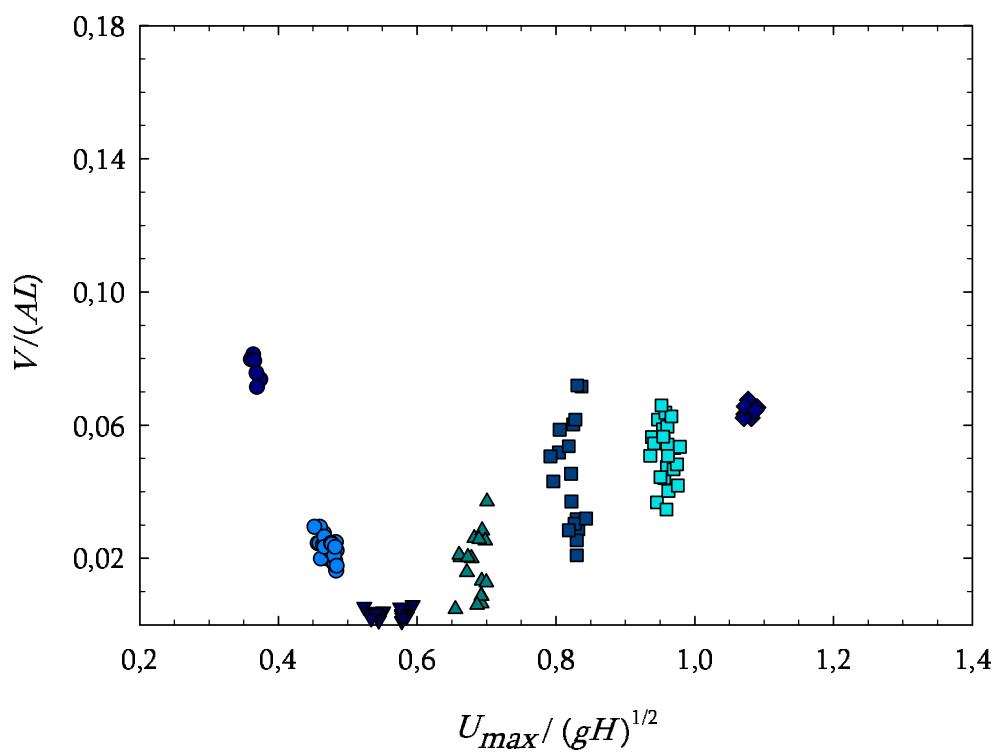

Figura 3.27: Resultados experimentales adimensionalizados, obtenidos en la máquina FIAP, de las cantidades de aire atrapado $(V /(A L))$ en función de la velocidad máxima del pistón $\left(U_{\max } /(g H)^{1 / 2}\right)$ para $f=0,5$. 


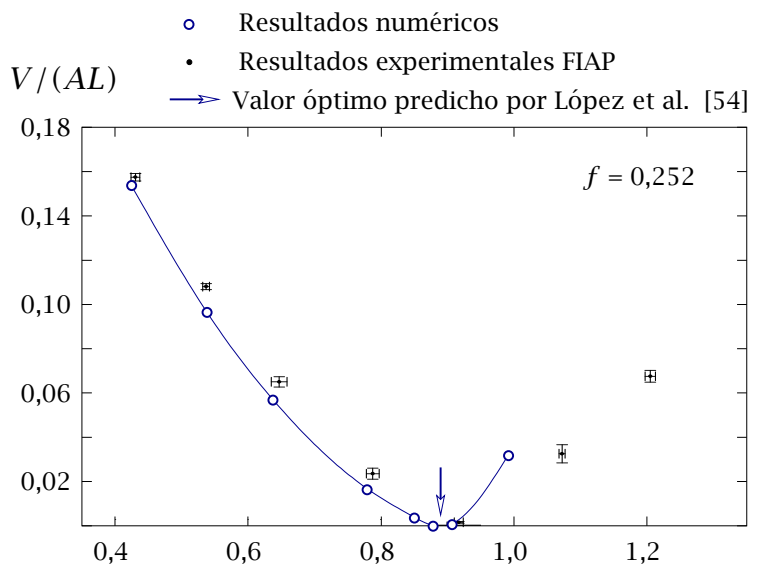

(a)

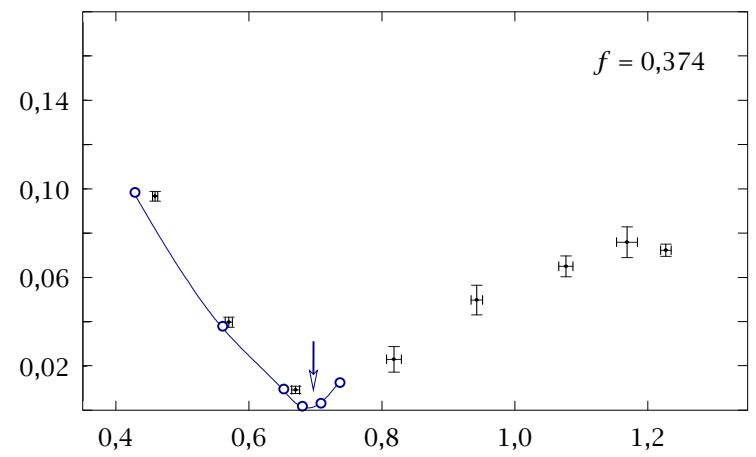

(b)

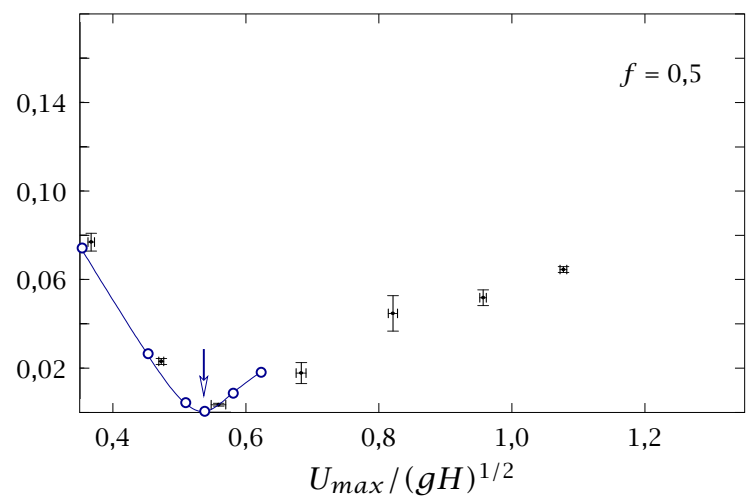

(c)

Figura 3.28: Resultados experimentales y numéricos del volumen adimensional de aire atrapado en función de la velocidad máxima alcanzada por el pistón, utilizando la ley de aceleración de la Ecuación 3.1 para fracciones iniciales de llenado $f$ de 0,252 (a), 0,374 (b) y 0,5 (c). 


\begin{tabular}{|c|c|}
\hline \multirow{2}{*}{$f$} & $\begin{array}{c}\text { Velocidad máxima del } \\
\text { pistón, } \mathrm{U}_{\max }\left(\mathrm{ms}^{-1}\right)\end{array}$ \\
\cline { 2 - 2 } & $\min \div \max$ \\
\hline 0,252 & $0,36 \div 0,84$ \\
\hline 0,374 & $0,37 \div 0,63$ \\
\hline
\end{tabular}

Tabla 3.4: Rango de velocidades máximas de pistón utilizadas en los ensayos de visualización.

chorro de pared a lo largo del techo requeriría llevar a cabo un análisis del flujo más detallado teniendo en cuenta, por ejemplo, efectos de tensión superficial y utilizando una malla de mayor resolución para simular los efectos de pequeña escala que se espera que aparezcan. Cabe destacar que el volumen de aire atrapado en la cámara, $V$, puede alcanzar valores superiores al diez por ciento del volumen total de la cámara $A L$, utilizando las condiciones de operación experimentales consideradas. También es de destacar el hecho de que utilizando en los experimentos el valor óptimo del parámetro de la aceleración del pistón, $\ell=L$, existe un valor óptimo de la velocidad máxima del pistón para el que el volumen de aire atrapado en la cámara de inyección se reduce a cero, incluso para la menor fracción inicial de llenado considerada.

Adicionalmente se ha incluido en la Figura 3.28, para cada valor de la fracción inicial de llenado, el valor óptimo de la velocidad máxima del pistón predicho por López et al. [54] (flecha vertical) utilizando el modelo CFD tridimensional y despreciando los efectos de reflexión de la ola contra la pared final de la cámara. Cabe destacar que éste valor es muy similar al correspondiente al valor mínimo del aire atrapado, lo que confirma el hecho de que, dentro del rango de los parámetros de aceleración del pistón considerados, la formación del chorro de pared a lo largo del techo de la cámara es el factor decisivo que determina el valor óptimo de $U_{\max }$ frente a los efectos de reflexión de la ola contra la pared final de la cámara.

\subsubsection{Comparación con resultados de visualización}

Se realizaron experimentos de visualización utilizando las fracciones iniciales de llenado $f=0,252$ y $f=0,374$ para diferentes velocidades máximas del pistón $U_{\max }$ (véase la Tabla 3.4).

En las Figuras 3.29 y 3.30 se comparan resultados de visualización con los resultados numéricos de los perfiles de la superficie de la ola en el plano de simetría en diferentes instantes, con una fracción inicial de llenado $f=0,374$ y las velocidades adimensionales máximas del pistón $U_{\max } /(g H)^{1 / 2}=0,43$ y 0,74 , respectivamente. A pesar de los efectos visuales debidos a la tridimensionalidad del problema, lo que hace difícil observar un perfil claro de la superficie de la 

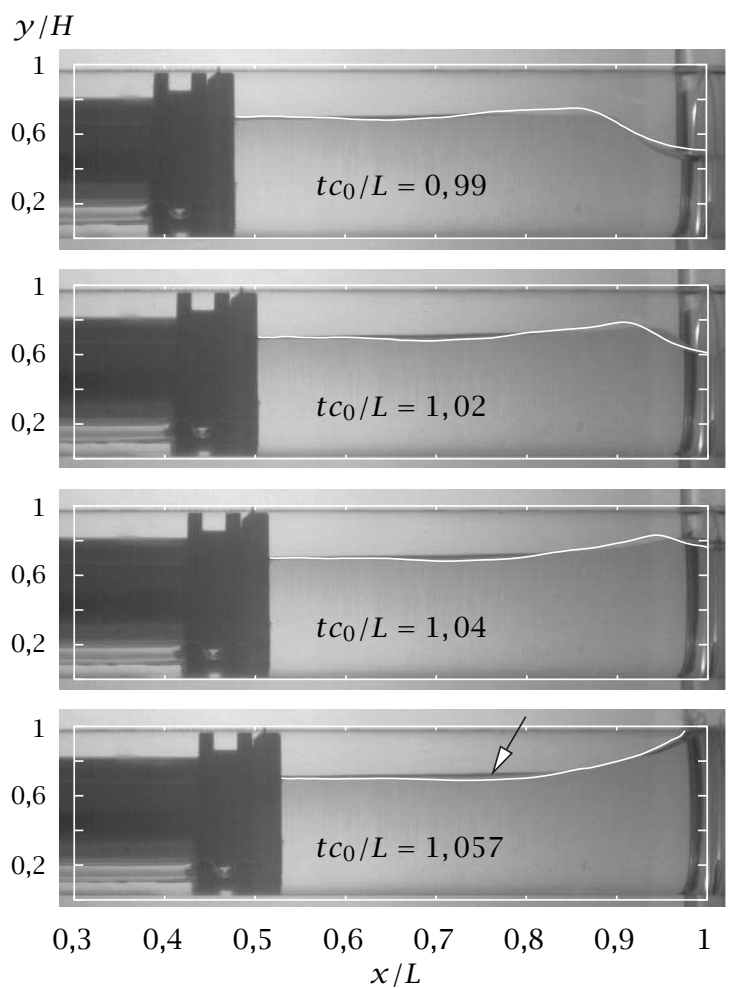

Figura 3.29: Comparación entre los resultados experimentales de visualización y numéricos de los perfiles de la superficie de la ola en el plano de simetría de la cámara para $f=0,374$ y $U_{\text {max }} /(g H)^{1 / 2}=0,43$. 

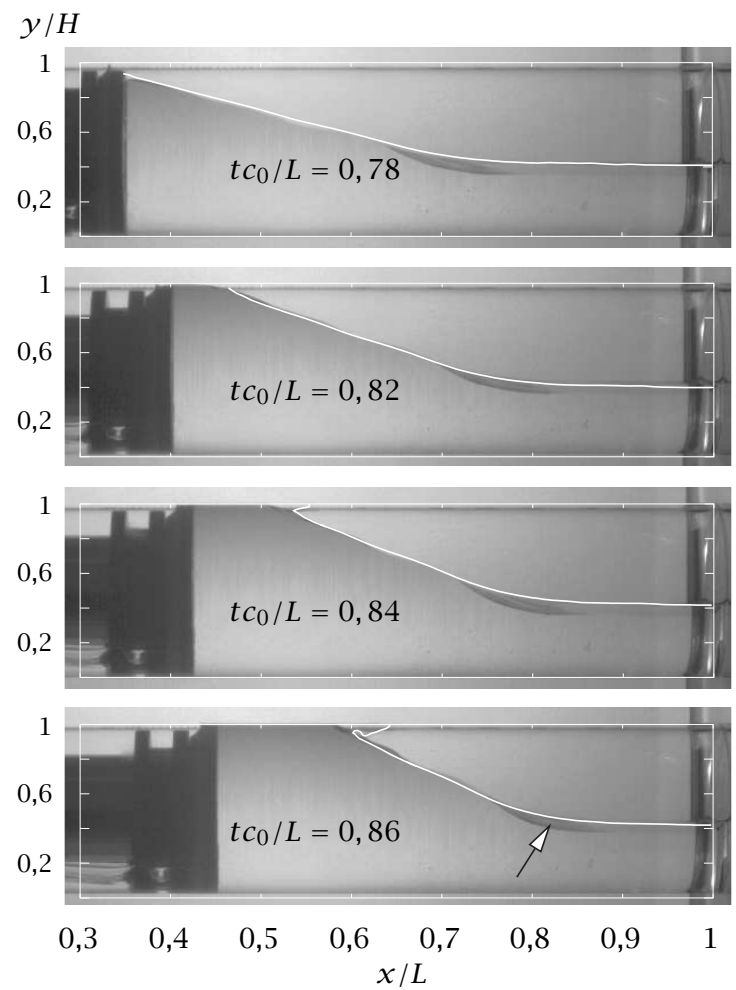

Figura 3.30: Comparación entre los resultados experimentales de visualización y numéricos de los perfiles de la superficie de la ola en el plano de simetría de la cámara para $f=0,374$ y $U_{\max } /(g H)^{1 / 2}=0,74$. 
ola (ver, por ejemplo, las sombras indicadas en las fotografías inferiores de las Figuras 3.29 y 3.30), se ha encontrado una concordancia muy buena entre ambos resultados, tanto en el caso en el que el agua alcanza el canal de colada como resultado de la reflexión de la ola contra la pared final de la cámara (véase la Figura 3.29), como en los dos últimos instantes correspondientes al caso representado en la Figura 3.30, donde la velocidad máxima utilizada era demasiada alta y se forma un chorro a lo largo del techo de la cámara. Este chorro de pared puede provocar la rotura de la superficie de la ola o el cierre del canal de colada, provocando atrapamiento de aire en ambos casos.

A continuación se presentan los resultados numéricos y experimentales del volumen adimensional de aire atrapado en la cámara de inyección, en función de $U_{\max } /(g H)^{1 / 2}$, para fracciones iniciales de llenado $f=0,252$ en 3.31 y $f=$ 0,374 en 3.32. Es posible observar una buena concordancia cuantitativa entre los resultados de ambos tipos, con la excepción de la velocidad máxima del pistón mas alta representada en la Figura 3.31, en la que como consecuencia de la formación de un chorro de pared a lo largo del techo de la cámara de inyección el flujo evoluciona de forma compleja. En este caso, con la finalidad de poder describir apropiadamente la evolución del chorro de pared del techo y la de obtener resultados precisos sobre el volumen de aire atrapado en la cámara, sería necesario utilizar una mayor resolución de malla e incluir los efectos de la tensión superficial como ya se indicó con anterioridad. Cuando la velocidad máxima del pistón es demasiado baja, en el momento en el que el líquido empieza a fluir a través del canal de colada aún queda en la cámara una cantidad considerable de aire (mayor del $15 \%$ del volumen total de la cámara de inyección para $f=0,252$ ).

Cabe destacar que existe un valor óptimo de la velocidad máxima del pistón, en cada caso, para el que se minimiza la cantidad de aire atrapado, resultando ser este valor muy similar al predicho por López et al. [54] $\left(U_{\text {opt }} /(g H)^{1 / 2}=0,89\right.$ para $f=0,252$ y 0,70 para $f=0,374)$. Del mismo modo podemos observar que, como se esperaba, la ley de aceleración del pistón de la Ecuación (3.1) [55], permite reducir a cero la cantidad de aire atrapado cuando se utiliza una valor apropiado de la velocidad máxima del pistón. En el caso de velocidades máximas superiores a la óptima, la formación del chorro en el techo anteriormente comentada produce un incremento significativo en la cantidad de aire atrapado en la cámara.

También se han incluido en las Figuras 3.33 y 3.34 los resultados de los ensayos experimentales en máquina FIAP y de visualización, del volumen adimensional de aire atrapado en función de $U_{\max } /(g H)^{1 / 2}$, para la fracciones iniciales de llenado $f=0,252$ y $f=0,374$, respectivamente. Se puede observar una muy buena concordancia entre ambos resultados de tipo experimental especialmente para velocidades inferiores a la crítica. 


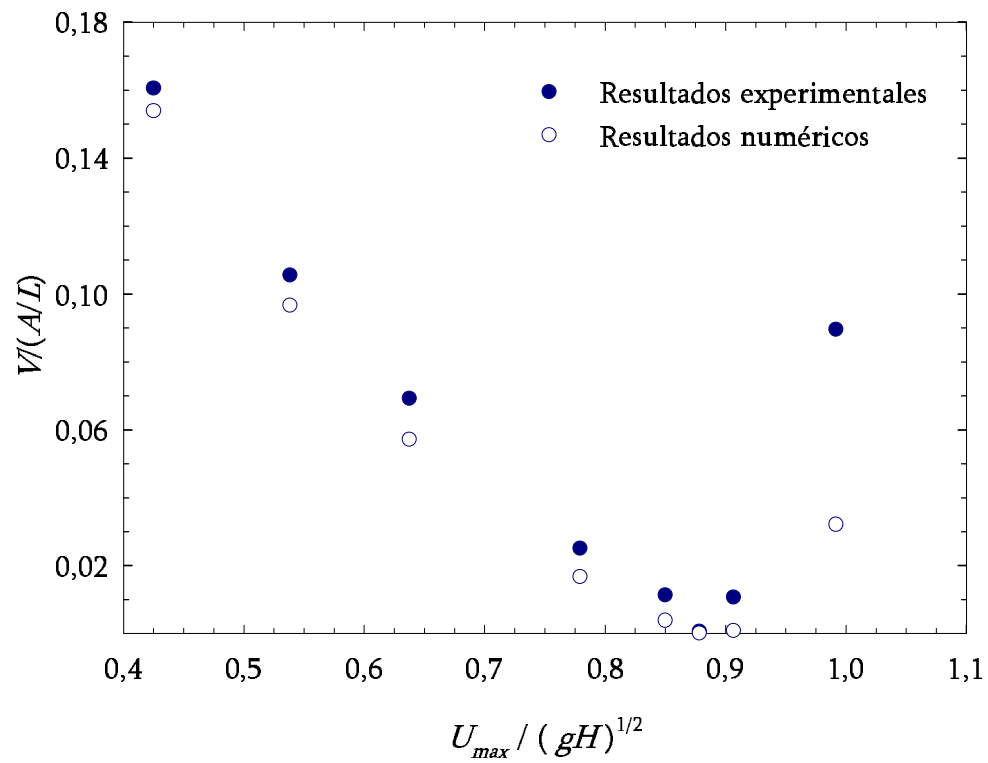

Figura 3.31: Resultados numéricos y experimentales de visualización del volumen adimensional de aire atrapado en función de $U_{\text {max }} /(g H)^{1 / 2}$, para una fracción inicial de llenado $f=0,252$.

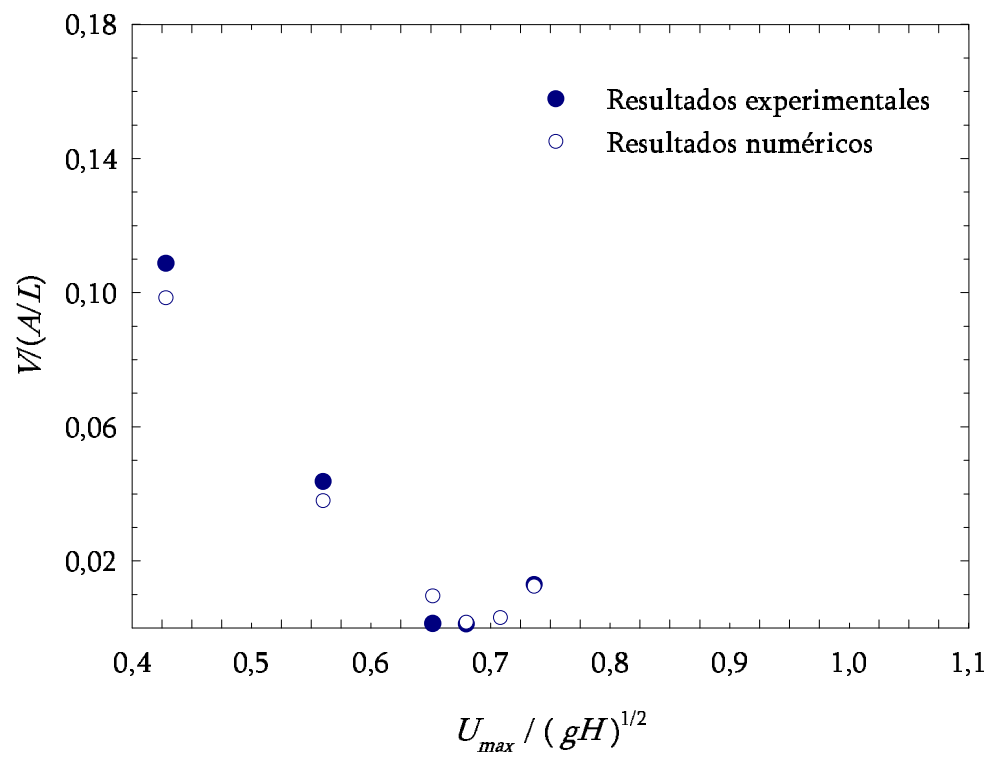

Figura 3.32: Resultados numéricos y experimentales de visualización del volumen adimensional de aire atrapado en función de $U_{\max } /(g H)^{1 / 2}$, para una fracción inicial de llenado $f=0,374$. 


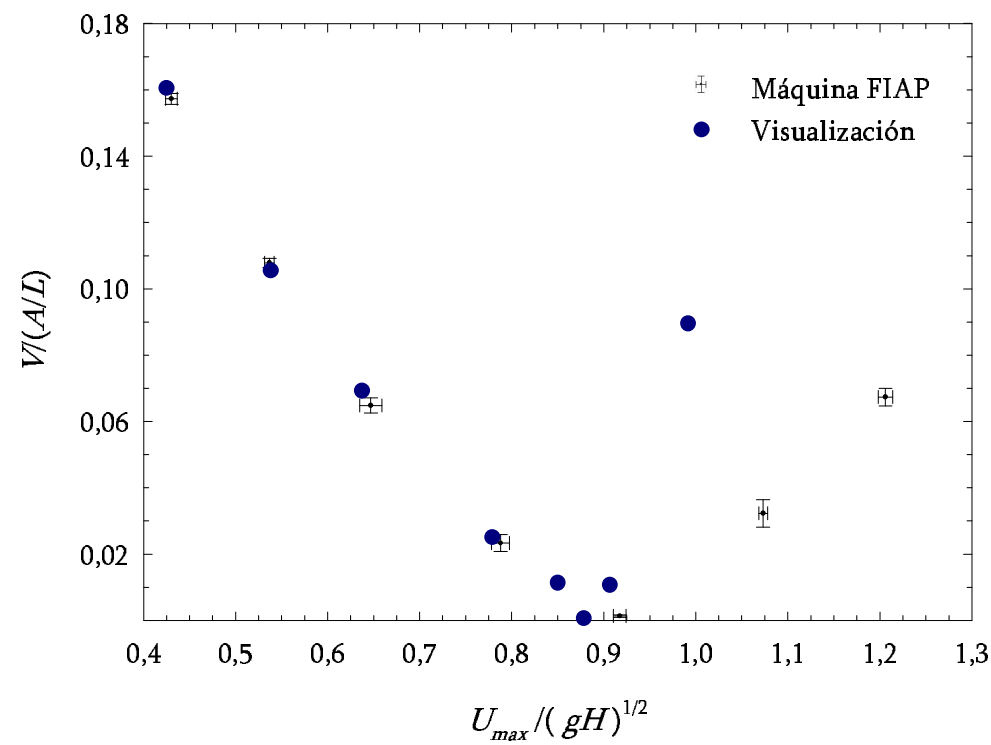

Figura 3.33: Resultados de los ensayos experimentales en máquina FIAP y de visualización del volumen adimensional de aire atrapado en función de $U_{\max } /(g H)^{1 / 2}$, para la fracción inicial de llenado $f=0,252$.

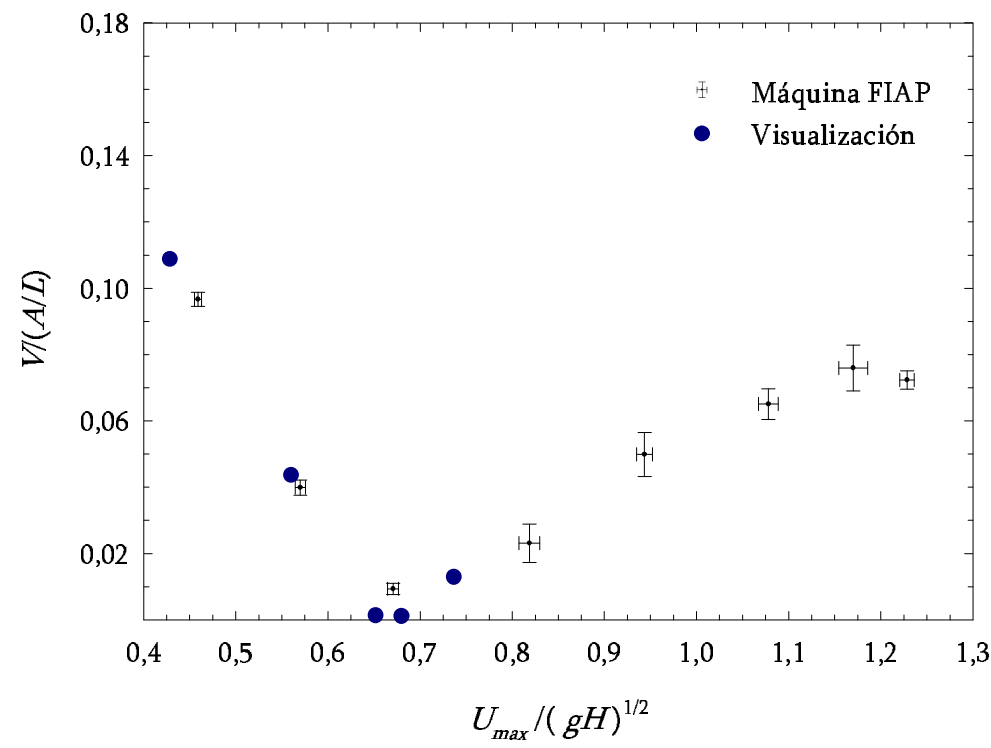

Figura 3.34: Resultados de los ensayos experimentales en máquina FIAP y de visualización del volumen adimensional de aire atrapado en función de $U_{\max } /(g H)^{1 / 2}$, para la fracción inicial de llenado $f=0,374$. 


\subsection{Conclusiones}

Se ha obtenido experimentalmente el volumen de aire atrapado en la cámara de inyección de una máquina para un amplio rango de velocidades máximas alcanzadas por el pistón y diferentes fracciones iniciales de llenado.

Los resultados experimentales se han comparado con los obtenidos con un modelo numérico tridimensional basado en el método de los elementos finitos y en el del método VOF para tratar la superficie libre con el fin de simular el flujo en la cámara de inyección para las mismas condiciones utilizadas en los experimentos. La concordancia entre los resultados experimentales y numéricos ha sido muy buena excepto en los casos en los que las velocidades máximas del pistón son superiores a las óptimas. En estos casos aparecen fenómenos de flujo fluido muy complejos que requieren de un análisis numérico más detallado de los mecanismos de atrapamiento de aire debidos a la formación de chorros de pared. Del mismo modo, se ha comprobado que la velocidad máxima óptima del pistón para la cual el volumen de aire atrapado es mínimo, pudiendo llegar incluso a ser cero, es muy similar a la que se había predicho mediante el modelo numérico. También se han comparado las predicciones numéricas con los resultados experimentales obtenidos utilizando técnicas de visualización del flujo obteniendo unos resultados excelentes. 


\section{A P Í T U L O 4}

\section{Estudio experimental de la velocidad crítica del pistón mediante ensayos con aluminio}

En el presente capítulo se ha estudiado la influencia de la velocidad máxima del pistón en la etapa lenta sobre la porosidad y los mecanismos de atrapamiento que la provocan en condiciones reales de operación, utilizando una aleación de aluminio de uso extendido en el ámbito de la fundición por inyección a alta presión. Los experimentos se han llevado a cabo utilizando el equipo descrito en el Capítulo 2. Para asegurar la repetibilidad de las condiciones de ensayo, se han establecido criterios para rechazar las inyecciones que no reproduzcan, con la suficiente precisión, la ley de movimiento utilizada. El cálculo de la porosidad se ha realizado utilizando el método gravimétrico basado en el principio de Arquímedes. Finalmente, se presenta un estudio del efecto de la presión sobre la evaluación de la porosidad mediante este método, acompañado de las pruebas de calibración y los ensayos preliminares realizados mediante el sistema de fusión al vacío desarrollado.

\subsection{Procedimiento experimental}

Previamente a la realización de los ensayos, se han estudiado detenidamente las características físicas de la aleación utilizada y la formación de porosidad por contracción en el tipo de pieza fabricada. El estudio de la porosidad en la etapa lenta ha requerido diseñar cucharas de colada apropiadas y modificar la geometría del molde existente así como el uso de una balanza hidrostática para la evaluación de la porosidad. 


\begin{tabular}{|c|c|c|c|c|c|c|}
\hline & $\mathrm{Si}$ & $\mathrm{Fe}$ & $\mathrm{Cu}$ & $\mathrm{Zn}$ & Mn & Otros \\
\hline EN AC-47100 (\%) & $11,0-13,0$ & 1,30 & 1,00 & 0,50 & 0,35 & 0,25 \\
\hline Análisis (\%) & 12,35 & 0,81 & 0,34 & 0,26 & 0,21 & 0,24 \\
\hline
\end{tabular}

Tabla 4.1: Composición porcentual de la aleación de aluminio utilizada.

\subsubsection{Propiedades físicas de la aleación empleada}

Los experimentos en condiciones reales de operación se han llevado a cabo con una aleación $\mathrm{Al}-\mathrm{Si}(\mathrm{Cu})$ típicamente utilizada en el sector de la fundición por inyección. Según la normativa europea en vigor (UNE-EN 1706:1998) para piezas moldeadas de aluminio y aleaciones de aluminio, a esta aleación le corresponden las siguientes designaciones ${ }^{1}$ :

Numérica EN AC-47100.

Simbólica EN AC-AlSi12Cu1(Fe).

Los porcentajes de los elementos aleantes (Tabla 4.1) se han determinado mediante espectrometría de emisión atómica ${ }^{2}$. En la parte inferior de la Tabla 4.1 se presentan los porcentajes máximos admitidos por la norma. El uso extendido de esta aleación se debe a que su composición se encuentra muy cercana al punto eutéctico, con un intervalo de solidificación, según norma, de $574 \div 582$ ${ }^{\circ} \mathrm{C}$, muy inferior a la temperatura de solidificación del aluminio puro, que es de unos $660^{\circ} \mathrm{C}$. Esto reduce, por un lado, el riesgo de formación de microporosidad por contracción durante la solidificación del metal, y por otro, la temperatura de fusión de la aleación con el consiguiente ahorro energético.

La presencia de Silicio en las aleaciones de aluminio disminuye la densidad y el coeficiente de expansión térmico, con lo que se consiguen aleaciones más ligeras y con menor riesgo a la formación de porosidad por contracción volumétrica. El contenido en silicio se suele encontrar entre 8 y $12 \%$ (véase la Figura 4.1), ya que con tales proporciones se mejora de manera considerable la fluidez y la resistencia a las fisuras en caliente.

Se ha llevado a cabo un estudio sobre la formación de microporosidad mediante el análisis de una serie de micrografías realizadas sobre muestras de la aleación recogidas de diversas secciones longitudinales y transversales de piezas

\footnotetext{
${ }^{1}$ Por regla general la designación simbólica se indica entre corchetes a continuación de la numérica: EN AC-47100 [AlSi12Cu1(Fe)].

${ }^{2}$ Análisis realizado en las instalaciones de la empresa ALCOA Transformación de Productos S.L. en Alicante.
} 


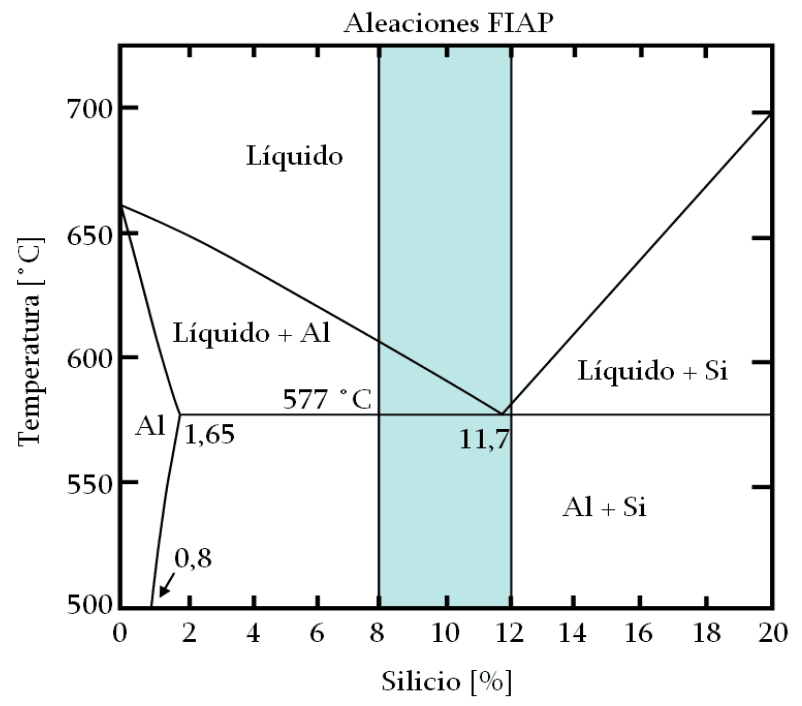

Figura 4.1: Diagrama de fases de la aleación Al Si.

inyectadas donde no se observan rastros de microporosidad apreciables. En las Figuras 4.2 y 4.3 se muestran como ejemplo dos de las micrografías realizadas.

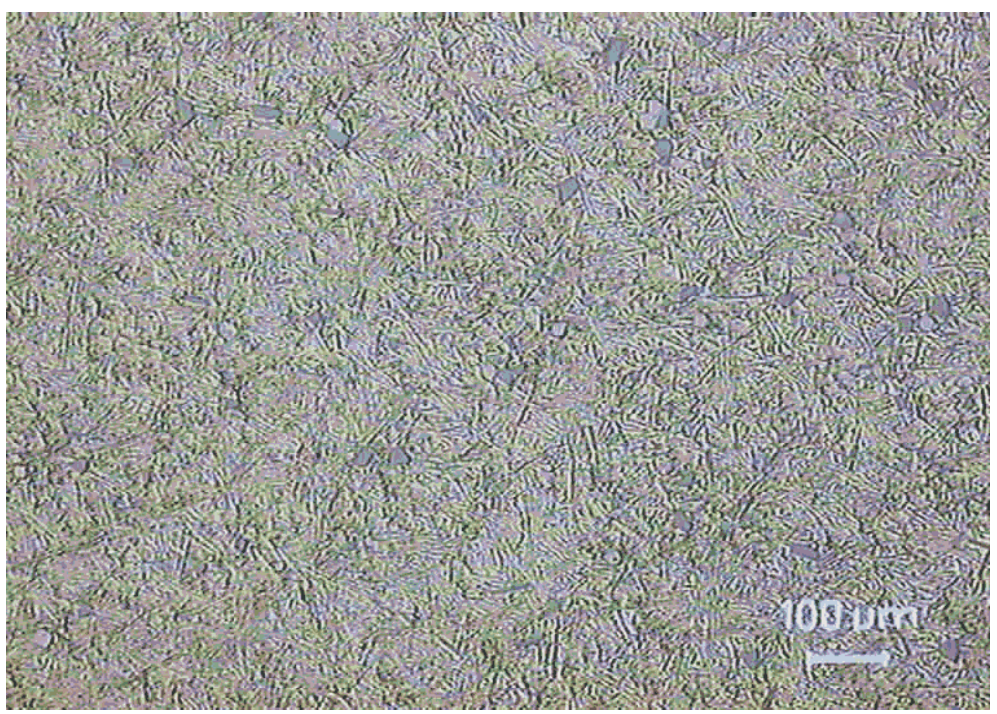

Figura 4.2: Micrografía de una sección transversal de una pieza ensayada, obtenida con 85 aumentos.

La densidad de la aleación utilizada se determinó mediante el método gravimétrico en una balanza hidrostática de gran precisión. Se realizaron 10 medidas sobre diferentes muestras lo que permitió establecer un valor medio igual a $2,68 \mathrm{~g} \mathrm{~cm}^{-3}$ con desviación estándar de $0,003 \mathrm{~g} \mathrm{~cm}^{-3}$. La Tabla 4.2 muestra los datos de las muestras analizadas.

Según la norma, este tipo de aleaciones tiene un coeficiente de dilatación de 21,6 ( $\mu \mathrm{m} / \mathrm{m} \mathrm{K})$. La determinación experimental del coeficiente de la aleación uti- 


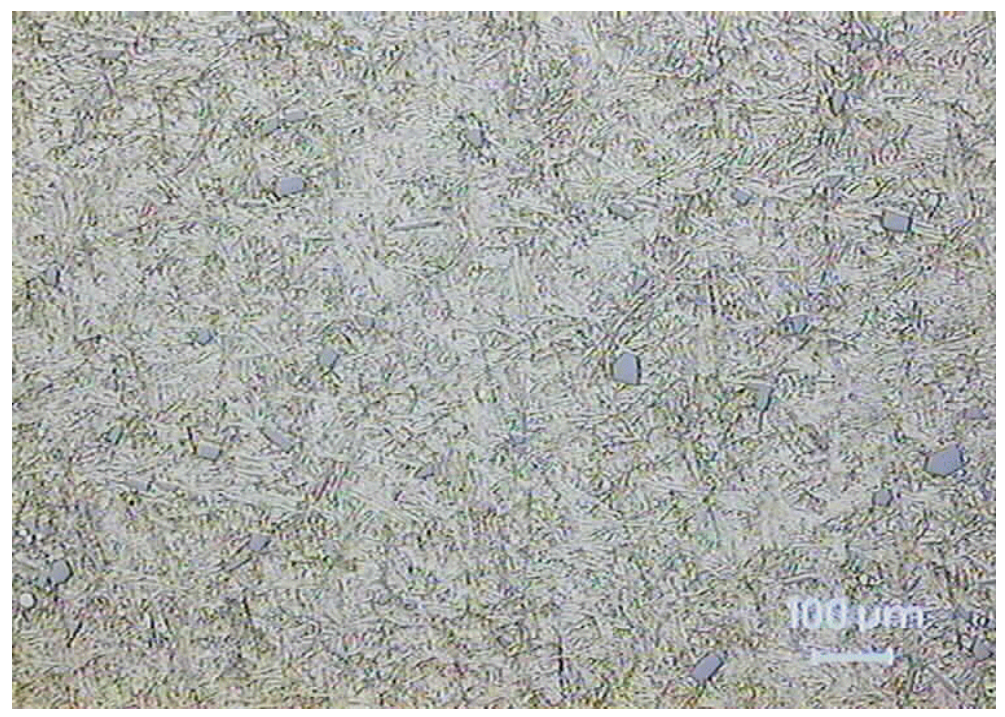

Figura 4.3: Micrografía de una sección longitudinal de una pieza ensayada, obtenida con 85 aumentos.

\begin{tabular}{|c|c|}
\hline Muestra & $\begin{array}{c}\text { Densidad } \\
\left(\mathrm{g} \mathrm{cm}^{-3}\right)\end{array}$ \\
\hline 1 & 2,682 \\
\hline 2 & 2,682 \\
\hline 3 & 2,687 \\
\hline 4 & 2,681 \\
\hline 5 & 2,689 \\
\hline
\end{tabular}

\begin{tabular}{|c|c|}
\hline Muestra & $\begin{array}{c}\text { Densidad } \\
\left(\mathrm{g} \mathrm{cm}^{-3}\right)\end{array}$ \\
\hline 6 & 2,684 \\
\hline 7 & 2,685 \\
\hline 8 & 2,680 \\
\hline 9 & 2,688 \\
\hline 10 & 2,684 \\
\hline
\end{tabular}

Tabla 4.2: Medidas de densidad de 10 muestras de la aleación. 
lizada en los ensayos se ha realizado mediante un dilatómetro diferencial. Se utilizó una probeta de $14,17 \mathrm{~mm}$ con una rampa de temperatura de $5 \mathrm{~K} \mathrm{~min}^{-1}$. El resultado de esta prueba determinó que hasta el punto de fusión ( $570^{\circ} \mathrm{C}$ aproximadamente), el coeficiente de dilatación lineal es $C_{d l}=1,228 \%$ lo que correspondería con 22,32 ( $\mu \mathrm{m} / \mathrm{m} \mathrm{K}$ ). El cálculo del coeficiente volumétrico hasta la temperatura de fusión (véase la Figura 4.4) se determina mediante la multiplicación por el factor 3 , lo que resulta en un coeficiente $C_{d v}$

$$
C_{d v}=C_{d l} \times 3=3,687 \%
$$

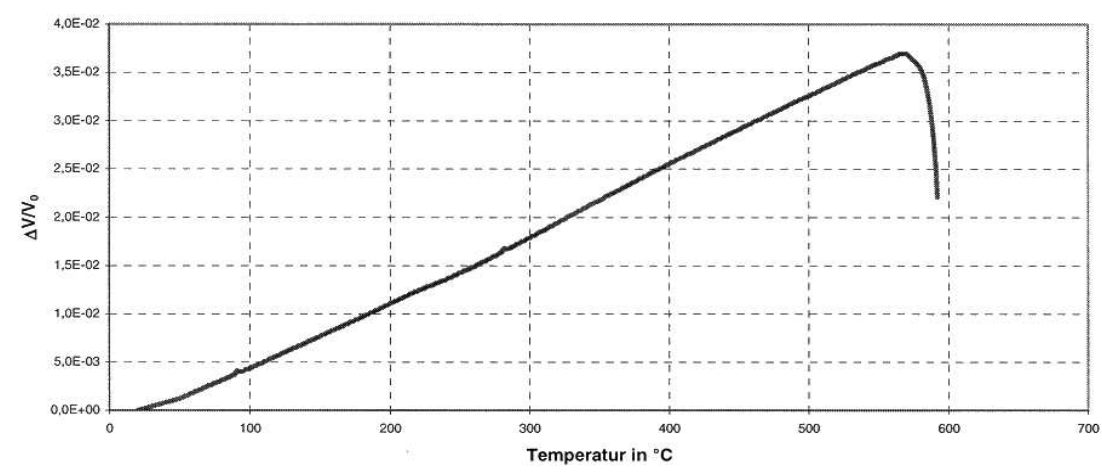

Figura 4.4: Curva de dilatación volumétrica de la aleación en función de la temperatura.

Para calcular el volumen de metal a temperatura de inyección requerido para obtener un determinado valor de la fracción inicial de llenado de la cámara se debe conocer el coeficiente de dilatación volumétrico que incluya desde la temperatura ambiente hasta la temperatura de colada $\left(20^{\circ} \mathrm{C} \div 690{ }^{\circ} \mathrm{C}\right)$ por lo que se realizaron diversos ensayos para estimar la contracción que sufría esta aleación. Concretamente se construyó un molde (véase la Figura 4.5) con geometría de tronco de cono con un volumen de $61,37 \mathrm{~cm}^{3}$. En la Figura 4.6 se puede ver una de las piezas obtenidas. Se realizó un enfriamiento forzado de la zona inferior del molde para minimizar la porosidad por rechupes internos y se comprobó su ausencia mediante el seccionamiento posterior de las piezas fabricadas.

La Tabla 4.3 muestra los valores de los volúmenes y coeficientes de dilatación calculados a partir de las medidas de densidad de las piezas fabricadas, utilizando el procedimiento gravimétrico. Según éstos, el incremento de volumen experimentado por la aleación desde $20^{\circ} \mathrm{C}$ a $690^{\circ} \mathrm{C}$ es del $3,93 \%$. El dato obtenido se ajusta bastante al valor de referencia (3,8\%) encontrado en la literatura ([26],[29]) para aleaciones de Al-12\% Si.

Conocido el coeficiente de dilatación en el rango de temperaturas utilizadas es preciso determinar la geometría de la cuchara a utilizar. La cuchara debe permitir realizar una dosificación exacta con niveles de repetibilidad aceptables. Esta tarea resulta bastante complicada debido a los problemas de precisión en 

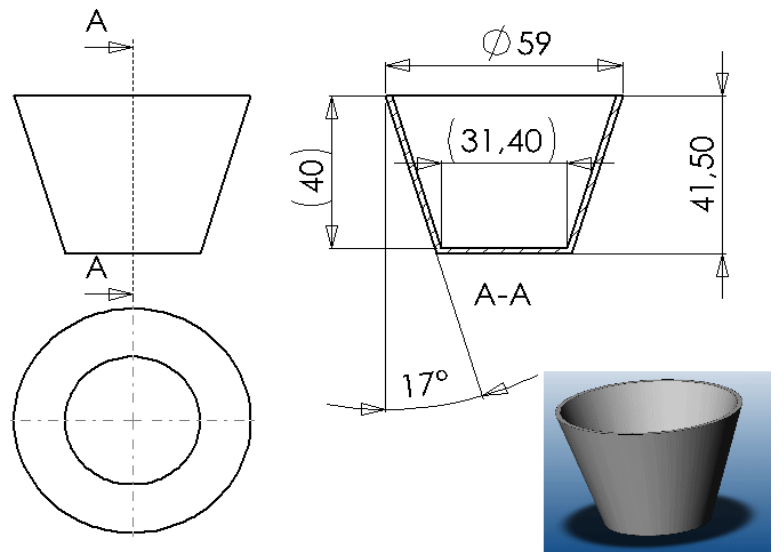

Figura 4.5: Molde utilizado para la determinación del coeficiente de dilatación volumétrico.

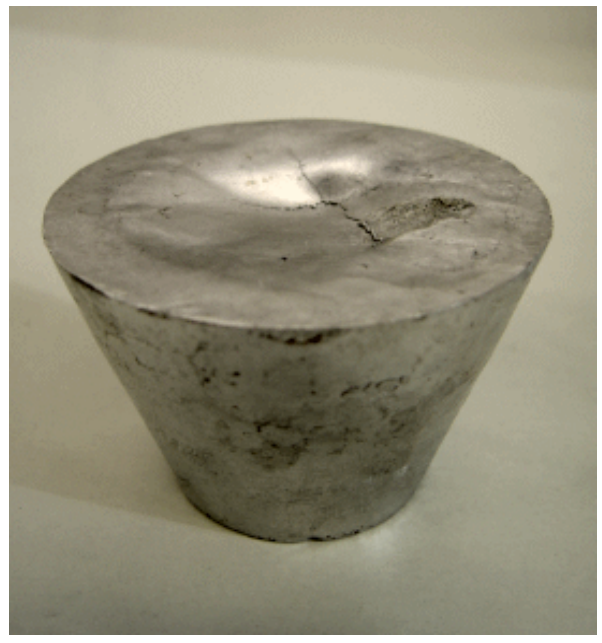

Figura 4.6: Ejemplo de pieza fabricada para la determinación del coeficiente de dilatación volumétrico. 


\begin{tabular}{|c|c|c|}
\hline Ensayo & Volumen $\left(\mathrm{cm}^{3}\right)$ & Coeficiente \\
\hline 1 & 58,99 & $3,88 \%$ \\
\hline 2 & 58,99 & $3,88 \%$ \\
\hline 3 & 58,95 & $3,94 \%$ \\
\hline 4 & 58,83 & $4,14 \%$ \\
\hline 5 & 59,04 & $3,80 \%$ \\
\hline 6 & 59,02 & $3,83 \%$ \\
\hline 7 & 59,05 & $3,78 \%$ \\
\hline 8 & 58,85 & $4,11 \%$ \\
\hline 9 & 58,96 & $3,93 \%$ \\
\hline 10 & 58,92 & $3,99 \%$ \\
\hline \multicolumn{2}{|c|}{} \\
\cline { 2 - 3 } & Media & $3,93 \%$ \\
\cline { 2 - 3 }
\end{tabular}

Tabla 4.3: Volúmenes calculados a partir de la densidad de 10 muestras de la aleación. Volumen de referencia $=61,37 \mathrm{~cm}^{3}$.

la dosificación que surgen como son la solidificación de la capa superior del metal fundido, las adherencias de la aleación sobre la cuchara o la aparición de un menisco debido a la tensión superficial. Según esto y tras realizar numerosas pruebas con diferentes tipos de cuchara se ha escogido una geometría cilíndrica. Con el fin de facilitar el vertido, se han practicado ranuras de $15 \mathrm{~mm}$ de ancho en la pared vertical de la misma. El material utilizado es acero inoxidable AISI 304 conformado en tubo de 73,2 mm de diámetro interior y 1,5 mm de espesor. La superficie de las cucharas utilizadas se ha recubierto con antiadherente para metales fundidos Moldline 100. La Figura 4.7 muestra una fotografía de la geometría escogida para la fabricación de las cucharas de colada. El cálculo de la altura a la que se debe practicar la ranura debe realizarse en función de la fracción inicial de llenado utilizada. Esta ranura permitiría una dosificación controlada aunque debido a los efectos que la tensión superficial de la aleación de aluminio fundido, se puede observar a simple vista la formación de un menisco (véanse las Figuras 4.8 y 4.9) que hace que la cantidad de metal que permanece en la cuchara una vez nivelada ésta, sea bastante difícil de estimar con precisión. Para ajustar el volumen se realizó una medición sobre la altura del menisco mediante el uso de un software de análisis de imagen (OPTIMAS v6.5) resultando ser de $h_{m e}=2,1 \mathrm{~mm}$ aproximadamente. Este menisco supone un volumen adicional $V_{\text {menisco }}=8,4 \mathrm{~cm}^{3}$ en la cuchara de diámetro antes mencionado.

\subsubsection{Estudio de la porosidad debida a la contracción}

Para determinar los niveles de porosidad debidos a la contracción que pueden aparecer en los ensayos que se llevarán a cabo en este capítulo, se han realizado 


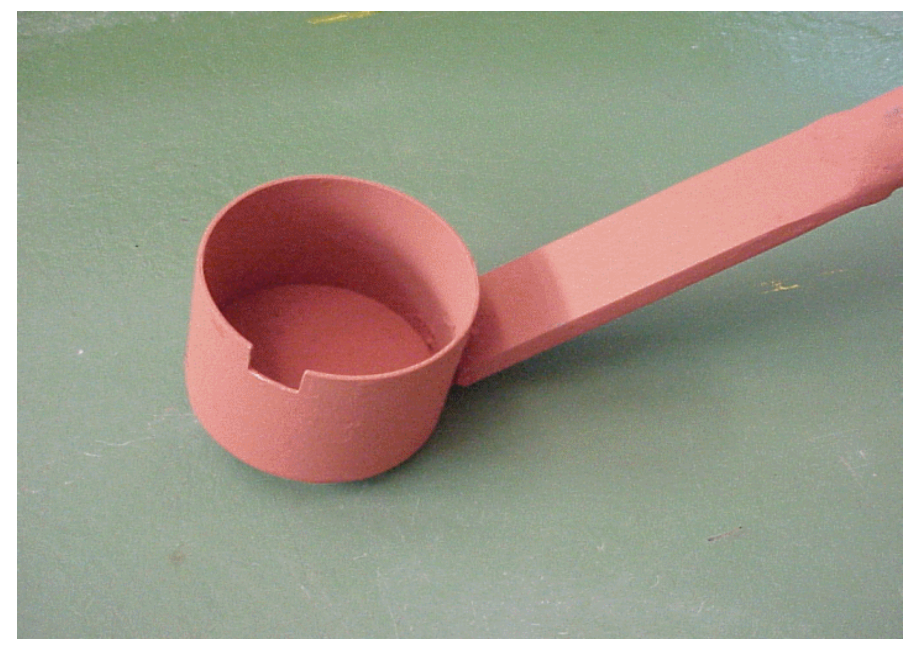

Figura 4.7: Cuchara de colada fabricada para la dosificación de una fracción inicial de llenado $f=0,252$.

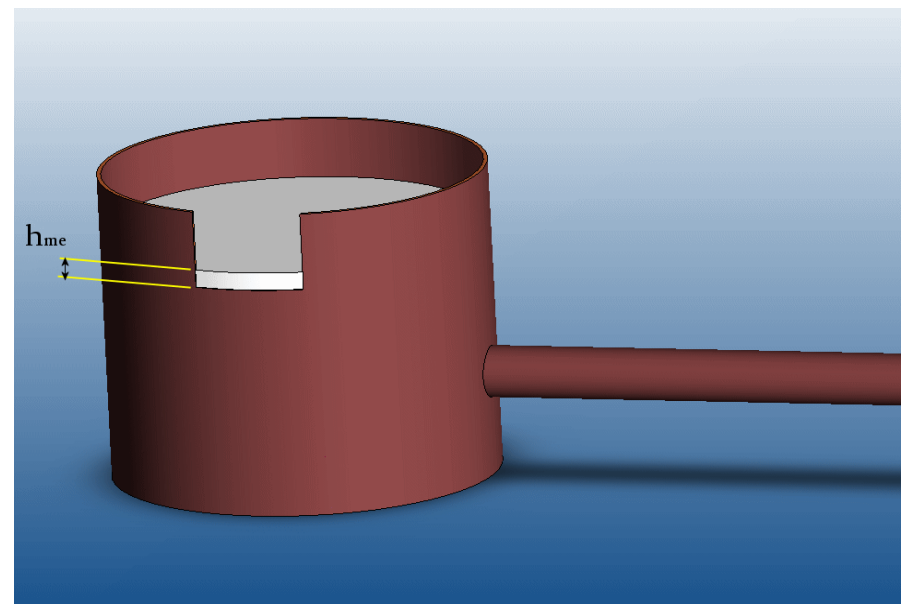

Figura 4.8: Modelo del menisco formado en la superficie del metal fundido en la cuchara de colada. 


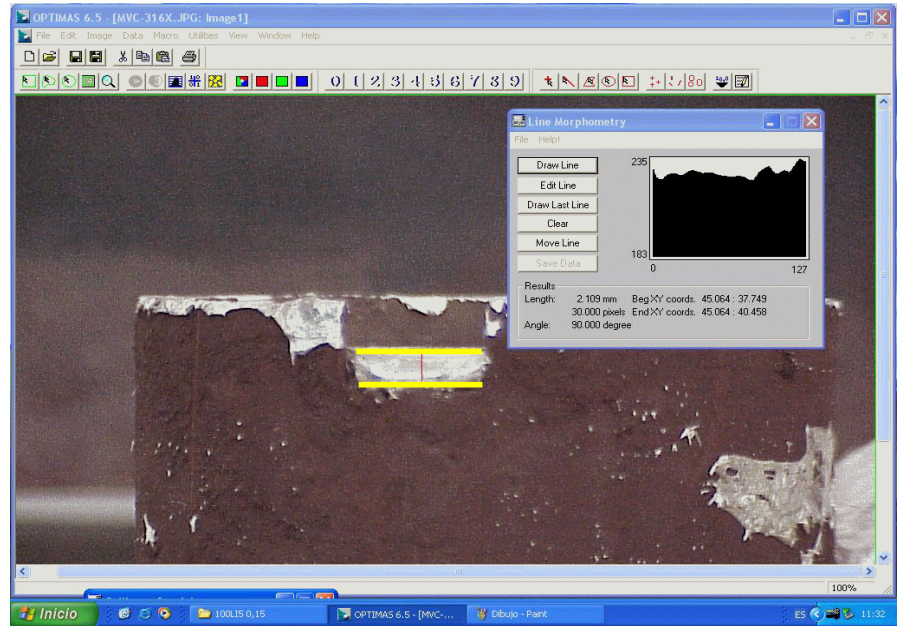

Figura 4.9: Medición de altura de menisco mediante el software de análisis de imagen OPTIMAS 6.5.

diversos ensayos utilizando condiciones de inyección para las que no se espera que aparezca atrapamiento de aire.

Concretamente se han realizado 10 inyecciones para cada una de las tres fracciones iniciales de llenado consideradas en este trabajo ( $f=0,252, f=0,374 \mathrm{y}$ $f=0,5)$ con la velocidad del pistón mínima posible, que en este caso es igual a $0,06 \mathrm{~ms}^{-1}$. Las piezas fabricadas de este modo se han seccionado como muestra la Figura 4.10. Como ejemplo, en la Tabla 4.4 se muestran los valores de porosi$\operatorname{dad}^{3}$ obtenidos en la serie realizada con $f=0,252$, resultando un valor medio de $0,49 \%$ con una desviación estándar de 0,05\%.

El estudio de la localización de esta porosidad revela que, como era de esperar, la mayor concentración de porosidad por contracción se encuentra en la zona central de la pieza (zona "B" con 1,10\%). Por otro lado, se observa que los niveles de porosidad de la zona "A" $(0,25 \%)$ son mayores que los de la zona " $C$ " $(0,12 \%)$. Esto puede ser debido a que la zona $C$ es la que se encuentra en contacto con la cara del pistón que suele estar refrigerada, lo que genera un mayor gradiente térmico que reduce el riesgo de formación de porosidad por contracción.

Como puede observarse en la Tabla 4.5, la porosidad media debida a la contracción disminuye conforme aumenta la fracción de llenado. Ahora bien, si tenemos en cuenta la masa de las piezas de las diferentes fracciones iniciales de llenado podemos calcular los volúmenes de la porosidad por contracción correspondientes a cada fracción. Como puede apreciarse en la Tabla 4.6, el volumen medio debido a la contracción en este tipo de piezas es bastante estable y se puede estimar en unos $0,61 \mathrm{~cm}^{3}$.

${ }^{3}$ Tal y como se detallará más adelante, la porosidad se ha calculado como $\frac{\rho_{0}-\rho_{p}}{\rho_{0}}$, donde $\rho_{0}$ es la densidad de la aleación $\left(2,68 \mathrm{~g} \mathrm{~cm}^{-3}\right)$ y $\rho_{p}$ es la densidad de la pieza, medida según el método gravimétrico. 


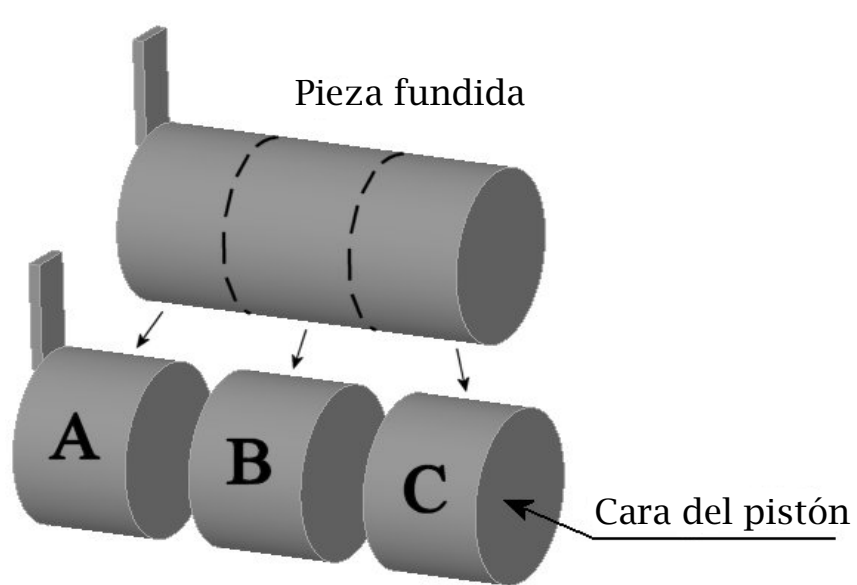

Figura 4.10: División efectuada en las piezas inyectadas para el análisis de la distribución de la porosidad.

\begin{tabular}{|c|c|c|c|c|}
\cline { 2 - 5 } \multicolumn{1}{c|}{} & \multicolumn{4}{|c|}{ Porosidad para $f=0,252$} \\
\cline { 2 - 5 } \multicolumn{1}{c|}{} & A & B & C & Media \\
\hline 1 & 0,15 & 1,08 & 0,11 & 0,45 \\
\hline 2 & 0,22 & 1,04 & 0,11 & 0,46 \\
\hline 3 & 0,30 & 1,04 & 0,07 & 0,47 \\
\hline 4 & 0,34 & 0,86 & 0,11 & 0,44 \\
\hline 5 & 0,04 & 1,12 & 0,07 & 0,41 \\
\hline 6 & 0,37 & 1,12 & 0,07 & 0,52 \\
\hline 7 & 0,15 & 1,19 & 0,15 & 0,50 \\
\hline 8 & 0,49 & 1,01 & 0,07 & 0,52 \\
\hline 9 & 0,34 & 1,04 & 0,30 & 0,56 \\
\hline 10 & 0,07 & 1,53 & 0,11 & 0,57 \\
\hline Media & 0,25 & 1,10 & 0,12 & 0,49 \\
\hline
\end{tabular}

Tabla 4.4: Medidas de porosidad por contracción en ensayos con $f=$ $0,252$.

\begin{tabular}{|l|c|c|c|}
\cline { 2 - 4 } \multicolumn{1}{c|}{} & \multicolumn{3}{c|}{ Porosidad por contracción (\%) } \\
\cline { 2 - 4 } \multicolumn{1}{c|}{} & $f=0,252$ & $f=0,374$ & $f=0,5$ \\
\hline Media & 0,49 & 0,34 & 0,26 \\
\hline Desviación estándar & 0,05 & 0,06 & 0,11 \\
\hline
\end{tabular}

Tabla 4.5: Porosidad media para diferentes fracciones iniciales de llenado. 


\begin{tabular}{|l|c|c|c|}
\cline { 2 - 4 } \multicolumn{1}{c|}{} & \multicolumn{3}{c|}{ Porosidad por contracción $\left(\mathrm{cm}^{3}\right)$} \\
\cline { 2 - 4 } \multicolumn{1}{c|}{} & $f=0,252$ & $f=0,374$ & $f=0,5$ \\
\hline Media & 0,60 & 0,62 & 0,61 \\
\hline Desviación estándar & 0,07 & 0,12 & 0,27 \\
\hline
\end{tabular}

Tabla 4.6: Porosidad media expresada en unidades de volumen para diferentes fracciones iniciales de llenado.

\subsubsection{Equipamiento}

A continuación se describirán las modificaciones realizadas sobre el equipo disponible descrito en el Capítulo 2 para realizar los ensayos con aluminio.

\subsubsection{Adaptación de la geometría del molde}

Para poder estudiar la primera etapa del proceso de inyección y los mecanismos de atrapamiento de aire que en ella se producen se decidió fabricar una pieza intercambiable que, una vez instalada en el molde disponible, impidiera que el metal accediese a la cavidad del molde.

La mayor parte del aire existente en la cámara de inyección, exceptuando el que queda atrapado, debería ser expulsado hacia el exterior. Para ello se mecanizó en la superficie exterior de esta pieza una cajera de $21 \mathrm{~mm}$ de ancho, 61,2 mm de alto y $3 \mathrm{~mm}$ de profundidad, a modo de canal de colada junto con un viento de $0,05 \mathrm{~mm}$ mecanizado junto a las zonas laterales y superior de la cajera (véanse las Figuras 4.11, 4.12 y 4.13). Esto permite una correcta evacuación del aire hacia el exterior impidiendo, por otro lado, la salida del metal fundido. De esta forma, la pieza inyectada quedará en el interior de la cámara de inyección. En la Figura 4.14 se puede observar la disposición final del molde una vez abierto tras una inyección donde se puede ver la extracción de una pieza fabricada con la cámara de $50 \mathrm{~mm}$ de diámetro.

\subsubsection{Condiciones de ensayo}

Se han realizado ensayos para tres fracciones iniciales de llenado $f=0,252$, $f=0,374$ y $f=0,5$ en una cámara de inyección de $50 \mathrm{~mm}$. En este estudio se ha utilizado la ley de aceleración de la Ecuación 3.1 propuesta por López et al. [55]. Para cada fracción de llenado, se realizaron diversas series de inyecciones para diferentes velocidades máximas del pistón (Tabla 4.7). En la Figura 4.15 se puede observar, como ejemplo, una serie de ensayos realizados con una fracción inicial de llenado $f=0,374$. El ajuste de la citada ley, se ha realizado mediante el software desarrollado y comentado en el Capítulo 2. En la Tabla 4.8 se muestra un ejemplo con los recorridos y aperturas de válvula utilizadas para conseguir una ley de movimiento con velocidad máxima de pistón de $0,63 \mathrm{~ms}^{-1}$. 


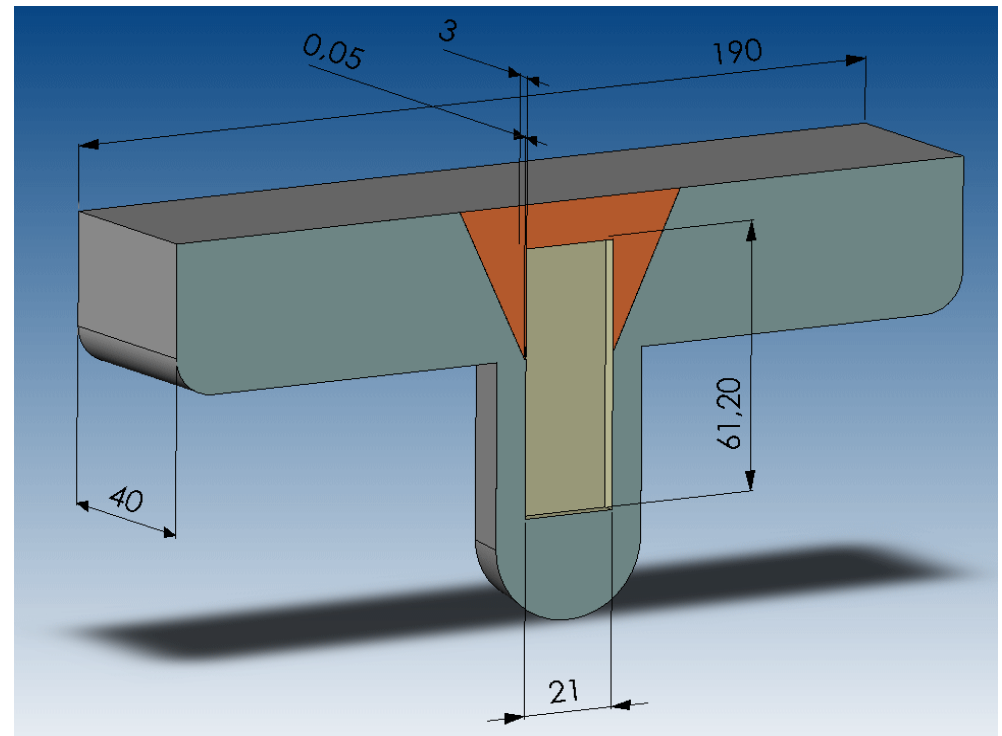

Figura 4.11: Modelo de la pieza intercambiable fabricada.

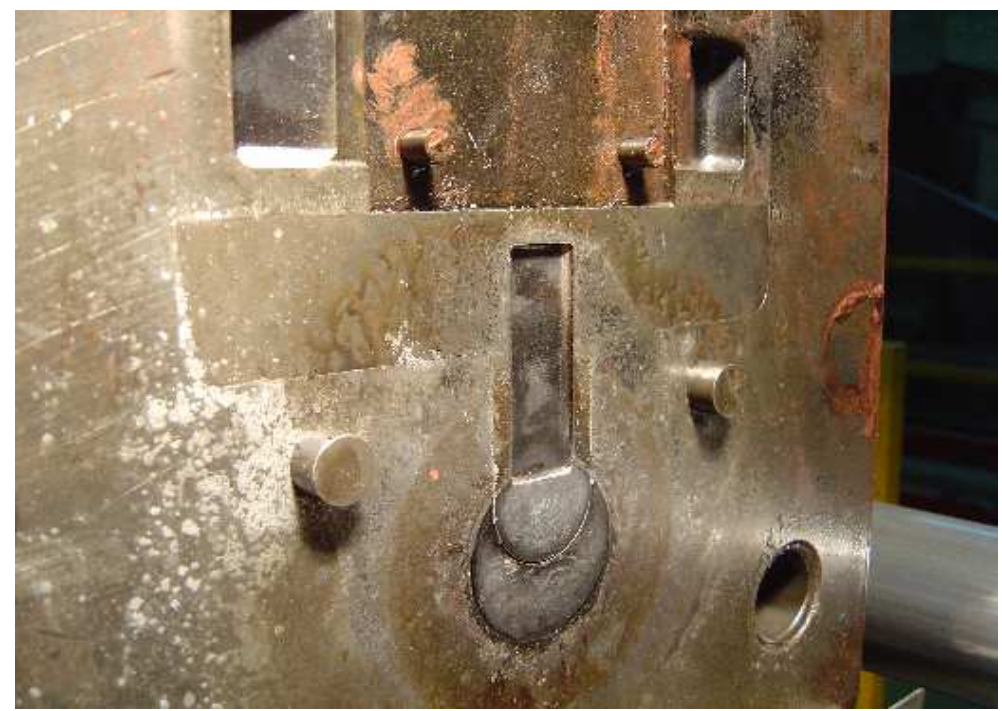

Figura 4.12: Fotografía de detalle de la pieza intercambiable montada en el molde.

\begin{tabular}{|c|c|c|c|c|c|c|c|c|}
\hline$f$ & \multicolumn{7}{|c|}{ Velocidad máxima $\left(\mathrm{m} \mathrm{s}^{-1}\right)$} \\
\hline 0,252 & 0,19 & 0,32 & 0,40 & 0,48 & 0,57 & 0,64 & 0,72 & 0,80 \\
\hline 0,374 & 0,19 & 0,33 & 0,41 & 0,50 & - & 0,64 & 0,73 & - \\
\hline 0,5 & - & - & 0,43 & 0,51 & - & 0,62 & 0,74 & - \\
\hline
\end{tabular}

Tabla 4.7: Velocidades máximas del pistón ensayadas. 


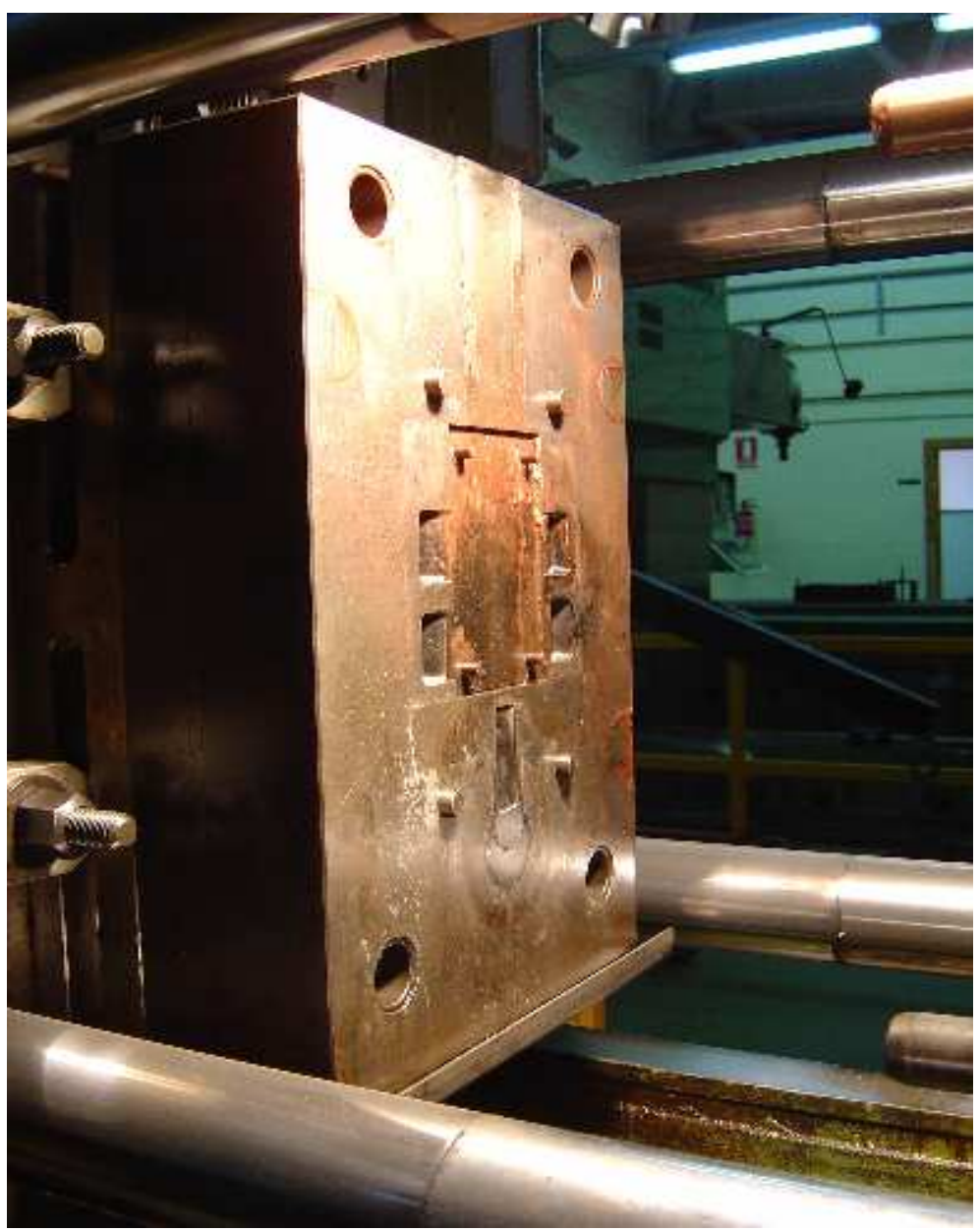

Figura 4.13: Parte móvil del molde adaptado para el estudio de la etapa lenta.
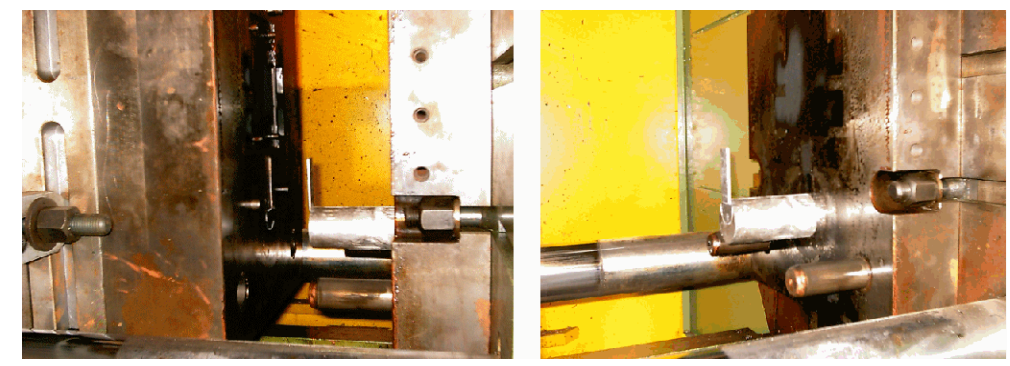

Figura 4.14: Pieza fabricada para el estudio de la etapa lenta. 


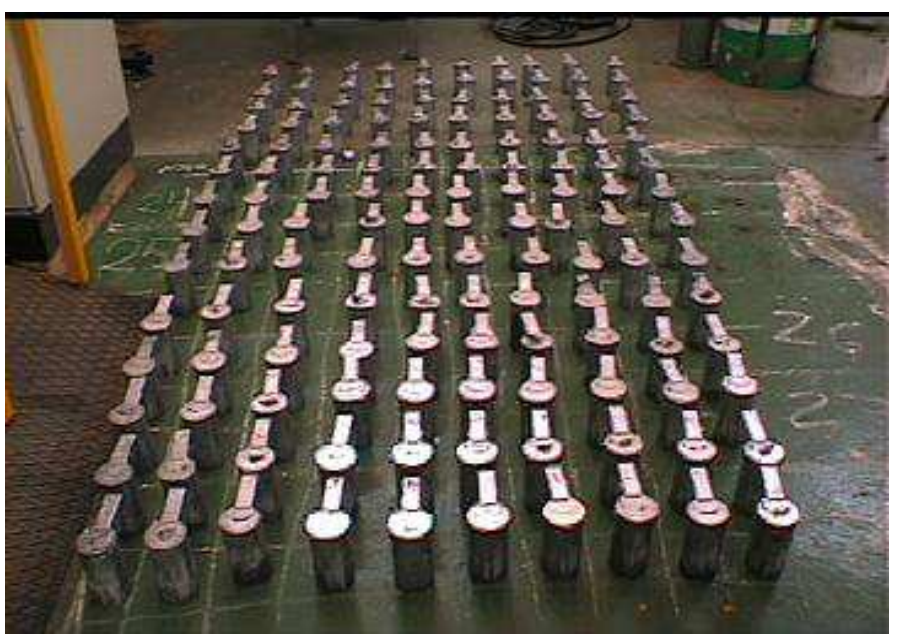

Figura 4.15: Ejemplo de una serie de piezas fabricadas con una fracción inicial de llenado $f=0,374$.

\begin{tabular}{|l|c|c|c|c|c|c|c|c|c|c|}
\hline & P1 & P2 & P3 & P4 & P5 & P6 & P7 & P8 & P9 & P10 \\
\hline Posición (mm) & 9 & 14 & 17 & 24 & 39 & 53 & 66 & 71 & 76 & 112 \\
\hline Apertura (\%) & 17 & 18 & 19 & 20 & 21 & 22 & 24 & 25 & 25 & 25 \\
\hline
\end{tabular}

Tabla 4.8: Ejemplo de configuración del software de control de la máquina (posición del pistón y apertura correspondiente) para conseguir una inyección con velocidad máxima del pistón de $0,63 \mathrm{~ms}^{-1}$ según la ley óptima de la Ecuación 3.1. 
Antes de realizar los ensayos se debe precalentar el molde y el contenedor. Para ello se aplica directamente una llama obtenida mediante una lámpara de propano. En unos 15 ó 20 minutos, la temperatura medida en estos componentes ronda los $100^{\circ} \mathrm{C}$. Posteriormente, se realiza un número no inferior a cinco vertidos de metal en la cámara de inyección con el molde cerrado y sin llegar a inyectar. Una vez que la temperatura media del contenedor alcanza en su zona inferior $\operatorname{los} 200^{\circ} \mathrm{C}$, se procede a realizar inyecciones a muy baja velocidad (en torno a $0,05 \mathrm{~ms}^{-1}$ ) hasta que la cámara y la zona inferior del molde alcanzan unos $245^{\circ} \mathrm{C}$ (temperatura media de trabajo). Cabe destacar que la temperatura media en la cámara experimenta una variación durante cada inyección de unos $\pm 30^{\circ} \mathrm{C}$. Una vez terminada la fase de precalentamiento, es necesario realizar inyecciones en condiciones de ensayo con el fin de que el sistema hidráulico también alcance el régimen de trabajo. Así, tras una serie de al menos 10 inyecciones se inician los ensayos.

En este punto cabe destacar la importancia que tiene el proceso de vertido del caldo dentro de la cámara con respecto al atrapamiento de aire y el tiempo de retardo que existe entre el vertido y la inyección. Existen trabajos experimentales, como el de Lewis et al. [50], que concluyen que el movimiento del pistón debería iniciarse cuando la ola provocada por el proceso de vertido ha desaparecido o se está moviendo en el mismo sentido en el que se realizará la inyección con el fin de minimizar el atrapamiento de aire en la cámara de inyección. Se realizaron diversas inspecciones visuales para las diferentes fracciones de llenado consideradas observándose que un tiempo de retardo de unos 5 segundos era suficiente para que la superficie del metal fundido quedara estabilizada. La pérdida de temperatura en la aleación provocada por este retraso queda compensada con el sobrecalentamiento de la aleación en el horno de mantenimiento por lo que se ha trabajado con una temperatura de horno de $690^{\circ} \mathrm{C}$ [31].

Como ya se comentó en el capítulo 2, a pesar de las mejoras introducidas en el sistema de control de la máquina, es indispensable verificar la ley de movimiento ejecutada en cada inyección, ya que se producen variaciones importantes entre inyecciones consecutivas realizadas para las mismas condiciones. A este problema se le añade la dificultad para conseguir dosificaciones precisas, incluso teniendo en cuenta los aspectos relacionados con la formación del menisco en la cuchara de vertido anteriormente citados.

Se han realizado numerosos ensayos durante el desarrollo de la presente tesis que han confirmado que el procedimiento seguido para la dosificación, con diferentes tipos de cucharas, tiene una variabilidad tal que alrededor del $40 \%$ de las dosificaciones realizadas han resultado incorrectas. El proceso de carga y dosificación se ha realizado de forma manual, lo que lleva a pensar que un sistema automatizado podría mejorar las condiciones de repetibilidad aunque no se eliminarían los problemas encontrados con las láminas de metal solidificado en la superficie de la cuchara y los de la nivelación del caldo debidos a la tensión superficial. Teniendo en cuenta todo lo anteriormente expuesto, se ha establecido 


\begin{tabular}{|l|c|c|c|}
\cline { 2 - 4 } \multicolumn{1}{c|}{} & \multicolumn{3}{|c|}{ Fracción inicial de llenado } \\
\cline { 2 - 4 } \multicolumn{1}{c|}{} & 0,252 & 0,374 & 0,5 \\
\hline Variación máxima medida & $\pm 0,91$ & $\pm 0,63$ & $\pm 1,95$ \\
\hline
\end{tabular}

Tabla 4.9: Variaciones máximas de la fracción de llenado medidas en las piezas evaluadas.

un criterio para detectar las inyecciones que no se ajustan a la ley de aceleración propuesta o a la fracción inicial establecida para cada ensayo.

En cuanto a la similitud entre la ley teórica y los desplazamientos reales del pistón, se ha utilizado el coeficiente de la Ecuación 2.5 especificado en el Capítulo 2. Con respecto a la fracción inicial de llenado, se decidió aceptar piezas cuya fracción inicial de llenado se encuentre en el rango de $\pm 2 \%$ aunque cabe destacar que el $83 \%$ de las piezas aceptadas se encuentran en el rango de $\pm 0,5 \%$. La Tabla 4.9 , muestra las variaciones máximas que se han obtenido en todos los ensayos realizados. Para ello se ha utilizado una balanza con una resolución de $0,01 \mathrm{~g}$ instalada a pie de máquina (véase la Figura 4.16). En la Tabla 4.10 se pueden

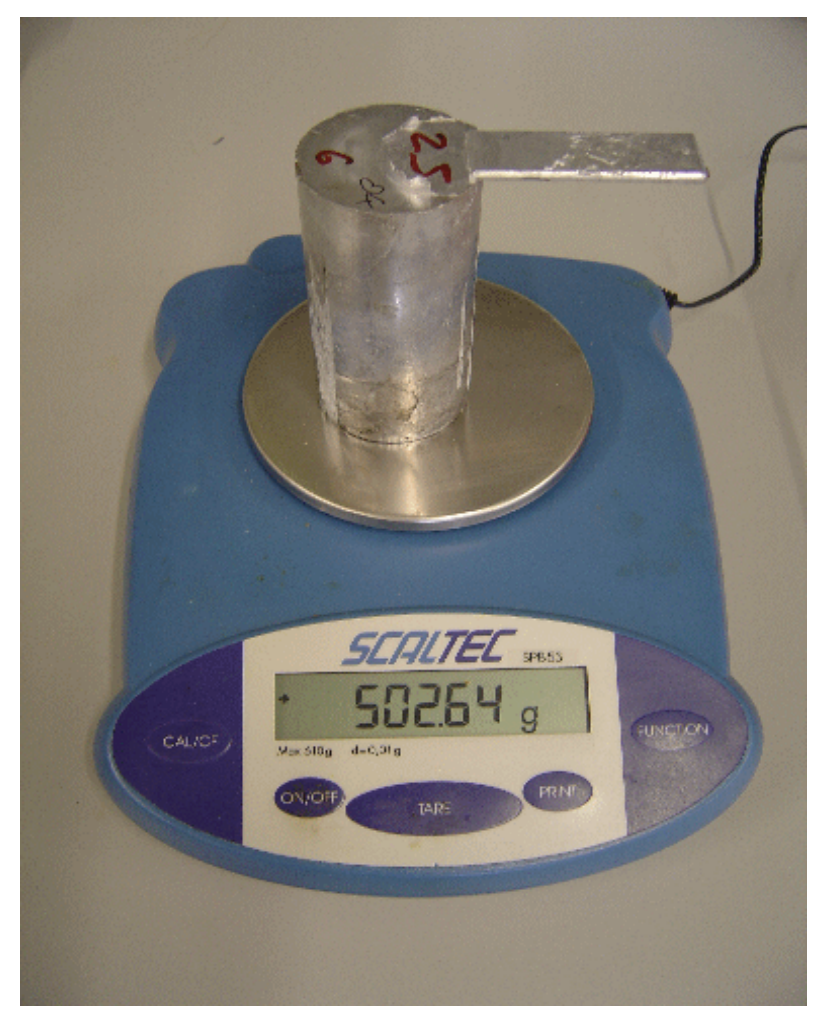

Figura 4.16: Ejemplo de pesada de una pieza de $50 \mathrm{~mm}$ de diámetro y $f=0,374$ en una balanza de resolución de $0,01 \mathrm{~g}$.

encontrar los rangos de masa válidos para un criterio de tolerancia de fracción 


\begin{tabular}{|c|c|c|c|}
\cline { 2 - 4 } \multicolumn{1}{c|}{} & \multicolumn{3}{c|}{ Masa de la pieza(g) } \\
\hline$f$ & Mínimo & Exacto & Máximo \\
\hline 0,252 & 310,64 & 337,39 & 364,13 \\
\hline 0,374 & 472,72 & 499,47 & 526,21 \\
\hline 0,5 & 641,84 & 668,58 & 695,32 \\
\hline
\end{tabular}

Tabla 4.10: Rango pesos válidos para inyecciones en cámara de $50 \mathrm{~mm}$ de diámetro y $264,5 \mathrm{~mm}$ de longitud $( \pm 0,02 f)$.

de $\pm 2 \%$ considerando las diferentes fracciones ensayadas para una cámara de inyección de $50 \mathrm{~mm}$ de diámetro y 264,5 mm de longitud.

\subsubsection{Procedimiento de cálculo de la porosidad}

El método utilizado en esta tesis para medir la porosidad ha sido el gravimétrico que, como se comentó en el capítulo de Introducción, está basado en el principio de Arquímedes. Una vez enfriadas las piezas, la porosidad correspondiente se calcula como $\frac{\rho_{0}-\rho_{p}}{\rho_{0}}$, donde $\rho_{0}$ es la densidad de la aleación $\left(2,68 \mathrm{~g} \mathrm{~cm}^{-3}\right)$ y $\rho_{p}$ es la densidad medida de la pieza. La medida se ha realizado en una balanza hidrostática con una resolución de 0,0001 g y una repetibilidad de \pm 0,0002 g, provista de un dispositivo para la medida de densidad (véanse las Figuras $4.17 \mathrm{y}$ 4.18). En el Anexo A se puede consultar con mayor detalle las características de este método.

Teniendo en cuenta que la masa del posible gas atrapado se puede despreciar frente a la masa total de la pieza, es posible determinar fácilmente el volumen de los poros formados (tanto los debidos a la contracción del metal como los debidos al atrapamiento de aire) mediante la siguiente expresión:

$$
V_{\text {poro }}=V_{2}-V_{1}=\frac{M}{\rho_{p}}-\frac{M}{\rho_{0}}=M\left[\frac{1}{\rho_{p}}-\frac{1}{\rho_{0}}\right],
$$

siendo M la masa de la pieza. En la Tabla 4.11 se pueden observar los valores del volumen de los poros correspondientes valores de porosidad entre el 1 y $6 \%$ en piezas fabricadas con masas entre 300 y $700 \mathrm{~g}$. En la Tabla 4.12 se expresa este valor en centímetros cúbicos de gas por cada $100 \mathrm{~g}$ de pieza, ya que ésta es la unidad de medida más utilizada en los trabajos publicados a este respecto.

Dada la geometría sencilla de las piezas fabricadas, es posible realizar, fácilmente, una estimación aproximada de su volumen, y por lo tanto de su porosidad. Con el fin de comprobar el grado de similitud obtenido en las medidas de porosidad mediante ambos métodos, se han comparado en la Figura 4.19. Como puede observarse existe una gran equivalencia entre ambos métodos, aunque aparecen ligeras desviaciones que indicarían que el método de gravimétrico ofrece valores menores para valores bajos de porosidad, invirtiendo esta tendencia en los casos de niveles de porosidad elevada. En cualquier caso, debe tenerse 

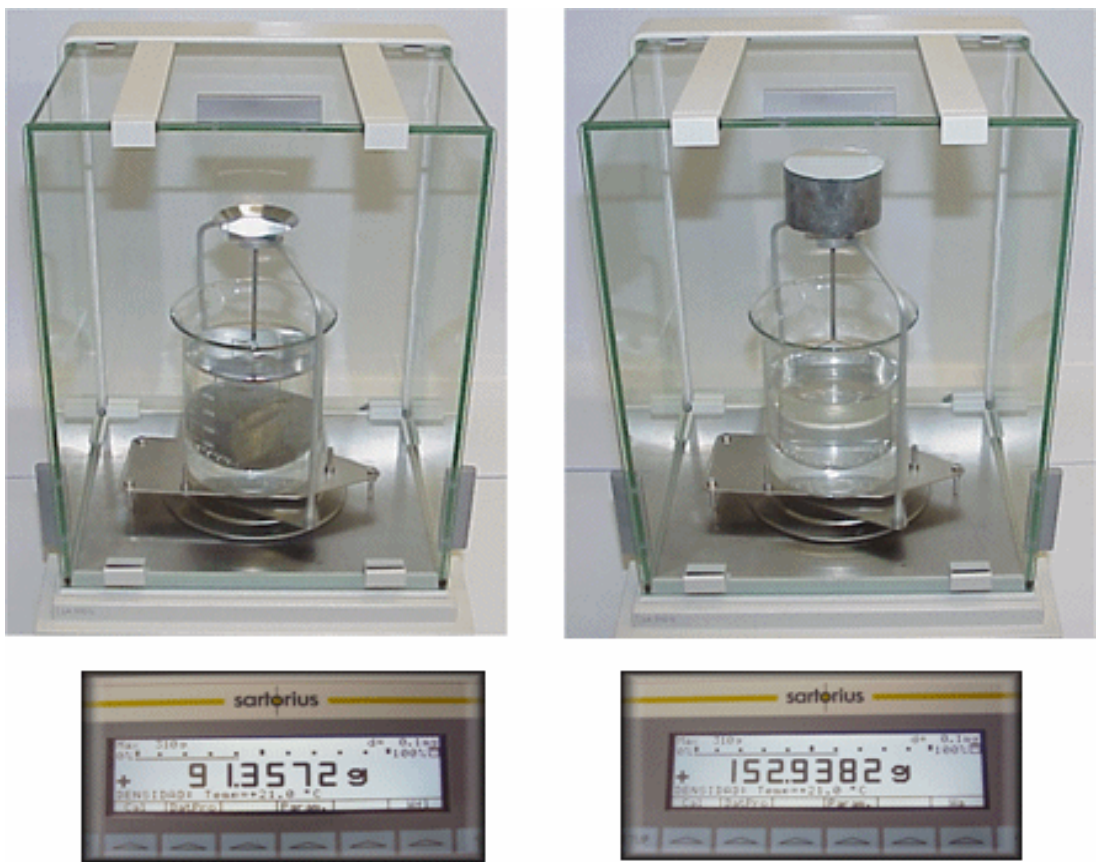

(a)

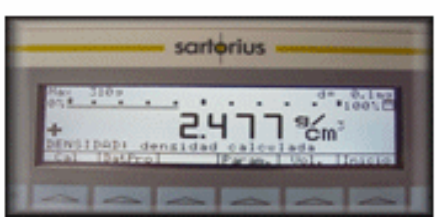

(b)

Figura 4.17: Procedimiento para la medida de densidad en la balanza hidrostática. a) Pesada en agua b) Pesada en aire.

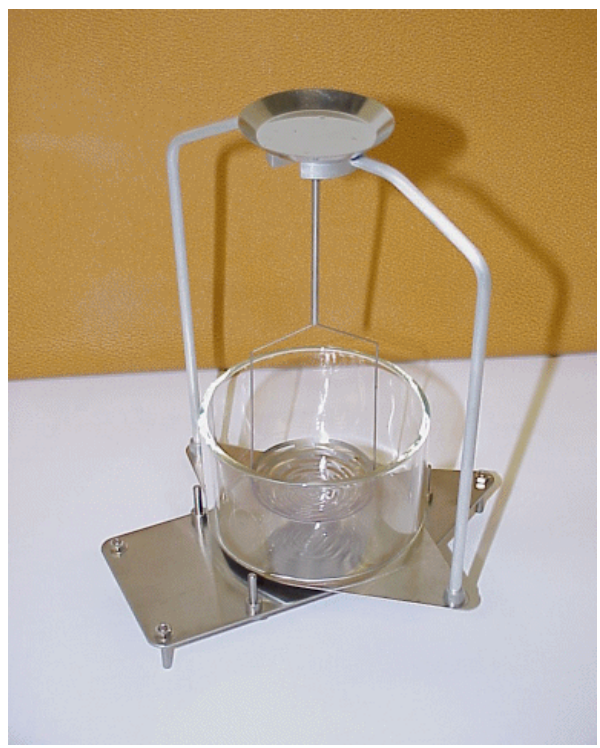

Figura 4.18: Dispositivo empleado para la medida de densidad en la balanza hidrostática. 


\begin{tabular}{|c|}
\hline Peso $(\mathrm{g})$ \\
\hline 300 \\
\hline 400 \\
\hline 500 \\
\hline 600 \\
\hline 700 \\
\hline
\end{tabular}

\begin{tabular}{|c|c|c|c|c|c|}
\hline \multicolumn{7}{|c|}{ Porosidad (\%) } \\
\hline 1 & 2 & 3 & 4 & 5 & 6 \\
\hline 1,13 & 2,28 & 3,46 & 4,66 & 5,89 & 7,15 \\
\hline 1,51 & 3,05 & 4,62 & 6,22 & 7,86 & 9,53 \\
\hline 1,88 & 3,81 & 5,77 & 7,77 & 9,82 & 11,91 \\
\hline 2,26 & 4,57 & 6,92 & 9,33 & 11,78 & 14,29 \\
\hline 2,64 & 5,33 & 8,08 & 10,88 & 13,75 & 16,67 \\
\hline
\end{tabular}

Tabla 4.11: Volúmenes de gas $\left(\mathrm{cm}^{3}\right)$ correspondientes a diferentes porcentajes de porosidad para la aleación utilizada.

\begin{tabular}{|c|c|c|c|c|c|c|}
\cline { 2 - 7 } \multicolumn{1}{c|}{} & \multicolumn{7}{c|}{ Porosidad (\%) } \\
\cline { 2 - 7 } \multicolumn{1}{c|}{} & 1 & 2 & 3 & 4 & 5 & 6 \\
\hline $\mathrm{cm}^{3} / 100 \mathrm{~g}$ & 0,38 & 0,76 & 1,15 & 1,55 & 1,96 & 2,38 \\
\hline
\end{tabular}

Tabla 4.12: Volumen de gas por cada $100 \mathrm{~g}$ de pieza correspondientes a diferentes porcentajes de porosidad.

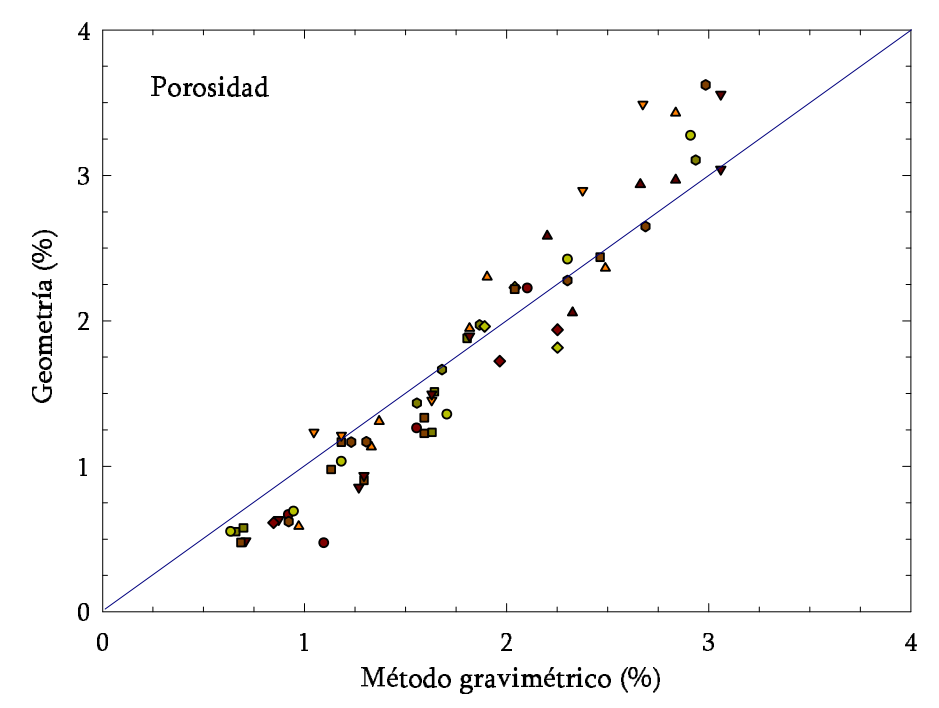

Figura 4.19: Comparación entre medidas de porosidad efectuadas mediante el método gravimétrico y la medición de longitud de la pieza para piezas inyectadas con fracción inicial $f=0,374$ y velocidades máximas entre 0,19 y $0,73 \mathrm{~ms}^{-1}$. 
en cuenta las posibles imprecisiones del sistema de medición debido a las pequeñas imperfecciones geométricas que pueden presentar las piezas, como por ejemplo las rebabas.

\subsection{Discusión de resultados}

Las Figuras 4.20, 4.21 y 4.22 muestran los resultados experimentales de las medias junto con los intervalos de confianza del 95\% (basados en una distribución t de Student) de la porosidad en función de la velocidad del pistón correspondientes a las fracciones iniciales de llenado $f=0,252, f=0,374$ y $f=0,5$ respectivamente. En ellas se incluyen los valores de la velocidad del pistón óptima predichos por Tszeng y Chu [81] analíticamente y los predichos numéricamente por López et al. [54], mostrados en la Tabla 4.13. Se puede observar una muy buena concordancia de los resultados experimentales con los teóricos, especialmente con los numéricos.

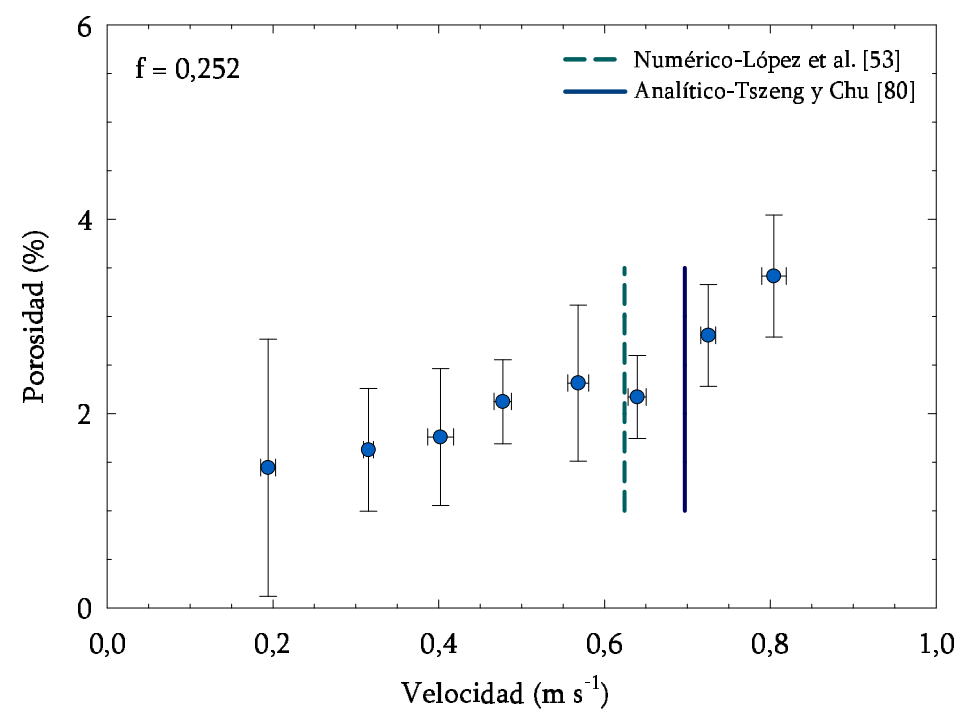

Figura 4.20: Porosidad media e intervalos de confianza del $95 \%$ en función de la velocidad máxima del pistón con $f=0,252$.

\begin{tabular}{|r|c|c|c|}
\cline { 2 - 4 } \multicolumn{1}{c|}{} & \multicolumn{3}{c|}{ Fracción inicial de llenado } \\
\cline { 2 - 4 } \multicolumn{1}{c|}{} & $f=0,252$ & $f=0,374$ & $f=0,5$ \\
\hline $\operatorname{Vmax}\left(\mathrm{ms}^{-1}\right)$ & \multicolumn{3}{|c|}{} \\
\hline Tszeng & 0,697 & 0,545 & 0,410 \\
\hline López & 0,624 & 0,488 & 0,376 \\
\hline
\end{tabular}

Tabla 4.13: Valores de la velocidad crítica del pistón predichos por los modelos de Tszeng y Chu [81] y López et al. [54]. 


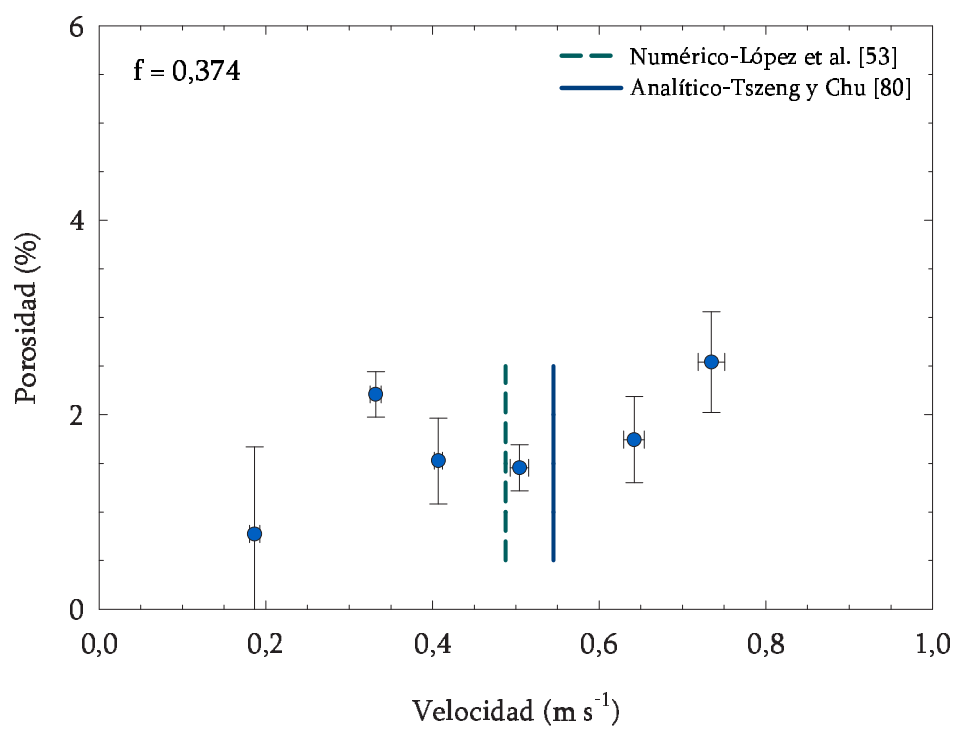

Figura 4.21: Porosidad media e intervalos de confianza del $95 \%$ en función de la velocidad máxima del pistón con $f=0,374$.

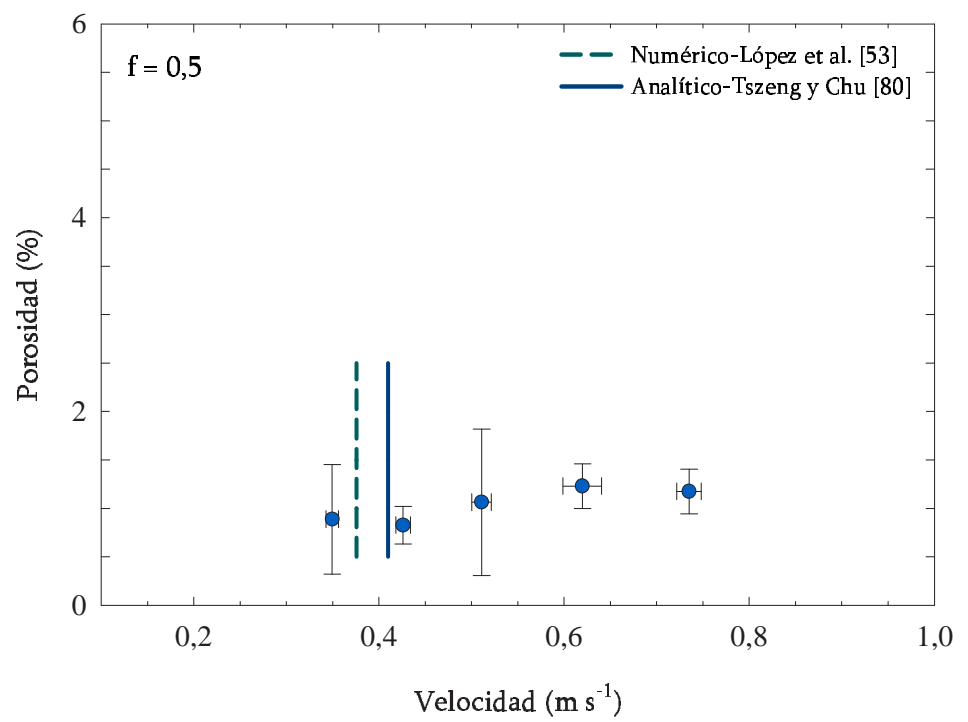

Figura 4.22: Porosidad media e intervalos de confianza del $95 \%$ en función de la velocidad máxima del pistón con $f=0,5$. 


\begin{tabular}{|l|c|c|c|}
\hline $\begin{array}{c}\text { Pieza } \\
\text { (num.) }\end{array}$ & $\begin{array}{c}\text { Masa } \\
(\mathrm{g})\end{array}$ & $\begin{array}{c}\text { Porosidad } \\
(\%)\end{array}$ & $\begin{array}{c}\text { Velocidad } \\
\left(\mathrm{ms}^{-1}\right)\end{array}$ \\
\hline P1 & 501,15 & 0,920 & 0,643 \\
\hline P2 & 500,02 & 1,679 & 0,654 \\
\hline P3 & 503,15 & 1,555 & 0,648 \\
\hline P4 & 501,15 & 1,182 & 0,640 \\
\hline P6 & 504,48 & 0,709 & 0,665 \\
\hline P9 & 503,15 & 0,970 & 0,663 \\
\hline P10 & 500,08 & 1,294 & 0,666 \\
\hline P19 & 504,95 & 2,040 & 2,040 \\
\hline P21 & 494,34 & 1,803 & 0,640 \\
\hline P22 & 504,81 & 1,269 & 0,601 \\
\hline P23 & 506,02 & 2,823 & 0,621 \\
\hline P24 & 501,62 & 2,177 & 0,640 \\
\hline P25 & 505,46 & 3,047 & 0,620 \\
\hline P26 & 499,77 & 2,923 & 0,672 \\
\hline
\end{tabular}

Tabla 4.14: Resultados experimentales para una fracción $f=0,374$ y una velocidad del pistón de $0,64 \mathrm{~m} \mathrm{~s}^{-1}$.

Cada punto de estas figuras se ha obtenido a partir de datos similares a los presentados en la Tabla 4.14.

Como se puede observar es posible detectar la aparición de un mínimo local de porosidad entorno a $0,64 \mathrm{~ms}^{-1}$ en el caso de $f=0,252$, aunque cabe destacar que la incertidumbre experimental es relativamente elevada en algunos casos. En la fracción $f=0,374$ vuelve a aparecer un mínimo local de porosidad en velocidades entorno a $0,52 \mathrm{~ms}^{-1}$, algo inferior a la conseguida con la fracción anterior. En el caso de $f=0,5$ podemos observar que el mínimo aparece en valores cercanos a $0,40 \mathrm{~ms}^{-1}$.

En general, se puede observar que la porosidad medida decrece conforme aumenta la fracción inicial de llenado independientemente de la velocidad del pistón. Del mismo modo, se observa que para cada fracción inicial de llenado, existe un valor de la velocidad del pistón para el que la porosidad alcanza un mínimo local. Este mínimo está menos pronunciado en las fracciones de llenado más altas.

Con el fin de analizar la distribución de la porosidad, cada pieza inyectada fue dividida en un número de partes de igual tamaño, en función del tamaño de la pieza. Obviamente, para una cierta cámara de inyección, el tamaño viene dado por la fracción inicial de llenado. Para las fracciones utilizadas en los ensayos se dividieron en dos partes las piezas correspondientes a $f=0,252$, y en tres partes las piezas con $f=0,374$ y $f=0,5$ según la configuración mostrada con 
anterioridad en la Figura 4.10 (la parte A corresponde a la zona de la pieza más alejada del pistón). En todos los casos se han recubierto las superficies seccionadas con un plástico adhesivo para cubrir cualquier posible poro que pudiera existir.

En las siguientes figuras $(4.23,4.24,4.25,4.26,4.27,4.28,4.29$ y 4.30$)$ se muestran los resultados experimentales de las medias (junto con los intervalos de confianza del 95\%) de la porosidad, en función de la velocidad del pistón, correspondientes a las tres fracciones iniciales de llenado y las diferentes partes en las que se han dividido las piezas ( $f=0,252 \mathrm{~A}-\mathrm{B}, f=0,374 \mathrm{~A}-\mathrm{B}-\mathrm{C}$ y $f=0,5$ A-B-C respectivamente). Cabe destacar que el seccionado de la pieza en varias partes puede causar la división de cavidades de aire existentes, lo que provoca que el intervalo de incertidumbre de la porosidad para cada pieza sea mayor que el del total de la pieza.

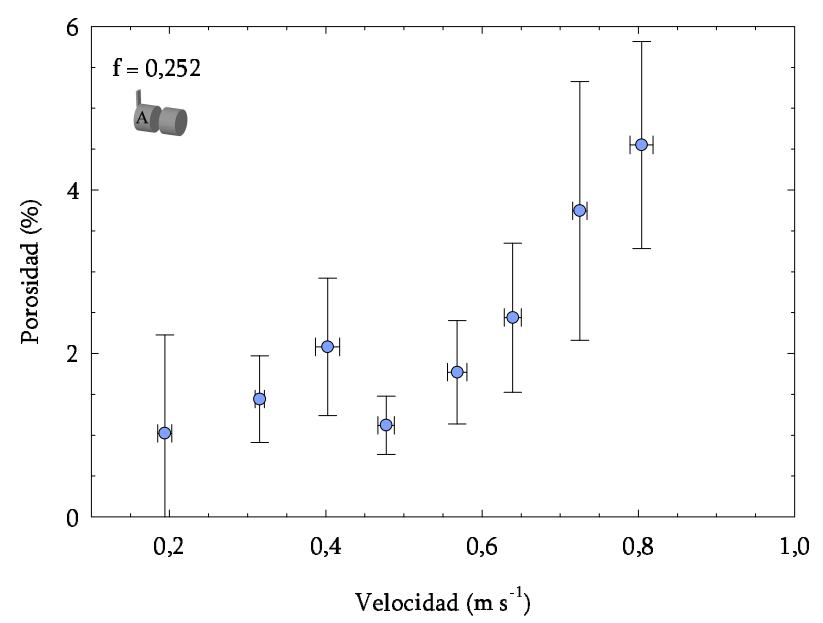

Figura 4.23: Porosidad media e intervalos de confianza del $95 \%$ en función de la velocidad máxima del pistón en la parte "A" con $f=0,252$.

Se puede observar como la porosidad medida tiende a ser superior en las secciones intermedias de la pieza o cerca del pistón para velocidades del pistón bajas, mientras que para velocidades del pistón altas tiende a acumularse en las partes cercanas a la pared final de la cámara. Nótese que la porosidad medida en la parte A, la cual es adyacente a la pared final de la cámara, es baja y aproximadamente constante para velocidades del pistón bajas y tiende a incrementarse con la velocidad del pistón para valores de ésta lo suficientemente altos. Este incremento puede atribuirse a los efectos de la rotura de la ola que se produce debido al impacto del metal fundido contra el techo de la cámara de inyección. En cuanto a las partes B y C, las variaciones de la porosidad con la velocidad del pistón son menos pronunciadas y, en general, no siguen una tendencia definida. A la vista de estos resultados se puede concluir que un comportamiento similar 


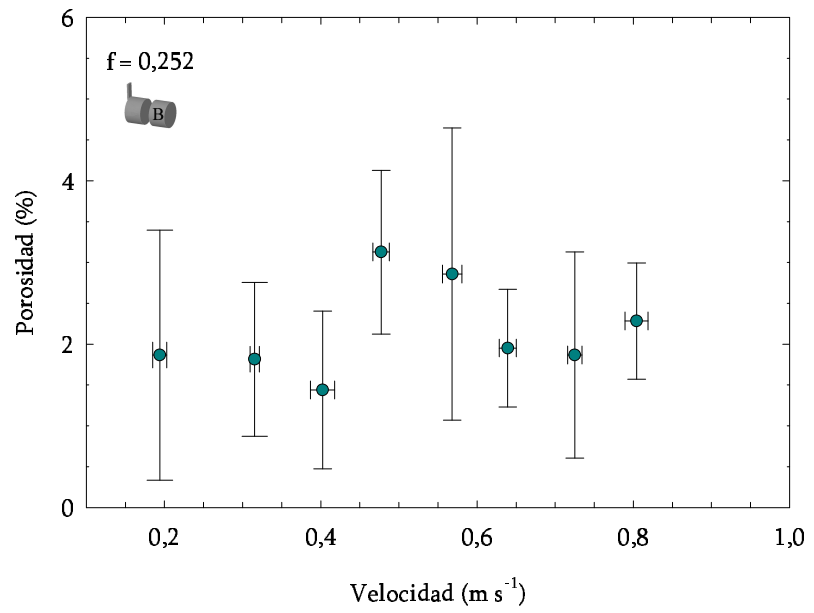

Figura 4.24: Porosidad media e intervalos de confianza del $95 \%$ en función de la velocidad máxima del pistón en la parte "B" con $f=0,252$.

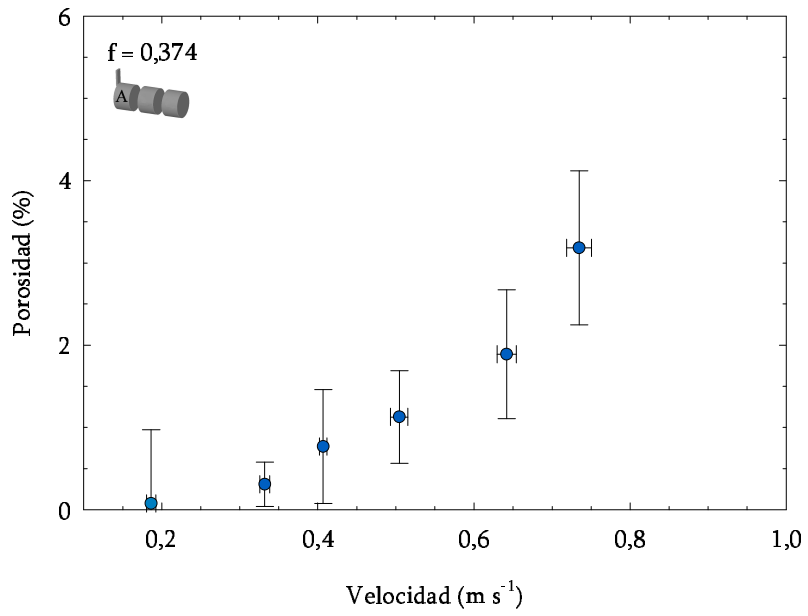

Figura 4.25: Porosidad media e intervalos de confianza del 95\% en función de la velocidad máxima del pistón en la parte "A" con $f=0,374$. 


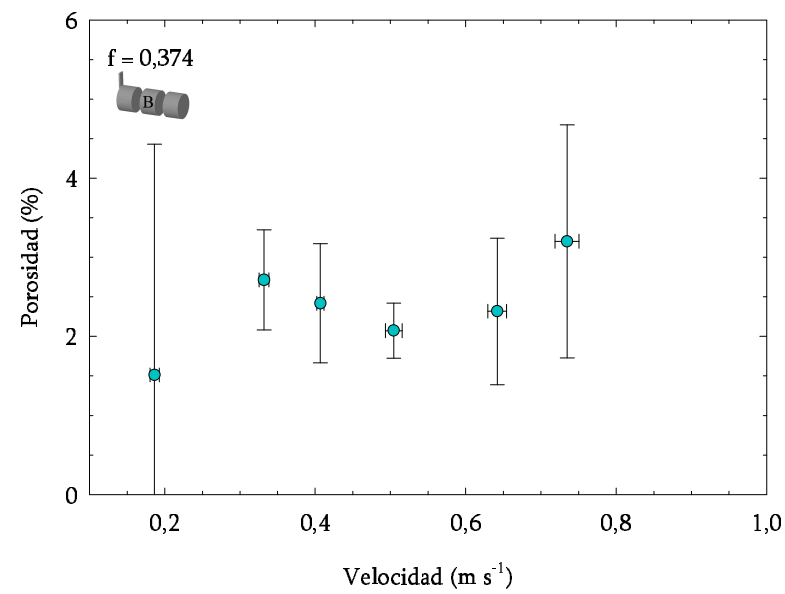

Figura 4.26: Porosidad media e intervalos de confianza del 95\% en función de la velocidad máxima del pistón en la parte "B" con $f=0,374$.

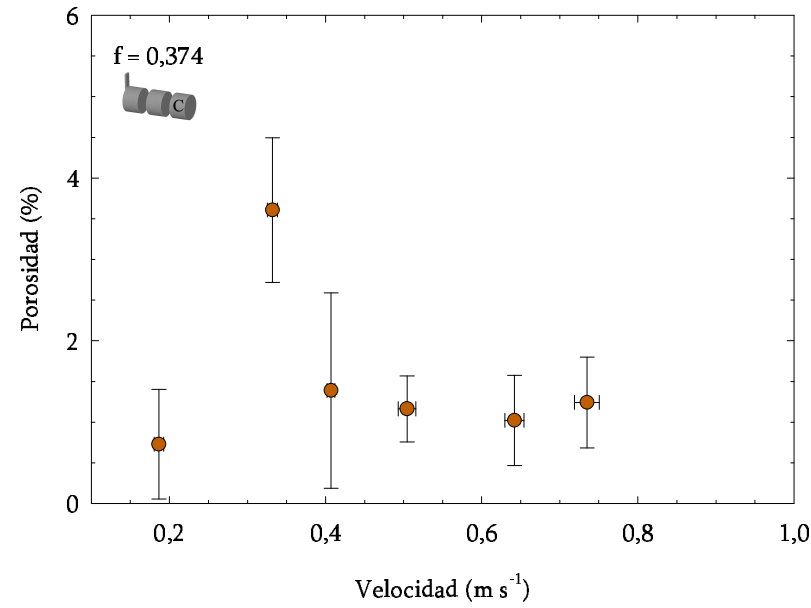

Figura 4.27: Porosidad media e intervalos de confianza del 95\% en función de la velocidad máxima del pistón en la parte "C" con $f=0,374$. 


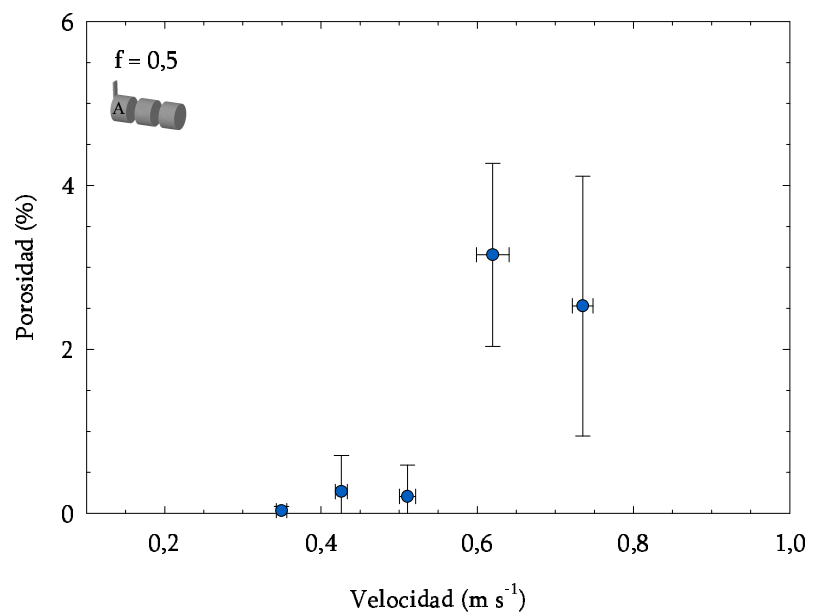

Figura 4.28: Porosidad media e intervalos de confianza del $95 \%$ en función de la velocidad máxima del pistón en la parte "A" con $f=0,5$.

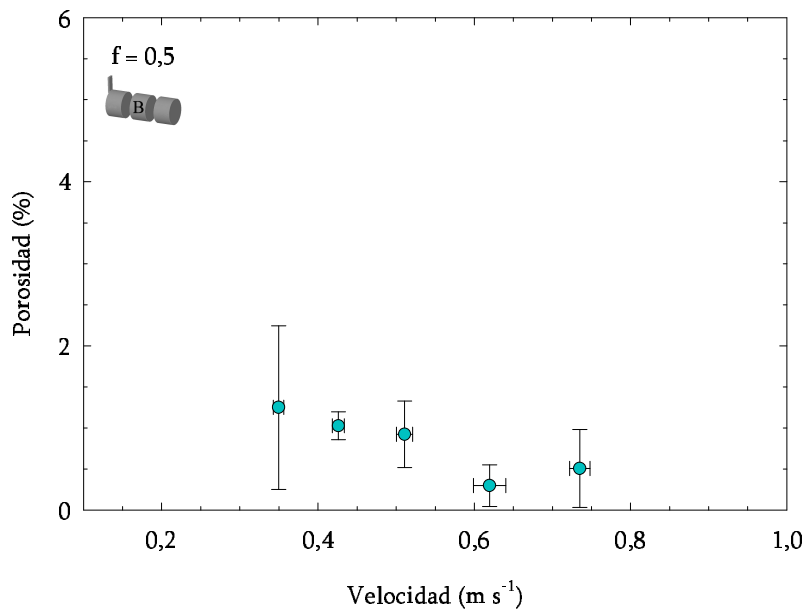

Figura 4.29: Porosidad media e intervalos de confianza del $95 \%$ en función de la velocidad máxima del pistón en la parte "B" con $f=0,5$. 


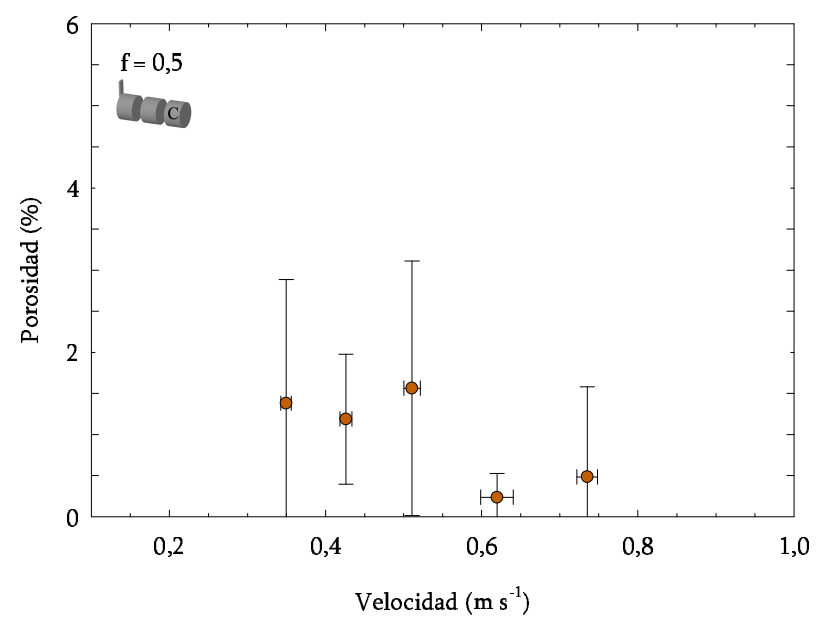

Figura 4.30: Porosidad media e intervalos de confianza del 95\% en función de la velocidad máxima del pistón en la parte "C" con $f=0,5$.

del flujo al indicado en la Figura 4.31(a) es el responsable del nivel de porosidad, relativamente alto, medido en las partes B y C con velocidades del pistón moderadamente bajas, para las que la porosidad en la parte A es baja.

La fotografía mostrada en la Figura 4.32, muestra una sección longitudinal de una pieza inyectada con una fracción del $f=0,374$ y una velocidad de 0,31 $\mathrm{ms}^{-1}$ donde se puede apreciar una mayor porosidad localizada en la parte en contacto con el pistón (parte C). En el caso de la Figura 4.33, se muestra una sección de una pieza fabricada con la misma fracción $(f=0,374)$ pero con una velocidad de $0,73 \mathrm{~ms}^{-1}$. En este caso se puede apreciar como la porosidad se desplaza hacia la zona alejada del pistón (parte A) lo que sugiere un mecanismo de atrapamiento de aire como el indicado en la Figura 4.31(b). Las Figuras 4.34 y 4.35 muestran una radiografía y un fotografía, respectivamente, de dos piezas diferentes fabricadas con $f=0,5$ y una velocidad del pistón elevada. En el caso de la Figura 4.35, se detuvo el pistón cuando el metal alcanzó en canal de colada. En todos estos casos, se ha podido verificar como con velocidades superiores a la crítica se incrementa la cantidad de aire atrapado por mecanismos como el indicado anteriormente.

Como puede observarse, el resultado obtenido mediante la visualización de estas secciones concuerda totalmente con los datos mostrados en las figuras anteriores. La localización de las zonas de aire atrapado en estas cuatro figuras son consistentes con los resultados de la serie de figuras de distribución de la porosidad.

Las imágenes obtenidas de las secciones longitudinales de las piezas han permitido analizar la morfología de la porosidad encontrada. Como ejemplo, se 


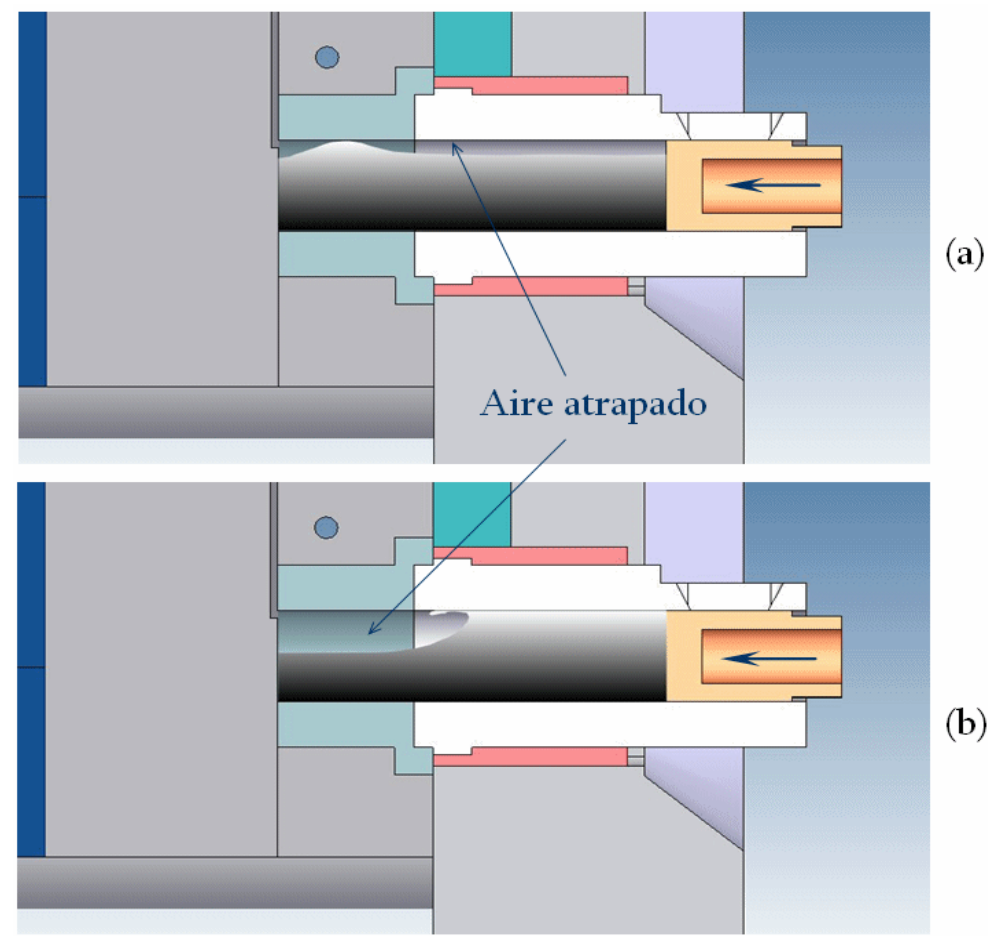

Figura 4.31: Mecanismos de atrapamiento de aire en la etapa lenta con una velocidad máxima del pistón (a) inferior y (b) superior a la óptima. 


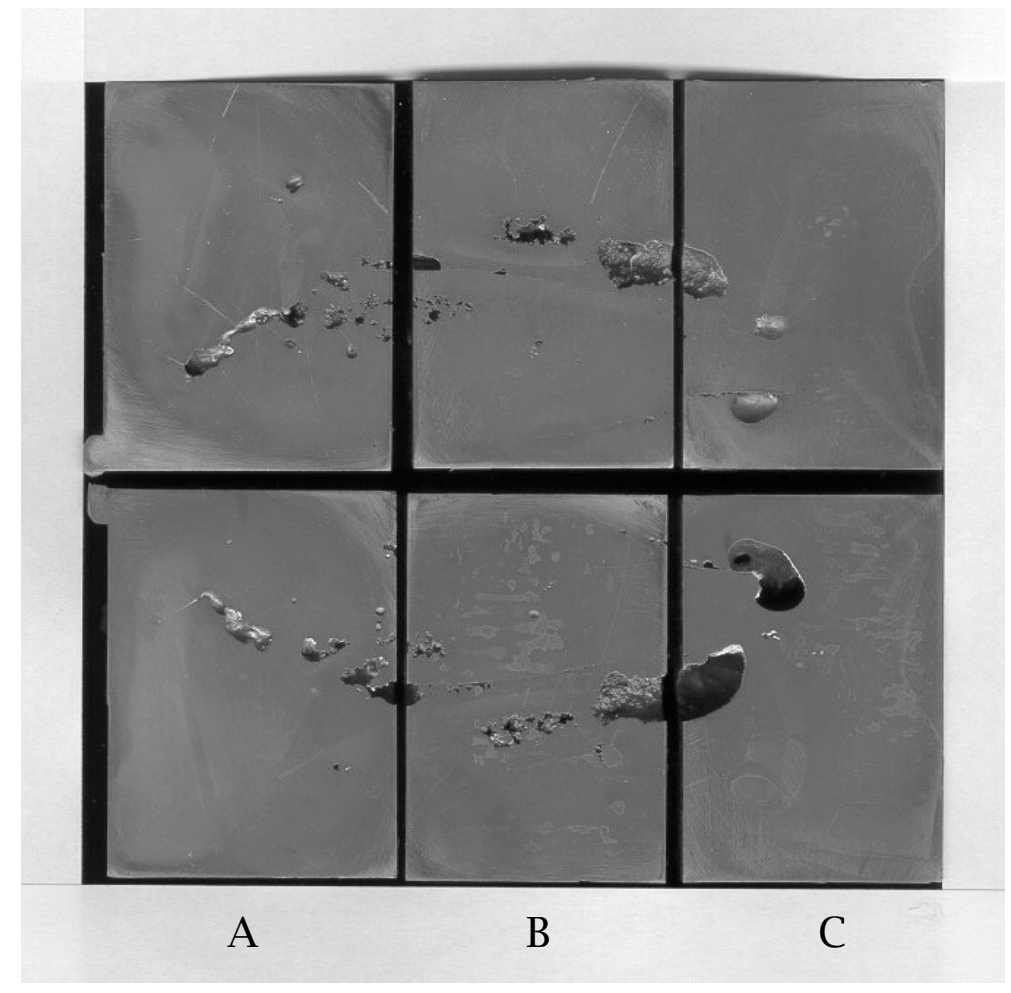

Figura 4.32: Sección longitudinal de una pieza previamente seccionada transversalmente, obtenida con velocidad máxima del pistón de $0,31 \mathrm{~ms}^{-1}$. 


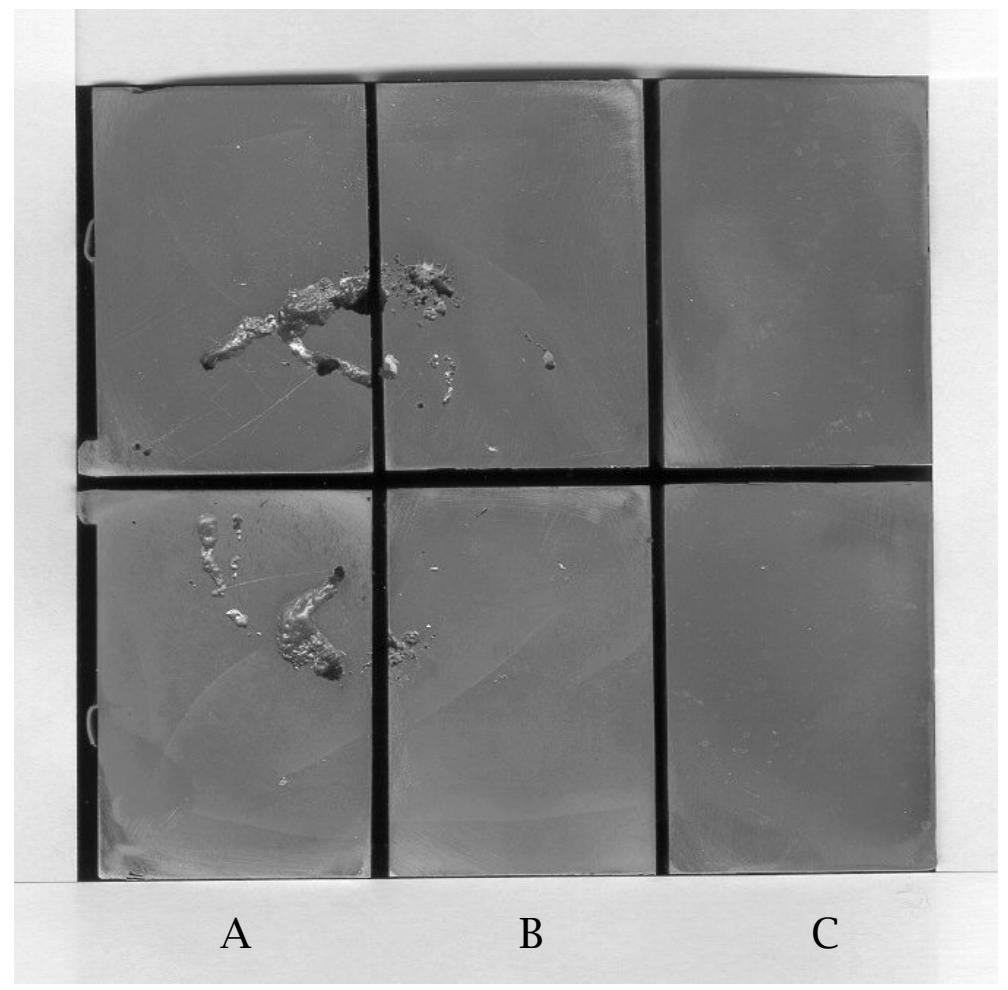

Figura 4.33: Sección longitudinal de una pieza previamente seccionada transversalmente, obtenida con velocidad máxima del pistón de $0,73 \mathrm{~ms}^{-1}$.

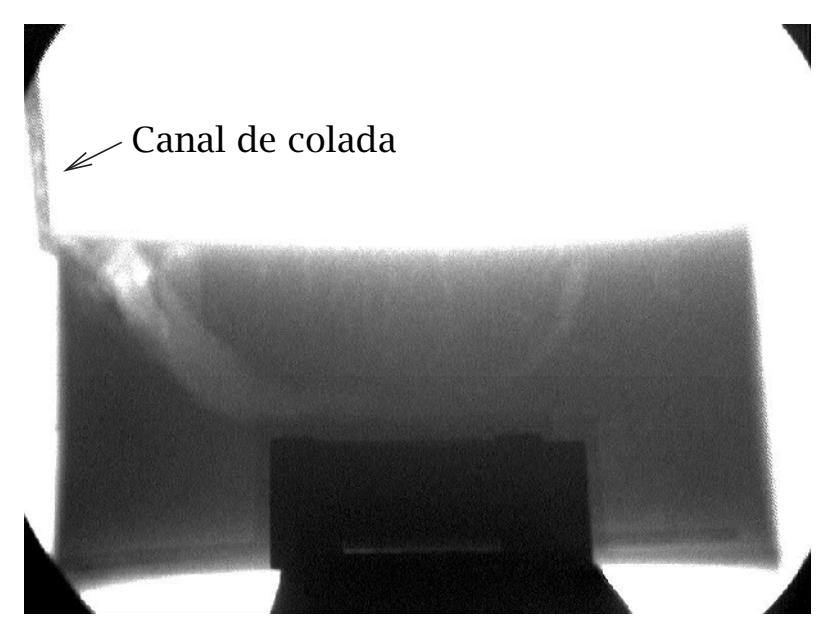

Figura 4.34: Fotografía de Rayos-X de una pieza fabricada con $f=0,5$ y una velocidad del pistón elevada. 


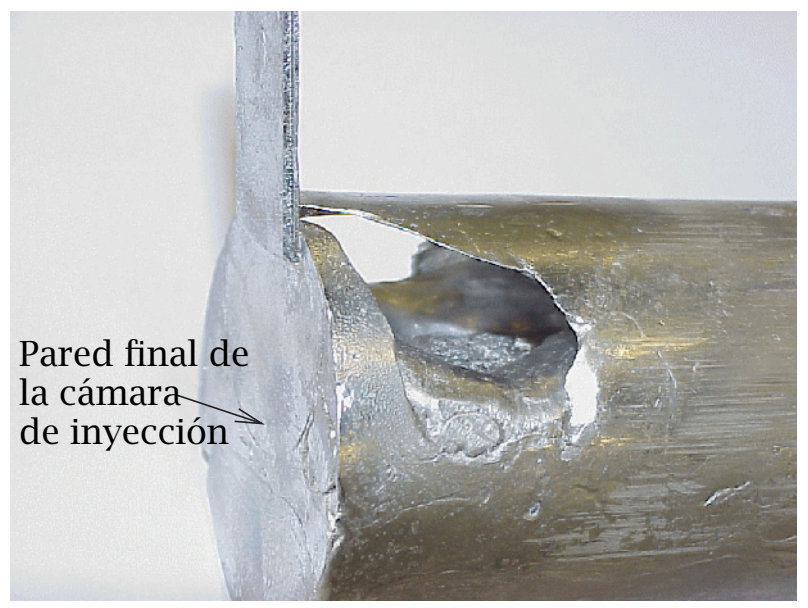

Figura 4.35: Fotografía de una pieza fabricada con $f=0,5$ y una velocidad del pistón elevada.

muestra una ampliación de la Figura 4.33 en la Figura 4.36, en la que se puede observar que, según lo comentado en el Capítulo 1, aparece porosidad por atrapamiento en la parte más aleja del pistón mientras que la porosidad de la parte central de la pieza correspondería, como es de esperar, a porosidad por contracción.

\subsubsection{Comparación con los resultados obtenidos con agua}

La existencia de gas a presiones desconocidas dificulta la valoración cuantitativa de la cantidad de gas atrapado en piezas de aluminio mediante el método gravimétrico. No obstante, como se ha comentado con anterioridad, es sencillo calcular el volumen de aire a presión atmosférica que correspondería a la medida de porosidad obtenida. Según esto, y partiendo de la información recogida en el capítulo anterior sobre el volumen de aire atrapado en experimentos con analogía con agua, es posible realizar una comparación de los resultados del volumen de gas atrapado en ambos casos bajo condiciones de inyección similares en cuanto a ley de movimiento empleada (véase la Figura 4.37).

A la hora de elegir el factor de escala para representar el volumen de aire atrapado en el caso de piezas aluminio, se ha utilizado como referencia un valor tal que permite comparar los valores mínimos de aire atrapado en los experimentos con agua.

Como era de esperar, las cantidades de aire atrapadas en los experimentos con agua son muy superiores a las calculadas para el aluminio debido al efecto de la presión. De cualquier modo, se puede observar como a pesar de las diferencias en valor absoluto, existe coincidencia en los valores de velocidad que minimizan las cantidades de aire atrapado aunque en los experimentos con aluminio, a pesar de encontrar valores mínimos, no aparecen valores nulos de aire atrapado. Cabe recordar que la incertidumbre experimental es mucho mayor en 

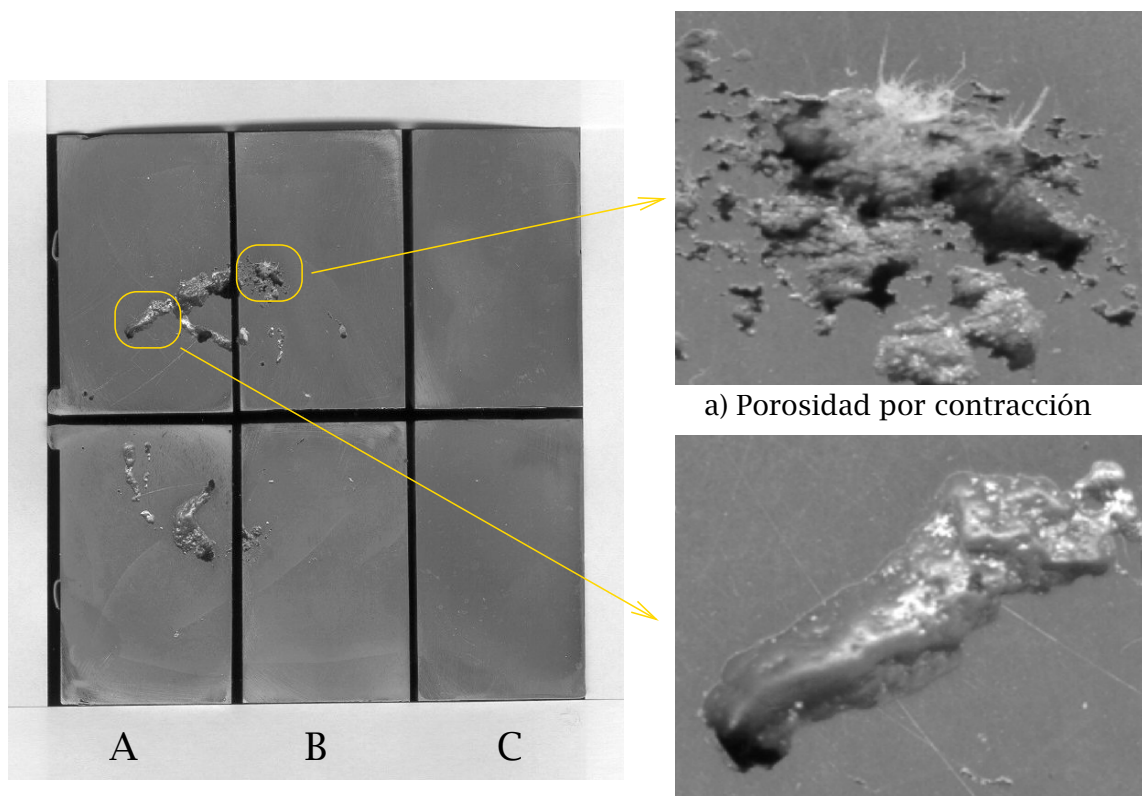

a) Porosidad por contracción

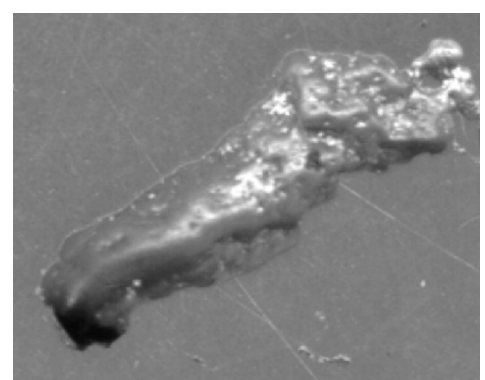

b) Porosidad por gas atrapado

Figura 4.36: Identificación de porosidad por contracción y por gas atrapado en zonas A y B de la pieza presentada en la Figura 4.33.

el caso de los experimentos realizados con aluminio y que hay que tener en cuenta el efecto de otras fuentes de porosidad ya comentadas como por ejemplo la porosidad por contracción.

\subsection{Resultados preliminares obtenidos con el sistema de fusión al vacío}

Para destacar la dificultad que presenta el método gravimétrico para determinar cuantitativamente la masa total de aire atrapado, algunas de las piezas obtenidas de sometieron a un tratamiento térmico que consistió en el calentamiento controlado a una temperatura de $540^{\circ} \mathrm{C}$ (unos $30^{\circ} \mathrm{C}$ por debajo del punto de fusión de la aleación) mantenida durante 2 horas. Para cada una de las piezas objeto del ensayo se realizó una medición de porosidad previa y otra posterior al tratamiento térmico mediante el método gravimétrico, pudiéndose comprobar, como muestran los resultados expresados en la Tabla 4.15, un aumento de la porosidad medio del 0,5\% debido a la expansión del gas atrapado durante el tratamiento térmico lo que demuestra la influencia de la presión del gas atrapado en el resultado final de porosidad obtenido con este método. La figura 4.38 muestra, como ejemplo, varias piezas en las que el aumento del volumen de los poros de gas cercanos a la superficie de la pieza se puede observar a simple vista.

Para evitar los efectos de la presión podría ser muy adecuado el uso del sis- 


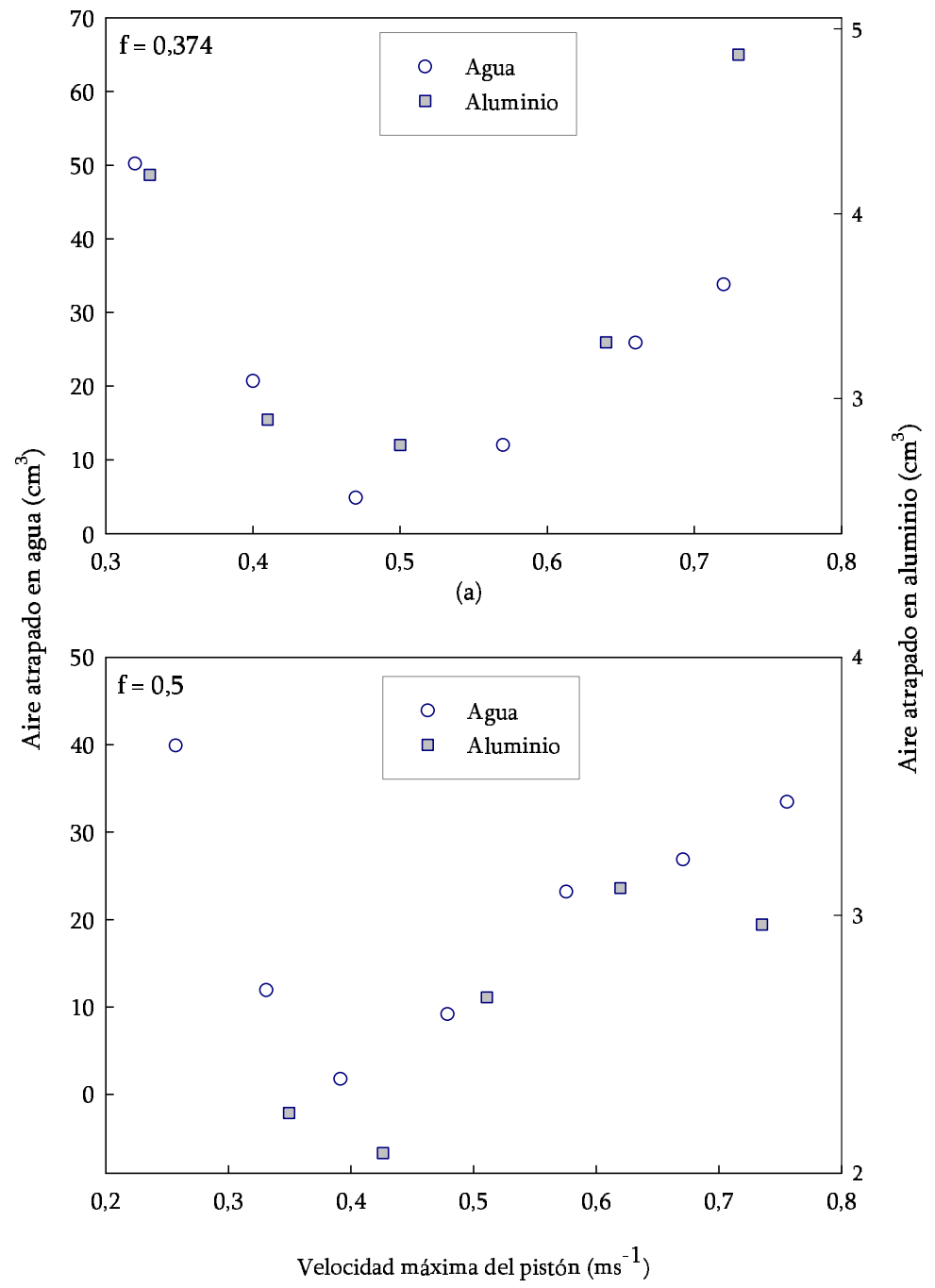

(b)

Figura 4.37: Comparativa de valores calculados de volumen de aire atrapado para ensayos realizados con una fracción inicial de llenado (a) $f=0,374$ y (b) $f=0,5$ en experimentos en máquina FIAP, con agua y con aluminio. 


\begin{tabular}{|c|c|c|}
\hline \multicolumn{3}{|c|}{ Porosidad (tratamiento térmico) } \\
\hline Previa & Posterior & Variación \\
\hline $0,00 \%$ & $0,60 \%$ & $+0,60 \%$ \\
\hline $0,04 \%$ & $0,41 \%$ & $+0,37 \%$ \\
\hline $0,07 \%$ & $0,41 \%$ & $+0,34 \%$ \\
\hline $0,11 \%$ & $0,67 \%$ & $+0,56 \%$ \\
\hline $0,49 \%$ & $0,52 \%$ & $+0,04 \%$ \\
\hline $0,63 \%$ & $1,04 \%$ & $+0,41 \%$ \\
\hline $0,67 \%$ & $0,82 \%$ & $+0,15 \%$ \\
\hline $2,61 \%$ & $3,69 \%$ & $+1,08 \%$ \\
\hline $8,73 \%$ & $9,70 \%$ & $+0,97 \%$ \\
\hline \multicolumn{2}{|c|}{ Media } & $+0,50 \%$ \\
\hline
\end{tabular}

Tabla 4.15: Medidas de porosidad en una serie de piezas antes y después de sufrir el proceso de calentamiento.
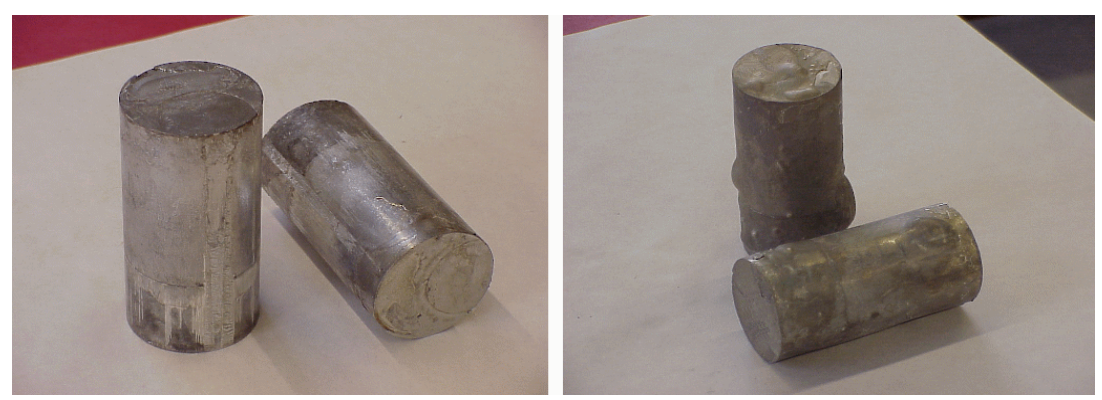

Figura 4.38: Ejemplo del efecto del tratamiento térmico sobre piezas fabricadas. 


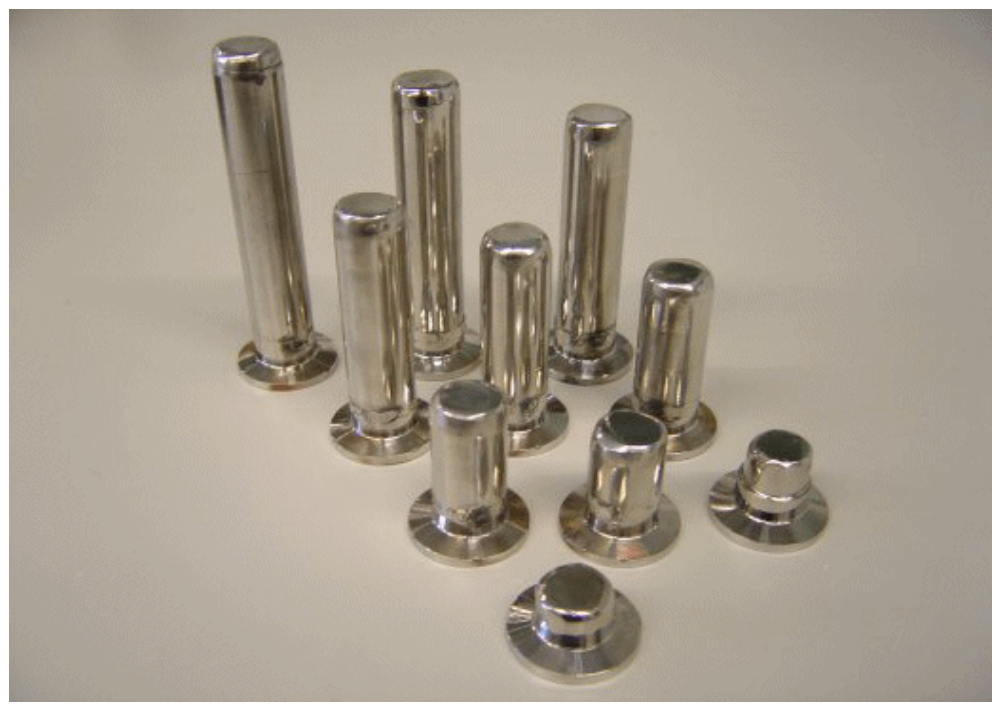

Figura 4.39: Conjunto de probetas fabricadas para la calibración del sistema.

tema de fusión al vacío descrito en el Capítulo 2.

\subsubsection{Pruebas de calibración y ensayos preliminares}

Como se ha comentado, el sistema construido permite registrar las variaciones de presión que se producen como consecuencia de la liberación del gas atrapado cuando se funden, en una cámara de vacío, las piezas de aluminio fabricadas. Según las características del sistema de fusión desarrollado, el gas liberado en el interior de la cámara de vacío se encuentra con un gradiente térmico muy importante ya que las paredes de la cámara deben estar refrigeradas. Esto dificulta la estimación de la masa de aire liberado al no conocer con precisión la distribución de temperaturas existente en el interior de la cámara. Por lo tanto, es necesario calibrar el equipo liberando cantidades de gas conocidas. Este proceso ha requerido la fabricación de una serie de probetas (Figura 4.39) que, una vez conectadas a la cámara de vacío mediante una válvula manual, permiten liberar en la cámara cantidades de aire conocidas (véase la Tabla 4.16).

En primer lugar se han realizado ensayos ${ }^{4}$, realizados a temperatura ambiente. En la Figura 4.40 se puede observar el incremento de presión medido en función del volumen de gas liberado en frío. Cada punto representado corresponde a la media de los valores de incremento de presión registrados en tres ensayos consecutivos repetidos en idénticas condiciones. Como puede observarse existe una excelente relación lineal que muestra valores muy cercanos a las determinadas teóricamente (obviamente, en este caso el gradiente térmico es prácticamente despreciable).

\footnotetext{
${ }^{4}$ La presión inicial en la cámara para realizar todos los ensayos de calibración fue de 0,188 Torr
} 


\begin{tabular}{|c|c|}
\cline { 2 - 2 } \multicolumn{1}{c|}{} & $\begin{array}{c}\text { Volumen de la } \\
\text { probeta }\left(\mathrm{cm}^{3}\right)\end{array}$ \\
\hline 1 & 5,93 \\
\hline 2 & 6,38 \\
\hline 3 & 8,36 \\
\hline 4 & 10,42 \\
\hline 5 & 12,54 \\
\hline 6 & 14,26 \\
\hline 7 & 16,36 \\
\hline 8 & 18,49 \\
\hline 9 & 20,43 \\
\hline 10 & 22,86 \\
\hline
\end{tabular}

Tabla 4.16: Volumen de las probetas utilizadas en la calibración del sistema de fusión al vacío.

Posteriormente se han repetido los ensayos liberando el gas mientras un termopar colocado en la zona que ocuparía la pieza se encontraba entorno a los $545^{\circ} \mathrm{C}$. En la Figura 4.40 también se incluye la relación obtenida en los ensayos en caliente. En cualquier caso se observa una excelente linealidad.

La Figura 4.41 muestra un ejemplo de la fusión de una pieza. Se puede apreciar claramente como, en un cierto instante, se produce un incremento de presión de unos 0,208 Torr teniendo en ese momento una lectura de un termopar colocado en el interior del horno de $638^{\circ} \mathrm{C}$. Para conocer la cantidad de gas que supone ese incremento de presión será necesario realizar una curva de calibración en la que la liberación de las probetas a esta temperatura. Como se espera que durante los diversos ensayos de fusión se registren diferentes incrementos de presión a diferentes temperaturas, será necesario realizar una serie de curvas de calibración que incluyan dicho rango de temperaturas.

\subsection{Conclusiones}

Se han realizado experimentos en una máquina FIAP en condiciones reales de producción que han permitido determinar velocidades óptimas del pistón que minimizan el atrapamiento de aire durante la etapa lenta. El estudio realizado valida las predicciones analíticas y numéricas previas. Así mismo se ha verificado que tanto la porosidad mínima como la velocidad óptima del pistón se incrementan conforme disminuye la fracción inicial de llenado. También se ha investigado la dependencia de la distribución espacial del aire atrapado en el metal fundido en función de la velocidad máxima del pistón. A pesar de las limitaciones que presenta el sistema de control de inyección a la hora de reproducir con precisión 


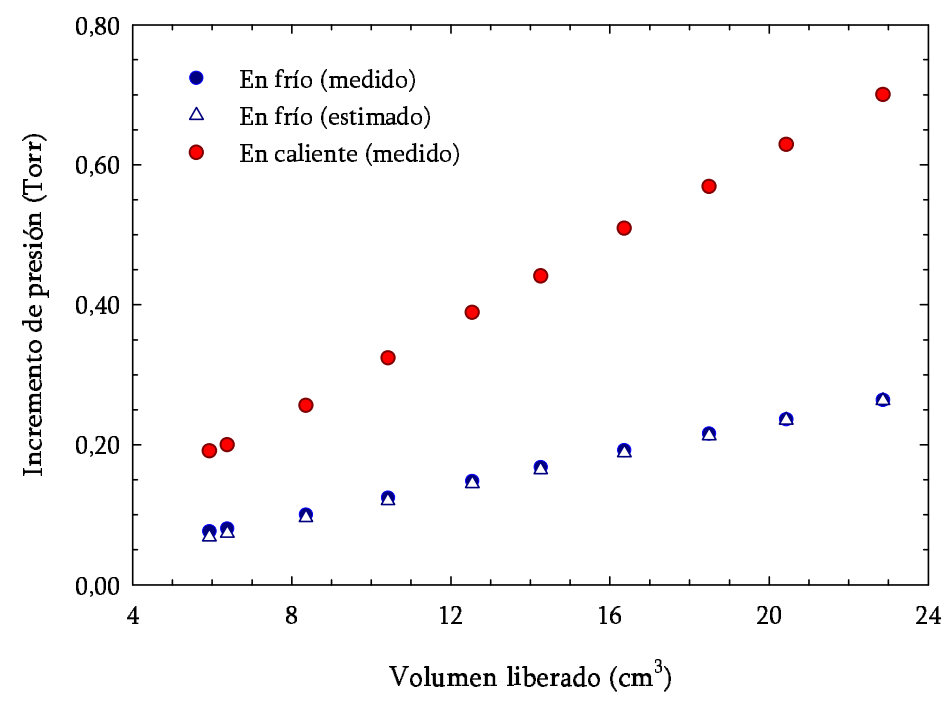

Figura 4.40: Incrementos de presión medidos en función del volumen de gas liberado (en frío $\mathrm{T}=20^{\circ} \mathrm{C}$, en caliente $\mathrm{T}=545^{\circ} \mathrm{C}$ ).

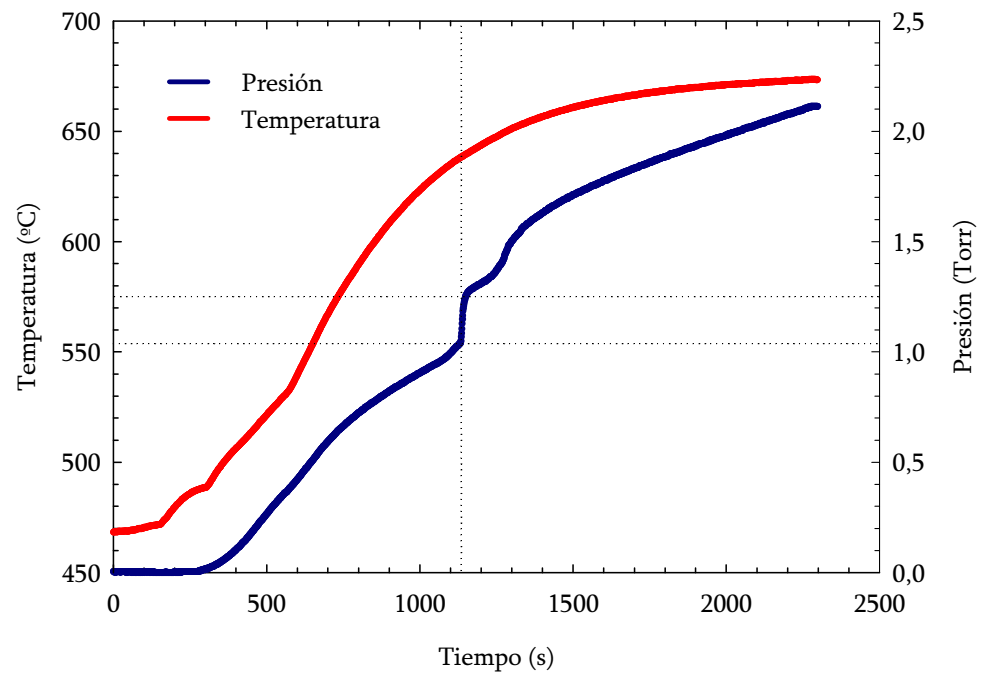

Figura 4.41: Registro de presión y temperatura durante un ensayo preliminar de la fusión una pieza FIAP. 
la ley de movimiento del pistón deseada y la presión final en la cámara, las incertidumbres debidas al procedimiento manual de colada del metal fundido y los efectos de la contracción, los resultados sobre la distribución de la porosidad en las diferentes zonas de la cámara de inyección permiten verificar los mecanismos de atrapamiento de aire que están descritos teóricamente para estos casos.

Finalmente se ha realizado la calibración del sistema de fusión al vacío mediante la liberación de cantidades de gas conocidas en diferentes condiciones de temperatura observándose una buena linealidad en el comportamiento. Se ha realizado un ensayo preliminar de fusión al vacío donde se observa un incremento de presión durante la fusión debido a la liberación de gas atrapado en la pieza. 


\section{A P Í T U L O 5}

\section{Conclusiones finales}

En la presente tesis se ha realizado un estudio experimental sobre el atrapamiento de aire en el metal fundido que tiene lugar en la cámara de inyección de máquinas de fundición por inyección a presión. Este estudio se ha basado, principalmente, en dos tipos de ensayos realizados en una máquina FIAP industrial (con agua y con aluminio) así como en los realizados en una instalación experimental que permite la visualización del flujo de agua en un modelo de cámara de inyección. Utilizando una metodología similar en todos los ensayos y teniendo en cuenta los resultados predichos por los modelos analíticos y numéricos desarrollados en trabajos anteriores del grupo de investigación, se ha llevado a cabo un análisis de distintas condiciones de operación que ha permitido concluir, de forma general, que los valores de las variables de proceso y de diseño obtenidas mediante los mencionados modelos, optimizan el proceso minimizando la aparición de porosidad debida al atrapamiento de aire durante la etapa lenta de inyección.

El estudio experimental en una máquina industrial ha permitido conocer, por un lado, las limitaciones de este tipo de máquinas a la hora de configurar la ley de movimiento del pistón durante la inyección y, por otro, la muy baja repetibilidad de los sistemas de inyección. Cabe destacar que gran parte del mercado mundial de maquinaria FIAP industrial presenta prestaciones muy similares a las de la máquina utilizada, lo que explica el escaso conocimiento que se tiene a nivel industrial sobre la influencia de la primera etapa de inyección en el atrapamiento de aire. Una gran parte de estos problemas se han solucionado o paliado en este trabajo mediante la sustitución del transductor de recorrido analógico por uno digital, así como desarrollando nuevas aplicaciones de software que aumentan las posibilidades de parametrización. Los ensayos realizados con posterioridad han mostrado la mejora de la repetibilidad, aunque persiste una cierta variabilidad debida principalmente a la configuración en lazo abierto del sistema de control, que no es capaz de ajustar y corregir los factores que afectan al funcionamiento del sistema hidráulico, tales como las temperaturas, los coeficientes de rozamiento o la propia variabilidad en el comportamiento de la válvula principal de descarga. Cabe también destacar los problemas que supone ajustar los 
parámetros de inyección de la máquina (información de posición y apertura de válvula asociada) para que el movimiento del pistón se realice según una determinada ley de movimiento.

Una importante aportación de la presente tesis es el desarrollo e implementación de aplicaciones de control del proceso de inyección que permiten facilitar extraordinariamente las tareas de configuración y control de las inyecciones realizadas en máquinas FIAP, ofreciendo información muy aproximada sobre la posible configuración de los parámetros de inyección requeridos, así como un criterio de rechazo que permite detectar las inyecciones que no se han realizado conforme a la ley de movimiento deseada según un determinado criterio. La presente tesis también ha permitido resolver problemas tecnológicos de cierta importancia. Por ejemplo, la influencia que puede tener la elección del periodo de diferenciación utilizado en el método de cálculo de las velocidades del pistón a partir de la información de posición del mismo, sobre el cálculo de la velocidad máxima alcanzada.

Previamente a los ensayos realizados con aleación de aluminio, se ha realizado la verificación de un código numérico comparando sus predicciones sobre los mecanismos de atrapamiento de aire con las de un modelo analítico más sencillo. También se han comparado los resultados numéricos con los experimentales obtenidos utilizando agua como material de trabajo, tanto en la máquina FIAP como en un banco de ensayos de visualización del flujo. La resolución numérica del problema se ha realizado mediante el código de elementos finitos mencionado, con el que se determinó la posición de la superficie libre en cada instante mediante el método "VOF", mientras que los resultados analíticos se han obtenido utilizando un modelo simple basado en una aproximación unidimensional de aguas poco profundas. La comparación de ambos tipos de resultados muestra un elevado grado de acuerdo entre los perfiles de la superficie libre mencionados, aunque cabe destacar que, según el modelo analítico, para condiciones de inyección que provocan una reflexión relativamente intensa de la ola contra la pared final de la cámara, el fluido alcanza el canal de colada con una ligera anticipación, debido precisamente a esta reflexión. Esta anticipación provoca que el modelo analítico prediga, en general, un mayor atrapamiento de aire en la cámara que el modelo numérico.

En cuanto a los ensayos en máquina FIAP, se ha calculado el volumen de aire restante en la cámara de inyección en el momento en el que el fluido alcanza el canal de colada. Para ello se ha construido un dispositivo de fácil montaje que permite la detección del paso del agua mediante un transductor fotoeléctrico. Como se ha comprobado, es preciso realizar una calibración muy rigurosa de los tiempos de respuesta del sistema de control establecido, debido a las altas velocidades de inyección requeridas. Así mismo, también se ha comprobado la ineficacia de utilizar tintes en el agua para su detección con el dispositivo diseñado. Este estudio se ha realizado utilizando la ley de aceleración del pistón propuesta por el grupo de investigación para diferentes velocidades máximas y 
diferentes fracciones iniciales de llenado de la cámara. Del estudio realizado se puede concluir que en todos los casos existe una velocidad máxima óptima para la cual se minimiza, o incluso se llega a eliminar, el volumen de aire atrapado en la cámara de inyección. Así mismo, tal y como predecían los modelos teóricos, se ha podido verificar experimentalmente que la velocidad óptima decrece conforme aumenta la fracción inicial de llenado de la cámara.

En los ensayos de visualización del flujo de agua en un modelo de cámara se ha utilizado una cámara de vídeo de alta velocidad con la que se ha registrado la evolución de la superficie libre del fluido bajo las diferentes condiciones experimentales. El cálculo del volumen de aire atrapado se ha realizado a partir del instante correspondiente al fotograma en el que se observa que el fluido alcanza el canal de colada. En el estudio comparativo entre los resultados numéricos y los ensayos de visualización se han conseguido resultados con una excelente concordancia, exceptuando los casos en los que la velocidad máxima del piston es elevada, donde la formación del chorro de pared formado en el techo de la cámara requiere un análisis numérico más detallado.

Los ensayos realizados con aleación de aluminio en máquina FIAP han permitido determinar la existencia de una velocidad máxima del pistón que minimiza la cantidad de aire atrapado para diferentes fracciones iniciales de llenado, utilizando la ley de aceleración comentada con anterioridad. Estos resultados concuerdan muy satisfactoriamente con los resultados analíticos, numéricos y experimentales obtenidos con las mismas condiciones de operación, resultando que, como se ha comentado, la porosidad en las piezas de aluminio inyectadas en máquinas FIAP de cámara fría, atribuibles a la etapa lenta de inyección, disminuye conforme aumenta la fracción inicial de llenado. Así mismo, las velocidades óptimas que minimizan esta porosidad se corresponden con las predicciones de los modelos teóricos.

La comparación entre los resultados experimentales de los ensayos realizados en la máquina FIAP, tanto con agua como con aluminio, han permitido confirmar que, a pesar de las diferencias obtenidas en los valores absolutos de cantidad de aire atrapado, existe una concordancia muy buena en los valores de la velocidad crítica obtenidos en ambos casos. Otro de los resultados de la presente tesis es el relativo a la distribución de la porosidad en las diferentes zonas de la cámara de inyección. Al respecto se han podido confirmar experimentalmente los distintos mecanismos de atrapamiento de aire que se espera que ocurran en los rangos de velocidad del pistón correspondientes.

En cuanto a los métodos de evaluación de porosidad, se han hecho evidentes las carencias del método gravimétrico, que por otra parte es el más comúnmente utilizado. En el caso de los procesos FIAP, el efecto que la presión del gas atrapado ejerce sobre las medidas de porosidad hace que sea más indicado utilizar otras técnicas como la de fusión al vacío. Al no existir en el mercado equipos apropiados para realizar los ensayos requeridos, se ha diseñado y construido un sistema de fusión al vacío que ha sido calibrado, tanto en frío como a una 
temperatura próxima a las condiciones de fusión, mediante la liberación en su interior de cantidades de gas conocidas. Finalmente, se han realizado ensayos preliminares que permiten presentar un primer ejemplo de cómo la fusión de la pieza en el sistema de fusión al vacío ha permitido registrar incrementos de presión atribuibles a la liberación del gas atrapado en la pieza durante la etapa lenta de inyección.

\subsection{Desarrollos futuros}

Para llevar a cabo el estudio experimental desarrollado en esta tesis ha sido necesario efectuar mejoras sustanciales en el sistema de control de la máquina FIAP, lo que ha permitido reducir considerablemente los errores de posición del pistón aumentando así la repetibilidad de los ensayos. En el futuro sería recomendable la instalación de un sistema de control en bucle cerrado que permitiera incrementar aún más la repetibilidad de los ensayos, con lo que se espera que mejorarían los intervalos de incertidumbre de los experimentos realizados con aluminio y aumentaría el número de experimentos, incluyendo diferentes leyes de aceleración o modificaciones de la geometría de la cara de los pistones y de la parte final de la cámara de inyección, entre otros. Con respecto a los ensayos de visualización, aunque los resultados obtenidos concuerdan muy satisfactoriamente con las predicciones numéricas, sería interesante el uso de un sistema láser que permita obtener de una forma más precisa la forma de la superficie libre del líquido en diferentes secciones de la cámara.

En cuanto al sistema de fusión al vacío, sería necesario ampliar el rango de temperaturas de su calibración así como con la posterior correlación entre incrementos de presión y cantidad de aire atrapado en las piezas fundidas.

Todo el trabajo presentado en esta tesis se ha centrado en la etapa lenta del proceso, aunque el equipamiento experimental desarrollado se ha diseñado teniendo en cuenta el estudio de las etapas de inyección posteriores. De esta forma, se dispone del equipo necesario para llevar a cabo en el futuro un estudio experimental de la segunda etapa del proceso de inyección. 


\section{A NEXOA \\ Método gravimétrico basado en el principio de Arquímedes}

La gravedad específica de un sólido se puede determinar, si se conoce la densidad del líquido desalojado, mediante el uso de una balanza hidrostática que permita pesar el sólido en aire así como sumergido en agua.

La gravedad específica de la muestra sólida se determina por medio de la ecuación:

$$
\rho=\frac{W_{a} \times \rho_{f l}}{W_{a}-W_{f l}},
$$

De forma similar, es posible determinar la densidad de un líquido mediante la ecuación

donde:

$$
\rho_{f l}=\frac{G}{V}
$$

$\rho=$ gravedad específica del sólido

$\rho_{f l}=$ densidad del líquido

$W_{a}=$ peso de la muestra en el aire

$W_{f l}=$ el peso de la muestra y la cesta en el agua

$G$ = fuerza vertical y hacia arriba del sólido sumergido

$V=$ volumen del sólido

\section{A.1. Fuentes de error y posibilidades para su corrección}

La fórmula mostrada anteriormente para determinar la gravedad específica de los sólidos es suficiente para obtener una precisión de $10 \times \mathrm{E}^{-1} \mathrm{o} 10 \times \mathrm{E}^{-2}$ unidades. Dependiendo de la precisión que se requiera, se pueden tener en cuenta las siguientes errores o factores de tolerancia:

- la densidad del líquido que provoca el empuje vertical ascendente depende de su temperatura, 
- el empuje vertical ascendente del aire cuando el sólido se pesa al aire,

- el cambio en el nivel de inmersión de la bandeja suspendida en la que se coloca la pieza sólida cuando se sumerge en el líquido,

- la adhesión del líquido sobre el cable de suspensión de la bandeja,

- las burbujas de aire en la muestra.

Algunos de estos errores se pueden corregir mediante el uso de la formulación adecuada midiendo la temperatura del líquido de referencia, corrigiendo su densidad de la forma adecuada, y definiendo el diámetro interior del recipiente que contiene el líquido de referencia.

Relación entre la densidad del líquido y la temperatura. La densidad del líquido que causa el empuje vertical ascendente depende de la temperatura. El cambio en la densidad por ${ }^{\circ} \mathrm{C}$ está en el rango de:

- 0,02\% para agua destilada

- 0,1\% para alcoholes e hidrocarburos

En otras palabras, esto puede permitir el llegar a obtener un tercer decimal en la determinación de la gravedad específica/densidad.

Para corregir la densidad del líquido por temperatura se pueden utilizar tablas densidad/temperatura en las que se muestra la densidad de los líquidos más utilizados normalmente (agua o etanol), a distintas temperaturas y proceder como sigue:

1. medir la temperatura del líquido usando un termómetro y

2. encontrar en la tabla densidad/temperatura, para la temperatura medida, la densidad del líquido que luego se utilizará para el valor de $\rho_{f l}$.

Empuje vertical ascendente del aire. Un volumen de $1 \mathrm{~cm}^{3}$ de aire tiene un peso de aproximadamente 1,2 $\mathrm{mg}$, dependiendo de su temperatura, humedad y presión. Cuando se pesa en aire, un solido es empujado verticalmente (y hacia arriba) por una fuerza por $\mathrm{cm}^{3}$ correspondiente a su volumen. El error que resulta si no se tiene en cuenta el empuje correspondiente al aire desocupado aparece en la tercera cifra decimal, y por lo tanto debería corregirse cuando se pretenda tener esta apreciación en la medida.

La siguiente ecuación tiene en cuenta el empuje debido al aire desalojado:

$$
\rho=\frac{W_{a} \times\left(\rho_{f l}-\rho_{a}\right)}{W_{a}-W_{f l}}+\rho_{a}
$$

donde $\rho_{a}=0,0012 \mathrm{~g} \mathrm{~cm}^{-3}$ es la densidad del aire bajo condiciones estándar (temperatura de $20^{\circ} \mathrm{C}$ y presión de 101,325 $\mathrm{kPa}$ ). 
Profundidad de inmersión. En la balanza utilizada, la bandeja en la que se coloca y sumerge la muestra durante la pesada en líquido, está unida rígidamente a dos cables y sumergida aproximadamente $30 \mathrm{~mm}$ por debajo de la superficie del líquido. Puesto que la balanza se tara antes de cada medida, el empuje adicional causado por la pieza sumergida del dispositivo de medida no se tiene en cuenta en la determinación de la gravedad específica. Cuando una muestra sólida se pesa en un líquido, se desplazará un volumen de líquido, que se corresponde con el volumen de la muestra sólida. Esto causa que los cables de conexión del conjunto estén sumergidos a una mayor profundidad y que generen un empuje adicional que introduce errores en la determinación de la gravedad específica. Es posible corregir este error mediante el uso de la siguiente ecuación:

$$
\rho=\frac{W_{a} \times\left(\rho_{f l}-\rho_{a}\right)}{0,99983 \times\left(W_{a}-W_{f l}\right)}+\rho_{a}
$$

Para determinar el factor corrector de 0,99983 es necesario tener en cuenta que el empuje causado por los cables sumergidos depende de la altura $h$ que sube el líquido cuando se sumerge la muestra. Aquí la muestra de volumen $V_{p r}$ corresponde al volumen de líquido $V_{f l}$. El volumen de la muestra se determina midiendo el empuje. Así:

$$
V_{p r}=V_{f l}
$$

O

$$
\frac{W_{a}-W_{f l}}{\rho_{f l}}=\frac{\pi \times h \times D^{2}}{4} .
$$

Por lo tanto:

$$
h=\frac{4 \times\left(W_{a}-W_{f l}\right)}{\rho_{f l} \times \pi \times D^{2}}
$$

El empuje $A$ causado por los cables sumergidos es:

$$
A=2 \times \frac{\pi \times d^{2}}{4} \times h \times \rho_{f l}
$$

sustituyendo $h$ :

$$
\begin{gathered}
A=2 \times \frac{\pi \times d^{2} \times 4 \times\left(W_{a}-W_{f l}\right) \times \rho_{f l}}{4 \times \rho_{f l} \times \pi \times D^{2}} \\
A=2 \times \frac{d^{2}}{D^{2}} \times\left(W_{a}-W_{f l}\right)
\end{gathered}
$$

Para tener en cuenta el empuje de los cables, se debe restar el empuje $A$ causado por los cables sumergidos al empuje determinado para la muestra: $G=$ $W_{a}-W_{f l}$. El empuje corregido $A$ corr para usar en este cálculo es entonces: $G-A$. 


$$
\begin{gathered}
A_{\text {corr }}=\left(W_{a}-W_{f l}\right)-2 \times \frac{d^{2}}{D^{2}} \times\left(W_{a}-W_{f l}\right) \\
A_{\text {corr }}=\left[1-2 \times \frac{d^{2}}{D^{2}}\right] \times\left(W_{a}-W_{f l}\right)
\end{gathered}
$$

En el caso que nos ocupa, los valores que se utilizan en la ecuación anterior son $d=0,7 \mathrm{~mm}$ y $D=76 \mathrm{~mm}$ y el factor de corrección es:

$$
A_{\text {corr }}=1-2 \times \frac{d^{2}}{D^{2}}=1-2 \times \frac{0,7^{2}}{76^{2}}=0,99983
$$

Si se utilizaran dispositivos con otras dimensiones, se debería calcular de nuevo el factor de corrección.

Adhesión del líquido al soporte de inmersión. Cuando se sumerge el recipiente de la muestra en líquido, éste provoca un empuje vertical, el líquido asciende por el cable a causa de las fuerzas de adhesión y genera un peso adicional en el rango de unos pocos miligramos. Puesto que el recipiente que aloja la muestra está en el líquido y causa un empuje vertical tanto durante las pesadas en aire como en líquido, y el equilibro está tarado al principio de cada procedimiento de medida, el efecto del menisco se puede ignorar. Para reducir la tensión superficial y la fricción del líquido en el cable, es recomendable añadir al agua destilada utilizada unas gotas de detergente. A causa de la subida del líquido por el cable, el peso puede cambiar lentamente incluso después de que la lectura se estabilice. Por lo tanto la lectura se debe tomar inmediatamente después de la estabilización.

Burbujas de aire adheridas a la muestra. El error de medida causado por las burbujas de aire que se adhieren a la muestra se puede estimar de la siguiente manera: una burbuja de aire con un diámetro de $0,5 \mathrm{~mm}$ causa un empuje vertical menor de 0,1 mg cuando se sumerge en agua una muestra. Una burbuja de aire de $1 \mathrm{~mm}$ de diámetro provoca un empuje adicional de 0,5 $\mathrm{mg}$ y una de 2 mm aproximadamente un empuje adicional de 4,2 mg. Las burbujas más grandes se deben eliminar con una fina escobilla u otro utensilio. También se puede humedecer la muestra en un recipiente separado antes de pesarla. 


\section{A N EXOB}

\section{Planos del molde}

A continuación se incluye una selección de los planos constructivos del molde diseñado.

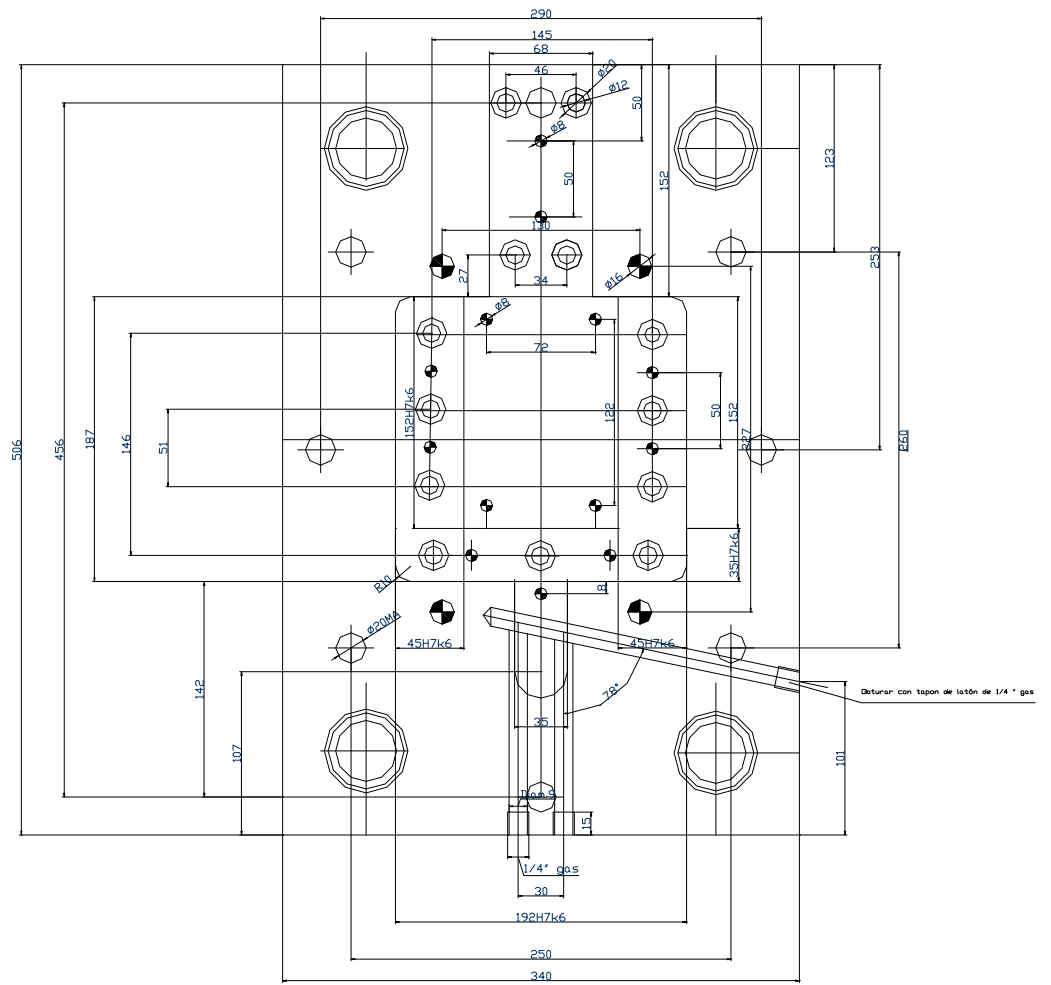

Figura B.1: Parte móvil. 


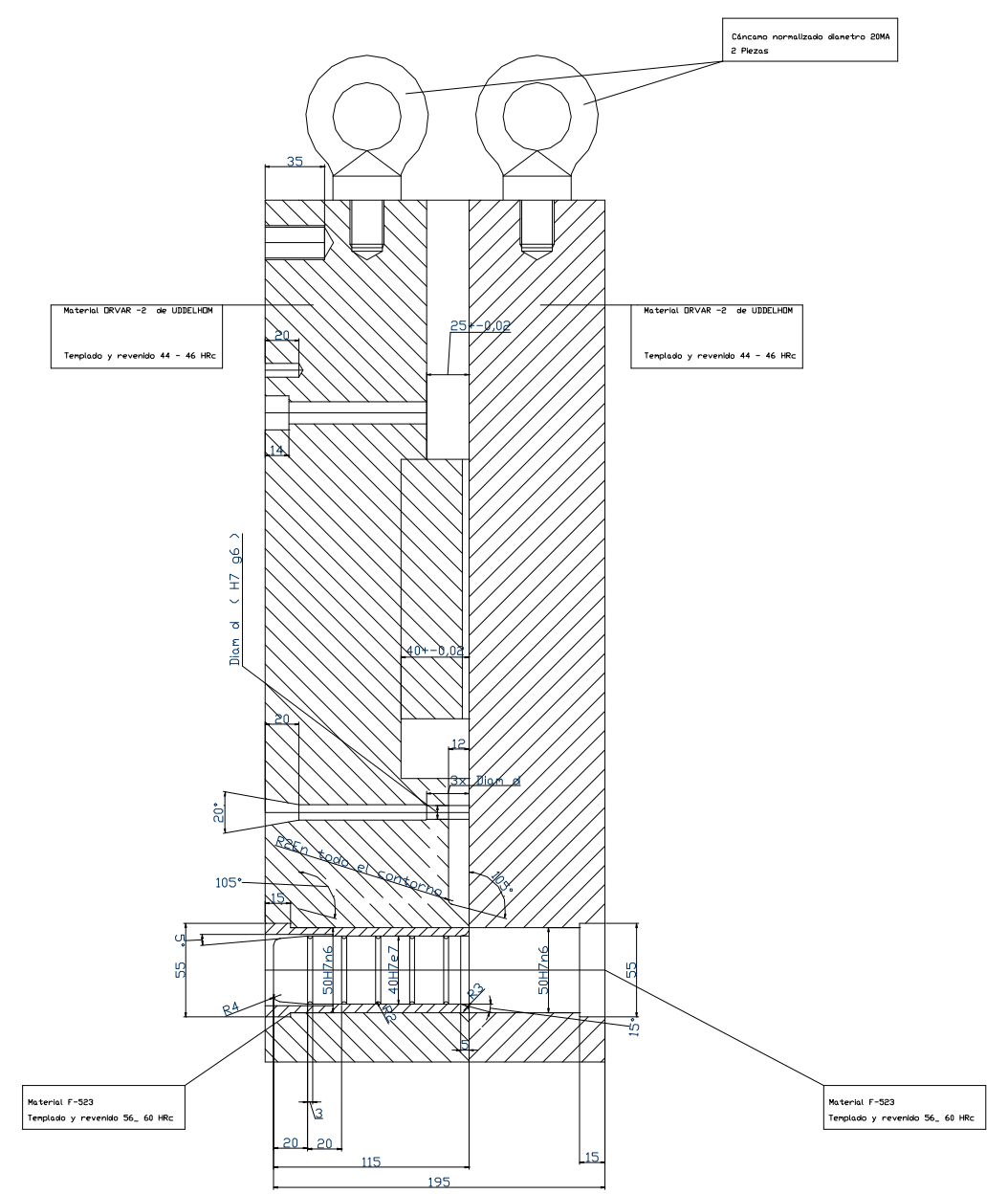

Figura B.2: Sección del molde completo (incluye pernos guía). 


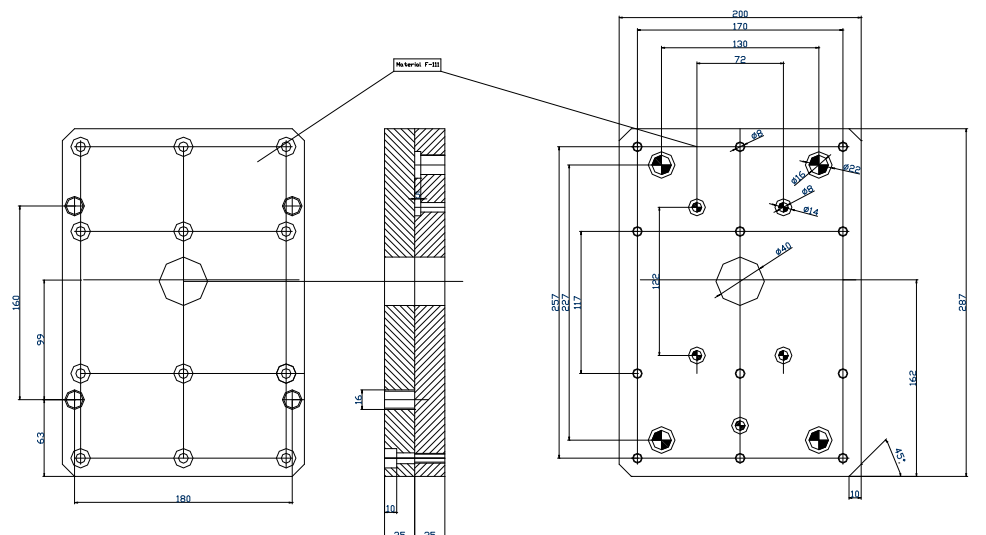

(a)
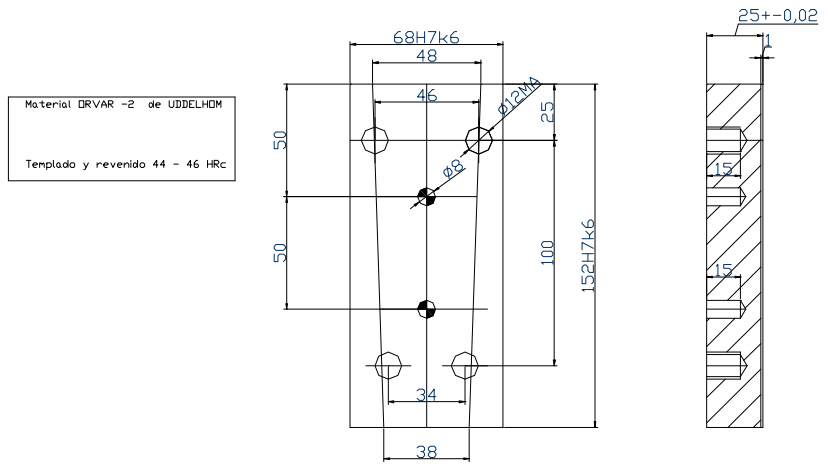

(b)
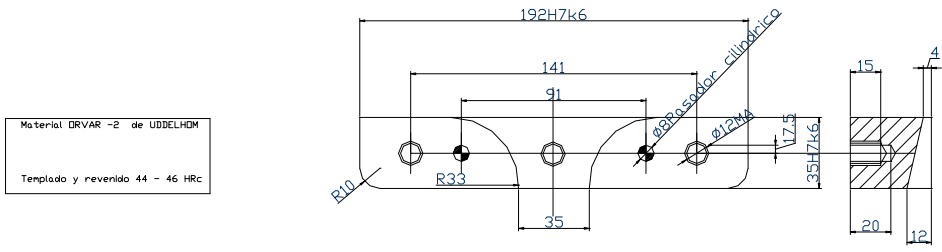

(c)

Figura B.3: (a) Placa de expulsores, (b) Pieza intercambiable para el viento, (c) Pieza intercambiable para el canal de colada. 


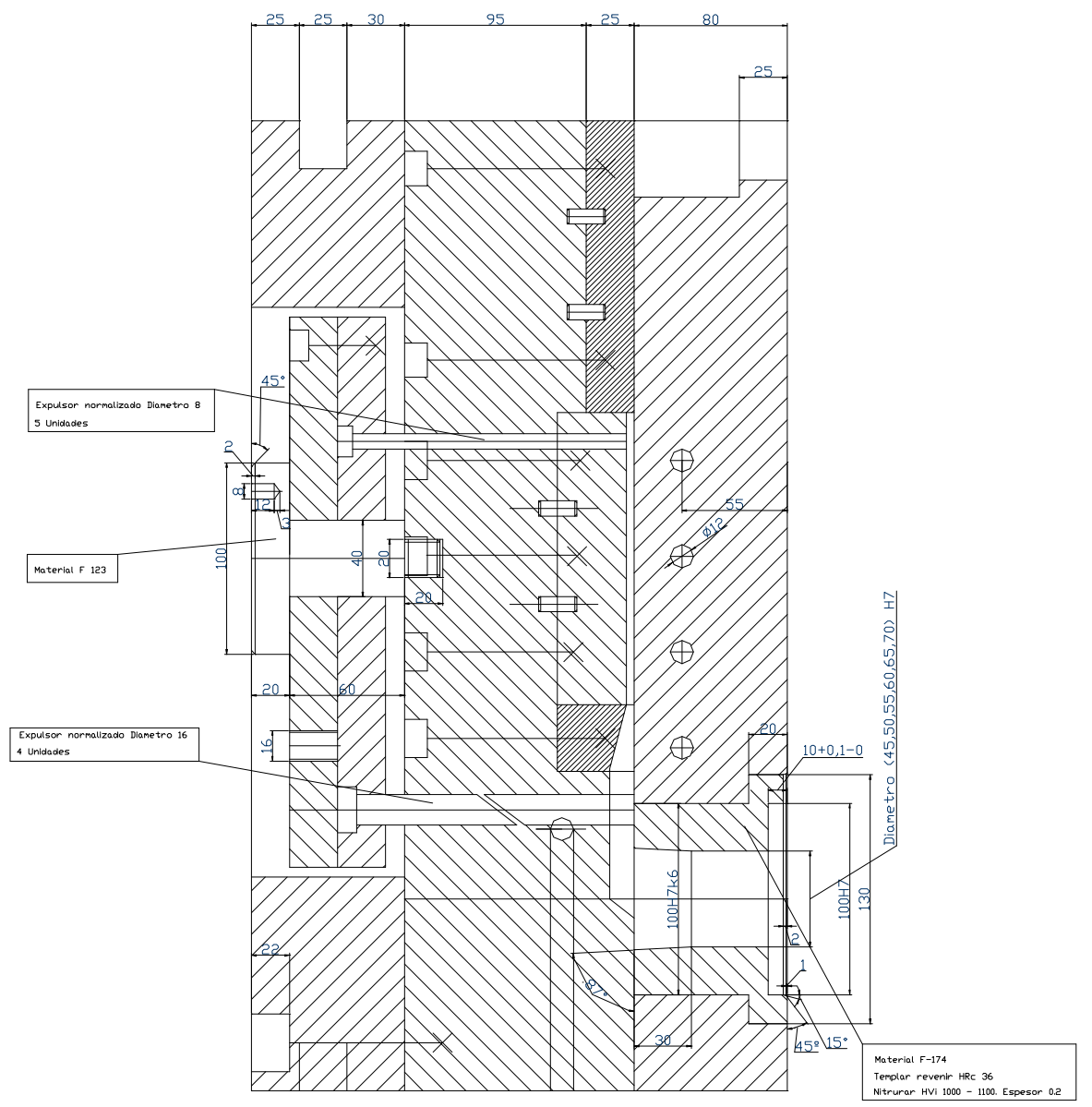

Figura B.4: Sección completa del molde (incluye casquillo intercambiable para cámara de inyección y placa de expulsores). 


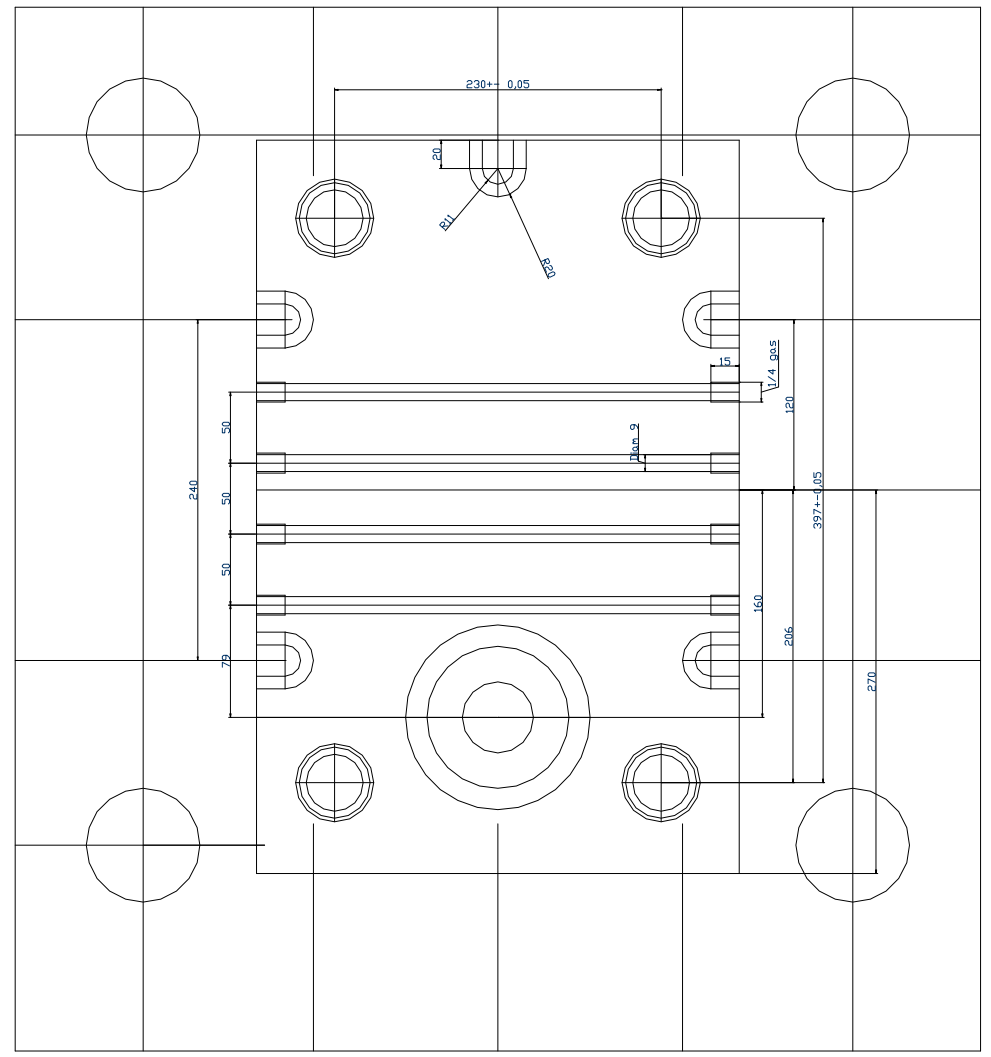

Figura B.5: Parte fija del molde (incluye líneas de enfriamiento). 

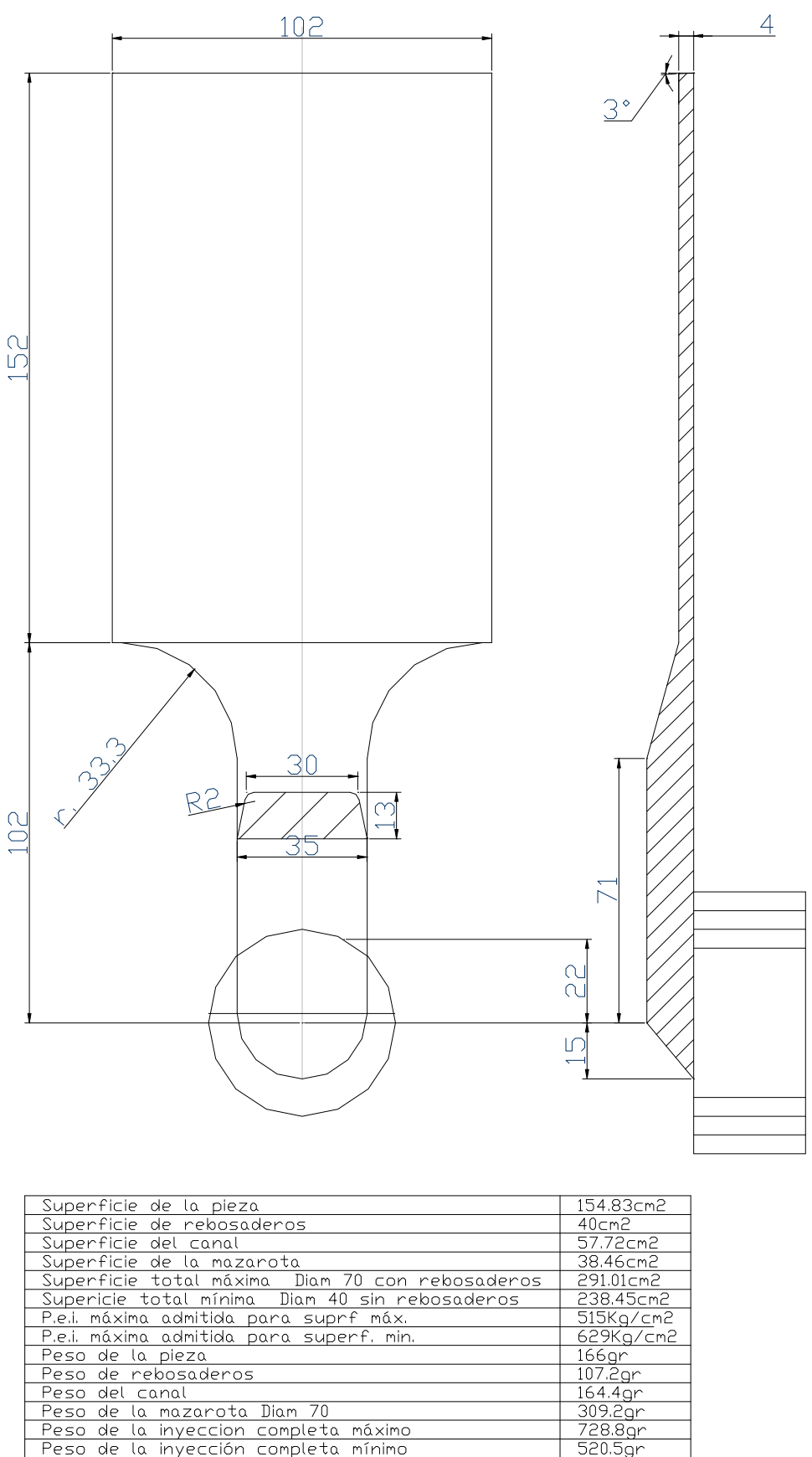

Figura B.6: Cavidad de la pieza en la parte móvil. 


\section{A N E X O C}

\section{Código fuente implementado}

Es este anexo se incluye una selección de los módulos de software implementados habiéndose descartado la inclusión de los procedimientos asociados al control de flujo del programa. En primer lugar se presenta la aplicación implementada en $\mathrm{C}++$ para la adquisición de los datos de posición del pistón generados por el nuevos transductor digital. Finalmente se presenta el código implementado en Visual Basic para el control del proceso de inyección.

\section{C.1. Módulo de adquisición de datos. (C)}

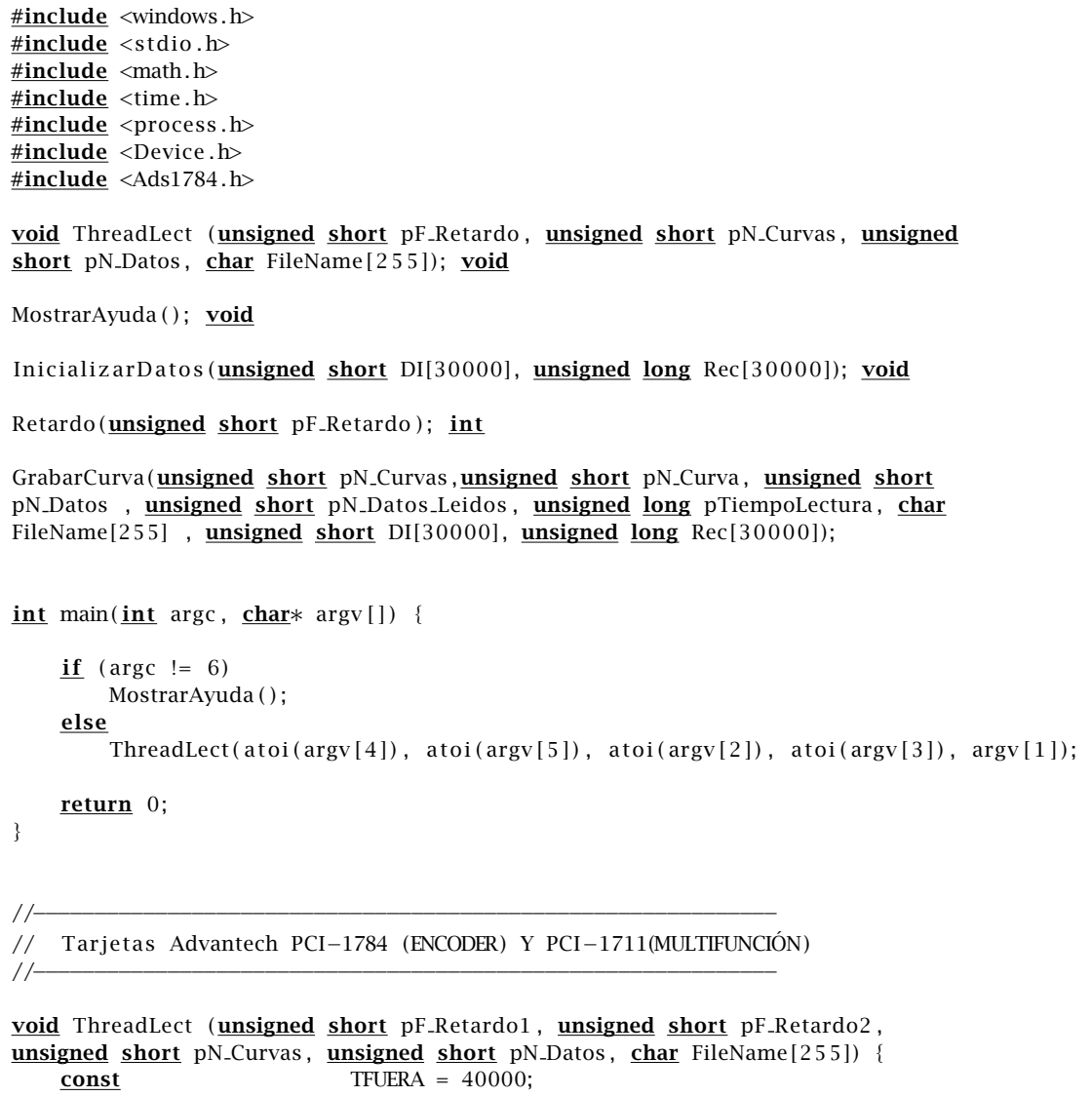

void ThreadLect (unsigned short pF_Retardo1, unsigned short pF_Retardo2, unsigned short pN_Curvas, unsigned short pN_Datos, char FileName[255]) \{ const TFUERA $=40000$ 


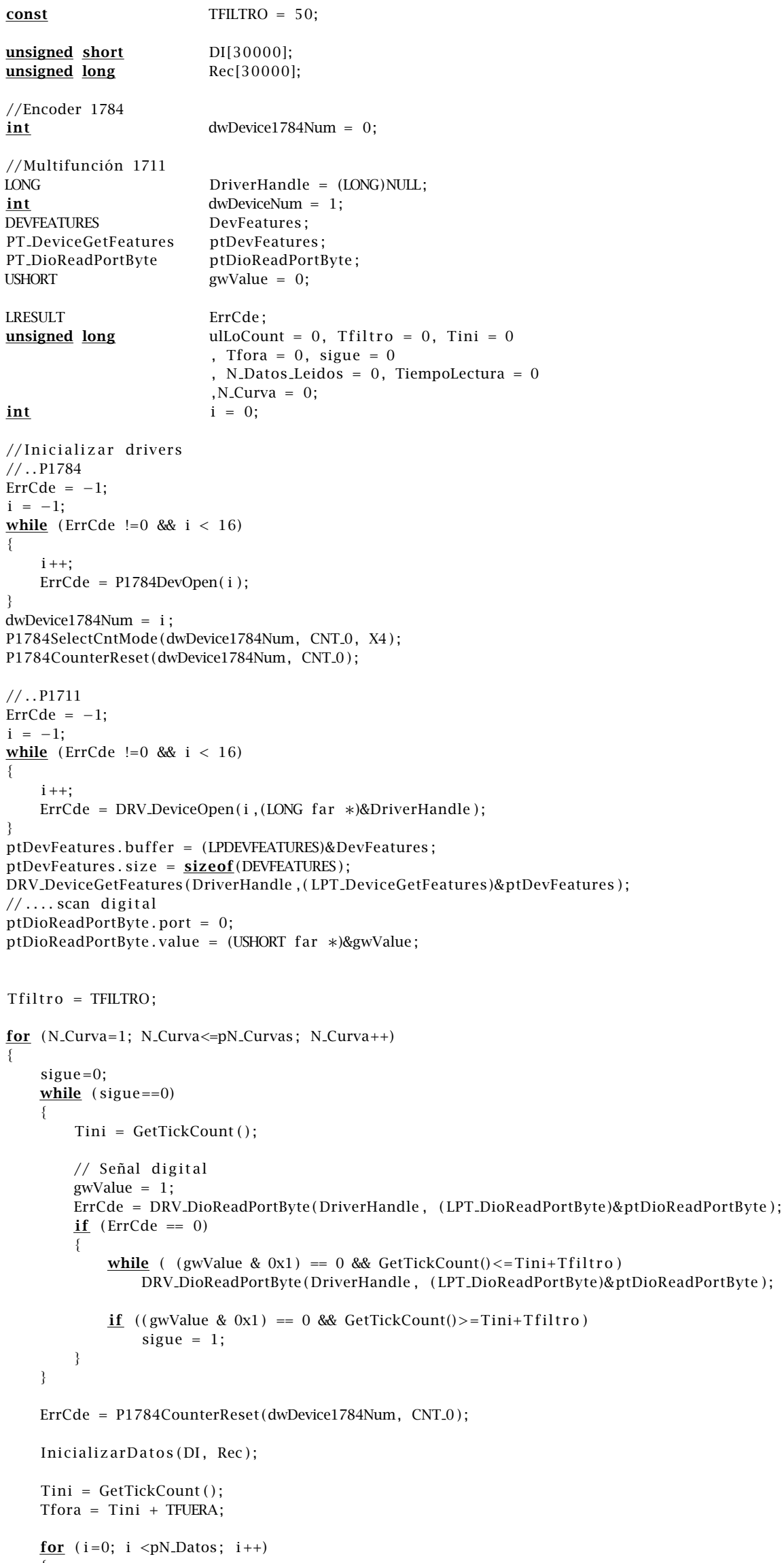




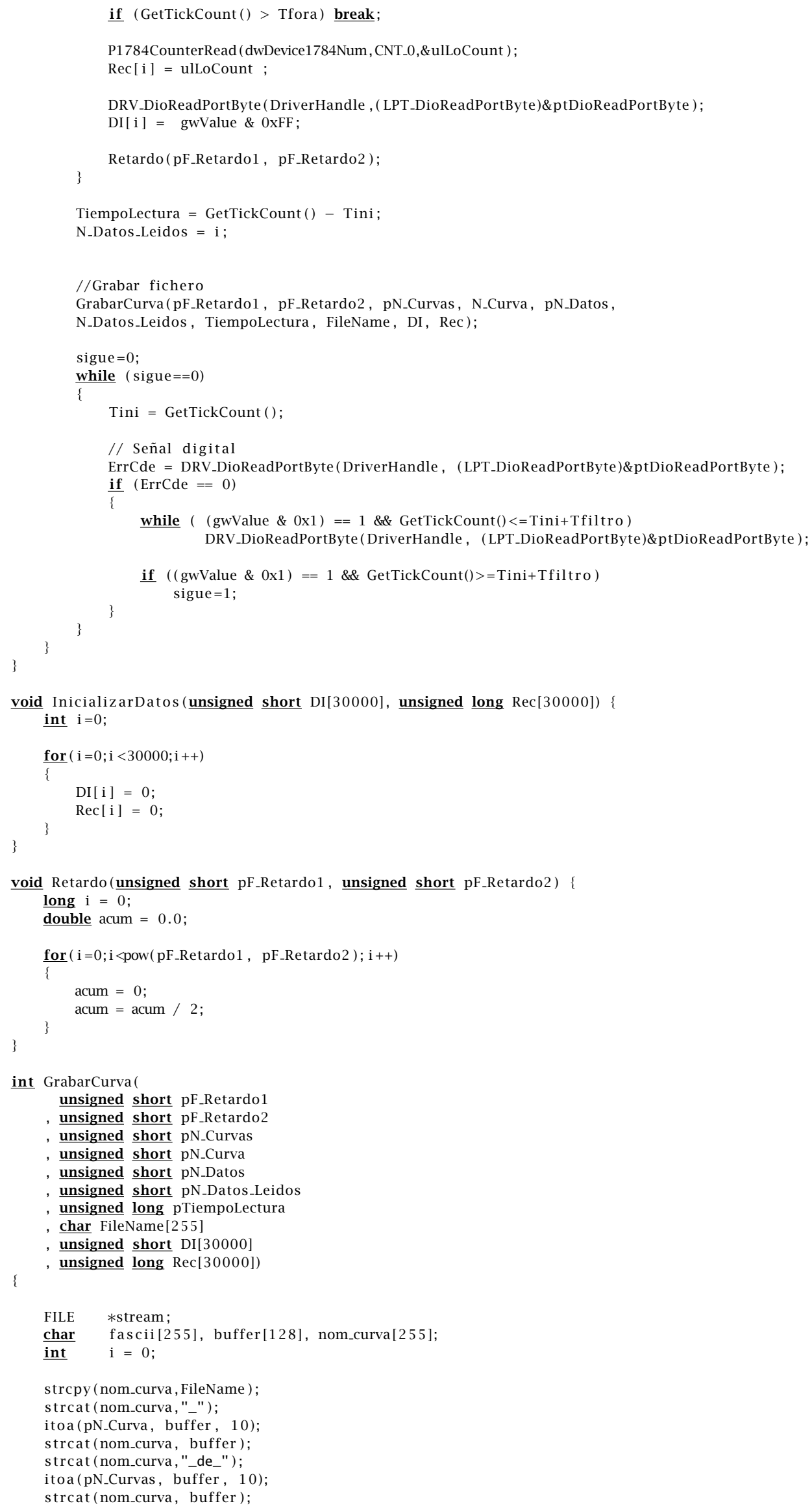




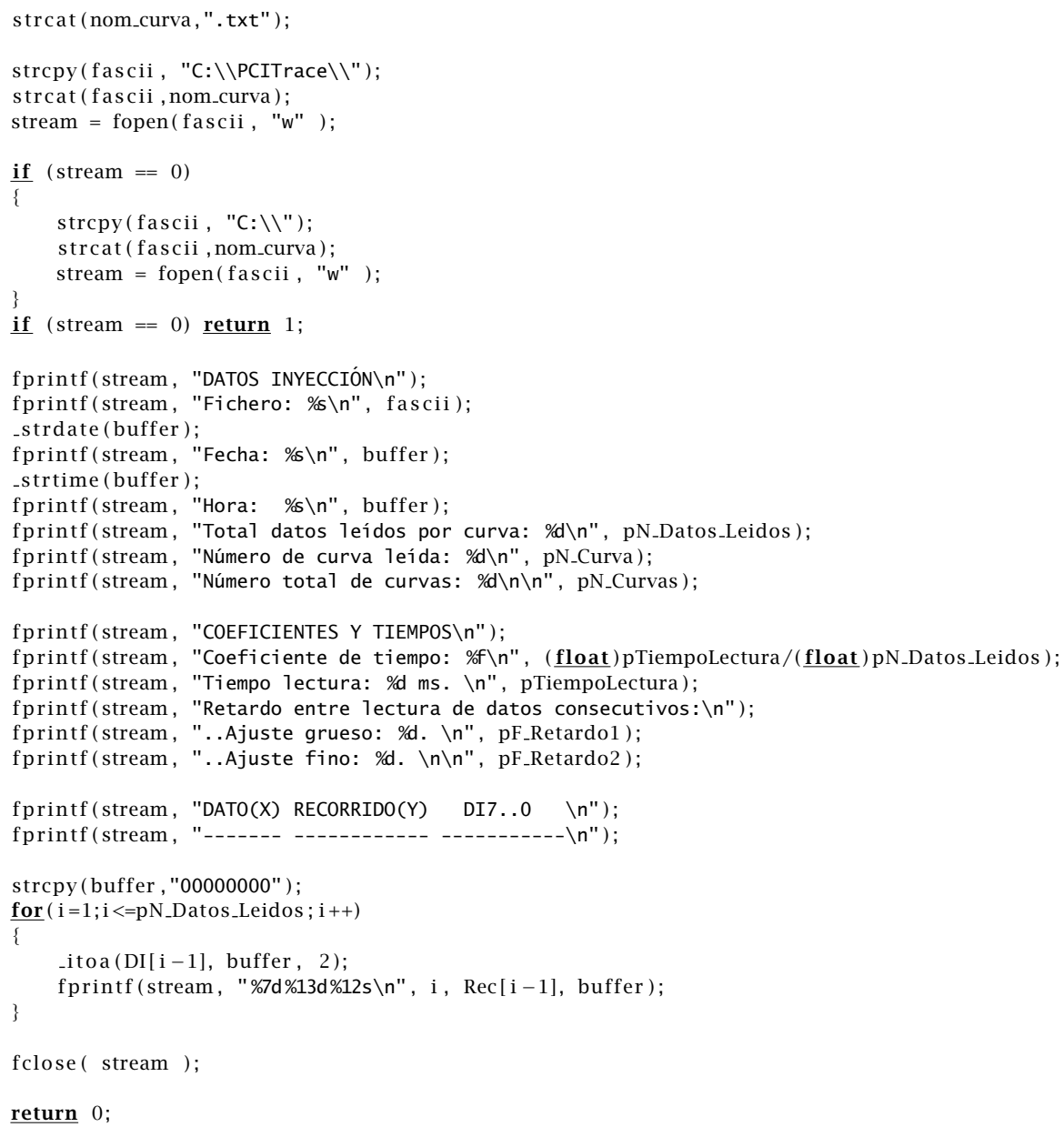

\section{C.2. Módulos de gestión de información de las inyeccio- nes. (VB)}

Global dato() As Single

Global recorrido() As Single

Global recorrido_sincero() As Single

Global presion() As Single

Global velocidad() As Single

Global velocity() As Single

Global velocity_2() As Single

Global acelera() As Single

Global sensor() As Byte

Global rec_sensor As Single

Global time_sensor As Single

Global work_file As String

Global Max As Integer

Global recorrido_r() As Single Global velocity_r() As Single

Global recorrido_t() As Single Global velocity_t() As Single

Global datos_calc_v As Integer Global rango_vmax As Integer 
Global posicion_vmax As Integer

Global lim_inf, lim_sup As Integer

Global primer_punto As Integer

Global curva As String

Global n_datos As Integer

Global t_lectura As Integer

Global coef_tiempo_pret As Single

Global coef_tiempo As Single

Global num_curva

Global c0, l As Single

Global stop_piston As Single

'Global t As Single

Global v_critica As Single

Global pos_vcritica As Single

Global resolucion

Global vol_camara As Single

Global v_aire As Single

Global retardo_sensor As Single

Global contador As Integer

Global tamano_serie As Integer

Global formato As Integer

Global iff, diametro, longitud As Single

Global indice As Integer

Global escalon As Boolean

Global error_dosifica As Single

Global perdidas As Single

Global llanura As Single

Global serie As String

$\underline{\text { Public Const }}$ pi $=3.14159265358979$

Global grupo() As inyeccion

Type inyeccion

coeficiente As Single

n_datos As Integer

dato () As Single

recorrido() As Single

presion() As Single

velocidad () As Single

End Type

Global condiciones () As condicion

Type condicion

nombre As Strin

diametro As Integer

fraccion As Single

ley As Integer

recorrido() As Integer

apertura () As Integer

comentario As String

End Type

Function calcula_velocity(limite As Integer)

For $\mathrm{i}=1$ To n_datos

$\operatorname{velocity}(i)=0$

velocity $2(i)=0$

Next i

velocity $($ limite $)=($ recorrido $(2 *$ limite $)-$ recorrido $(1)) /$

(limite $* 2 *$ coef_tiempo)

$\mathrm{m}=$ velocity (limite) / limite , pendiente de zona de aceleración

For $\mathrm{i}=1$ To limite -1 $\operatorname{velocity}(\mathrm{i})=\mathrm{m} * \mathrm{i}$

Next i

For $\mathrm{i}=$ limite +1 To n_datos - limite

velocity $(\mathrm{i})=($ recorrido $(\mathrm{i}+$ limite $)-\operatorname{recorrido}(\mathrm{i}-$ limite $)) /$

$\underline{\text { Next }} \mathrm{i}$

(limite $* 2 *$ coef_tiempo)

$\mathrm{m}=-$ velocity (n_datos - limite) / limite

For $\mathrm{i}=\left(\mathrm{n}_{-}\right.$datos - limite +1$)$ To $\left(\mathrm{n}_{-}\right.$datos -1$)$

velocity $(\mathrm{i})=\left(\operatorname{recorrido}\left(\mathrm{n}_{-}\right.\right.$datos $)-\operatorname{recorrido}\left((\mathrm{i} * 2)-\mathrm{n}_{-}\right.$datos $\left.)\right) /$

Next i

$\left(\left(n_{-}\right.\right.$datos - i ) *2* coef tiempo)

End Function

Function covarianza(vector1() As Single, vector2() As Single) As Single

$\mathrm{ml}=\operatorname{media}($ vector 1$)$

$\mathrm{m} 2=\operatorname{media}($ vector 2$)$

suma $=0$ 


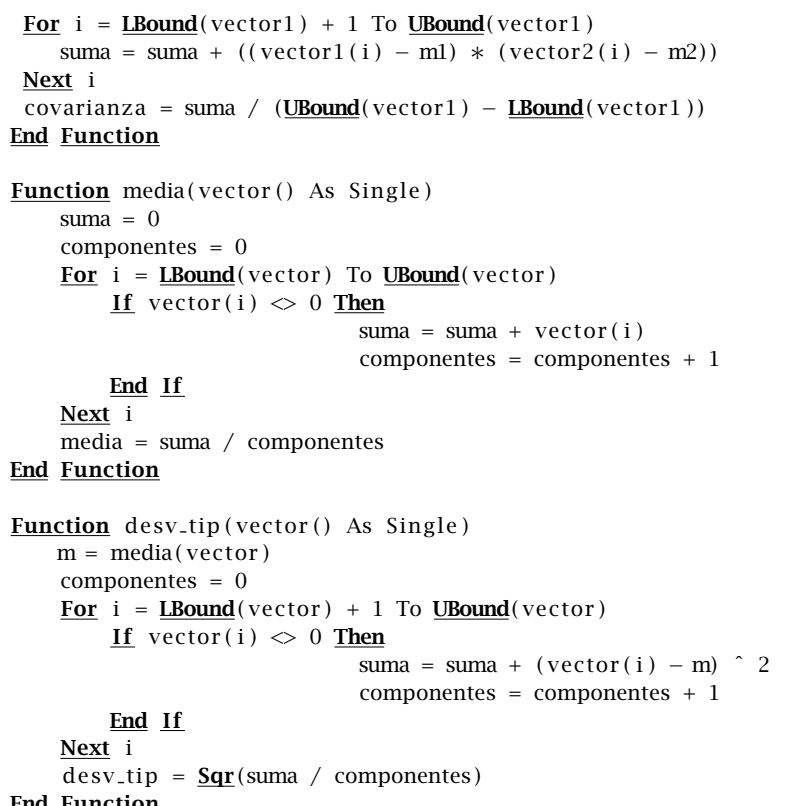

End Function

Function coef_correl(vector1() As Single, vector2() As Single) As Single coef_correl $=($ covarianza $($ vector 1()$, \operatorname{vector} 2())) /$

(desv_tip(vector 1()$) *$ desv_tip(vector 2()$))$

End Function

Function simil(vector1() As Single, vector2() As Single) As Single suma $=0$

For $\mathrm{i}=\underline{\text { LBound }}($ vector 1$)+1$ To UBound (vector 1$)$

suma $=\operatorname{suma}+\operatorname{Sqr}((\operatorname{vector} 1(i)-\operatorname{vector} 2(i)) \wedge 2)$

Next i

$\underline{\text { simil }}=$ suma $/((\underline{\text { UBound }}($ vector 1$)-\underline{\text { LBound }}($ vector 1$))+1)$

End Function

Function simil_rango(vector1() As Single, vector2() As Single, mini As Integer, maxi As Integer) As Single

suma $=0$

For $\mathrm{i}=$ mini To maxi

suma $=$ suma $+(\operatorname{vector} 1(i)-\operatorname{vector} 2(i)) \wedge 2$

Next i

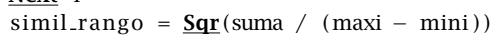

End Function

Public Function apertura(vel As Single) As Single

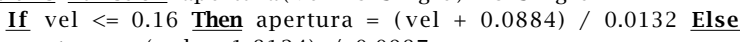

apertura $=($ vel +1.8124$) / 0.0987$

End Function

Public Sub carga_parametros()

Open "c: $\backslash$ param. txt" For Input As \#1

Line Input \#1, linea

Line Input \#1, linea

pos = InStr (linea, "=")

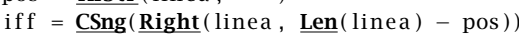

Line Input $\# 1$, linea

pos $=\underline{\text { InStr }}$ (linea, " =")

diametro $=$ CSng $($ Right $($ linea, Len $($ linea $)-$ pos $))$

Line Input \#1, linea

pos = InStr $($ linea , "=")

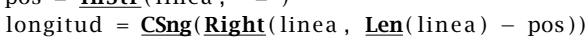

Line Input \#1, linea

pos = InStr (linea , "=")

datos_calc_v $=\underline{\operatorname{CSng}(\text { Right }}($ linea, Len $($ linea $)-$ pos $))$

Line Input \#1, linea

pos = InStr (linea , "=")

rango_vmax $=\mathbf{C S n g}($ Right $($ linea, Len $($ linea $)-$ pos $))$

Line Input \#1, linea

pos = InStr (linea , "=")

retardo_sensor $=\underline{\operatorname{CSng}}(\underline{\operatorname{Right}}($ linea,$\underline{\text { Len }}($ linea $)-$ pos $))$

Line Input \#1, linea

pos = InStr (linea, "=")

perdidas $=\underline{\operatorname{CSng}}(\underline{\text { Right }}($ linea, Len $($ linea $)-$ pos $))$

Line Input \#1, linea

pos = InStr (linea , "=") 


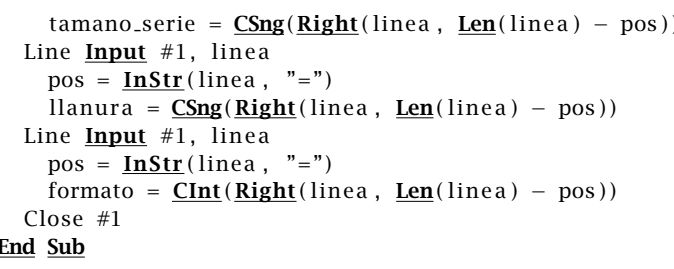

Public Function vmax_media(posicion_vmax As Integer) As Single

suma $=0$

For $\mathrm{i}=$ posicion_vmax $-\left(\operatorname{rango\_ vmax} / 2\right)$ To posicion_vmax $+\left(\operatorname{rango\_ vmax} / 2\right)$

$\underline{\text { Next }}$ i suma $=$ suma $+\operatorname{velocity}(i)$

vmax_media $=$ suma $/($ rango_vmax +1$)$

End Function

Public Sub carga_recorrido_y_sensor $(\mathrm{j})$

$\underline{\text { Dim }}$ parametros(1 To 11) As String

$\mathrm{i}=0$

limitador $=$ ":

encontrado $=$ False

Screen. MousePointer $=11$

Do Until $\mathrm{i}=11$

caracter $="$

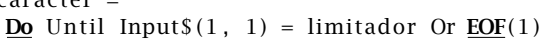

Loop

If EOF(1) Then GoTo 10

$\mathrm{i}=\mathrm{i}+1$

Line Input $\# 1$, tira

$\underline{\text { If }} \mathrm{i}<=3$ Then parametros $(\mathrm{i})=$ tira $\underline{\text { Else }} \operatorname{parametros}(\mathrm{i})=\underline{\text { Val }}($ tira $)$

Loop

n datos $=$ Val $($ parametros $(4))$

curva $=$ parametros $(5)$

num_curva $=$ parametros $(6)$

t_lectura $=$ Val $($ parametros $(8))$

coef_tiempo $=$ t_lectura $/ \mathrm{n}_{-}$datos

coef_tiempo_pret $=\underline{\operatorname{CSng}}(\operatorname{parametros}(7))$

For $\mathrm{i}=1$ To 3

Line Input \#1, tira

Next i

ReDim dato (n_datos)

ReDim recorrido (n_datos)

$\underline{\text { ReDim }}$ recorrido_sincero (n_datos)

ReDim sensor (n_datos)

For $\mathrm{i}=1$ To $\mathrm{n}_{-}$datos

$\operatorname{dato}(i)=\underline{\operatorname{Val}}(\operatorname{Input} \$(7,1))$

recorrido $(i)=\underline{\operatorname{Val}}(\operatorname{Input} \$(13,1)) / 10$

$\mathrm{kk}=\operatorname{Input} \$(10,1)$

sensor $(\mathrm{i})=\operatorname{Val}(\operatorname{Input} \$(1,1))$

If $\operatorname{sensor}(\mathrm{i})=0$ And Not encontrado Then

encontrado $=$ True

rec_sensor $=$ recorrido $(\mathrm{i})$

End If

time_sensor $=$ dato $(i) *$ coef_tiempo

Line Input \#1, tira

Next $\mathrm{i}$

$\mathrm{j}=1$

For $i=1$ To $n$ datos

If recorrido(i) $<0$ Then

recorrido_sincero $(\mathrm{j})=$ recorrido $(\mathrm{i})$

End If

Next i

n_datos $=j-1$

ReDim recorrido (n_datos)

ReDim presion (n_datos)

ReDim velocity ( $n_{-}$datos)

ReDim velocity_2 (n_datos)

$\underline{\underline{\text { For }} \mathrm{i}}=1$ To $\mathrm{n}_{-}$datos

recorrido $(i)=$ recorrido_sincero $(i)$

Next $i$

For $\mathrm{j}=1$ To 0

For $\mathrm{i}=3$ To (n_datos -2$)$

recorrido $(i)=(\operatorname{recorrido}(i-2)+\operatorname{recorrido}(i-1)+\operatorname{recorrido}(i)+$ recorrido $(i+1)+\operatorname{recorrido}(i+2)) / 5$

Next

Next j

Screen. MousePointer $=0$

End Sub 


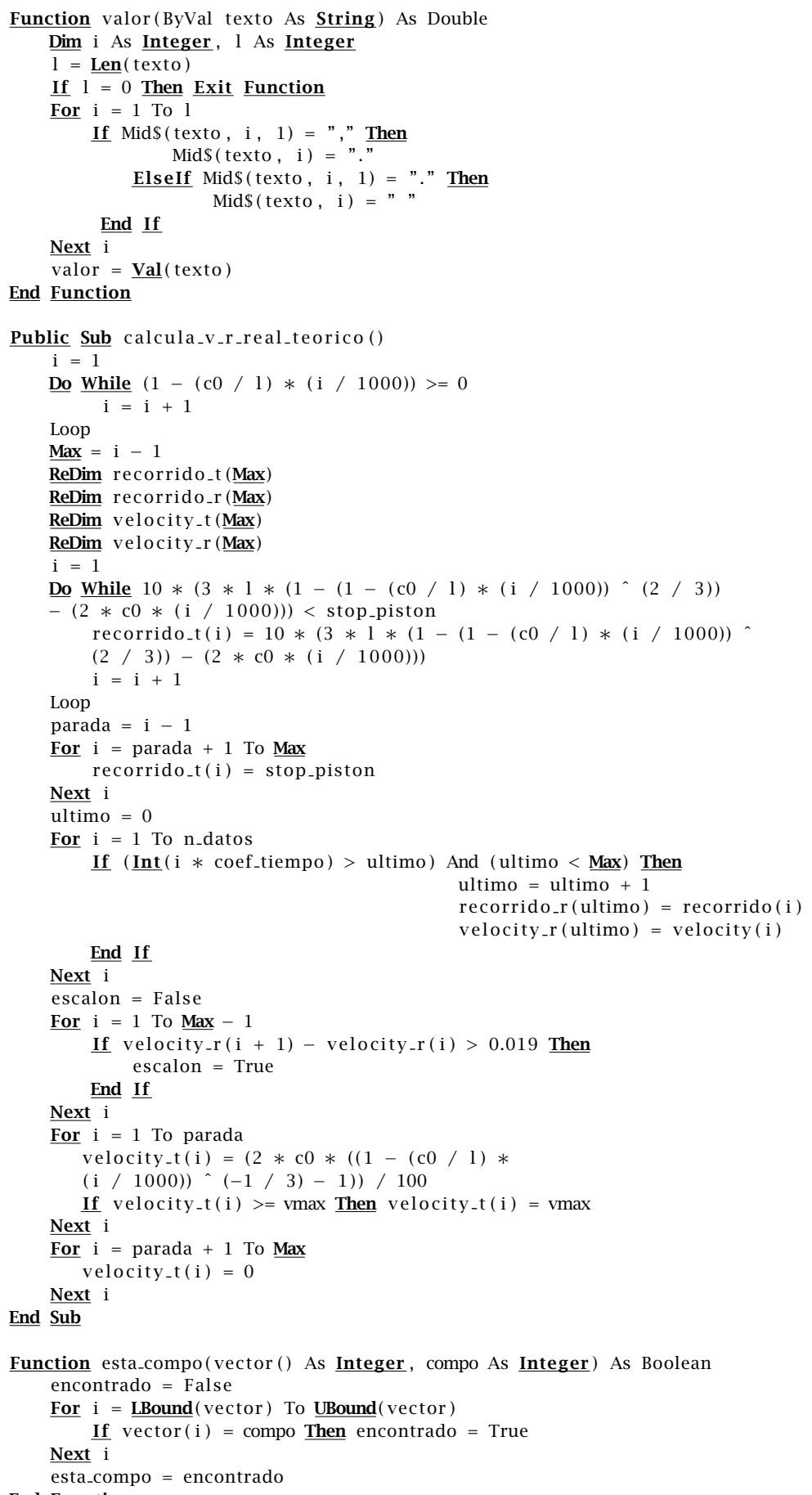

\section{End Function}

Function coef_determ_2(vector1() As Single, vector2() As Single, mini As Integer, maxi As Integer) As Single

Dim numerador, denominador, denom_1, denom_2, media_1, media_2 As Single numerador $=0$

denominador $=0$

media_1 = media $($ vector 1()$)$

For $\mathrm{i}=$ mini To maxi

numerador $=$ numerador $+(\operatorname{vector} 1(i)-\operatorname{vector} 2(i)) \wedge 2$

Next i

For $\mathrm{i}=\operatorname{mini}$ To maxi

denominador $=$ denominador $+(\operatorname{vector} 1(\mathrm{i})-$ media -1$) \wedge 2$

Next i

coef_determ_2 = $1-$ (numerador $/$ denominador $)$

End Function 
Public Function maximo_valor (vector() As Single) As Single

$\operatorname{maxi}=0$

For $\mathrm{i}=1$ To $\underline{\text { UBound }}($ vector ()$)$

If $\operatorname{vector}(\mathrm{i})>\operatorname{maxi}$ Then

$$
\text { End If }
$$

Next i

maximo_valor $=\operatorname{maxi}$

End Function

$\overline{\operatorname{maxi}}=\operatorname{vector}(\mathrm{i})$

Public Function maximo_posicion(vector () As Single) As Single

$\operatorname{maxi}=0$

pos_maxi $=0$

For $\mathrm{i}=1$ To $\underline{\text { UBound }}($ vector ()$)$

If $\operatorname{vector}(\mathrm{i})>\operatorname{maxi}$ Then

$\operatorname{maxi}=\operatorname{vector}(\mathrm{i})$

pos_maxi $=\mathrm{i}$

Next i

\section{End If}

maximo_posicion $=$ pos_maxi

End Function

Public Function posicion_llanura(vector() As Single, vector2() As Single, indice As Integer) As Integer

maximo $=$ vector $($ indice $)$

$\underline{\text { If }}$ indice $<\underline{\text { UBound }}(\operatorname{vector}()) \underline{\text { Then }} \mathrm{i}=$ indice $+1 \underline{\text { Else }} \mathrm{i}=$ indice

$\underline{\text { Do }}$ While vector $(\mathrm{i})>($ maximo $*(1-($ llanura $/ 100)))$ And

vector $2(\mathrm{i})<0$ And $\mathrm{i}<$ UBound(vector ()$)$

$\mathrm{i}=\mathrm{i}+1$

Loop

posicion_llanura $=(\mathrm{i}-1)$

End Function

Function coef_determ(vector1() As Single, vector2() As Single,

mini As Integer, maxi As Integer) As Single

Dim numerador, denominador, denom_1, denom_2, media_1, media_2 As Single

numerador $=0$

aux $=0$

denominador $=0$

media_1 = media $(\operatorname{vector} 1())$

componentes $=(\operatorname{maxi}-\operatorname{mini}+1)$

For $\mathrm{i}=$ mini To maxi

aux $=\operatorname{aux}+((\operatorname{vector} 1(i)-$ media_1 $)) \wedge 2$

Next i

numerador $=$ aux $/$ componentes

aux $=0$

For $\mathrm{i}=\operatorname{mini}$ To maxi

aux $=$ aux $+(\operatorname{vector} 1(i)-\operatorname{vector} 2(i))$

Next i

aux $=$ aux $/$ componentes

denominador $=$ aux + numerador

coef_determ $=$ (numerador $/$ denominador $)$

End Function

Public Sub carga_recorrido_old ( $j$ )

Dim parametros(1 To 26) As String

$\mathrm{i}=0$

limitador $=$ ":

Screen. MousePointer $=11$

Do Until $\mathrm{i}=21$

caracter $="$

Do Until $\operatorname{Input} S(1,1)=$ limitador $\operatorname{Or} \underline{\mathbf{E O F}}(1)$

Loop

If EOF (1) Then GoTo 10

$\mathrm{i}=\mathrm{i}+1$

If $\mathrm{i}=10$ Then

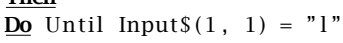

Loop

$\mathrm{kk}=\operatorname{Input} \$(2,1)$

num $=\operatorname{Input} \$(1,1)$
Do while num $<>, ")$

tfase $1=$ tfase $1+$ num

Loop

num $=\operatorname{Input} \$(1,1)$

$\underline{\text { End }} \underline{\text { If }} \mathrm{i}=11 \underline{\text { Then }}$

Do Until $\operatorname{Input} \$(1,1)=$ "

Loop

$\mathrm{kk}=\operatorname{Input} \$(2,1)$

num $=\operatorname{Input} \$(1,1)$

Do While num $<>$ ")"

tfase $2=$ tfase $2+$ num 


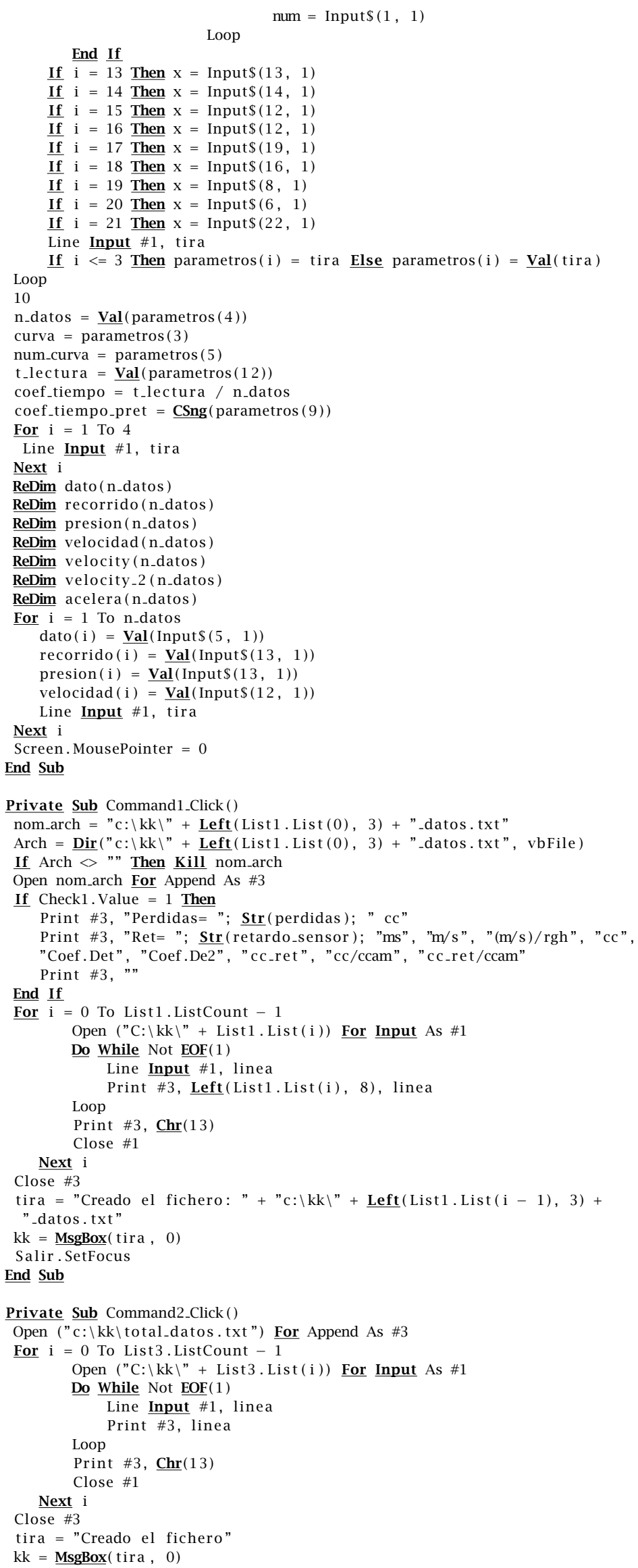




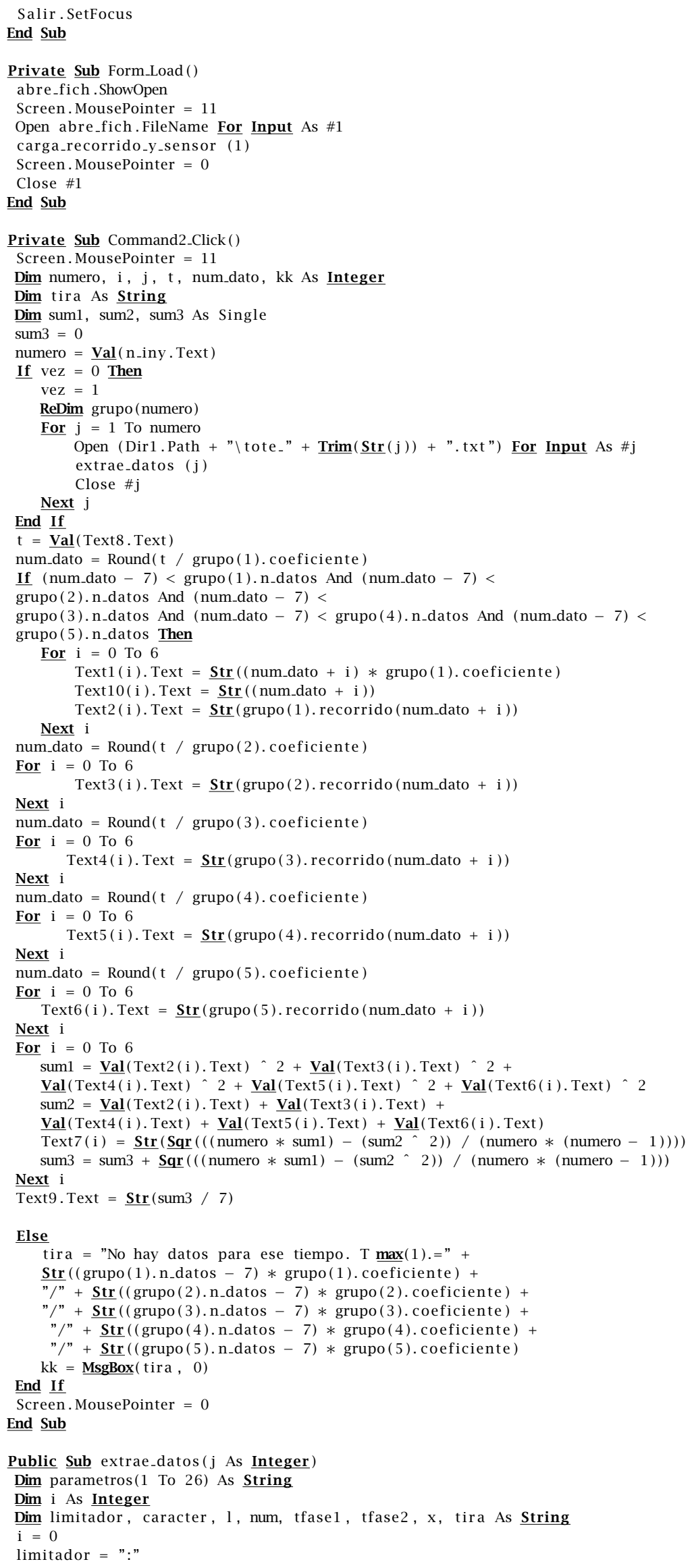


Do Until i $=21$

caracter $="$

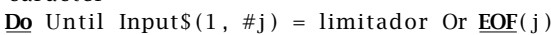

Loop

If $\underline{\operatorname{EOF}(j)}$ Then GoTo 10

$\mathrm{i}=\mathrm{i}+1$

If $\mathrm{i}=10$ Then

Do Until $\operatorname{Input} \$(1, \# \mathrm{j})=" 1 "$

Loop

$1=\operatorname{Input} \$(2, \# \mathrm{j})$

num $=\operatorname{Input} \$(1, \# \mathbf{j})$

Do While num $<>$ ")"

tfase $1=$ tfase $1+$ num

Loop

End If num $=\operatorname{Input} \$(1, \# \mathrm{j})$

$\underline{\text { If }} \mathrm{i}=11 \underline{\text { Then }}$

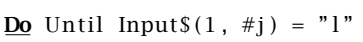

Loop

$l=\operatorname{Input} \$(2, \# \mathrm{j})$

num $=\operatorname{Input} \$(1, \# \mathrm{j})$

Do while num $<$ ")"

tfase $2=$ tfase $2+$ num

Loop

End If

num $=\operatorname{Input} \$(1, \# \mathbf{j})$

If $\mathrm{i}=13$ Then $\mathrm{x}=\operatorname{Input} \$(13, \# \mathrm{j})$

If $\mathrm{i}=14$ Then $\mathrm{x}=\operatorname{Input} \$(14, \# \mathrm{j})$

If $\mathrm{i}=15$ Then $\mathrm{x}=\operatorname{Input} \$(12, \# \mathrm{j})$

$\underline{\text { If }} \mathrm{i}=16 \underline{\text { Then }} \mathrm{x}=\operatorname{Input} \$(12, \# \mathrm{j})$

$\underline{\text { If }} \mathrm{i}=17 \underline{\text { Then }} \mathrm{x}=\operatorname{Input} \$(19, \# \mathrm{j})$

If $\mathrm{i}=18 \underline{\text { Then }} \mathrm{x}=\operatorname{Input} \$(16, \# \mathrm{j})$

If $\mathrm{i}=19$ Then $\mathrm{x}=\operatorname{Input} \$(8, \# \mathrm{j})$

If $\mathrm{i}=20$ Then $\mathrm{x}=\operatorname{Input} \$(6, \# \mathrm{j})$

$\underline{\text { If }} \mathrm{i}=21 \underline{\text { Then }} \mathrm{x}=\operatorname{Input} \$(22, \# \mathrm{j})$

Line Input $\# \mathrm{j}$, tir a

Loop

If $\mathrm{i}<=3$ Then parametros $(\mathrm{i})=$ tira $\underline{\text { Else }}$ parametros $(\mathrm{i})=\underline{\text { Val }}$ (tira)

curva $=$ parametros $(3)$

t_lectura $=\underline{\text { Val }}($ parametros $(12))$

coef_tiempo $=$ t_lectura $/$ n_datos

coef_tiempo_pret $=\underline{\mathbf{C S n g}}($ parametros $(9))$

For $\mathrm{i}=1$ To 4

Line Input $\# \mathbf{j}$, tira

Next i

ReDim $\operatorname{grupo}(\mathrm{j})$. dato ( $\mathrm{n}_{-}$datos )

ReDim grupo(j). recorrido (n_datos)

$\underline{\operatorname{ReDim}} \operatorname{grupo}(\mathrm{j})$. presion (n_datos)

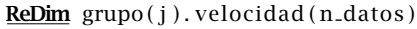

$\operatorname{grupo}(j)$. coeficiente $=$ coef_tiempo

$\operatorname{grupo}(\mathrm{j}) . \mathrm{n}_{-}$datos $=\mathrm{n}_{-}$datos

For $\mathrm{i}=1$ To n_datos

$\operatorname{grupo}(j) \cdot \operatorname{dato}(i)=\underline{\operatorname{Val}}(\operatorname{Input} \$(5, j))$

$\operatorname{grupo}(j) \cdot \operatorname{recorrido}(i)=\underline{\operatorname{Val}}(\operatorname{Input} \$(13, j))$

$\operatorname{grupo}(j) \cdot \operatorname{presion}(i)=\operatorname{Val}(\operatorname{Input} \$(13, j))$

$\operatorname{grupo}(j) \cdot \operatorname{velocidad}(i)=\underline{\operatorname{Val}}(\operatorname{Input} \$(12, j))$

Line Input $\# \mathrm{j}$, tira

Next i

End Sub

Private Sub Leer_Click()

Screen. MousePointer $=11$

Dim posicion_vmax_r As Integer

Dim curvas_a_proc As Integer

Dim posicion_vmax_r_llanura As Integer

For $\mathrm{j}=0$ To List 1 . ListCount -1

Open (Dir1.Path + " " + List1.List(j)) For Input As \#

Select Case formato

Case 0

Case 1

carga_recorrido_old ( j )

carga_recorrido_y_sensor $(\mathrm{j})$

End Select

calcula_velocity (datos_calc_v / 2)

vmax $=$ maximo_valor $($ velocity ()$)$

posicion_vmax $=$ maximo_posicion $($ velocity ()$)$

calcula_v_r_real_teorico

vel_max_media $=$ vmax_media $($ posicion_vmax $)$

velo_max $=$ vmax

posicion_vmax_r $=0$ 


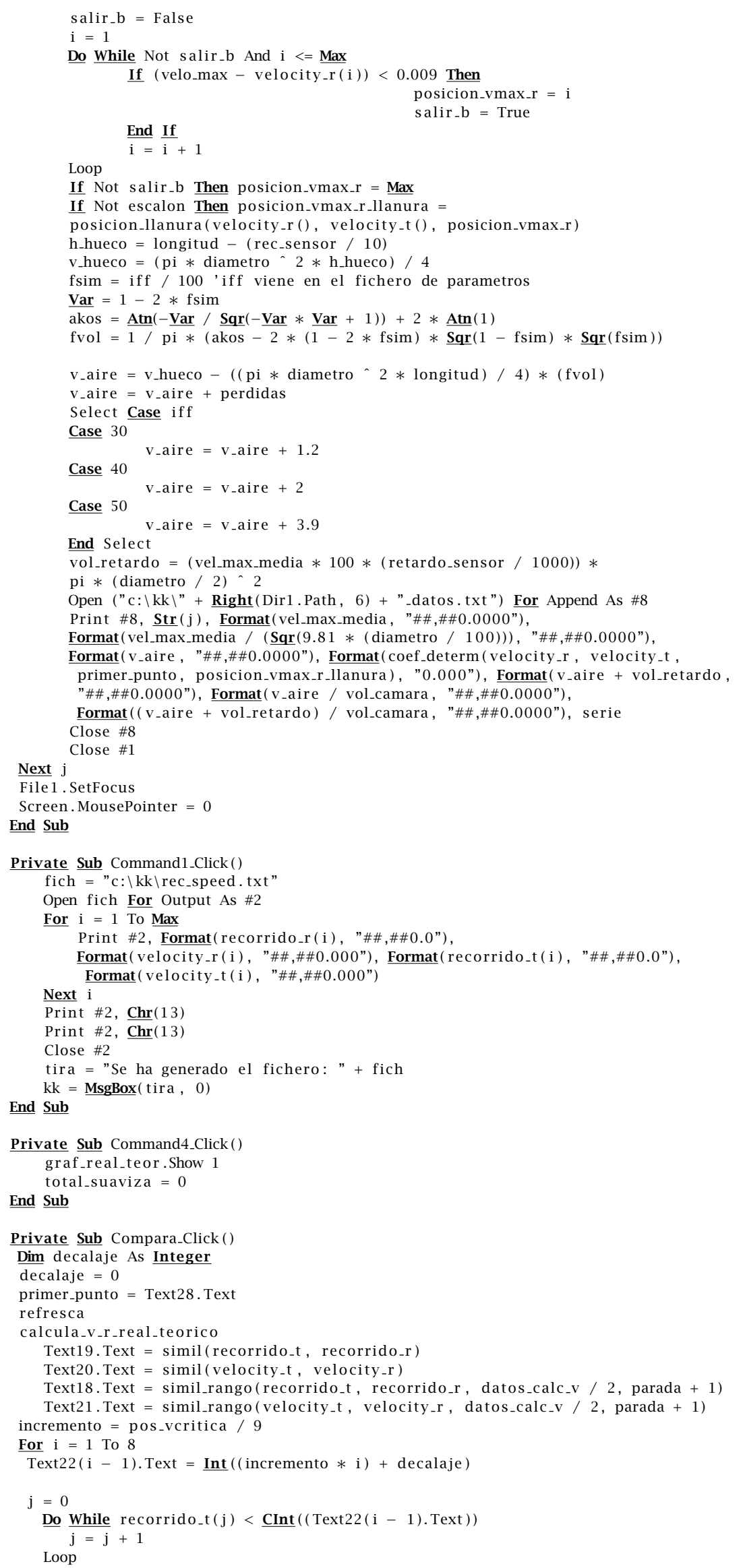


$\operatorname{Text} 23(\mathrm{i}-1) \cdot$ Text $=\operatorname{Round}\left(\operatorname{apertura}\left(\operatorname{velocity} \_t(j-1)\right)\right)$

Next i

Text22(8). Text $=\underline{\text { Int }}($ pos_vcritica $)+$ decalaje

$\operatorname{Text23}(8)$. Text $=$ Round $\left(\operatorname{apertura}\left(v_{-}\right.\right.$critica $\left.\left./ 100\right)\right)$

Text22(9). Text $=$ Int $((($ stop_piston + pos_vcritica $) / 2))+$ decalaje

Text23(9). Text $=$ Round $\left(\right.$ apertura $\left(v_{-}\right.$critica $\left.\left./ 100\right)\right)$

Text24. Text $=\underline{\text { Int }}($ stop_piston $)+$ decalaje

Command4. SetFocus

End Sub

Private Sub Form_Load ()

Text2. Text $=$ iff

Text 3. Text $=$ longitud

Text 4 . Text $=$ diametro

refresca

End Sub

Public Static Sub refresca()

fsim $=$ CSng (Text2. Text $) / 100$

$\underline{\text { Var }}=1-2 *$ fsim

$\underline{\operatorname{akos}}=\underline{\operatorname{Atn}}(-\underline{\text { Var }} / \underline{\operatorname{Sqr}}(-\underline{\operatorname{Var}} * \underline{\operatorname{Var}}+1))+2 * \underline{\operatorname{Atn}}(1)$

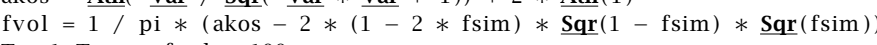

Text1. Text $=$ fvol $* 100$

diametro_c $=\underline{\mathbf{C S n g}}($ Text 4 . Text $)$

long $_{-} \mathrm{C}=\mathbf{C S n g}($ Text 3 . Text $)$

altura_l $=$ diametro_c $*$ fsim

Text5. Text $=$ altura_l

$\mathrm{c} 0=\operatorname{Sqr}\left(\left(981 *(\mathrm{pi} / 4) *\right.\right.$ diametro_c $\left.{ }^{2} * \mathrm{fvol}\right) /$

$\left(2 * \underline{\operatorname{Sqr}}\left((\right.\right.$ diametro_c $*$ altura_l $)-$ altura_l $\left.\left.\left.{ }^{*} 2\right)\right)\right)$

Text6. Text $=\mathrm{c} 0$

Select Case fsim

Case 0.3

$v_{-}$critica $=62.4$

Case 0.4

Case 0.5

v_critica $=48.8$

Case Else

End Select

v_critica $=37.6$

Text7. Text $=v_{-}$critica

$1=$ long_c

Text8. Text $=1$

$\mathrm{t}=(1 / \mathrm{c} 0) *\left(1-\left(1 /\left(\left(\mathrm{v}_{-}\right.\right.\right.\right.$critica $\left.\left.\left.\left./(2 * \mathrm{c} 0)\right)+1\right) \sim 3\right)\right)$

Text9. Text $=\mathrm{t}$

pos_vcritica $=10 *(3 * 1 *(1-(1-(\mathrm{c} 0 / 1) * \mathrm{t}) \wedge(2 / 3))-$

$(2 * \mathrm{c} 0 * \mathrm{t}))$

Text10. Text $=$ pos_vcritica

vol_camara $=$ long_c $*(($ diametro_c $/ 2) \wedge 2 *$ pi $)$

Text11. Text $=$ vol_camara

vol_g_liq $=$ vol_camara $*($ fvol $)$

Text12. Text $=$ vol_g_liq

coef_contra $=\underline{\operatorname{CSng}}($ Text13. Text $)$

densidad $=$ CSng $($ Text 15 . Text $)$

vol_g_sol $=$ vol_g_liq $*(1-($ coef_contra $/ 100))$

Text14. Text $=$ vol_.g_sol

masa $=$ vol_g_sol $*$ densidad

Text16. Text $=$ masa

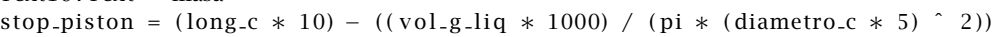

Text17. Text $=$ stop_piston

Text26. Text $=$ rec_sensor

h_hueco $=$ long_c $-\left(\right.$ rec_sensor $\left._{-} 10\right)$

v_hueco $=($ pi $*$ diametro_c $>2 *$ h_hueco $) / 4$

$v_{-}$aire $=v_{-}$hueco $-v_{\text {vol_g_liq }}$

Text25. Text = Format $\left(v_{\text {_aire }}, " \# \#, \# \# 0.00 "\right)$

Text27. Text $=$ time_sensor

End Sub

Private Sub Command1_Click()

Arch $=\operatorname{Dir}(" \mathrm{c}: \backslash \mathrm{kk} \backslash "+\operatorname{Left}(\operatorname{List} 1 . \operatorname{List}(0), 3)+$ "-datos.txt", vbFile $)$

If Arch $<>$ " Then Kill ("c: $\backslash k \mathrm{kk} \backslash$ " Left $(\operatorname{List1}$. List (0), 3) + "-datos.txt")

Open ("c: $\backslash k \mathrm{k} \backslash$ " + Left $($ List1.List (0), 3) + "_datos.txt") For Append As \#3

For $\mathrm{i}=0$ To List 1 . ListCount -1

Open ("C: $\backslash \mathrm{kk} \backslash "+$ List1.List(i)) For Input As \#1

Print \#3, Left (List1. List (i), 7)

Do While Not EOF (1)

Line Input \# 1 , linea

Print \#3, linea

Loop

Print \#3, $\underline{\mathbf{C h r}}(13)$

Close \#1

Next i 


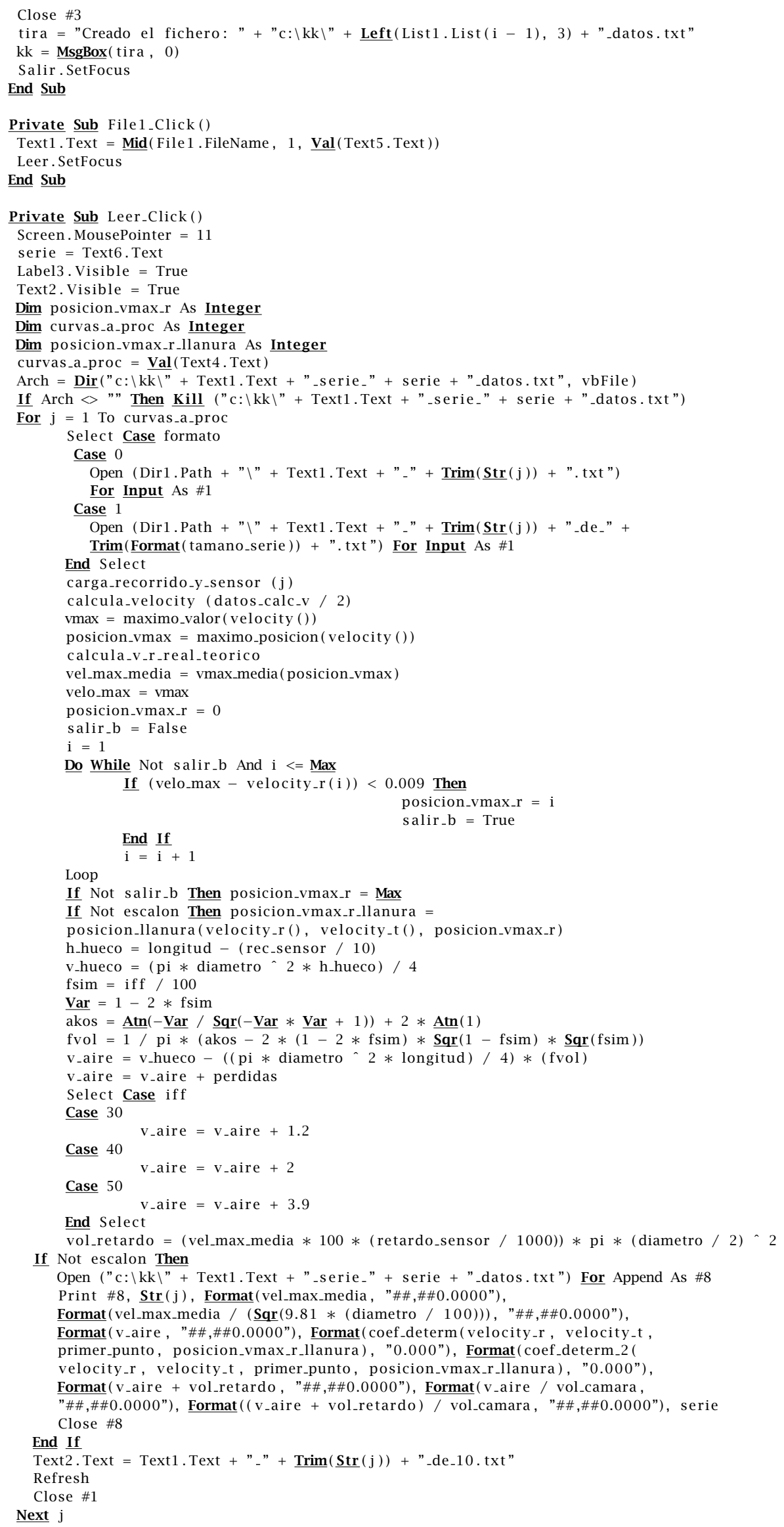




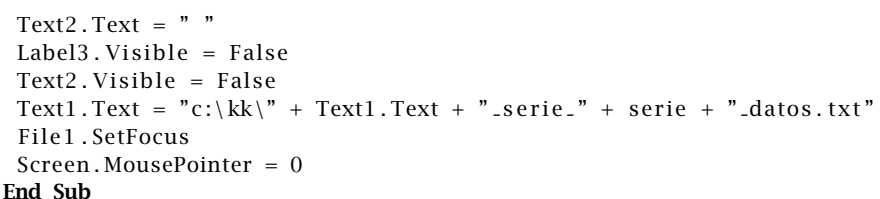

End Sub

Private Sub Dibuja_Click()

n_curvas $=11$

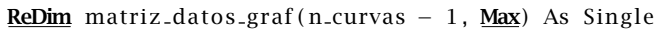

decena $=0$

If Check2 Then decena $=10$

If Check3 Then decena $=20$

Text 1. Text $=\underline{\text { Left }}($ Text 1. Text, $\underline{\text { Val }}($ Text 3. Text $))$

For $\mathrm{i}=1$ To $\left(\mathrm{n}_{-}\right.$curvas -1$)$

If Check1 $(\mathrm{i}-1)=1$ Then

fichero = Dir 1. Path + "\" + Text 1. Text + "-" +

$\underline{\operatorname{Trim}}(\underline{\operatorname{Str}}(\mathrm{i}+$ decena $))+$ "_de_" + $\underline{\operatorname{Trim}}(\underline{\text { Format }}($ tamano_serie $))+$ +.txt"

Open fichero For Input As \#1

Select Case formato

Case 0

carga_recorrido_old (j)

Case 1

carga_recorrido_y_sensor (j)

End Select

calcula_velocity (datos_calc_v / 2)

Close \#1

ultimo $=0$

For $\mathrm{k}=1$ To $\mathrm{n}_{-}$datos

If (Int $(\mathrm{k} *$ coef_tiempo $)>$ ultimo ) And (ultimo < Max) Then

ultimo $=$ ultimo +1

matriz_datos_graf $(\mathrm{i}$, ultimo $)=\operatorname{velocity}(\mathrm{k})$

End If

Next $k$

End I

Next

graf 1 . ColumnCount $=n_{-}$curvas

graf1. RowCount $=$ Max - primer_punto

If Check1 (n_curvas - 1$)=1$ Then

For $\mathrm{j}=1$ To (Max - primer_punto)

graf 1 . Column $=11$

graf 1 . Row $=\mathrm{j}$

graf 1 . Data $=$ velocity_t $(j+$ primer_punto $)$

Next $\mathrm{j}$

Else: $\quad \underline{\text { For }} \mathrm{j}=1$ To (Max - primer_punto)

graf 1 . Column $=11$

graf 1 . Row $=\mathrm{j}$

graf 1 . Data $=0$

End If

Next j

For $\mathrm{i}=1$ To n_curvas -1

For $\mathrm{j}=1$ To (Max - primer_punto $)$

graf 1 . Column $=i$

graf 1 . Row $=\mathrm{j}$

graf1. Data $=$ matriz_datos_graf $(i, j+$ primer_punto $)$

Next j

Next i

End Sub

Private Sub Command1_Click()

lim inf $=$ Val $($ Text 1 . Text $)$

$\lim _{\text {sup }}=\mathbf{\text { Val }}($ Text 2. Text $)$

Dim suma As Single

suma $=0$

For $\mathrm{i}=$ lim_inf To lim_sup

suma $=$ suma + velocity $(i)$

Next i

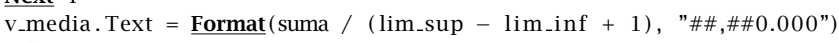

End Sub

Private Sub Command2_Click()

cur $=\underline{\text { Mid }}$ (curva , 3, 12)

fich = "c: $\backslash$ kk $\backslash$ velocity_" + cur + " - + num_curva + ".txt"

Open fich For Output As \#2 


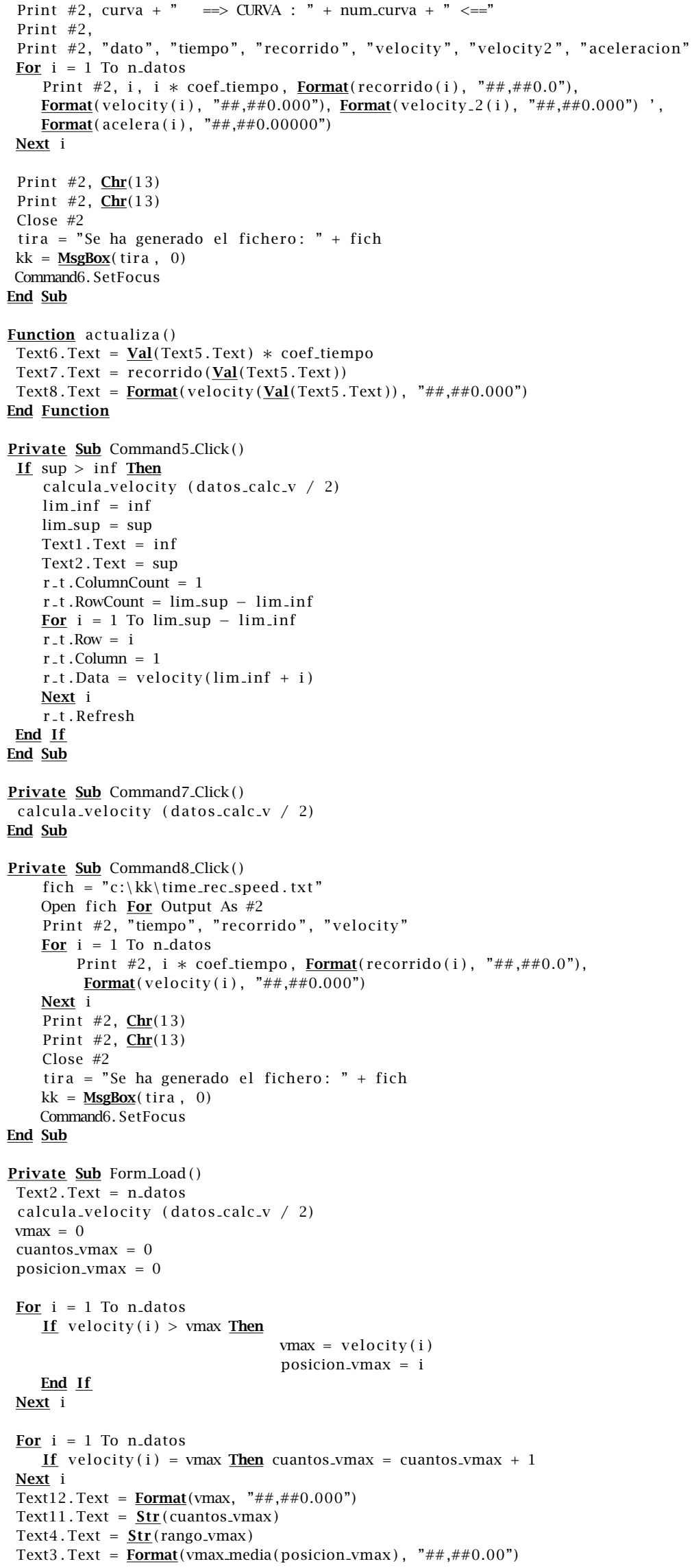




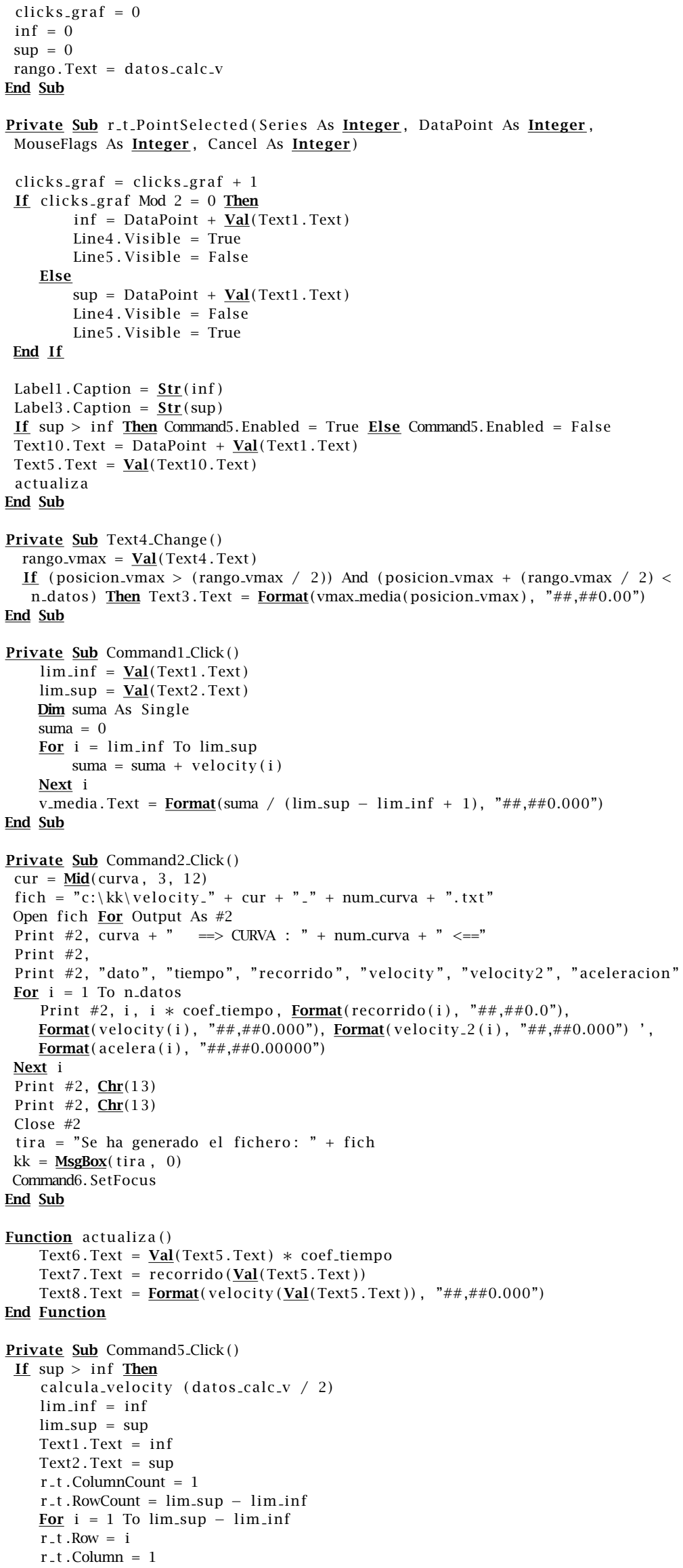




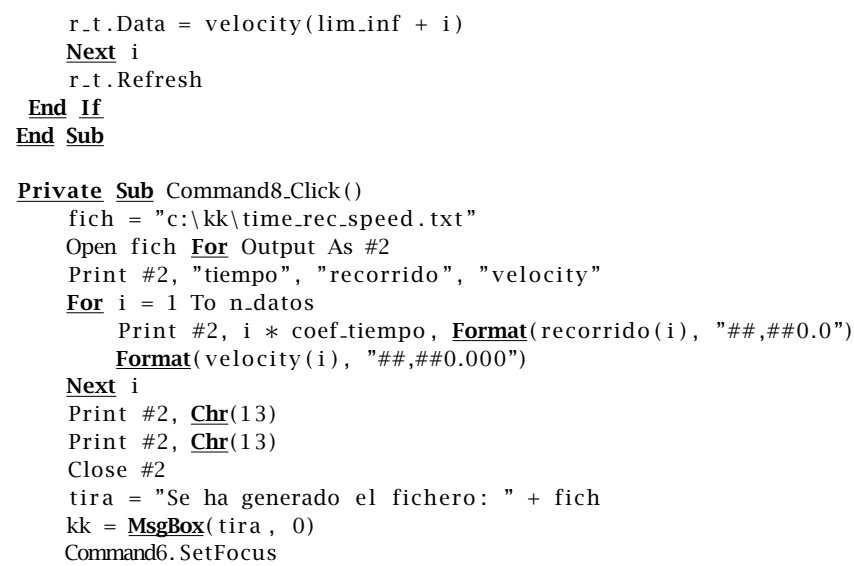

End $\underline{\text { Sub }}$

Private Sub Form_Load()

Text 2 . Text $=\mathrm{n}_{-}$datos

calcula_velocity (datos_calc_v / 2)

vmax $=0$

cuantos_vmax $=0$

posicion_vmax $=0$

For $\mathrm{i}=1$ To $\mathrm{n}$ datos

If velocity(i) > vmax Then

vmax $=$ velocity $(i)$

End If

Next

For $\mathrm{i}=1$ To n_datos

If velocity $(\mathrm{i})=$ vmax $\underline{\text { Then }}$ cuantos_vmax $=$ cuantos_vmax +1

Next i

Text12. Text $=$ Format $($ vmax, $" \# \#, \# \# 0.000 ")$

Text11. Text $=\mathbf{S t r}($ cuantos_vmax $)$

Text 4. Text $=\underline{\underline{\operatorname{Str}}}($ rango_vmax $)$

Text 3. Text $=\underline{\text { Format }}($ vmax_media $($ posicion_vmax $), " \# \#, \# \# 0.00 ")$

clicks_graf $=0$

inf $=0$

$\sup =0$

rango. Text $=$ datos_calc $\_$v

End Sub

Private Sub r_t_PointSelected(Series As Integer, DataPoint As Integer, MouseFlags As Integer, Cancel As Integer

clicks_graf $=$ clicks_graf +1

If clicks graf Mod $2=0$ Then

inf $=$ DataPoint + Val $($ Text 1. Text $)$

Line 4 . Visible $=$ True

Line 5 . Visible $=$ False

Else

sup $=$ DataPoint + Val $($ Text 1. Text $)$

Line 4 . Visible $=$ False

End If

Line 5 . Visible $=$ True

Label1. Caption $=\underline{\mathbf{S t r}}($ inf $)$

Label3. Caption $=\underline{\mathbf{S t r}}(\sup )$

If $\sup >$ inf Then Command5. Enabled $=$ True Else Command5. Enabled $=$ False

Text10. Text $=$ DataPoint $+\underline{\text { Val }}($ Text 1. Text $)$

Text 5 . Text $=\underline{\text { Val }}($ Text 10. Text $)$

actualiza

End Sub

Private Sub Text4_Change()

rango_vmax $=$ Val $($ Text 4 . Text $)$

If (posicion_vmax $>$ (rango_vmax / 2)) And (posicion_vmax $+\left(\operatorname{rango\_ vmax} / 2\right)<$

n_datos $)$ Then Text 3 . Text $=$ Format $(\operatorname{vmax}$ media $($ posicion_vmax $), " \# \#, \# \# 0.00 ")$ End $\underline{\text { Sub }}$

Private Sub Command1_Click()

g_crit. RowCount $=$ Max - primer punto +1

g_crit. Column $=1$

For $\mathrm{i}=$ primer_punto To Max

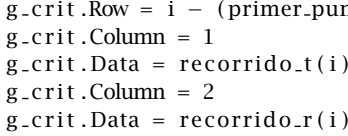


Next i

Text1. Text $=$ work_file

g_crit.Plot.Axis $(1,1)$. AxisTitle. Text = "Recorrido (mm)"

g_crit. Refresh

Command2. SetFocus

End Sub

Private Sub Command2_Click()

g_crit. RowCount $=\underline{\text { Max }}-$ primer_punto +1

g_crit. Column $=1$

For $\mathrm{i}=$ primer_punto To Max

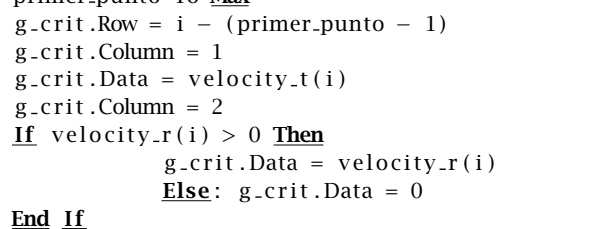

Next i

Text 1 . Text $=$ work_file

g_crit.Plot.Axis $(1,1)$. AxisTitle. Text = "Velocidad $(\mathrm{m} / \mathrm{s}) "$

g_crit. Refresh

Text 3. Text $=\underline{\mathbf{S t r}}($ datos_calc_v $)+$ Datos"

Commandl. SetFocus

End Sub

Private Sub Command3_Click()

Unload graf real teor

datos_llenado!Command2. SetFocus

End Sub

Private Sub Command4_Click()

veces_suaviza $=\mathbf{V a l}($ Text 4. Text $)$

total_suaviza $=$ total_suaviza + veces_suaviza

Command4. Caption = "Suavizado" + $\underline{\text { Str }}($ total_suaviza $)$

For $\mathrm{j}=1$ To veces_suaviza

For $\mathrm{i}=3$ To $(\mathbf{M a x}-2)$

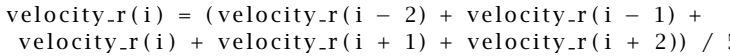
Next

Next $\mathrm{j}$

g_crit. RowCount $=$ Max - primer_punto +1

g_crit. Column $=1$

For $\mathrm{i}=$ primer_punto To Max

g_crit.Row $=\mathrm{i}-($ primer_punto -1$)$

g_crit.Column $=1$

g_crit. Data $=$ velocity_t $(\mathrm{i})$

g_crit. Column $=2$

If velocity_r(i) $>0$ Then

g_crit.Data $=$ velocity_r $(i)$

Else: g_crit. Data $=0$

Next i

End If

Text 1 . Text $=$ work_file

g_crit.Plot.Axis $(1,1)$. AxisTitle. Text = "Velocidad $(\mathrm{m} / \mathrm{s})$ "

g_crit.Refresh

Text3. Text $=\underline{\text { Str }}($ datos_calc_v $)+$ Datos"

Command1. SetFocus

End Sub

Private Sub Form_Load (

total_suaviza $=0$

g_crit. RowCount $=\underline{\text { Max }}-$ primer_punto +1

g_crit.Column $=1$

For $\mathrm{i}=$ primer_punto To Max

g_crit. Row $=\mathrm{i}-($ primer_punto -1$)$

g-crit. Column $=1$

g_crit.Data $=$ recorrido_t $(\mathrm{i})$

g_crit. Column $=2$

Next i

g_crit.Data $=$ recorrido_r $($ i $)$

Text 1 . Text $=$ work_file

Text2. Text $=\underline{\mathbf{S t r}}($ primer_punto $)+" \mathrm{~ms} "$

g_crit.Refresh

End Sub

Private Sub g_crit_PointSelected(Series As Integer, DataPoint As Integer, MouseFlags As Integer, Cancel As Integer

Text5. Text $=\mathbf{S t r}($ DataPoint $)+$ primer_punto

End Sub

Private Sub menu_fichero_abrir_Click() 
abre_fich. ShowOpen

Screen. MousePointer $=11$

Open abre_fich.FileName For Input As \#1

work_file $=$ abre_fich.FileName

Select Case formato

Case 0

Case 1

carga_recorrido_old (1)

End Select

carga_recorrido_y_sensor (1)

calcula_velocity (datos_calc_v / 2)

Screen. MousePointer $=0$

Close \#1

datos_llenado. Show 1

End Sub

Private Sub Command1_Click()

Kill ("c: $\backslash$ param. txt")

Open "c: \param. txt" For Output As \#1

Print \#1, "1\# —_ ARCHIVO DE PARÁMETROS

Print \#1, "2\# iff $="+$ Text1. Text

Print \#1, "3\# diametro $="+$ Text 2 . Text

Print \#1, "4\# longitud =" + Text 3 . Text

Print \#1, "5\# datos_calc_v $="+$ Text 4 . Text

Print \#1, "6\# rango_vmax =" + Text5. Text

Print \#1, "7\# retardo_sensor $="+$ Text6. Text

Print \#1, "8\# perdidas =" + Text7 . Text

Print \#1, "9\# tamaño_serie =" + Text8. Text

Print \#1, "10\# llanura $="+$ Text9. Text

Print \#1, "11\# formato $="+$ Text 10 . Text

Close \#1

iff $=\underline{\operatorname{CSng}}$ (Text 1 . Text $)$

diametro $=\mathbf{C S n g}($ Text 2 . Text $)$

longitud $=\mathbf{C S n g}($ Text 3. Text $)$

datos_calc_v $=\underline{\operatorname{CSng}}($ Text 4 . Text $)$

rango_vmax $=\underline{\mathbf{C S n g}}($ Text 5 . Text $)$

retardo_sensor $=\mathbf{C S n g}($ Text 6 . Text $)$

perdidas $=$ CSng $($ Text 7 . Text $)$

tamano_serie $=\mathbf{C S n g}($ Text8. Text $)$

llanura $=\underline{\operatorname{CSng}}($ Text9. Text $)$

formato $=$ CInt $($ Text10. Text $)$

Unload parametros

MsgBox ("El fichero c: $\backslash$ param.txt ha sido actualizado")

End Sub

Private Sub Form_Load ()

Text 1. Text $=$ iff

Text 2. Text $=$ diametro

Text 3. Text $=$ longitud

Text4. Text $=$ datos_calc_v

Text 5 . Text $=$ rango_vmax

Text 6 . Text $=$ retardo_sensor

Text 7 . Text $=$ perdidas

Text8. Text $=$ tamano_serie

Text9. Text = llanura

Text10. Text $=$ formato

End Sub 



\section{Bibliografía}

[1] Ampuero, J., Charbon, Ch., Hoadley, A.F.A., y Rappaz, M.A., 1991, "Modeling of Microporosity Evolution During the Solidification of Metallic Alloys", Materials Processing in the Computer Age, pp. 377-388.

[2] Anastasiou, K. S., 2002, "Optimization of the Aluminium Die Casting Process Based on the Taguchi Method", Proceedings of the Institution of Mechanical Engineers Part B-Journal of Engineering Manufacture, vol. 216, no. 7, pp. 969-977.

[3] Andrews, L.T., Klingler, J.W., Schindler, J.A., Begeman, M.S., Farron, D., Vaughan, B., Riggs, B., y Cestaro, J., 1991, "Detection and Visualization of Porosity in Industrial CT Scans of Aluminum Die Castings", Extracting Meaning From Complex Data: Processing, Display, Interaction II, 1459, pp. 125135.

[4] ASTM B311-93, Test Method for density determination for Powder Metallurgy (P/M) Materials Containing Less Than Two Percent Porosity", ASTM, Vol 02-05

[5] ASTM E1441-00, Standard Guide for Computed Tomography (CT) Imaging, ASTM, Vol 03-03.

[6] ASTM E155-00. Standard Reference Radiographs for Inspection of Aluminum and Magnesium Castings, ASTM International, 10-Dic-2000, 4p.

[7] Backer, G. y Sant, F., 1997, "Using Finite Element Simulation for the Development of Shot Sleeve Velocity Profiles", Transactions of the International Die Casting Congress (The Many Faces of Die Casting), NADCA, Minneapolis, Minnesota, pp. 17-20.

[8] Balasundaram, A. y Gokhale, A.M., 2001, "Digital Image Analysis Technique for Characterization of Shrinkage and Gas (Air) Porosity in Cast Magnesium Alloys”, Magnesium Technology 2001, pp. 155-159.

[9] Barton, H. K., 1963, "How to Vent Die Casting Dies", Foundry, vol. julio, pp. 52-59.

[10] Beeley, P., 2001, Foundry Technology, Biddles Ltd. 
[11] Bennett, C.H., 1987, "Clear Plastic Model Experiments-Cold Chamber Injection Analysis”, Transactions of the 14th SDCE International Die Casting Congress and Exposition, SDCE (NADCA), Toronto, Ontario, Canada, Paper No. G-T87-016, pp. 1-7.

[12] Brevick, J.R. y Mobley, C., 2001, “Correlation of Die Casting Weight and Density With Processing Variables", Transactions of the 21st International Die Casting Congress, NADCA, Cincinnati, Ohio, T01-073.

[13] Brevick, J.R. y Cheng.P.S., 1995, "Evaluating the Quality of Vacuum Die Castings”, Transactions of the 18th International Die Casting Congress Exposition, pp. 145-148.

[14] Brevick, J.R., Duran, M., y Karni, Y., 1991, "Experimental Determination of Slow Shot Velocity-Position Profile to Minimize Air Entrapment", Transactions of the 16th International Die Casting Congress \& Exposition Driving Die Casting Into The 21st Century, NADCA, Detroit, T91-OC4, pp. 399-404.

[15] Brevick, J. R., Armentrout, D.J., y Chu, Y.L., 1994, “Minimization of Entrained Gas Porosity in Aluminum Horizontal Cold Chamber Die Castings", Transactions of the North American Manufacturing Research Institution of Sme, Vol Xxii, 1994, pp. 41-46.

[16] Chvorinov, N., 1940, Giesserei, vol. 27, pp. 177-186,201-208,222-225.

[17] Coca, P. y Rosique, J., 1989, Tecnología Mecánica y Metrotecnia, Pirámide, Madrid.

[18] Davis, J.A. y Asquith, S.J., 1985, "Water Analogue Studies of Fluid Flow in the Die Casting Process", Transactions of the 12th International Die Casting Congress \& Exposition, SDCE (NADCA), Milwaukee, WI, Paper No. G-T85-063, pp. 1-6.

[19] Doehler, H.H., 1910, “Art of and Apparatus for Casting Fluid Metal”, United States Patent 973,483, United States Patent and Trademark Office, Washington, D.C.

[20] Duran, M., Karni, Y., Brevick, J., Chu, Y., y Altan, T., 1991, “Minimization of Air Entrapment in the Shot Sleeve of a Die Casting Machine to Reduce Porosity", The Ohio State University, Technical Report ERC/NSM-C-91-31.

[21] Eckert, E. R. G., 1989, "Similarity Analysis Applied to the Die Casting Process", ASME Journal of Engineering Materials and Technology, vol. 4, no. 111, pp. 393-398.

[22] Elmore, S., McLaughlin, M., Kim, C.W., y Backer, G., 2003, "Integration of Shot Sleeve Motion into Die Casting Filling Analysis”, 2003 Transactions Nadca Congress Sessions, SDCE (NADCA), Indianapolis, T03-048. 
[23] European Aluminium Association, 2003, “Aluminium for Future Generations: Progressing through dialogue".

[24] Faura, F., Lopez, J., y Hernandez, J., 2001, "On the Optimum Plunger Acceleration Law in the Slow Shot Phase of Pressure Die Casting Machines", International Journal of Machine Tools \& Manufacture, vol. 41, no. 2, pp. 173-191.

[25] Flemings, M.C., 1974, Solidification Processing, McGraw-Hill Book Co., New York.

[26] Flinn, R.A., 1963, Fundamentals of Metal Casting, Addison-Wesley Publishing Co.

[27] Garber, L. y Draper, A.B., 1979, “The Effects of Process Variables on the Internal Quality of Aluminum", Transactions of the tenth SDCE International Die Casting Exposition \& Congress, St. Louis, Missouri, Paper No. G-T79-022, pp. 1-11.

[28] Garber, L. W., 1982, “Theoretical Analysis and Experimental Observation of Air Entrapment During Cold Chamber Filling”, Die Casting Engineer, vol. 26, no. 3, pp. 14-22.

[29] Gordon, A., Meszaros, G., Naizer, J., y Mobley, C., 1993, "Equations for Predicting the Percent Porosity in Die Castings", Die Casting Technology in Harmony With the Environment, NADCA, Cleveland, Ohio, T93-024, pp. 55-62.

[30] Hansen, P.N. y Sahm, P.R., 1988, "How to Model and Simulate the Feeding Process in Casting to Predict Shrinkage and Porosity Formation", Modeling of Casting and Welding Processes IV, TMS, pp. 33-42.

[31] Herman, E.A., 2003, Die Casting Process Control, NADCA, Rosemont, IL.

[32] Hernandez, J., Lopez, J., Faura, F., y Gomez, P., 2003, “Analysis of the Flow in a High-Pressure Die-Casting Injection Chamber", ASME Journal of Fluids Engineering, vol. 125, no. 2, pp. 315-324.

[33] Hernandez, J., Lopez, J., y Faura, F., 2001, "Influence of Unsteady Effects on Air Venting in Pressure Die Casting”, ASME Journal of Fluids Engineering, vol. 123 , no. 4 , pp. 884-892.

[34] Hernández, J., Gómez, P., Crespo, A., López, J., y Faura, F., 2001, “Breaking Waves in a High-Pressure Die-Casting Injection Chamber", 4th International Conference on Multiphase Low, Louisiana, USA.

[35] Hernández, J., López, J., Gómez, P., y Faura, F., 1999, “Influence of NonHydrostatic and Viscous Effects on Shot Sleeve Wave Dynamics in Die Casting Injection", Proceedings of the 3rd ASME/JSME Joint Fluids Engineering 
Conference. Forum on Advances in Free Surface and Interface Fluid Dynamics, San Francisco, USA., 248.

[36] Hernández, J., Gómez, P., López, J., y Faura, F., 2000, “Numerical Simulation of Free Surface Flows in Die Casting Injection Processes”, Eighth International PHOENICS User Conference, Luxembourg.

[37] Huang, Y.J. y Lu, S.Z., 2002, “A Measurement of the Porosity in Aluminum Cast Alloys Using Fractal Analysis”, 2nd International Aluminum Casting Technology Symposium, ASM.

[38] Huang, Y. J., Hu, B.H., Pinwill, I., Zhou, W., y Taplin, D.M.R., 2000, “Effects of Process Settings on the Porosity Levels of AM60B Magnesium Die Castings", Materials and Manufacturing Processes, vol. 15, no. 1, pp. 97-105.

[39] Hwang, W. S. y Stoehr, R.A., 1983, "Fluid-Flow Modeling for Computer-AidedDesign of Castings”, Journal of Metals, vol. 35, no. 10, pp. 22-29.

[40] Hwang, W.S. y Stoehr, R.A., 1988, Modeling of Fluid Flow, ASM Metals Handbook, v.15 Casting.

[41] ISO10049. Aluminium alloy castings - Visual method for assessing the porosity

[42] Kalpakjian, S., 1995, Manufacturing Engineering and Technology, Addison Wesley, New York.

[43] Karban Jr., R., 2001, “The Effects of Intensification Pressure, Gate Velocity \& Intermediate Shot Velocity on the Internal Quality of Aluminium Die Castings", Transactions of the 21st International Die Casting Congress, NADCA, Cincinnati, Ohio, paper T01-074.

[44] Karni, Y., 1991, "Selection of Process Variables for Die Casting”, PhD thesis The Ohio State University, Ohio, USA..

[45] Khayat, R. E., 1998, “A Three-Dimensional Boundary Element Approach to Confined Free-Surface Flow As Applied to Die Casting”, Engineering Analysis With Boundary Elements, vol. 22, no. 2, pp. 83-102.

[46] Kimio, K. y Pehlke, R.D., 1985, "Mathematical Modeling of Porosity Formation in Solidification”, Met.Trans., vol. 16B, no. junio, pp. 359-366.

[47] Kirkman, S., 2003, Shrinkage Porosity: A Guide to Correcting the Problems, NADCA, Rosemont.

[48] Klein, F. y Wimmer, P., 1995, "Porosity in Zinc Die Castings", Congress and Exposition (The Starting Line for Die Casting Innovation ), NADCA, Indianapolis, Indiana, paper T95-035, pp. 101-111. 
[49] Kuo J.H. y Hwang W.S., 1998, "Flow Pattern Simulation in Shot Sleeve During Injection of Diecasting”, American Foundrymen's Society Transactions, vol. 63, pp. 497-503.

[50] Lewis, L., Kim, H., y Chu, Y.-L., 1989, “Experimental Investigation into the Influence of Shot Delay Time on Air Entrapment and Metal Flow in Cold Chamber Die Casting", Transactions of the 15th International Die Casting Congress and Exposition, NADCA, St. Louis, MO, Paper No. G-T89-061, pp. $1-6$.

[51] Lindsey, D. y Wallace, J.F., 1972, "Effect of Vent Size and Design, Lubrication Practice, Metal Degassing, Die Texturing and Filling of Shot Sleeve on Die Casting Soundness", Transactions of 7th SDCE International Die Casting Congress and Exposition, Chicago, USA, paper 10372, pp. 1-15.

[52] Lopez, J., Faura, F., y Hernandez, J., 2000, “Analysis of a New Plunger Acceleration Law in the Slow Phase of Die Casting Processes", Die Casting Engineer, vol. 44 , no. 5, pp. 82-87.

[53] Lopez, J. y Faura, F., 2005, Fundamentos de conformación por fusión de metales, (En imprenta) Ed. UPCT, Cartagena.

[54] Lopez, J., Faura, F., Hernandez, J., y Gomez, P., 2003, “On the Critical Plunger Speed and Three-Dimensional Effects in High-Pressure Die Casting Injection Chambers”, ASME Journal of Manufacturing Science and Engineering, vol. 125 , no. 3, pp. 529-537.

[55] Lopez, J., Hernandez, J., Faura, F., y Trapaga, G., 2000, "Shot Sleeve Wave Dynamics in the Slow Phase of Die Casting Injection", ASME Journal of Fluids Engineering, vol. 122, no. 2, pp. 349-356.

[56] López, J., Hernández, J., Faura, F., y Gómez, P., 2000, “Effects of Shot Sleeve Wave Reflection on Air Entrapment in Pressure Die Casting Processes", Proceedings of the ASME Fluids Engineering Conference. Symposium on Fluids in Manufacturing Processes, Boston, USA, 251.

[57] López, J., 2000, “Estudio Analítico y Numérico de los Procesos de Fundición por Inyección a Presión”, Tesis Doctoral, Universidad Politécnica de Cartagena.

[58] Luis-Martín, L., Rosa, T., y Pérez, J., 1979, “Influence of Porosity and Effect of Heat Treatment on the Variation of Some Physical and Mechanical Properties of Die Castings", Transactions of the 10th International Die Casting Congress \& Exposition, SDCE, St Louis, Missouri, Paper No. G-T79-055, pp. 1-12.

[59] Luis, L. y Robla, J.I., 1987, “Determination of Gas Volume in Zinc Die Castings and Its Relationship With Porosity", Trans. of 14th International Die Casting Congress and Exposition, paper No G-T87-029. 
[60] Luis, L. y Robla, J.I., 1983, "Evaluation of Gas Porosity in Zinc Die Castings", Transactions of the 12th International Die Casting Congress \& Exposition, SDCE (NADCA), Minneapolis, Paper No. G-T83-052, pp. 1-15.

[61] Luis, L. y Rosa, T.d.l., 1977, "Influence of the Second Phase Length and the Filling of Cold Chamber on Plunger Velocity and Die Casting Characteristics”, Transactions of the 9th SDCE International Die Casting Congress \& Exposition , SDCE (NADCA), Wisconsin, Paper No. G-T77-014, pp. 1-13.

[62] McClain, S.T., 1997, “A Study of Porosity Quantification Techniques and Pore Morphology in Aluminum Alloy Castings”, MS Degree Thesis, Mississippi State University.

[63] Niyama, E., Uchida, T., Morikawa, M., y Saito, S., 1982, “A Method of Shrinkage Prediction and Its Application to Steel Casting Practice”, International Cast Metals Journal, vol. 7, no. 3, pp. 52-63.

[64] Ostermann, F. y .et al., 1993, Aluminium Materials Technology for Automobile Construction, Mechanical Engineering Publication Limited, London.

[65] Palanisamy, S., Nagarajah, R., y Iovenitti, P., 2003, “Automated Ultrasonic Classification of Defects in Aluminum Die Castings", NADCA 2003 Transactions, Indianapolis, NADCA, pp. 93-100.

[66] Pellini, W. S., 1953, "Factors With Determine Riser Adequacy and Feeding Range”, American Foundrymen's Society Transactions, vol. 61, pp. 61-80.

[67] Poirier, D. R., Yeum, K., y Maples, A.L., 1987, “A Thermodynamic Prediction for Microporosity Formation in Aluminum-Rich Al-Cu Alloys", Metallurgical Transactions A-Physical Metallurgy and Materials Science, vol. 18, no. 11, pp. 1979-1987.

[68] Pokorny, H.H., 1968, "Balancing Die Casting Gates for 80 Per Cent First Shot Success”, Transactions 5th National Die Casting Congress, SDCE (NADCA), Detroit, Michigan, Technical Paper No. 52, pp. 1-15.

[69] Press W.H, et al., Numerical recipes in Fortran 77: The art of scientific computing, Cambridge Univertsity Press, 1992.

[70] Prucha, T.E. y Nath, R., 2003, "New Approach in Non-Destructive Evaluation Techniques for Automotive Castings”, 2003 SAE World Congress, SAE International.

[71] Robla, J. I. y Luis, L., 1987, "Device for Quantitative Determination of Occluded Gases in Zinc Die Casting by Vacuum Melting”, J.Vac.Sci.Technol., vol. 4, pp. 2693-2695. 
[72] Rosa, T. de la, Pérez, J., y Luis, L., 1975, “Medida, Registro y Regulación de la Velocidad del Émbolo de una Máquina de Fundición a Presión”, Rev.Metal. CENIM, vol. 11, no. 6, pp. 314-324.

[73] Sant, F. y Backer, G., 1995, “Application of WRAFTS Fluid Flow Modeling Software to the Bench Mark Test Casting”, Modeling of Casting, Welding and Advanced Solidification Processes VII, TMS, pp. 983-990.

[74] Sheptak, N., 1963, "Water Analogy Study of Fluid Flow in the Cold Chamber", American Foundrymen's Society Transactions, vol. 71, pp. 349-357.

[75] Smith, W. E. y Wallace, J.F., 1963, "Gating of Die Castings", American Foundrymen's Society Transactions, vol. 71, pp. 325-348.

[76] Syrcos, G. P., 1-4-2003, "Die Casting Process Optimization Using Taguchi Methods”, Journal of Materials Processing Technology, vol. 135, no. 1, pp. 68-74.

[77] Thome, M. C. y Brevick, J.R., 1993, "Modeling Fluid Flow in Horizontal Cold Chamber Die Casting Shot Sleeves", American Foundrymen's Society Transactions, vol. 101, pp. 343-348.

[78] Thome, M.C. y Brevick, J.R., 1995, "Optimal Slow Shot Velocity Profiles for Cold Chamber Die Casting”, Congress and Exposition (The Starting Line for Die Casting Innovation ), NADCA, Indianapolis, Indiana, paper T95-024.

[79] Tsoukalas, V. D., Mavrommatis, S., Orfanoudakis, N.G., y Baldoukas, A.K., 2004, "A Study of Porosity Formation in Pressure Die Casting Using the Taguchi Approach", Proceedings of the Institution of Mechanical Engineers Part B-Journal of Engineering Manufacture, vol. 218, no. 1, pp. 77-86.

[80] Tsoukalas, V. D., 2003, “The Effect of Die Casting Machine Parameters on Porosity of Aluminium Die Castings", International Journal of Cast Metals Research, vol. 15, no. 6, pp. 581-588.

[81] Tszeng, T. C. y Chu, Y.L., 1994, “A Study of Wave Formation in Shot Sleeve of a Die-Casting Machine”, ASME Journal of Engineering for Industry, vol. 116, no. 2, pp. 175-182.

[82] VDG-Merkblatt P201: Volumendefizite von Gußstücken aus Nichteisenmetallen, 16 S, Verein Deutscher Giessereifachleute, Düsseldorf, Mai 2002

[83] Walkington, W., 2004, Gas Porosity: a Guide to Correcting the Problems, NADCA, Rosemont.

[84] Wang, C.M., 1990, “Computer Modeling of Fluid Flow and Heat Transfer in Metal Castings”, PhD Thesis, University of Pittsburg. 
